From Conflict

to Inclusion

in Housing

Interaction of

Communities, Residents ${ }_{\mathrm{I}}, \ldots$...... and Activists

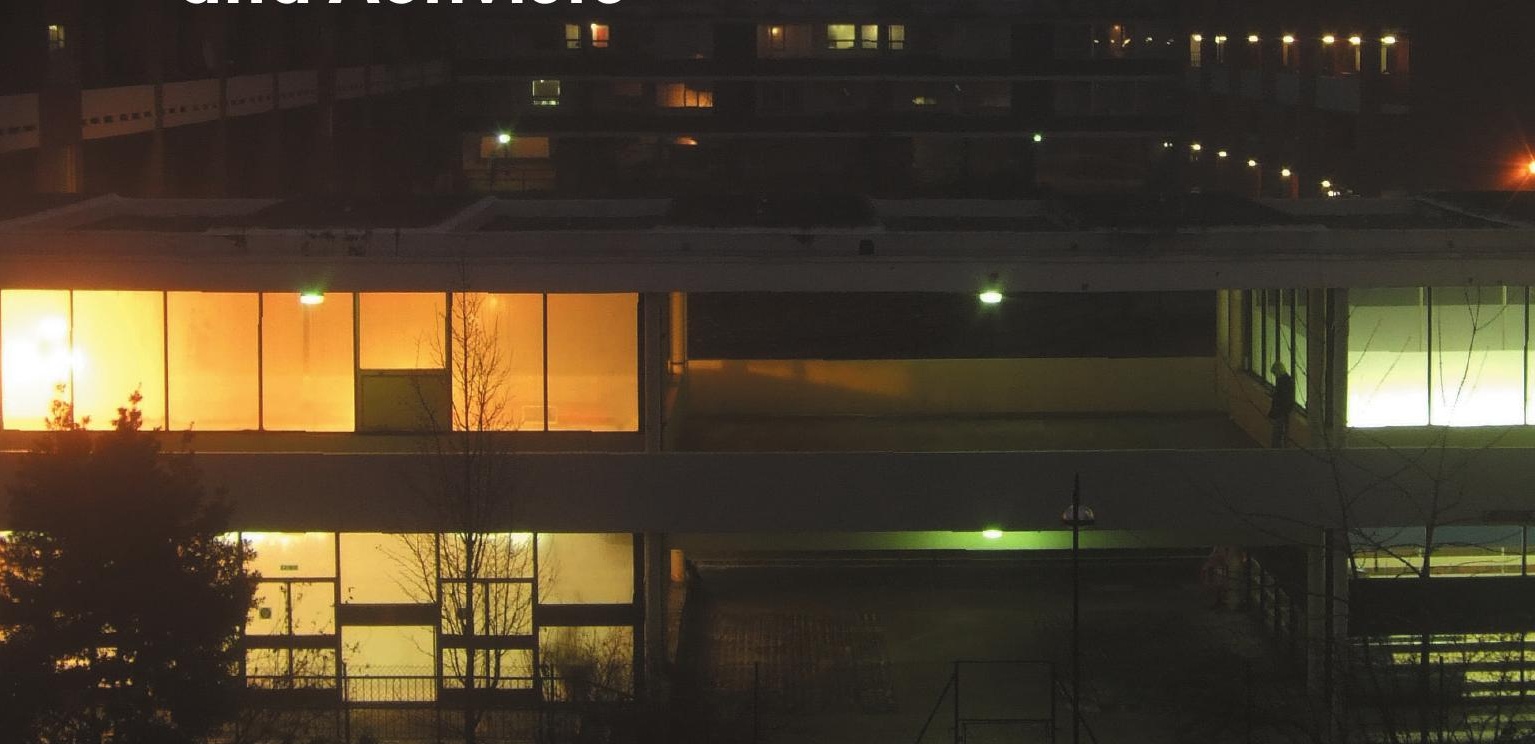

Edited by

Graham Cairns, Georgios Artopoulos

and Kirsten Day 
From Conflict to Inclusion in Housing 
HOUSING: CRITICAL FUTURES

\author{
Series Editor \\ GRAHAM CAIRNS
}

\begin{abstract}
Housing: Critical Futures is an innovative book series that offers a platform for leading international academics to debate housing and related issues. While the books explore a range of geographically specific concerns, together they investigate the challenges of providing affordable and sustainable housing in a global context.
\end{abstract}

Graham Cairns is an academic and author in the field of architecture. $\mathrm{He}$ is the director of the academic research organisation AMPS, and Executive Editor of its associated journal Architecture_MPS. 


\section{From Conflict to Inclusion in Housing}

Interaction of Communities, Residents and Activists

Edited by

Graham Cairns, Georgios Artopoulos and Kirsten Day 
First published in 2017 by

UCL Press

University College London

Gower Street

London WC1E 6BT

Available to download free: www.ucl.ac.uk/ucl-press

Text (C) Contributors, 2017

Images (C) Contributors and copyright holders named in List of figures, 2017

The authors have asserted their rights under the Copyright, Designs and Patents Act 1988 to be identified as the authors of this work.

A CIP catalogue record for this book is available from The British Library.

This book is published under a Creative Common 4.0 International license (CC BY 4.0). This license allows you to share, copy, distribute and transmit the work; to adapt the work and to make commercial use of the work providing attribution is made to the authors (but not in any way that suggests that they endorse you or your use of the work). Attribution should include the following information:

Graham Cairns, Georgios Artopoulos and Kirsten Day (eds), From Conflict to Inclusion in Housing. London, UCL Press, 2017.

https://doi.org/10.14324/111.9781787350335

Further details about CC BY licenses are available at http://creativecommons.org/licenses/

ISBN: 978-1-78735-035-9 (Hbk.)

ISBN: 978-1-78735-034-2 (Pbk.)

ISBN: 978-1-78735-033-5 (PDF)

ISBN: 978-1-78735-032-8 (epub)

ISBN: 978-1-78735-031-1 (mobi)

ISBN: 978-1-78735-030-4 (html)

DOI: https://doi.org/10.14324/111.9781787350335 


\section{Contents}

Figures vii

Tables $\quad \mathrm{x}$

Contributors $\quad$ xi

Introduction $\quad 1$

Graham Cairns

Editorial commentary: on the architecture of housing commons 6 Georgios Artopoulos

Section 1 Socially engaged practices of housing and contested environments (participatory practices and negotiation policies/sharing and relation with place)

1. Occupied city: Hotel Cambridge and central

São Paulo between urban decay and resurrection

Jeroen Stevens

2. Conflict sites in a time of crisis: negotiating a space and place for Gypsies and Travellers

Jo Richardson

3. Aceh post-tsunami housing reconstruction: a critical analysis of approaches, designs and socio-cultural implications

Yenny Rahmayati

Section 2 Spatial politics of housing (affordable housing, self-build, re-building and the economics/policies of housing)

4. Postproduced: how adaptive redesign and participatory approaches can transform ageing housing

Sandra Karina Löschke and Hazel Easthope 
5. Integrated approaches and interventions for the regeneration of abandoned towns in southern Italy

May East

6. The role of community-driven finance in bridging formal and informal practices in housing: insights from Vinh, Vietnam

Johanna Brugman

7. Clearing stock of the invisible: effects of cosmopolitan power on the supply of affordable housing Kane Pham

\section{Section 3 Non-standard practices of housing (art practice and alternative forms of engagement with housing)}

8. Art does matter: creating interventions in our thinking about housing

Keely Macarow

9. Uncanny home: considering race and American housing policy in Mike Kelley's Mobile Homestead Lee Azus

10. The real 'housos': reclaiming identity and place Michael Darcy and Dallas Rogers

11. Sharing the domestic through 'residential performance' Jonathan Orlek

12. Contesting 'dilapidated dwelling'

Matthew Thompson

Notes

Index 


\section{Figures}

Figure 0.1 Green corridor at Crescent House residential block, Golden Lane Estate, Barbican, London, UK. Author's image

Figure $0.2 \quad$ Staircase landing and transitional spaces at Crescent House residential block, Golden Lane Estate, Barbican, London, UK. Author's image

Figure 0.3 The open-air, multi-storey, atria of the Crescent House residential block, Golden Lane Estate, Barbican, London, UK. Author's image

Figure 1.1 Hotel Cambridge, facing Avenida Nove de Julho. Author's image

Figure 1.2 Central São Paulo's hodgepodge of morphologies, typologies and infrastructures. Author's image

Figure 1.3 'Hotel Cambridge threatened, a landmark of the city'. O Estado de S. Paulo

Figure 1.4 Hotel Cambridge, after its occupation by MSTCFLM. November 2012, archives MSTC-FLM

Figure $1.5 \quad$ Mutirão, and the piecemeal architectural reclaim of the derelict hotel. November 2012, Archives MSTC-FLM

Figure 1.6 Weekly occupation 'assembleia', meeting of inhabitants and co-ordination. Author's image

Figure $3.1 \quad$ Historical transformation of housing typology.

Figure 4.1 Toronto residential tower redevelopment proposal. Image: Graeme Stewart, ERA Architects, courtesy of Cityscope. (Citiscope is a nonprofit news outlet that covers innovations in cities around the world. Read more at Citiscope.org)

Figure 5.1 Ghost towns holding the tension between preserving the past and planning the future. Author's image 
Figure 5.2 Built in local stone and lime over 700 years, Torri

Superiore presents a unique urban layout with several five-storey buildings. Author's image

Figure 5.3 Architectural interventions and their effects on the character of the historic fabric. Author's image $\quad 99$

Figure 6.1 Operation of Vinh's community development fund (CDF). Author's image

Figure 7.1 Barangaroo and the adjacent suburbs of Millers Point and The Rocks holding significant stock of affordable housing in the Sydney CBD. Author's image adapted from Google Maps and atlas.id data

Figure 7.2 Age comparisons: age groups as a percentage of total. Cred Community Planning, Social Impact Assessment of the Potential Social Impacts on the Existing Millers Point Community, and the Broader Social Housing System (2013)

Figure 8.1 Untitled Collective, 2014, Open for Inspection, West Space Gallery, Melbourne, mixed-media installation. Photo: Christo Crocker

Figure 9.1 The Mobile Homestead looking east from Woodward Avenue. MOCAD at left.

Author's image

Figure 9.2 The Mobile Homestead looking north-east from Canfield Street. Author's image

Figure 9.3 Cape Cod Revival style illustration in Principles of Planning Small Houses, 1940 edition, page 2. Federal Housing Administration (Washington, DC)

Figure 9.4 'Basic Plan, One-Story, Two-Bedrooms', from Principles of Planning Small Houses, 1940 edition, page 16. Federal Housing Administration (Washington, DC)

Figure 9.5 The Kelley Family House (left), Northlawn Subdivsion, Westland, Michigan. Author's image

Figure 11.1 Building OPERA 1 partitions using plywood reclaimed from CNC manufacturing process. Photo: Studio Polpo

Figure 11.2 A private bed-space in OPERA 1. Photo: Studio Polpo 
Figure 11.3 Screen printing evening event during OPERA 1. Photo: Studio Polpo

Figure 11.4 One of many shared meals during OPERA 1. Photo: Studio Polpo

Figure 11.5 Doing the washing up at OPERA 1, with a view to the street. Photo: Elizabeth Jordan

Figure 11.6 Mapping showing how writing and documentation have become an integral part of the OPERA prototyping practice. Photo: Studio Polpo

Figure 12.1 A familiar image of dilapidated dwelling in Liverpool's inner-city neighbourhoods.

Author's images

Figure 12.2 Weller Street Co-op resident-led design, well managed and in better condition today compared with surrounding housing built afterwards. Author's images

Figure 12.3 Hatton houses in Liverpool's urban core, overshadowed by Radio City tower and the Anglican Cathedral. Author's images

Figure 12.4 Granby Street in the late 1960s, a oncebustling shopping street before decline and demolition, compared to the replacement housing built by HMR. Ronnie Hughes' blog (www.asenseofplace.com) and author's image

Figure 12.5 Homebaked bakery emblazoned with its slogan and the terraced row the CLT is hoping to acquire from the council for affordable housing. Author's images 


\section{Tables}

Table 5.1 Causes of abandonment of towns in the USA, UK, Australia and Italy $\quad 89$

Table 5.2 Comparing and contrasting hospitality models 97

Table 6.1 Conditions of loans supported by Vinh CDF in $2012 \quad 111$ 


\section{Contributors}

Georgios Artopoulos, Assistant Professor, works on immersive and performative spaces, virtual environments, and interaction design and digital simulation. Georgios holds a Master of Philosophy in Architecture and the Moving Image (University of Cambridge, UK, 2004) and a PhD, conducted at the Department of Architecture, University of Cambridge (2005-10) with a Doctoral Award from the Arts and Humanities Research Council, UK, where he assisted as Tutor and Research Assistant. Georgios has contributed to 12 international research programmes and received the Best International Short Film award at the Mestre Film Festival, Venice. His work has been presented at the International Biennale of Contemporary Art, Czech National Gallery, Prague; the International Exhibition Computational Turn in Architecture, MAV, Marseille; the Hong Kong and Shenzhen Bi-City Biennale of Architecture and Urbanism; the 11th and 12th Biennale of Young Creators of Europe; the 63rd Venice Film Festival; La Biennale di Venezia, Venice; the Royal Institute of British Architects, London; the BALTIC Centre for Contemporary Art, Newcastle; the London Design Festival; the Ukrainian Institute of Modern Art; Chicago, the ISEA 2006 and 2008; the British Council, Brussels; and in many international film festivals and art exhibitions. His work has been published in more than 24 peer-reviewed journals and books of architecture, and in 35 international conference proceedings and exhibition catalogues.

Lee Azus received a Master of Science in Architecture at Taubman College of Architecture and Urban Planning at the University of Michigan, and a Master of Science in Historic Preservation at Eastern Michigan University. He has presented work on Mike Kelley's Mobile Homestead and its relationship to the 'minimum house' at the Museum of Contemporary Art, Detroit, and at the AMPS (Architecture, Media, Politics, Society) Mediated City conference in London. His current research examines the history of urban renewal and infrastructure in Ypsilanti, Michigan, as part of an ongoing project on race, private property and United States housing policy in the twentieth century. 
Johanna Brugman is an urban development planner with experience working with government, non-government and urban poor communities across South-East Asia, Australia and Latin America in the context of housing, planning and community development. In 2012 she completed an MSc in Urban Development Planning at UCL and is currently finalising a PhD at the University of Queensland. Johanna's interests include community-driven practices for land access, housing and upgrading, urban informalities, social and spatial justice, collective action, participatory planning processes and methodologies, and the new ways of thinking about cities and planning practice.

Graham Cairns is an academic and author in the field of architecture who has written extensively on film, advertising and political communication. He has held Visiting Professor positions at universities in Spain, the UK, Mexico, the Gambia, South Africa and the USA. He has worked in architectural studios in London and Hong Kong, and previously founded and ran a performing arts organisation, Hybrid Artworks, specialising in video installation and performance writing. He is author and editor of multiple books and articles on architecture as both a form of visual culture and a socio-political construct. He developed this book during a two-year period as Visiting Scholar at Columbia University New York. He is currently director of the academic research organisation AMPS (Architecture, Media, Politics, Society), and Executive Editor of its associated journal Architecture_MPS. He is Honorary Senior Research Associate at the Bartlett School of Architecture, UCL.

Michael Darcy is Adjunct Professor of the Urban Research Program at Western Sydney University. He is a prominent researcher on social housing policy and management, and the connections between social disadvantage and place. His recent work questions orthodox approaches to concentration and de-concentration of disadvantage, and the way in which constructs of social capital and social mix have been deployed in public policy. His research approach reflects a commitment to deep engagement with local communities and organisations.

May East is a sustainability educator and designer, and serves as the CEO of Gaia Education. Designated one of the 100 Global SustainAbility Leaders three years in a row, she currently works in 43 countries with community-based organisations and intergovernmental agencies in the creation of policy guidance for sustainable development and for delivery of projects seeking to strengthen climate resilience, food security and livelihood strategies. A UNITAR Fellow, she has an MSc in Spatial Planning 
from the University of Dundee with a specialisation on the rehabilitation of abandoned villages. Her passion is to co-develop project-based learning trajectories supporting indigenous and migrant communities and their traditions to survive in rapidly changing environments while enhancing their skills to become the designers of their desired future.

Hazel Easthope is an Australian Research Council Future Fellow and Senior Research Fellow at the City Futures Research Centre at the University of New South Wales in Sydney, Australia. With a background in sociology and human geography, she undertakes research in the fields of urban studies and housing. She has a particular interest in residential decision-making, apartment living and the intersections between mobility, identity and home.

Sandra Karina Löschke is a Senior Lecturer and Director of Architecture, Design and Technology at the Faculty of Architecture, Design and Planning at the University of Sydney, Australia. She is a professional architect with wide-ranging experience in international practice in the UK, Australia and Germany. Her research investigates links between aesthetics, design and technology from the early twentieth century to the present and focuses on how these linkages advanced architectural knowledge at its interfaces with art and science. She has published widely, most recently Architecture and Materiality (Routledge, 2016), of which she is editor and contributing author. Her work engages theoretical and historical frameworks with the reality of contemporary architectural design practice. She is currently working on an edited volume, Rethinking the Production of Architecture (forthcoming in 2018).

Keely Macarow is an Associate Professor and Deputy Head, Research \& Innovation, School of Art, RMIT University, Melbourne. Keely has worked as a creative producer, artist, curator and writer for film, video, performance, exhibition and applied research projects which have been presented and published in Australia, the UK, Europe and the USA. Keely's research is collaborative and focuses on social practice, health and well-being, and her creative practice spans media, sound and visual arts, performance, curation and design. She works with artists, designers, social scientists, housing activists, medical and engineering researchers in Australia and Sweden to explore how art and design interventions and thinking can be applied to healthcare, political and housing settings. Keely views her research as a matter of social, spatial and health justice and is committed to developing new ideas, artefacts, tools and thinking for community benefits. She collaborates with artists, 
designers, housing researchers and activists based in Australia and Sweden to advocate for Homefullness (rather than homelessness).

Jonathan Orlek is a collaborative $\mathrm{PhD}$ student currently undertaking research into Artist Live/Work projects with East Street Arts, Leeds, and The University of Huddersfield, School of Art, Design and Architecture. His $\mathrm{PhD}$ investigates the artistic and public value of live/work schemes through embedded ethnographic research. Jonathan is also a director of Studio Polpo, a social enterprise architecture practice. With Studio Polpo he has worked on a number of projects concerning shared living, including art commissions, performances, newspaper publications and co-housing design.

Kane Pham is an associate at the Institute for Public Policy and Governance at the University of Technology, Sydney, where he is also a doctoral candidate. His current research interests are at the intersection of urban studies, urban theory and public policy. He has published on public space development in global cities and socio-political conflicts surrounding megaprojects and is currently conducting research on the application of assemblage thinking within frameworks of urban governance.

Yenny Rahmayati is a Postdoctoral Research Fellow at Centre for Design Innovation (CDI), Swinburne University of Technology, Melbourne. Sheis aLeadResearcherforHumanitarian HabitatandDesign Project, one of the CDI's core projects. Currently she is leading a collaboration project with Binus University Indonesia on designing temporary shelters and facilities for flood disasters (case study: Jakarta, Indonesia) as the Principal Investigator. Yenny received her $\mathrm{PhD}$ in Architecture from School of Design and Environment, National University of Singapore and has a Masters in Sustainable Heritage Development and Management from the Australian National University. She holds a Bachelor Degree in Architecture from University of North Sumatra, Indonesia. She had been working with recognised international aid agencies and non-profit organisations including the UN-ILO, UNESCO, UNFPA, World Bank, Environmental Resource Management (Barcelona), Global Heritage Fund (California) and German Technical Cooperation Agency (GIZ), primarily in the areas of disaster and reconstruction, architecture, cultural heritage, community development, housing and urban studies. She has held various positions, including Researcher, Project Manager, Consultant, Technical Expert, Project Officer, Project Coordinator and Program Assistant. For more than 10 years, she has also established and run a local non-profit community-based organisation that was 
concerned with architectural and cultural-heritage issues in Aceh, Indonesia, particularly in a post-disaster context. Yenny's work focuses on the processes of societal socio-cultural transformation and changing lifestyles short term as well as long term, paying a great deal of attention to post-disaster new housing visions, processes and programmes. Her current research proposes new post-disaster housing reconstruction attitudes and a new type of action based upon local, down-to-earth, real contexts and concerns.

Jo Richardson is Professor of Housing and Social Research and Associate Dean (Research \& Innovation) based in the Faculty of Business and Law at De Montfort University, Leicester (DMU). Her recent research projects include a study funded by the Joseph Rowntree Foundation looking at conflict resolution in site management and delivery for Gypsies and Travellers, plus three pieces of work evaluating projects for councils and housing organisations across the country. She has published a number of books and papers on the topic of Travellers, including Gypsies and Travellers: Empowerment and Inclusion in British Society (Policy Press, 2012). Jo is currently undertaking research on homelessness and social deprivation in Leicester and continues to take a 'co-production' approach to her research and consultancy. In her teaching Jo is particularly interested in place, space and identity, and she has recently developed a module on this which she delivers to students undertaking the MA Politics course at DMU. You can follow Jo on Twitter: @socialhousing.

Dallas Rogers is Senior Lecturer within the Faculty of Architecture, Design and Planning at the University of Sydney. His scholarship investigates the relationships between globalising urban space, discourse and technology networks, and housing poverty and wealth. He has undertaken a critical analysis of Australian urbanism through fine-grained empirical research with low-income urban citizenries as well as superrich transnational property investors and their agents.

Jeroen Stevens is architect and urbanist. He is currently engaged in doctoral research at the OSA Research Group on Urbanism and Architecture at the University of Leuven in Belgium. His work explores whether and how occupation movements precipitate latent prototypical urbanisms 'in the making', prefiguring and provisionally piecing together more inclusive urban futures. Interested in the intersection of anthropological and architectural research methodologies, this work critically inquires the nexus of urban movements and movements of urbanism. His research is developed with the support of the Belgian Development Cooperation and carried out in close collaboration with 
social movements, cultural collectives, human rights associations and governmental institutions in São Paulo.

Matthew Thompson is Postdoctoral Research Fellow at the Heseltine Institute for Public Policy and Practice at the University of Liverpool, where he also teaches undergraduate and postgraduate students in the Department of Geography and Planning. He is currently researching the scale, scope, social value and political potential of the social economy across the Liverpool City Region, having completed his $\mathrm{PhD}$ at the University of Manchester in 2015 on Liverpool's history of collective housing alternatives and community-led neighbourhood regeneration, which is due to be published by Liverpool University Press. For several years he has volunteered as a board member of EPIC, a community-based housing association in Stoke-on-Trent. Matt has previously worked in the Liverpool City Region Local Enterprise Partnership (LEP), where he contributed to the formulation of urban policy, and began his current research on how to incorporate the social and solidarity economy into local economic development in the context of austerity and devolution. 


\title{
Introduction
}

\author{
Graham Cairns
}

From Conflict to Inclusion in Housing: Interaction of Communities, Residents and Activists is the result of the ongoing work of a consortium of international scholars collaborating in various ways with the research programme Housing - Critical Futures. Organised by the UK-based nonprofit research group AMPS (Architecture, Media, Politics, Society), this programme gives its name to the book series that this publication launches.

As such, both the book and its underlying research programme confront a critical issue at a critical time. In London, a leading capital of global finance, there is a chronic shortage of affordable housing for those that service 'the service' sector. The crisis is at levels not seen since the Second World War. In Beijing, capital of the twenty-first century's political powerhouse, the displacement of long-standing communities is a daily occurrence. In Mumbai, the biggest health risk faced by the city today has been identified as overcrowded housing, while in São Paulo, football's 2014 World Cup took place against a backdrop of community unrest and the chronic living conditions of the poor. The private sector, the state and residents themselves are searching for solutions. Whether housing refugees in conflict areas, providing safe water to the households in the developing world or ensuring key workers can live in the cities they support in the West, the question of housing is not only global, but critical.

Reflecting the diversity of issues outlined in this scenario, this book offers multiple perspectives on its principal issue of examination, the role of communities in project developments. Taking this as its starting point, the book offers a provocative analysis of the socio-political debates, community struggles, direct actions, governmental policies, managerial initiatives and resident resistances to the politics of the home'. Drawing on an eclectic range of theory and an equally diverse 
range of practice models and ongoing struggles, it examines real cases of community action and resident participation in both successful and failed housing initiatives from several countries. It examines how communities, professionals and politicians have variously engaged, developed, supported and/or resisted the multiple and contradictory forces that shape the homes we live in - whether these forces be government policy, military action, religious division, community segregation or 'architectural visions'. It thus offers critique, analysis and, in some significant instances, proposals for ways forward.

Organised in three broad sections, it brings together scholars in categories defined as 'Socially engaged practices of housing and contested environments', looking primarily at issues of participatory practice and policies of negotiation and sharing in relation to place; the 'Spatial politics of housing', looking at issues of affordable housing, selfbuild and the economics of housing; and finally 'Non-standard practices of housing' which bring together authors documenting and exploring art practice and alternative forms of user engagement with housing policy and practice.

In Section 1, 'Socially engaged practices of housing and contested environments', we find essays by academics and practitioners from several countries documenting issues of relevance locally and globally. Jeroen Stevens' 'Occupied city: Hotel Cambridge and central São Paulo between urban decay and resurrection' opens the book with a fascinating documentation and consideration of community resistance in São Paulo, Brazil. Pinpointing the events of 23 November 2012 and the occupation of the abandoned Hotel Cambridge in central São Paulo, he documents the occasional 'power' of direct action in forcing affordable housing onto the political agenda with very real results. Moving to the UK context Jo Richardson shifts attention to a quite different section of contemporary society, Traveller communities. Outlining a historical development of the conflict surrounding accommodation for Travellers in the UK context, she seeks to explore the origins of the 'conflict' around their mode of living and more 'standard' readings of home in Western cultures. More specifically she outlines a theoretical framework which she claims can offer different perspectives on land use and notions of home and place. Concluding this short section of the book Yenny Rahmayati looks at the housing implications of the 2004 Indian Ocean earthquake, tsunami and subsequent rebuilding programme for the community of Banda Aceh, Indonesia in 'Aceh post-tsunami housing reconstruction: a critical analysis of approaches, designs and sociocultural implications'. Critiquing the modus operandi of the rebuilding 
programme for its focus on material necessity over longer-term concerns of community, she argues for more attention on the intangible aspects of socio-cultural phenomena informing people's sense of well-being and happiness in the housing context to sit alongside the tangible parameters of location, environmental configuration, and forms and sizes of housing, and the immediate need to rebuild in post-disaster contexts.

In Section 2 of the book, 'Spatial politics of housing', Sandra Löschke and Hazel Easthope in 'Postproduced: how adaptive redesign and participatory approaches can transform ageing housing' shift attention to issues of design directly related to the long-term maintenance of communities. Suggesting a need to adapt current housing whilst still in use, they open up not only a design-related discourse, but one that potentially contributes to keeping communities together, increasingly threatened by developments that see existing housing stock in purely material terms. This shift towards design and policy is repeated in May East's 'Integrated approaches and interventions for the regeneration of abandoned towns in southern Italy', which focuses its attention on villages and communities in the south of Italy. Looking at the consequences of depopulation of rural villages, she identifies that it is necessary, and possible, to redevelop the material infrastructure of these villages in ways that highlight the importance and role of the community-led initiatives opening up debates about lifestyle choices, new ownership structures and livelihood strategies - an interrelated set of arguments made more complex by the recent migrations of refugees entering Europe through southern Italy.

In 'The role of community-driven finance in bridging formal and informal practices in housing: insights from Vinh, Vietnam', Johanna Brugman develops a different strand from these policy- and designfocused chapters with a consideration of perceptions and associated policies of housing in the global south, with particular emphasis on Vietnam. Arguing that informal practices play an important role in land provision, shelter and finance for the urban poor, she suggests that 'informal' modalities of developing housing have the potential to inform more mainstream practices, particularly in terms of funding models. Kane Pham picks up on the finance issues related to housing affordability but in a very different context, the continued development of Sydney, Australia. Ending this second section and its focus on planning, design and policy, he frames his arguments in the terminology of 'the right to the city' in the chapter entitled 'Clearing stock of the invisible: effects of cosmopolitan power on the supply of affordable housing. More specifically, he argues that Sydney's transformation is typical of the changes 
occurring to post-industrial cities worldwide and is resulting not only in affordability issues for local residents but in the homogenisation of people, lifestyles and design templates in the new post-industrial landscape.

Section 3, 'Non-standard practices of housing', takes the issues of community activism, policy and design approaches discussed previously and examines them through a quite different mode of critique, art practice. Keely Macarow in 'Art does matter: creating interventions in our thinking about housing' - operating in a similar geographical context to Kane Pham, Australia - opens this section, looking at the issue of housing and affordability through the prism of art practice. Specifically outlining ideas underlying the installation Open for Inspection, she parallels approaches in Australia and Sweden to discern how socially engaged art, political and housing activism, and urban and participatory design can facilitate innovative housing initiatives. Lee Azus in 'Uncanny home: considering race and American housing policy in Mike Kelley's Mobile Homestead' expands this art-led critique of housing policy, provision and accompanying social perceptions through a consideration a very particular lens, that of Mike Kelley's Mobile Homestead, a 2013 sculptural artwork located in Detroit, Michigan, through which he is able to critique and nuance our understanding of the current situation in Detroit. Setting the artwork in the context of the depopulation of Detroit as the model of post-industrial decline par excellence in the West, Azus also opens up an alternative consideration of racial issues around housing in the context of the United States through the setting of Kelly's work in the phenomenon of white flight and the broader issue of suburbanisation.

Returning to Australia, Michael Darcy and Dallas Rogers' 'The real "housos": reclaiming identity and place' looks at residents' use of film and video to challenge stereotypes and stigmatisation, suggesting that in both the popular imagination and in policy discourse, recognisable features of the built form of public housing are commonly conflated with negative press and thus perception. Their chapter highlights work done during a four-year residency programme, 'Residents' Voices - Advantage, Disadvantage, Community and Place', and offers commentary on digital storytelling disseminated through a website, tenant-driven media analysis of the popular Australian television parody Housos, and a short dramatic fictional film written and directed by tenants in a highly stigmatised estate.

Jonathan Orlek's chapter 'Sharing the domestic through "residential performance"' is also concerned with issues of media performance and documentation, but in this case is centred in Sheffield, England, and 
is artist initiated. He discusses the work of Studio Polplo and specifically the project OPERA in a chapter that investigates how performance art practice can reimagine and reconfigure domestic space by offering new insights into shared domestic living. Done through a form of art occupation of abandoned spaces, the project he discusses leads to a proposal for 'autoethnography' as an appropriate research method for residential performance projects, and in the process reimagines uses for derelict buildings and more sociable and affordable modes of living.

Ending this section, and thus the book itself, Matthew Thompson's 'Contesting "dilapidated dwelling"' picks up on the work of Patrick Keiller, specifically his film The Dilapidated Dwelling, to discuss social and economic issues related to housing provision in the UK, with particular emphasis on Liverpool. Using Keiller as a springboard from which to explore the issues raised by art-led housing projects in Liverpool such as Homebaked, and less directly, the award-winning projects of Assemble at the Granby Four Streets, he weaves into the art discourse on housing the political underpinnings and conflicts that have existed for decades in this particular city. Referencing the writing of Henri Lefebvre in this artistic-political conceptualisation of housing, his chapter integrates many of the issues raised across the book, from the politics of housing to questions of finance, community and resident activism in conditions of contestation. As such, it is an ideal chapter with which to bring the volume to a close and through which to encourage continued crossdisciplinary engagements with the often conflictive issue of affordable housing provision and its community and social importance in the UK and internationally. 


\section{Editorial commentary}

\section{On the architecture of housing commons}

Georgios Artopoulos

Housing is the contested terrain that stages the act of the negotiation of boundaries between competing ontologies, theoretical considerations, economic interests and political agendas, all of which are simultaneously pursued by individual incentives and result from the group dynamics of the participating actors. This book is the result of parallel conversations initiated during a series of conferences organised by the research organisation AMPS that were convened with the objective to rethink the transitive identity of the relationship between public-interlaced and private-singular spatial activities, in concert with the politics involved in housing. By staging this discussion in a global context, as well as by sourcing cases from widely different political, cultural and social landscapes, the book aspires to contribute to the contemporary discourse of social housing by means of an anthology of exemplary cases of policies and practices of self-organisation and activist initiatives.

This anthology provides a fresh socio-political view on the act of housing, a topical subject worldwide due to the economic and migration crises of recent years, as well as the relevant phenomenon of transregional movement more generally. This topic is approached with an interdisciplinary eye - by engaging in the conversation of not only sociologists and political scientists but also planners and architects. Most importantly, though, this book presents the views of stakeholders that are typically left unaccounted for in the process of housing development. The book introduces a conversation about various competing factors and actors of the 'politics of the home' by promoting the voice of the 'other' - the points of view of communities, residents and activists, for example. Also it proposes, through carefully selected case studies, a course of action and future directions with an intention to reposition the 
current discourse about housing by bringing to the fore issues of poverty, resident solidarity, activism and social inclusion.

These cases are discussed in the context of their capacity for community generation and the economic parameters of spatial production, as well as the new opportunities of occupation that are created by novel methodologies of social housing. One such example is presented by May East in her 'Integrated approaches and interventions for the regeneration of abandoned towns in southern Italy', which makes the case for the reactivation of abandoned settlements, the so-called ghost towns in southern Europe, as an alternative housing solution that comes with embedded collective memory and offers 'locally adaptable, culturally rooted' opportunities for communities. However, is the locale of historical, and vernacular, architecture a prerequisite condition for the emergence of said opportunities, or are these opportunities actually being driven by socio-spatial capacities that transcend architectural styles and forms?

In the history of architecture, modernism has actively proclaimed social housing as one of its emblematic new models for living in our emerging urban societies and promoted a new physical infrastructure as one of the canonical types of our contemporary built environment. However, modernism has mostly approached space via abstract concepts, and this has arguably failed to produce sustainable social tectonics. Numerous modernist residential blocks and settlements contributed to this end as their design embraced the fallacy for strict control and the over-determinism of social activities, which was promoted by an urge to regulate variation in patterns of spatial occupation. This approach compromised the acclaimed quest of modernism for activation of social space, and sometimes produced contested spaces to live in.

Dehumanising, bland, characterless, depressing, mechanistic all these characteristics are attributed today to modernist examples of social housing, from the Soviet Union and Germany, to France, the UK and the USA. Contemporary affordable housing is mostly abandoned to the hands of developers, who promise an antidote to what is misrepresented as the oppressive residential complexes of the recent past. The European post-war right to housing has now been replaced by the dream of a flat or house ownership, most frequently advertised in media depictions of illustrious lifestyle representations. But what is not apparent at first sight is what gets discarded from these new housing developments, namely the spaces that enable participation, promote social interaction and enhance accessibility and inclusion. These are the common spaces 
in between the private and the public that were an indispensable characteristic of modernism and are now reduced to a circulatory minimum. In the context of modernist practices these spaces were perceived sometimes successfully, and other times unsuccessfully, as social condensers - that is, as spaces of social interaction, association and identification. In this framework, the veiled privatisation of common space that nowadays characterises most developments internationally challenges the potential of these places to host out-of-control social interactions due to their over-determination by design.

Kenneth Frampton described Peter and Alison Smithson's Golden Lane Estate, London, as of high historical importance due to its functioning as an evolutionary step for modernism, given its role in expressing criticism of the modernist orthodoxy of high-rise apartment blocks and clearly divided functional zoning. Unlike their modernist counterparts who focused on visual aspects and framed views of the architecture and its environment to communicate spatial qualities of their designs, the Smithsons were interested in promoting human association and placemaking.' ${ }^{1}$ Taking this remark as a starting point, one could then argue that inverting what is typically approached as a 'causal' relationship between the architect's motives when designing a space and the actual occupation patterns of that space after it was built might offer a fresh view of the everyday life of housing complexes.

Based on this hypothesis, From Conflict to Inclusion in Housing is different from architectural books that illustrate designers' subjective narratives, and instead it pursues an analysis of the mechanisms involved in the emergence of social interaction in the development, construction or occupation of housing projects. Generating inclusive housing spaces is considered a creative action that is analysed through practices that inspire users to seek new opportunities for association and connection. Moving away from design practices that pursue optimisation of architectural space in order to fit with a simulacrum of how modern-era humans should live by relying on reductive descriptions of a quantified statistical mean - such as Existenzminimum (subsistence dwelling), ${ }^{2}$ or the Modulor (Le Corbusier's approach to materialising a way of living in maximum existence) - architects today recognise the singularity of housing conditions and the plurality of needs for dwelling in socially enriched built environments. ${ }^{3}$

It is evident that Peter and Alison Smithson's concept for Golden Lane shared many aspects with Le Corbusier's Unité d'Habitation model: in particular, the central role played, in both examples, by the topology and operation of a main corridor that performs 
multiple functions beyond that of merely serving as a circulation plateau. Historically this is a diagram of a spatially expressed function which already by that time had been evolving for a few decades. It was Eugène Hénard with his drawings of the 'City of the Future' (1910) ${ }^{4}$ who first raised pedestrian circulation above car roads and thus laid the grounds for untangled circulation infrastructure in the city, by the way he envisioned transferring the socially activated layer of the street from the ground level (pedestrian routes) to raised corridors. Michiel Brinkman's Spangen Quarter in Rotterdam (1919-21) consisted of blocks that were also connected by pedestrian streets in the air. But most significantly it was the team of OI, Ivanov and Lavinsky, who proposed an internal corridor which was symbolically transformed into a double-direction street in their submission for the OSA housing competition (1927), with alternatively interlocking maisonettes - a solution that was adopted in the Unité d'Habitation.

All these projects, amongst others, ${ }^{5}$ explored different architectonic solutions in order to pursue the introduction of the spatial qualities of urban environments, such as the capacity for street life, in the topological configuration of the housing complex, and subsequently of residential blocks. Some were more successful than others, but what is important for the conversation staged in this book is the reverberation of the hybridity of these interstitial spaces, which lie between the city (public) and the dwelling units (private), in the assemblage of correlated procedures of housing production, namely the social, economic and political aspects. This dialectic is exemplified in Jeroen Stevens' 'Occupied city: Hotel Cambridge and central São Paulo between urban decay and resurrection', which presents the opportunities offered by another kind of urbanism wherein an occupied high-rise building is converted into a housing block and, through the self-organised reclaiming process, is transformed into a living city. Stevens' chapter is an attempt to identify some of the terms and characteristics of this kind of localised urban reform and its associations with other aspects of social urban life in order to reflect on the factors of its generation and elaborate on the architectural impact of this bottom-up urban reform.

The first section of this book aims to illustrate through exemplary cases how agent-based co-creation practices and participatory design can be employed in the process of generating the right spatial conditions to extend beyond the production of dwelling units and most importantly focus on housing commons. This interest stems from the understanding that, even in canonical modernist housing projects that were built around the concept of Existenzminimum, the articulation of communal 
spaces with the private spaces of the dwelling units has always been considered a significant factor of their success. The occupation of communal spaces, though, is a fundamental cultural activity and as such it requires that these spaces are articulated in consent with the occupational practices and cultural identities of their users; further, these spaces are ever-developing, with their users always being engaged in this continuous transformation (as the users' needs change). The creation of housing, though, has typically been approached through a static dichotomy: common space is produced as abstract and generic (in order to flexibly accommodate multiple occupations), while dwelling units are considered to be private spaces that need to be specialised and differentiated, in order to respond to the unique character of individual residents.

This contradistinction raises typological considerations regarding the regulation of variation in spatial configurations, which can be identified in housing projects ${ }^{6}$ more than in any other form of dwelling spaces due to their scale, which imposes criteria of standardisation among the units. However, as the chapters of this section highlight, the impact that different approaches for exercising control on irregularity have on the "fitness" of the produced spaces depends on the framework through which various opportunities are given to existing communities, stakeholders and future users for contributing to their production process, as well as on the timing of engaging these key players in this process. In particular, the first section focuses on participatory practices and the adoption of negotiation policies in housing production and management, and offers examples of sharing space, as well as of associating with a place. Analysing Aceh housing reconstructions as a case of producing unsatisfactory houses, 'Aceh post-tsunami housing reconstruction: a critical analysis of approaches, designs and socio-cultural implications' highlights the importance of following an appropriate method when engaging users in the participatory design process. Yenny Rahmayati's chapter tacitly illustrates how, even in cases where the relevant authorities and actors facilitate users' support during the production of housing, the process can practically fail to consider socio-cultural family practices and the relevant local users' living values and norms, a shortcoming that leads to difficulties in fulfilling the users' needs.

Motivated by an examination of the same cause, and being occupied with a similar interest in exploring alternative approaches to user engagement and participation in housing production, Jo Richardson in 'Conflict sites in a time of crisis: negotiating a space and place for Gypsies and Travellers' reflects on the introduction of new principles in existing policies that need to be followed in order to achieve lower 
expenses for municipalities and establish better negotiation procedures. Richardson's interest is in devising processes that facilitate the establishment of policies to recognise the needs of communities from the outside, and the ephemeral conditions of the relationship between a place and its inhabitants. One of the key considerations of this book is to reflect on the aspects of alternative methods that enable integrating and hybridising the agendas of the stakeholders of housing development projects, such as local and regional authorities, state agencies and architectural practices, with the narratives of users and local communities of tenants. This understanding is supported by the presentation of unsuccessful cases of top-down initiatives imposed by the authorities, and is tangibly illustrated in Matthew Thompson's chapter, 'Contesting "dilapidated dwelling"', which studies Liverpool's history of housing programmes in order to highlight the positive impact of community land trusts on the sustainability of the built environment, against the questionable results of large-scale state-led comprehensive redevelopment projects.

Equally, if not more important to user-led methods of housing projects for successful living and sustainable development is the use of conceptual tools that can offer a better understanding of the impact of the relevant actors' conflicting agendas on the housing market. This reflective process has long been promoted by art practices in order to complement policy making for housing development. More specifically, Keely Macarow in 'Art does matter: creating interventions in our thinking about housing' argues for a holistic understanding that stems from the pursuit of well-being and integrates the residents' individual, cultural, social, artistic and environmental potential. To reiterate, this integrated approach is adopted in this Editorial Commentary as the lens through which the reader should approach the contents of this book in order to contextualise the politics of user participation and activism in housing.

The discursive formation of shared spaces that become housing commons, and which are continuously appropriated throughout their life, is well exemplified by the community of elderly residents of Chamberlin, Powell and Bon's Golden Lane Estate in London. Longterm tenants of the Crescent House block, which is considered among the canonical housing estates of the British Council Flats scheme of the 1950s, ${ }^{8}$ have appropriated most of the communal areas as their outdoor green spaces (Figure 0.1). Chamberlin, Powell and Bon won the competition for the design of the Golden Lane Estate over Peter and Alison Smithson, who went on to build their concept of the Golden Lane, cited above by Frampton, on other sites across the UK (e.g. the Robin Hood Gardens in Tower Hamlets and Park Hill Estate in Sheffield). ${ }^{9}$ The design 


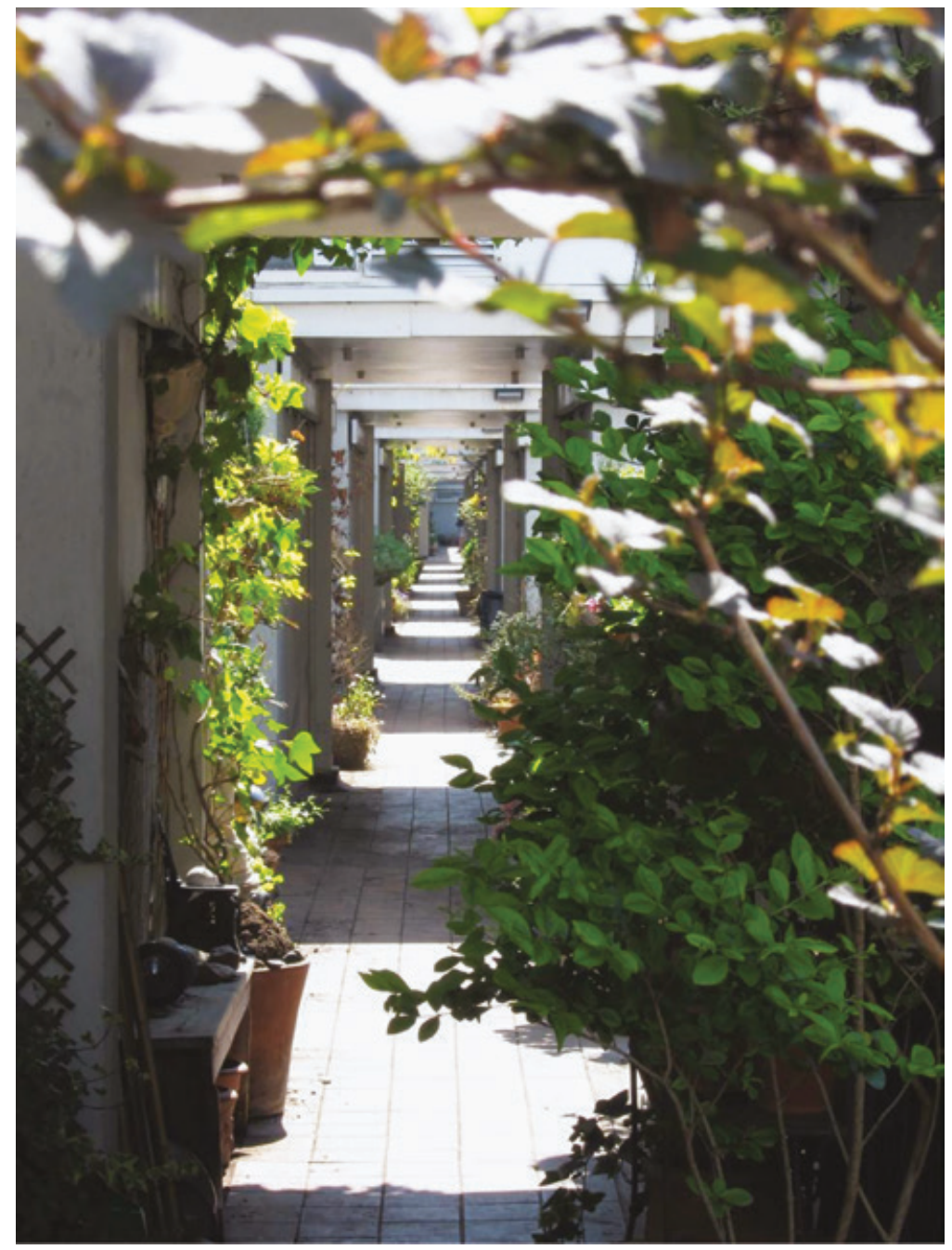

Figure 0.1 The communal space of the corridor is transformed into a green belt punctuated by sunlit clearings that are appropriated by each tenant at Crescent House residential block, Golden Lane Estate, Barbican, London, UK.

of Chamberlin, Powell and Bon was deemed successful and the City of London further commissioned the practice to build what was meant to become a symbol of British post-war architecture, the Barbican Estate (1976). ${ }^{10}$ The two estates lie next to each other and have clearly achieved the provision for equitable housing models that are adaptive to changing demographics described by Kane Pham in 'Clearing stock of the 
invisible: effects of cosmopolitan power on the supply of affordable housing'. Since their construction, Golden Lane and the Barbican Estate have managed to attract diverse groups of tenants always avoiding gentrification of the neighbourhood despite their different identity and branding - the former was built as council flats, the latter was envisioned as an iconic development in the centre of the City. The success of the communal areas of the Crescent House block is best illustrated in the degree of their appropriation by the tenants and can be attributed to a balancing act between individuals' initiatives and the sharing of interests and identities, such as aesthetics, hobbies and leisure time (Figure 0.2). However, these intangible factors are enabled and accelerated by the architectonic characteristics of the space itself: its size, scale, proximity to flats (offering intimacy), its material construction and its optical connection with the city life of central London. Another important aspect of the space is its organisation in clusters and pockets of activity that are allocated around open-air multi-storey atria that facilitate privacy and take advantage of natural lighting and ventilation at all levels of the block (Figure 0.3).

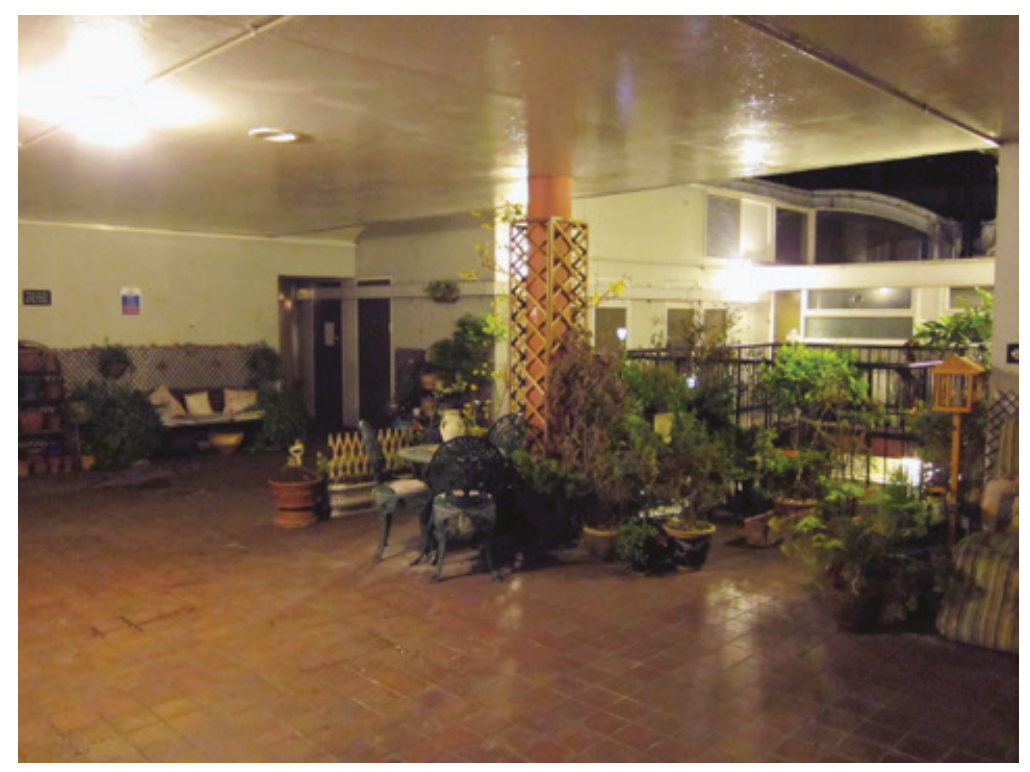

Figure 0.2 Appropriating the left-overs: Crescent House can serve as exemplary case of converting the generic space of the staircase landing and the transitional areas of the corridors into personal 'gardens' that are nursed by the tenants, and intimate niches for social interaction. 


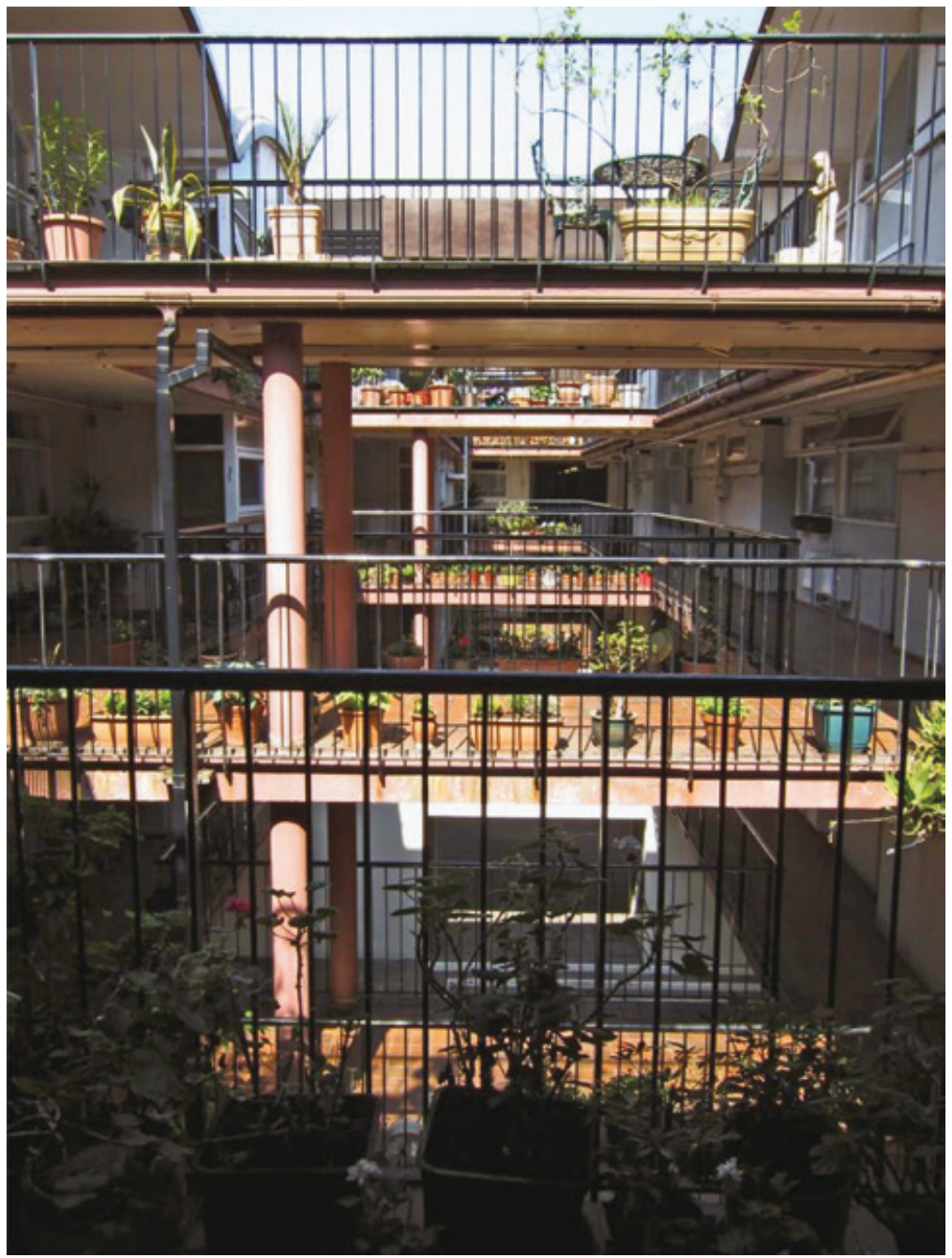

Figure 0.3 Community building through co-creation activities by means of furniture equipment and the decoration of the open-air, multi-storey atria of Crescent House. This spatial practice exercised by the tenants not only enables them to appreciate and enjoy natural lighting and ventilation at all levels of the five-storey block, but also promotes belonging and association with the place.

Contributions in this book, such as 'Postproduced: how adaptive redesign and participatory approaches can transform ageing housing', are motivated by the extension of this need for regulating variation. It is a need that has arguably shifted today towards the privatised areas 
of housing complexes which ostentatiously ignore the importance of the spatial complexity of communal spaces (in the form of correlated occupation patterns) needed for social interaction and association with the place - activities that promote a sense of belonging. In their essay, Sandra Karina Löschke and Hazel Easthope stress the positive impact of adaptive redesign in sustainable communities and the significant occupation opportunities these strategies can offer to their residents, as well as the economic benefits of this approach for the built environment.

However, there is a historical line of flight that was created by experimental - some would say utopian - architectures in their pursuit of an alternative approach to the management of variation and irregularity in architectonic configurations of housing and the respective social patterns of dwelling. This can be traced in the work of visionaries such as Yona Friedman and Takis Zenetos. In his renowned projects the Architecture Mobile manifesto and studies for La Ville Spatiale (1956-60), Friedman, who worked against the established mechanisms of control in urban assemblages, was motivated by an abstract notion of ecology. His work envisioned a new malleable relationship between public and private space, and natural and man-made artifice, via mechanisms of symbiosis. Focusing on a process of micro-community formation, Friedman developed his technique of three-dimensional urban planning which allowed the juxtaposition of different neighbourhoods or their superimposition over the existing palimpsest of historic/dense city centres. ${ }^{11}$ This transformational process of addition (superimposition) of public and private space, of natural and man-made artifice, puts primacy on the interstitial space that performs as urban commons and contributes to the shared resources of the place. User participation and agent-based co-creation in Friedman's bottom-up concept of urban form differentiated it from his contemporaries' work, ${ }^{12}$ like Constant Nieuwenhuys' New Babylon, and instead brings it into dialogue with the work of the Greek architect Takis Zenetos.

Moving one step closer to the real-world constraints of construction, and by using technology (e.g. the world-wide web, ICT, working from home) as the starting point of his quest, Zenetos proposed his concept of Electronic Urbanism (first published in 1956), wherein the free will of individuals to form communities and neighbourhoods defines the relative location and position of spaces built and occupied. Truthful to a logic-based idea of bottom-up space formation intrinsically linked with the ephemeral emergence of spatially distributed situational activities, Zenetos envisions a housing platform that is populated by 'special public spaces of the residential units' which will enable inhabitants to become 
purely creative in their everyday lives. ${ }^{13}$ Zenetos' utopian vision of urban cohabitation raises topical and still pressing issues not only of aesthetics but also of ethical concern: how could an architectural model of dwelling integrate both technological innovation and ever-active sociopolitical transformations of communities of inhabitants? In addition, we have to reconsider the struggle of housing practices for enabling the co-habitation and co-existence of individuals in nested symmetries of dwelling within larger assemblages (e.g. home, street, neighbourhood, district, city, region and the world-wide web). This has to be done in a context in which the integration of the technological means Zenetos envisioned back in the 1960s have become ubiquitous in everyday activities (e.g. smartphones, the internet of things).

This book responds to these inquiries by studying the role of the interplay between the concepts of control and irregularity, ${ }^{14}$ and the informal on the everyday operation of community places that need to accommodate ever changing pluralities, and at the same time be adaptable to a dynamic process of identity transformation. It does so by questioning the politics of the symmetry between the abstract (Cartesian) understanding of space and the designing of spaces based on overdetermined occupation patterns, and by reconsidering the impact of this politics on the capacity of said places to accommodate future possibilities in use, change, accident and chance. French architect Bernard Cache suggests that 'there is progress in thought when we invent ever more abstract invariants that encompass ever wider varieties'. ${ }^{15}$ Thus framed in contemporary architectural thinking, it can be argued that one should expect these places of dwelling to emerge not from a creative process that merely privileges the point of view of the users that still relies on the motivation and the agenda of the creator-individual, but rather through alternative approaches that are creatively practised within space.

An interesting take on site-specific housing practices of user engagement is the work of R\&Sie(n), who materialised Friedman's concept of Architecture Mobile, in particular the way the latter envisioned a continuously re-forming urban fabric for his aerial city, which would be fluid and transformable. True to this vision, today R\&Sie(n)'s I've heard about project $(2005)^{16}$ exemplifies a materially ephemeral architecture by means of the synthesis of computational logic, digital fabrication and new material technologies.

The public sphere is everywhere, like a pulsating organism driven by postulates that are mutually contradictory and nonetheless true. The rumours and scenarios that carry the seeds of its future 
mutations negotiate with the vibratory time of new territories. ... The cells [dwelling units] were no longer enclosures to protect from the outside. 'When you say interior-exterior you are creating a prison without even knowing it.' Now there were 'habitable networks, woven space,' an exfoliation of constantly reconfigured habitable organisms whose elasticity was not psychological but physiological. ${ }^{17}$

The non-standard methods of robotic construction, the politics of authorship and co-creation, and the economy of sharing and individuation of R\&Sie(n)'s anarchist proposal might be novel in their procedural formation and materialisation, but its motives, population thinking ${ }^{18}$ and user-driven perspective are akin to less exuberant proposals and projects, such as that of the Huu Nghi community presented in Chapter 6 of this volume. Johanna Brugman's chapter highlights the 'conflicting rationalities' that are exercised in housing development processes due to the competition between the various stakeholders and actors involved, and their different agendas. There is significant literature concerning projects that respond to the need for co-creation or contribute alternative strategies and funding schemes, but the example presented in 'The role of community-driven finance in bridging formal and informal practices in housing: insights from Vinh, Vietnam' adds new holistic methodologies to the relevant discourse as it hybridises a self-funding scheme in housing development with a community-driven design process. Similarly in R\&Sie(n)'s experiment users curate the on-site, robotically (and therefore self-driven) construction of their dwelling units for as long as they remain tenants of the block; when the user moves elsewhere, the unit is disassembled in order to be rebuilt on a new location. This thinking relates to ethics of co-creation and economy, which (although approached with a different agenda in R\&Sie(n)'s work) still underlie the contents of this book.

The last section of this book hosts a discussion about the everyday activities of inhabitation, performances and emerging narratives that are at stake in historical and contemporary housing projects approached from multiple points of entry - in other words, from various disciplines. In doing so it considers the production of inclusive housing spaces as an activist practice of enabling the socially interwoven formalisation of non-preprogrammed spaces. This practice calls us to rethink the need for control in the conception, development and operation of housing spaces that now become 'unstable' - that is, of a transitive identity - in order to accommodate the distinct needs of different occupants. In this 
context, 'Sharing the domestic through "residential performance"' discusses how autoethnography can be employed as a research method for the expression, documentation and communication of residential performance projects. In his chapter Jonathan Orlek builds on Latourian postphenomenological concepts of socially mediated space to explore in practice how art can be used to enable social and material actants engaging with said generative processes of control (i.e. architectural scenarios). Orlek argues for the necessity of introducing new methods that will complement housing processes with collaborative ethnographic approaches, and use empirical tools sourced from the performing arts in order to reveal hidden political and spatial geographies.

The politics of these design-enabled practices are discussed in other chapters of this book from various viewpoints, including selforganisation, art, community engagement and participatory design, and cost-effective self-building construction methods, as well as housing economics, governmental policies and the role of private initiatives in housing solutions. These viewpoints complement each other in an attempt to offer a new, dynamic overview of user participation and empowerment topics. It is envisioned that mapping such a diverse set of creative activities will exemplify the significance of these good practices to our urbanised form of dwelling for a socially sustainable future. For example, Michael Darcy and Dallas Rogers, in 'The real "housos": reclaiming identity and place', theorise about a user-driven experimentation with new media-orientated methodologies for reclaiming and intensifying specific identities, and strengthening rootedness. The objective of the projects presented in the chapter was to offer tenants a stage to express and discuss their feelings about the places they live in. In this way the creation of this stage is presented as an alternative methodology that enables users to participate in research that enquires for the challenges of disadvantaged people and places, and to contribute their personal views in the process. Pursuing the same cause from another point of view, Lee Azus' 'Uncanny home: considering race and American housing policy in Mike Kelley's Mobile Homestead' offers a critical view of site-specific art practices in the context of the activist discourse about the current neoliberal housing market that disconnects communities from the place. Azus reflects on the implications of Mike Kelley's Mobile Homestead in his effort to identify the socio-political consequences of this neoliberal agenda - segregation policies, for examplefor the historic development of public housing projects.

The purpose of this Editorial Commentary was to anchor the connecting thread that permeates the contents of this book. It traced the 
tension between the architectural creation of housing spaces and the occupation patterns of their inhabitants, arguably a relationship that is dynamic and should be understood as holistic and inclusive rather than as one that generates dichotomies and competition between the actors of the process. The chapters of this book examine the causes and results of the production, occupation and adaptation of housing estates and residential blocks from the users' point of view by means of a select number of housing projects. These are studied as large-scale laboratories for creative experiments with the multiple ways that architecture shapes living, and also as artefacts of investigating modes of habitation rather than a clearly defined end-product of design. The book contextualises these topics in the broader issues of gentrification, immigration and natural disaster relief. Issues such as equality and accessibility to housing, biopolitics of dwelling and its associated activism, planning initiatives for social sustainability and the cohabitation of the urban terrain are timely and essential in architectural education and academic discourse.

In the history of architecture the project of the housing complex has been mostly occupied with the exercise of control as a design tool for delimiting variation, and this book discusses how typical architectural approaches have been slowly replaced during the last few decades by non-standard creative practices for regulating the uncertainties associated with the production of housing. This book tries to capture an ecosystem of theoretical explorations, art practices, participatory policies and critical views on the logistics of housing production. In doing so, it contributes creative methodologies for staging dialogues on the accessibility of common resources in favour of social inclusion. It recognises that practices capable of generating shared identities based on cocreation and occupation of common spaces can serve as a good example for the contemporary architectural discourse about equal opportunities and sustainable interaction of multicultural societies in the metropolis.

Thus the contribution of this book to the contemporary discourse about housing futures is the widening scope of hybridity that characterises the presented multifaceted non-standard practices that introduce new models of co-operation and integration between the many factors, aspects and variables constituting housing production's illdefined design problem. In support of that argument the book performs a balancing act amongst multiple stakeholders' views in order to offer the reader well-defined cases of good practices from the international scene. Housing is still a pressing need of humanity today - even more so due to intensified waves of population movements stemming from natural-disaster phenomena and war - despite the countless efforts of 
architects, authorities and key stakeholders over the past century to overcome housing shortages. Responding to the pressing needs of contemporary societies for social inclusion and sustainable multicultural urban environments, this book highlights the potential of informal practices of social resilience in the context of the formal housing policies pursued by government authorities and market-driven industry. 
Section 1

Socially engaged practices of housing and contested environments

Participatory practices and negotiation policies/sharing and relation with place 



\section{Occupied city}

\section{Hotel Cambridge and central São Paulo between urban decay and resurrection}

Jeroen Stevens

\section{Introduction}

On 23 November 2012, about 200 sem-teto ('roofless' or 'homeless') families occupied the abandoned Hotel Cambridge, 216, Avenida Nove de Julho, central São Paulo, Brazil (Figure 1.1). The organised group of squatters was part of MSTC (Movimento Sem Teto do Centro, or 'Homeless Movement of the Centre'), which was a group affiliated with the larger FLM (Frente de Luta por Moradia, the 'Frontline of the Struggle for Housing'). In 2012, FLM occupied about 15 buildings in the central region of São Paulo, a number which has grown to 19 since. Together with 11 occupied terrains in the city's periphery, these squatted sites house about 10,000 low-income residents. By the time this anthology is published, these numbers will be outdated again. The city of occupations is remarkably volatile and elusive, a kinetic infusion that percolates the material culture of the city. Today, the former Hotel Cambridge is one of the movement's strongholds in the centre, accommodating 170 low-income families in what used to be a mirror palace of insouciance and extravagance.

The occupied hotel is exemplary, but not exceptional in the city. Central São Paulo has become a provisional product of myriad occupations. Over the last few decades, due to a decrease in population, the city centre has slipped 


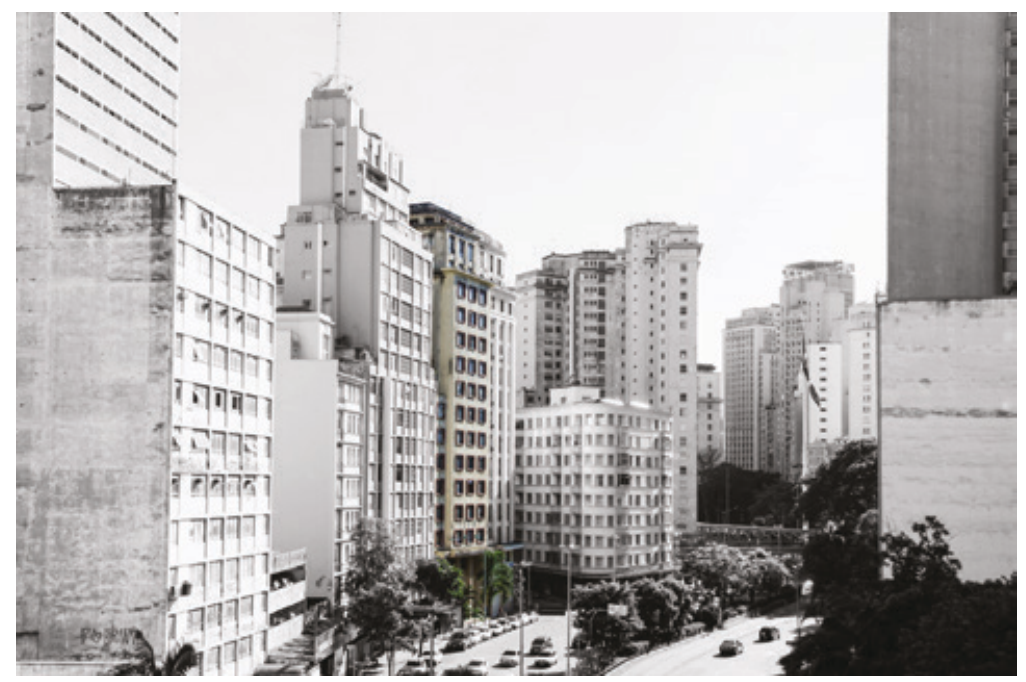

Figure 1.1 Hotel Cambridge, facing Avenida Nove de Julho.

into decay and dilapidation with high vacancy rates. Simultaneously, urban movements such as MSTC and FLM have increasingly (re)occupied the abandoned building carcasses. Semi-derelict constructions have been converted into peculiar transitional low-income dwellings. Other ways of living together have germinated from the fissures and ruptures of the centre's eroding spatial organisation, which in itself created a unique cityness emanating from the re-appropriated wasteland of unbridled urbanisation. The resulting 'occupied city' is simultaneously imagined and pieced together on the corpse and decrepit debris of the old one.

This chapter will discuss the transformation of the Hotel Cambridge as a prototypical instance of the centre's erratic oscillations between degeneration and regeneration. As a 'centre in the centre', the building's transformation will be devised as a pars pro toto for the concurrent metamorphosis of downtown São Paulo. The focus lies on the mutual transformation of the building and its built environment vis-à-vis occupation practices that seek to carve out spaces for collective dwelling for some of the city's most vulnerable population, by reclaiming the idle architecture of vacated hotels, offices, factories and commercial buildings. The chapter sets off by presenting the entangled idiographies of Hotel Cambridge and the central area of São Paulo. First, the ambitious inauguration and glorious heydays of the hotel will illustrate the centre's alleged revival. Secondly, their looming deterioration will be examined. The third section will focus on the popularisation that simultaneously 
permeated the centre and the vacated hotel. Subsequently, the rise of central occupation movements and their tactical repertoire for reappropriating vacant structures will be explored. Finally, an architectural analysis of the present-day occupation will illustrate some aspects of the contradictory proto-urbanity that is propagated by the centre's collection of occupations.

\section{Centre of prosperity}

In the early twentieth century, São Paulo mutated from a modest town into a global metropolis. While the city rapidly expanded, its former colonial centre utterly transformed. The iconic inauguration of Latin America's very first skyscraper in 1929 - the Martinelli building - was a harbinger of the centre's surge of reconstruction. ${ }^{1}$ Two decades later, the colonial settlement is almost entirely replaced by vertical constructions. Some of them are remarkable architectural masterpieces, yet most present banal replicas of the same model that turns minimal land properties into maximum profits. Still and all, a new centre is supplanting the old one, a 'modern' high-rise metropolis fudged together on the wreckage of the old, and Hotel Cambridge is one of the paragons of the metamorphosis.

Before its outworn remains were squatted, for almost 30 years Hotel Cambridge was one of the most exclusive and fashionable hotels in town. The building was erected in 1951 by the Paulistano businessman Alexandre Issa Maluf, after the design by the Hungarian-Brazilian architect Francisco Beck and inaugurated two years later. The luxurious edifice flanks the brand-new Avenida Nove de Julho, one of the recently implemented 'grand avenues' Prestes Maia had foreseen in his influential Plano de Avenidas (1930), the city's first comprehensive masterplan dedicated to salvage the congested centre from further 'slumification'. Backed by a steadily growing economy, the plan brought the centre back onto the radar of investors such as Maluf. The latter's sparkling new hotel covered a built area of 8,600 square metres, with 94 apartments and 26 suites, spread over 16 floors, including a generous lobby, a spacious bar, a restaurant and a beauty salon. Managed by a group of Spanish entrepreneurs, it soon made its name as one of most chic venues in downtown São Paulo.

The building façade was static and symmetric, with a sequence of square windows looking over the Anhangabau Valley, the crucible of São Paulo's initial settlement. A monumental portal facing the avenue gave access to a double-height ceiling lobby. Massive concrete columns 
framed a patchwork of carpets, leather sofas and small wood-crafted tables that today would be designated as genuinely 'vintage'. Marble walls were cautiously decorated with dark woodwork and plentiful modern chandeliers draped the interior in soft yellow light. Two central elevators - the mechanic innovation that sparked high-rise construction from the 1920s onwards - encircled by a fairly majestic marble staircase, led up to two rooftop terraces, offering stunning views over the city. The hotel was primarily celebrated for its elegant bar, accessible from the back door, and embellished with three large murals by the influential Italian-Brazilian artist Danilo Di Prete. Over the course of the 1950s and 1960s, the cafe turned into a beloved rendezvous for bossa-nova and jazz fanatics. International celebrities such as Nat King Cole, Ivon Curi and Dick Farney, as well as famed sport teams, frequented the place and embued it with a mythical imaginary.

If anything, the architecture of the hotel yearned to resemble the centre's ostensible renaissance as the aspirational metropolitan epicentre of Latin America's progress, encapsulated in an architectural vocabulary of extravagance. Against the backdrop of São Paulo's fierce industrialisation and ostensible leap into modernity, the city emerged as the continent's economic powerhouse. While Brazil's modernist movement was devoted to materialising the radically new 'modern' capital of Brasília, Hotel Cambridge and its analogues constituted an architectural pseudo-modernist spin-off, carried out by joint investors and architects jumping on the bandwagon of development and modernisation, albeit without much of the social reform agenda proposed by modernists of the period. These are the characteristics of modernisation rather than of modernism.

\section{Centre of decline}

Despite significant investments in the centre's renewal, for better and for worse, incentives for recuperation never enforced a complete makeover. ${ }^{3}$ Hotel Cambridge, and other opulent investments (as much as they bear testimony to the centre's purported resurrection), equally mirrored the centre's stagnant incapacity to live up to over-ambitious renovation projects. By the end of the 1970s, the global financial crises had caused unemployment and poverty among many denizens that had been drawn to the city during the decades of prosperous development. The convergence of dwindling wages with escalating rent and property prices largely impeded 'formal' dwelling opportunities for the city's 
low-income population, and pushed them together with new arrivals to large informal settlements that aggregated on the periphery of the metropolis. ${ }^{4}$

As the city's periphery urbanised, its old centre paradoxically peripheralised. Although urbanistic interventions in part sought to prevent it from complete collapse, they contributed to its gradual disintegration. Up to the mid-twentieth century, most urban interventions were devoted to the concentration of tertiary activities, and to 'sanitising' overcrowded slums, which also had the effect of wiping out numerous neighbourhoods inhabited by workers. ${ }^{5}$ The aforementioned Plano de Avenidas further engendered destructive reconversion works that wedged the centre between concentric ring roads, transversely intersected by a major north-south expressway taking over the former valley of the Anhangabau River. Meanwhile, renewed building codes encouraged almost unbridled verticalisation of the centre's built tissue. ${ }^{6} \mathrm{~A}$ series of highways and viaducts were amassed in the vicinity of the centre, geared towards improving the macro-accessibility of the metropolis' south-west area. On the rebound, the old centre increasingly surfaced as an isolated island amidst giant traffic junctions, traversed by overdimensioned infrastructures that eradicated vast sections of its built tissue and viciously disrupted the urbanity of popular neighbourhoods. The 1972 zoning plan unwittingly added insult to the injury by rigidly designating the centre as a merely commercial enterprise. ${ }^{7}$ Large areas were pedestrianised as well, to square off over-congested traffic. While major road constructions mutilated the centre's morphology, the historic Praça da Sé was designated as the leading junction for the new metro network, encircled by the new principal bus terminals. Slowly but surely, the centre became an outstretched walkable transfer hub, a vital site for commerce, trade, exchange and passage, not of residence or inhabitation. It became overcrowded during the day but deserted during the night.

The recurrent tinkering with the centre eventually propagated a vast exodus of inhabitants. Chief banks and corporations migrated from the 'old' to 'new' prestigious centres around the Avenida Faria Lima (1968) and the enlarged Avenida Paulista (1974), south-west of the city. ${ }^{8}$ Most of the high-rise buildings that were hastily cobbled together during the 'verticalisation decades' proved insufficient for the demands of contemporary offices, lacking car accessibility, parking facilities, airconditioning or technological requirements in general. Also numerous cultural and recreational institutions abandoned their decrepit downtown infrastructures, while multiple public departments left the outmoded centre for more illustrious locations. ${ }^{9}$ Although the metropolitan 
population increased by 42 per cent during the last two decades of the twentieth century, Sé - the centre's oldest district - lost approximately 40 per cent of its inhabitants..$^{10}$ While new developments precipitately mushroomed around the city, the discredited historic core successively imploded (Figure 1.2).

The withdrawal of businesses, cultures and residences left a stockpile of obsolete building carcasses behind. In Sé, 3,055 dwellings were found abandoned in the census of 2000, accounting for a vacancy rate of 26.77 per cent. As a whole, the centre counted about 40,000 registered vacant dwellings that did not require structural refurbishment works. ${ }^{11}$ This accounted for almost 20 per cent of the centre's building fabric that was obsolete, although fit for inhabitancy. Actual vacancy rates remained uncharted, as the census did not include the assortment of deserted hotel buildings, office towers, governmental institutions, commercial buildings, factories and industrial warehouses, nor residential constructions with structural deficiencies. In other words, at least onethird of the centre's architecture was probably abandoned, leaving derelict architectural relics, which were gradually falling apart because their functionality had been temporarily suspended. Altogether, the Fundação Pinheiros estimated that almost 600,000 buildings were inhabitable but vacant in the metropolitan region of São Paulo. In the same yearly report, the institution calculated the metropolitan region's housing deficit at 582,129. ${ }^{12}$ São Paulo counted and still counts more dwellings without people than people without a dwelling. Ironically, while one-third

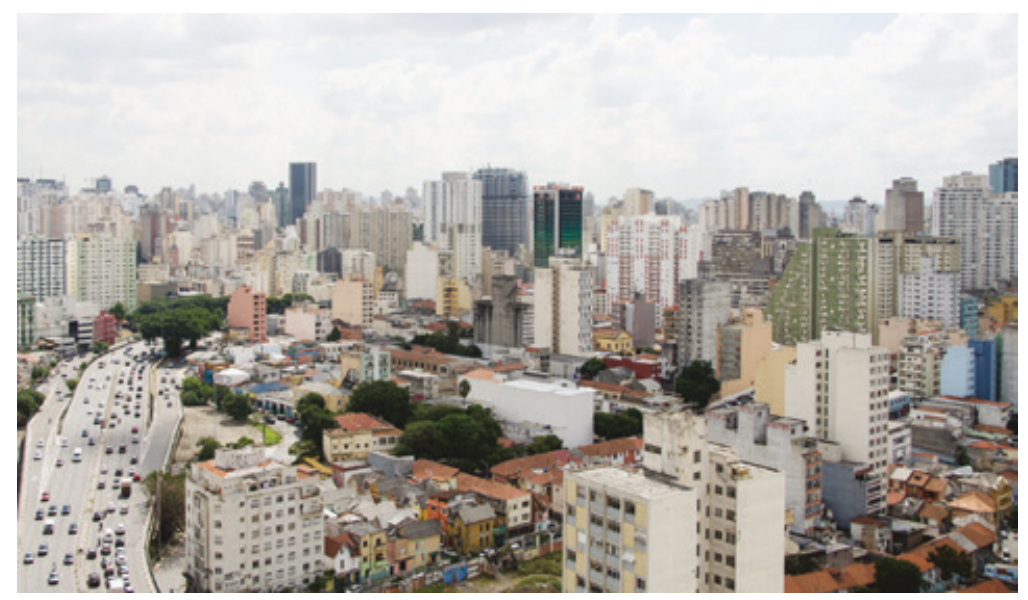

Figure 1.2 Central São Paulo's hodgepodge of morphologies, typologies and infrastructures. 
of the city's architecture was left in obsolescence, another third of the urban population was living in unacceptable dwelling conditions.

Hotel Cambridge symbolised the centre's gradual erosion. While the urban elite fled the discredited historical area, cars increasingly dominated the building's surroundings. Given the escalating traffic congestion on the Avenida Nove de Julho, its splendour waned, and much of the building tissue along the avenue was left obsolescent. As the population withdrew, criminality rose. Unsurprisingly, the hotel's highbrow clientele was lured away by alternative hangouts. What had been the 'centre' was no longer an aristocratic 'place to be'. The hotel managed to stand firm for a long time, despite fierce financial issues and erupting disputes between the owners and the managers. In the early 1990s, the building was drastically renovated, a last resort to reclaim lost glamour. Afterwards, the hotel's bar showed up in popular media, reminiscent of its 'charm of the 1950s', and celebrated for maintaining the 'nostalgic' atmosphere of long gone days. ${ }^{13}$ It was by now managed by a young migrant from Pernambuco, one of the many who moved from the poorer Nordeste Region of Brazil to São Paulo on the promise of more desirable work and dwelling opportunities. Many of these new arrivals filled the vacated building stock in the centre, as they became the dominant population of the centre's cortiços (substandard tenement rooms). ${ }^{14}$ The owner passed away in 1998 and the building was left to his two sons. It became a popular backdrop for photographic shoots, theatre plays and film scenes that sought to recapture the character of the 1950s. ${ }^{15}$ The building was already a simulacrum of what it allegedly used to be. It continued to function up to 2002, when it finally closed its doors (Figure 1.3).

\section{Centre of popularisation}

As middle-class residents and activities evaded the centre, many of their renounced spaces were recycled by poorer residents and secondary enterprises. Posh establishments made room for popular lanchonetes (snackbars), exclusive galleries became mundane bazaars, renowned cinemas turned into peepshows, well-known hotels into motels for promiscuity. In addition, the concentration of commuters attracted informal street vendors and small businesses. Many of the ramshackle building remnants of more glorious building decades turned into cortiços, and the homeless increasingly inhabited residual spaces beside and below infrastructures. Many left-behind vacant properties are squatted. Ironically, 


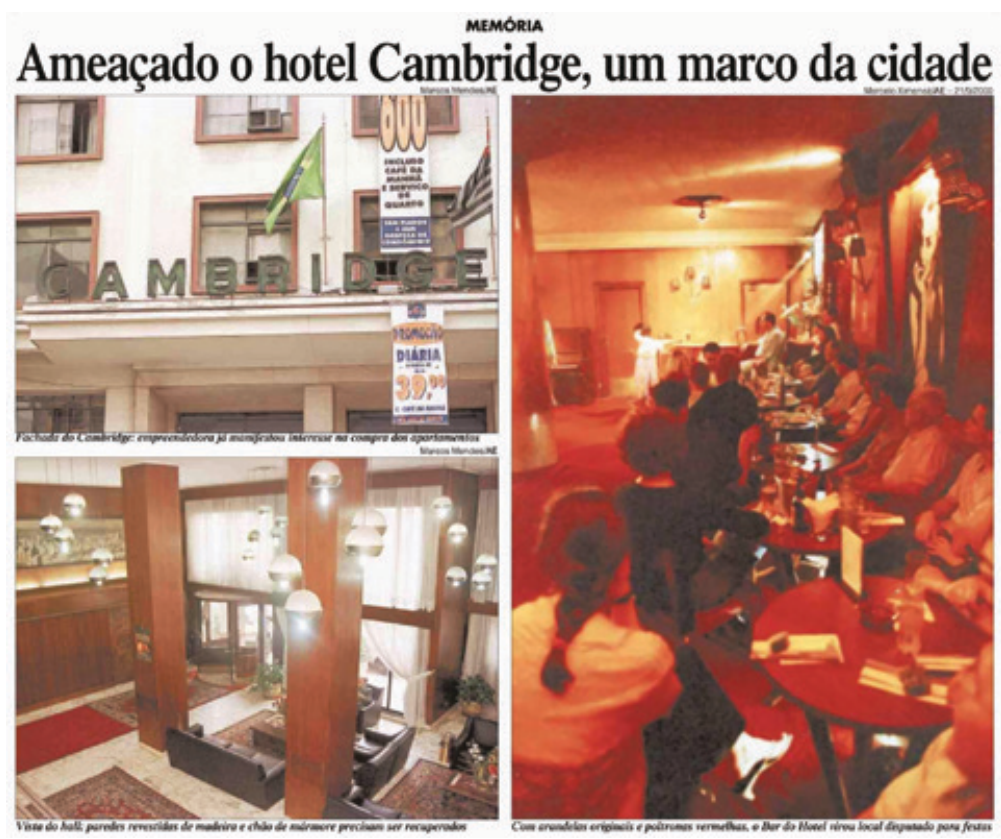

Figure 1.3 'Hotel Cambridge threatened, a landmark of the city'.

Latin America's once so vigorously proclaimed 'pioneer' skyscraper, the Edificio Martinelli, in the 1970s turned into the city's first vertical slum, a monumental cortiço of 27 floors. ${ }^{16}$ The surging proliferation of socalled 'subaltern' claims on the architectural remains of what the elite had forsaken, in turn, only accelerated the departure of middle-class occupations. The centre turned more and more into a central periphery, ${ }^{17}$ a secondary centre, in the shadow of other development fronts, and in that sense easily harboured what Remy and Voyé designated as a 'weak legitimacy', fostering other ways of being by virtue of remaining somehow off the radar and out of sight. ${ }^{18}$

The centre also remained 'central' in many ways, in part because its diachronically accumulated symbolic value could hardly be reproduced elsewhere. ${ }^{19}$ Paradoxically, the same districts that suffered the highest population decrease simultaneously collected most urban services and jobs, now more tailored towards low-income workers. For those that depended on public transport, it was still the best-equipped area of the city, congregating low-skilled jobs, public social and educational institutions, and affordable cultural amenities. Although it was less and less inhabited, daytime urbanity was thriving. 
In the meantime, Hotel Cambridge entered a popular afterlife as underground night club. 'Trash 80s' DJ sessions took over from jazz and bossa nova, while Nat King Cole made room for DJ Tonyy and the hits of Abba and Rádio Taxi. ${ }^{20}$ The new party spot was a hit, and the former hotel's large communal spaces were jam packed from Thursday to Sunday. The extravagant concrete structure that once sought to evoke elitist prestige was subverted, from jazz to pop, from elegance to 'trash', from elitist to popular, and - arguably - from exclusiveness to inclusiveness. The upper 14 floors remained vacant, and slipped into gradual decay.

\section{Centre of recrudescence}

On the night between 8 and 9 March 1997, about 1,000 members of the ULC (Unificação de Lutas dos Cortiços, 'Unification of Cortiço Struggles'), undertook what became known as the first organised building occupation in São Paulo, simultaneously occupying four abandoned buildings in the centre. The ULC emerged at the end of the 1980s, together with various other movements, and supported by the Housing Pastoral of the Catholic Church and human rights associations, to fight for better living conditions in the centre's cortiço-packed regions. The occupants' accomplishment to stand firm and successfully negotiate with the property owners proved to be an impetus for insurgence, and sem-teto groups were invigorated for the years to come. They transposed the occupation strategies of the well-organised MST (Movimento dos Trabalhadores Rurais Sem Terra, the 'Landless Movement') to the inner city and turned their mass-organised claim for rights to the city into a struggle over rights to the centre of the city, incorporating all the pragmatic and ideological aspects 'centrality' entails. ${ }^{21}$

By 1999, building occupations were pervasively entrenched in the centre's architectural landscape, in their material presence openly criticising the lamentable quantity and quality of social housing, exacerbated by the abundance of vacant buildings in the centre of the city. After a fatal accident in one of the occupations the same year, many movement leaders withdrew from long-term occupations, advancing instead political negotiations, every now and then supported by short symbolic occupations. Some did keep durable occupations as a vocation and established the MSTC, in 2004 joining forces with other radical movements under the umbrella of FLM. Over the years, FLM became the largest housing movement active in the centre, and one of the most outspoken advocates of ocupar para morar (occupy to live): occupation 
not solely as a political performance, but to inhabit. This set them apart from Brazil's largest union of housing movements, the UMM (União de Movimentos de Moradia, 'Union of Housing Movements'). A principal FLM slogan is Ocupar, Resistir, Construir, Morar! (Occupy, Resist, Construct, Dwell!), openly shifting the focal point of the Landless Movement's mantra Ocupar, Resistir, Produzir, from 'production' to 'construction' and 'dwelling'. Over the years, FLM became highly professionalised in organised squatting, involving a thorough screening of abandoned properties - collaborating with notaries, lawyers and journalist collectives - as well as in self-managed 'reform' techniques, turning obsolete building cascos (shells, stripped-down structures) into genuine transit-housing complexes. This way, they refused to unequivocally choose a side in movement debates over 'reformism' versus 'revolutionism', as they purposively combined political participation with direct action. They 'demonstrated' not only politically, but also pragmatically, by pre-fabricating provisional responses for the issues they denounced. Their occupations practiced what they preached, demanding political action without waiting for it to come, but instead prefiguring it piecemeal. Notwithstanding their affiliation with the Brazilian Partido dos Trabalhadores (communist labour party), their approach to housing was remarkably anarchistic, advocating the kind of solutions that 'would be made if we were living in the kind of society we envisage [putting forward] anarchist answers that can be tried out here and now'. ${ }^{22}$

The impact of occupations on the centre's gradual reform has been significant. Sanches illustrates how occupation movements managed to put the centre back on the 'urban agenda', and forced the federal, regional and municipal governments to improve living conditions in the centre. ${ }^{23}$ In 2002, Hotel Cambridge was shortlisted for reconversion through the municipal 'Morar no centro' ('Living in the centre') programme, but, as so often, the project got stuck in red tape. While Madre de Deus, the first successful central social housing project initiated by an occupation movement, was under subsidised self-construction, social movements began an initial register of vacant buildings eligible for reconversion. The list was picked up by a dedicated task force (Grupo Técnico de Analyse de Imóveis, GTAI) of the city's Housing Secretary (Secretaria Municipal de Habitação, SEHAB). Between 2001 and 2004, they charted 317 abandoned properties in the centre. ${ }^{24}$ In 2009, COHAB (Companhia Metropolitana de Habitação, the 'Metropolitan Housing Company') appointed FUPAM (Fundação para Pesquisa Ambienta, 'Foundation for Environmental Research'), at the University of São Paulo (FAU-USP) to update the 
old list and identify vacant structures suitable for housing. In total, a detailed report compiled information on 221 buildings, of which 53 were found directly suitable for expropriation, renovation and social habitation. ${ }^{25}$ Hotel Cambridge was one of the 53 selected buildings, and in September 2010 it was indicated for the Renova Centro ('renovate the centre') programme, which promised to expropriate and reform all 53 buildings. Eventually the last underground party in the hotel's basement took place in June 2011. Together with seven other FUPAM-listed hotels, Hotel Cambridge was bought by the municipality under wide media coverage, applauded by social groupings, and condemned by many middle-class residents, who regarded social housing in the centre as yet another 'out of place' disgrace that the area had to endure. The building was now part of an ambitious project to partially renew the centre with and for low-income social groups.

Nonetheless, Hotel Cambridge remained vacant due to bureaucratic complications. A year and a half after the expropriation, on 23 November 2012, the building's gate was forced open by a group of sem-tetos from MSTC-FLM in intense turmoil, occupying it to take the municipality at its word, and pressurise the building's reconversion (Figure 1.4). For months, families had been preparing for the breakin in one of the movement's basegroups. Their weekly meetings resonated Freire's controversial 'Pedagogy of the Oppressed', ${ }^{26}$ advocating a labourer-liberation stemming from conjoined critical reflection, stimulated through dialogical popular education, as the necessary impetus for radical praxis, the 'humanising' resurrection of the poor. In the basegroups, families were introduced to the ideological currents and strategic tactics that MSTC and FLM have developed over the years. This is also the place where occupations are meticulously prepared and carefully orchestrated. Mostly, buildings are simultaneously occupied as a set, to gain visibility and encumber police. Different groups gather in secluded localities and are synchronically mobilised to different target buildings. Often, this implies the coordination of a few thousand occupants, in part transported with a series of buses from peripheral locations. There seems to be a sense of urbanistic thinking latently underpinning the whole operation, a deliberate contemplation on where, when and how to act on the city, which remains at the same time largely impromptu, 'on the spot', experimental and hence prototypical at any time.

The occupation moment bears resemblance to Victor Turner's rite de passage, a liminal moment of breaking with the established 


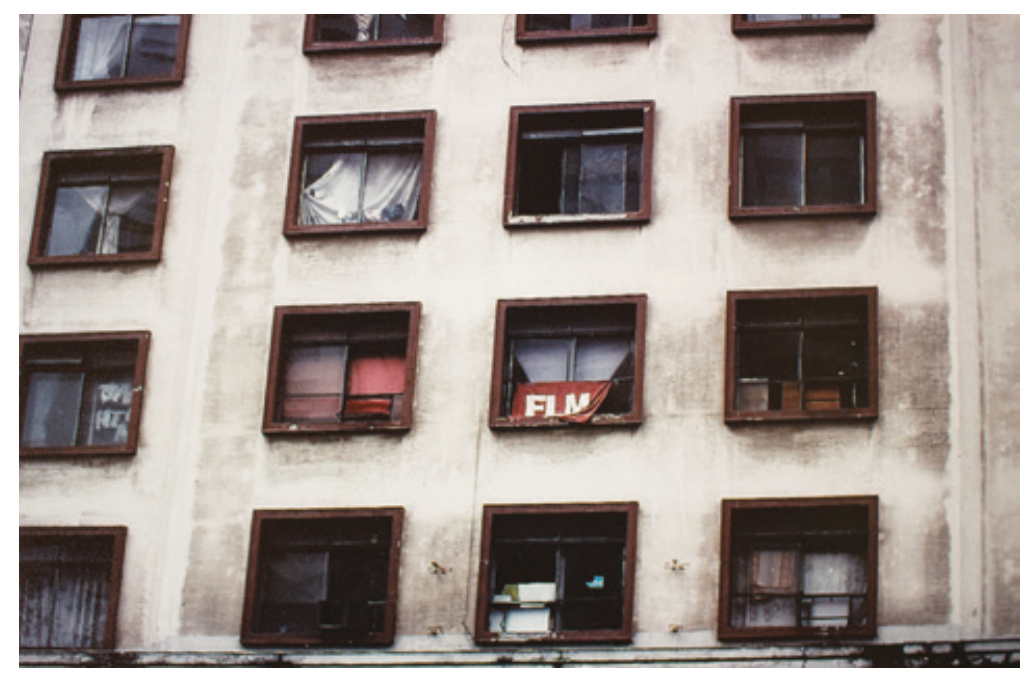

Figure 1.4 Hotel Cambridge, after its occupation by MSTC-FLM.

order of the personal and the urban status quo through an iconoclastic act of creative destruction, smashing, shivering and dismantling the material obstructions that separate the publicness of the street from the interior's reserved private sphere. ${ }^{27}$ It is nominated a dia da festa (a party day), as a semantic affirmation of the occupation's ritual nature, an event-like festivity to hanker for. For many participants, it is a transgressive and cathartic experience of self-liberation. At the same time, the slumber of the building is disrupted, entering a liminal upheaval, betwixt and between established spatial orders. The occupied city is a joint transition for the building and its occupants. When the Cambridge Hotel was occupied, the military police intervened promptly and forcefully, entrusted to redress the disturbed order. Avenida Nove de Julho was blocked, and the group of sem-tetos driven off with teargas and batons. The occupants set up a linha da frente ('front line') of mainly elderly people, women and children to discourage violence. For a number of days, policemen blocked the entrance, and participants later recalled how they hoisted food through windows at the back of the building, while the military were trying to starve them out. Despite the deplorable conditions inside some 200 families stood firm. The group locked itself down, welding the iron entrance gate from the inside. The movement's flag was draped out, an almost militaristic seizing of power over a newly acquired territory, inducting the former sanctuary of richness into a bastion of popular resistance. 


\section{Centre of proto-urbanity}

On the first night of the occupation, a rudimentary campsite was constructed in the ruins of the 1950s landmark. Dedicated task forces initiated specific commissions: defend the entrances, set up collective cooking and eating facilities, provide water, repair electrical and hydraulic infrastructures, initiate cleaning works or furnish provisional sleeping places. Decay had left its traces, and during the first weeks, no fewer than 25 trucks of refuse, piled up over years of neglect, were taken out of the building. Construction and management took the form of mutirão, a notion derived from communal help systems in rural territories that eventually came to depict mainly collective building-related practices. ${ }^{28}$ Families settled rapidly, and as the military cordon left the place, a convoy of mattresses, ovens, refrigerators and furniture entered the building to increase the costs and hence impede eviction. Most furniture resulted from shopping rua ('street shopping'), was collected in the streets or was scavenged from dumpsites. The proto-project is by definition a recycling project, concurrently reclaiming a group of residual buildings, orphaned household goods and an allegedly 'lost' and largely abandoned population (Figure 1.5).

Solnit eloquently illustrated how extraordinary communities emerge from the precarious displacement caused by large disasters, as germs of a 'paradise' under construction that effloresce from ruined

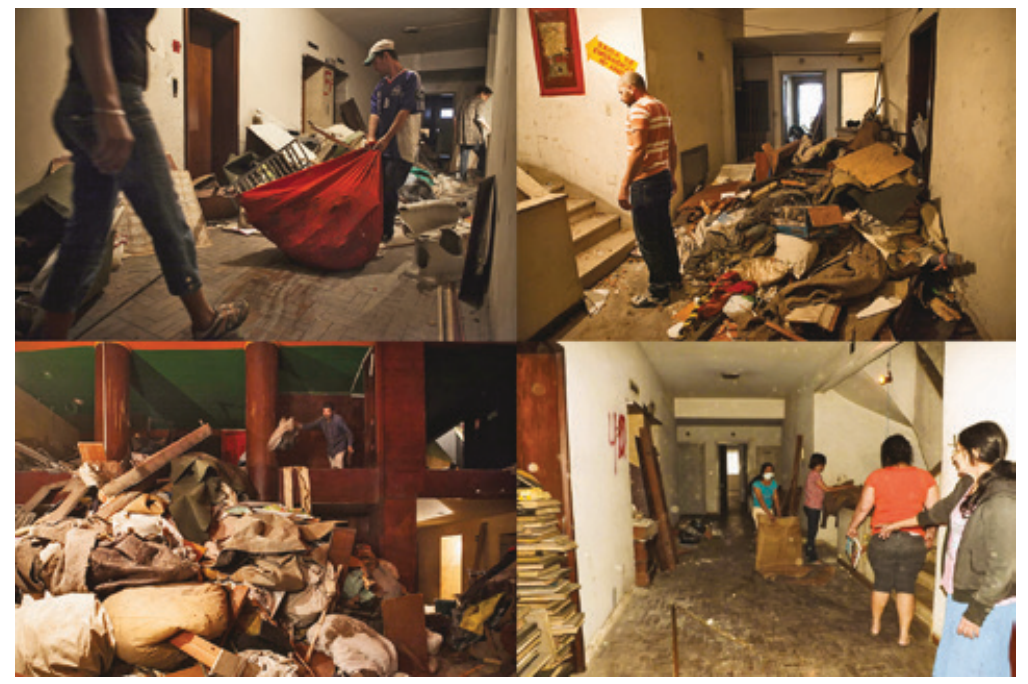

Figure 1.5 Mutirão, and the piecemeal architectural reclaim of the derelict hotel. 
architectures. ${ }^{29}$ Differently but likewise, a peculiar emergent sense of communitas was forged by the precarious working and living together in the newly occupied building. Community, here, indeed emanated from a shared state of crisis, part and parcel of a strategy for survival, or at least improvement. ${ }^{30}$ In fact, the peculiar collectivity that emerges in the occupations is inextricably bound up with its (in part deficient) architecture. It is exactly the building's demand for adaptation and patching-up to make it fit new purposes that compels collective action and decisionmaking. Precisely this incremental architectural proto-project inheres other ways of living together, albeit stemming more from an 'imperative' to build than from Turner and Fichter's ideological 'freedom' to build, ${ }^{31}$ 'confusing freedom to act with the necessity to survive'. ${ }^{32}$ Rather, it is the defective architectural performance and the necessity of material repair and reprogramming as well as the implicit obligation to reconsider spatial uses that compels some kind of community to become established. Hence, mutirão dictates the everyday, encompassing some kind of architectural and societal laboratory, even if that results from exigency much more than from premediated utopianism. ${ }^{33}$

Between 2012 and 2016, Ocupação Cambridge developed into one of the movement's most cherished bulwarks in the city, proudly displayed to potential members and envied by other movements. Although the occupations are broadly criminalised by conventional media, Cambridge slowly made its name as an 'ocupação chic', one to be proud of, where the label 'sem-teto' was carried in a kind of allegoric 'black pride' celebration of subaltern culture, and as material proof of what the 'urban outcast' autonomously can accomplish. For the movement it remained a provisional solution, an instrumental device for personal improvement and political pressure, but not a final destination in itself. For many inhabitants, however, things stood differently, as the majority was less concerned with the movement's political agenda, and more with improving their living conditions. It is an ambiguous condition, wherein the movement strives to accelerate inclusion into the conventional housing mechanisms of the city as is, while simultaneously striving for a peculiar kind of 'exclusion', claiming increasingly rights to build another city - indeed, 'for the defense and strengthening of difference and autonomy'. ${ }^{34}$ Similar ambiguity plays out in the movement's legal tactics, legitimising transgressive squatting actions by the unconditional constitutional right to decent housing, and the 'social function of property' (since 2001 the 'City Statute' has legally obligated properties to be 'proper' - that is, serving a social purpose). For FLM, sem-tetos are legitimised and even impelled to violate the right to private property in order 
to rectify the unlawful homelessness to which they had been subjected, and the affluence of 'improper' properties. The occupied city simultaneously breaks and enforces the law, stemming from the demands of an everyday political agenda.

With the means at hand, the architecture of the building has been adjusted to comply with the occupants' ever-changing aspirations. The entrance was reinforced, branded in the movement's red-and-white house style and tagged with movement logos. The graphical language is defensive, often aggressive. The large ground-floor windows are deliberately covered up with brickwork. The reception desk is reused as a gatekeeper's portal; no one gets in or out without signing the respective list. The occupied city is firmly defensive, exclusive in its own way. Ironically, architectural filters that used to reconcile the hotel's strict exclusive nature with a mimicry of openness and accessibility are now recycled to regulate the movement's ambivalent border control. The lobby has been turned into a large meeting space (Figure 1.6). Walls are blackboard-painted, and daily announce upcoming actions and meetings as well as miscellaneous communication. Others carry movement slogans: Quem não luta, ta morto! ('Who is not fighting, is dead!') the most popular one, reminiscent of Freire's pedagogy again, underscoring the poor's duty to fight for a humanised living. Also, Ocupação, uma canteira de obra ('The occupation, a construction site'): the occupation as a

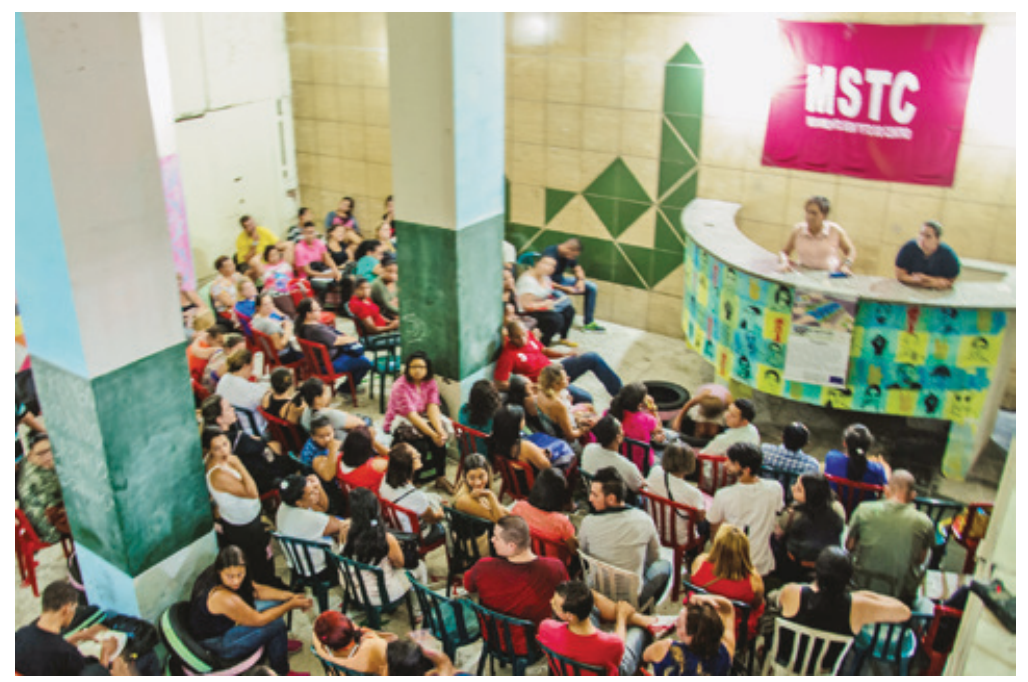

Figure 1.6 Weekly occupation 'assembleia', meeting of inhabitants and co-ordination. 
continuous project-in-the-making, a bricolage of bits and pieces that has to 'make do' with 'whatever is at hand', by reallocating 'a collection of oddments left over from human endeavours'. ${ }^{35}$

Former collective hotel spaces now mediate the occupation's inpredictable nature. The bar is appropriated as a polyvalent space, functioning, amongst others, as a film set, a capoeira hall, a cinema space, a meeting room, a concert hall and party club. From 2015 onwards, the space has recurrently staged a second-hand market and a genuine cultural sem-teto festival. A snack bar and hair salon are daily open to the street. The large restaurant space above is organised as a library, a meeting room and a small office space. The elevators' engines were stolen during the years of abandonment, making the staircase the backbone for internal vertical circulation, as well as the confluence of daily chitchat and gossip, the urban forum where one enters the communal debate willy-nilly. The former beauty salon is used as a sewing workshop, where inhabitants make a living from cloth-decoration. Each of the upper floors has its own sub-coordinator, and collective corridors and spaces are maintained daily according to a rotating mutirão list. Most floors have shared bathrooms, with variable degrees of cleanliness.

The occupation's individual apartments differ strongly, depending on the priorities and aspirations of the residents. Some invest heavily in the temporary dwelling, renew floors and ceilings, repair windows, decorate walls and organise elegant interiors. Others preserve the aesthetics of a campsite, a temporary shelter, awaiting new opportunities to continue dynamic dwelling trajectories. The temporary nature of the settlement implies that investments remain an ambiguous matter, as although many are eager to devote themselves to 'domesticating' the acquired space, it is a certainty that it will be a volatile home, an interim residence that after an unknown time will have to be returned to more conventional cycles of urban reproduction. Temporality and permanence also differ greatly among occupations. Many only last for a few days, while Ocupação Maua has been inhabited by FLM members since 2007. Despite negotiations, evictions often end up in violent confrontations with the military's special choque (shock) forces, involving teargas bombs, rubber bullets and multiple arrests. It remains a contentious city. The protourbanism is an 'ephemeral' urbanism, not as a recurrent yearly 'festival city' such as the one recently praised by Mehrotra and Vera, ${ }^{36}$ but as a rhizomatic urban constellation that perpetually mutates, shifts, adapts, disappearing from one place only to pop up again somewhere else, at the same time transiently intangible (as every parcel in itself is temporary by nature) and structurally present (as the system endures). 
In fact, squatting practices are de facto bound up with practices of urbanism, whether as the most archetypical but 'hidden' history of housing, ${ }^{37}$ as a broadly applied strategy to impede urbicide renewal schemes, or as an instrument to demand more cautious urban renewal. ${ }^{38}$ Ocupação Cambridge and other occupations carried out by FLM seem to combine traits of the European autonomous and squatter movement that proliferated in the downtown areas of for instance Amsterdam, Barcelona and London ${ }^{39}$ with Latin America's long-standing legacy in mass social mobilisation and organised land occupations, without simply replicating any of either. Downtown occupations in Latin American cities remain hardly documented, with the recently evaded Torre David in Caracas as the most illustrious exception. ${ }^{40}$ With hindsight, this absence from discourse reaffirms the prototypical nature of FLM's occupied city, experimenting with an idiosyncratic practice within the intricate genealogy of urban movements.

Although for many participants the final objective is to gain access to opportunities encapsulated in the central architecture of the city, at the same time a distinctive kind of 'cityness' emerges within the occupied set of buildings. Hotel Cambridge is one instance out of an ever-shifting constellation of occupations where another kind of living together, based on mutirão, is perpetually tested out. Inclusion is intermittently manufactured in a dialectic play of reallocating and resignifying obsolete architecture with minor amendments. The distinctive urbanity that germinates inside is highly fragile and ambivalent, as it continuously has to adapt to shifting circumstances. It is an urbanity that is time and again in a phase of experimentation, never to actually establish or consolidate. It is a kind of proto-urbanism, a preliminary, provisional laboratory prefiguring possible urbanisms yet to come, empirically put to the test on site, as a sequential demonstration of imaginable and feasible cities. It is prototypical because it remains concurrently volatile and contingent, as well as exemplary and emblematic, a project for the city ceaselessly under construction, but at the same time meaningful and significantly impactful. 


\section{2}

\section{Conflict sites in a time of crisis}

\section{Negotiating a space and place for Gypsies and Travellers}

Jo Richardson

\section{Introduction}

Within the realm of the 'politics of home' the debate on provision and management of sites is often conflict-ridden. The result is a shortage of sites for Gypsies and Travellers to live on, leading to poorer health, educational and employment outcomes. Also, observable in the many areas with insufficient site accommodation is an increase in unauthorised encampments and, in parallel, a decline in social cohesion. Conflict arises in social and political discourse on the subject of Gypsy and Traveller sites, for example when a proposed site is planned for an area. This conflict occurs particularly, but not exclusively, when Gypsies and Travellers stop on the roadside, or other public spaces, and create unauthorised encampments. However, there are examples where the complexity of this challenge is acknowledged by a range of organisations and people in one area, and where a more agile approach to problem solving is achieved to move from conflict to inclusion in accommodation for Gypsies and Travellers. This chapter argues that conflict is important in redressing power imbalances, but that better management through negotiation can move the situation on to one of inclusion and accommodation. This contribution will first set out a historical development of the conflict surrounding accommodation for Travellers, to explain the current context of conflict. It then examines a theoretical 
framework of different perspectives on land use for 'home' and the relationship with various notions of home and place; this draws particularly on explanations from Lefebvre's discussion of perceived and conceived spaces to try to understand the complex challenges and to frame the political and social struggles inherent in site delivery. ${ }^{1}$ Finally, the chapter will move from conflict to inclusion by examining some of the findings from a research project funded by the Joseph Rowntree Foundation (JRF) which sought to understand the different levels of and conditions for, and conflict within, Gypsy and Traveller site delivery and management in order to offer principles on negotiation that may help people and places relate to one another in a more inclusive way. Some ideas, such as negotiated stopping, could achieve lower costs for local authorities and better cohesion for communities; in some cases, improved outcomes are negotiated to improve policy, planning, design and delivery of sites.

\section{Historical development of accommodation conflict}

There is little accurate data for the population size of Roma, Gypsies and Travellers; they live in most member states of Europe and it is estimated that there are approximately ten million across the continent. The size of Britain's Traveller and Gypsy population is also an estimate, with Council of Europe figures compiled by Liégeois putting it at between 150,000 and 300,000, with approximately two-thirds now living in settled housing (some through choice but many because there were insufficient sites and continuous evictions forced many to move into houses). ${ }^{2}$ Whilst the majority of Roma, Gypsies and Travellers are found in Europe, there are populations of Roma, Gypsies and Travellers throughout the world, but most particularly in the Middle East and the United States of America.

Gypsies were first recorded in British history in 1502 in Scotland, and in England from 1514. ${ }^{3}$ Roma populations across Europe are members of the same ethno-social group as British Gypsies, but their ancestors settled in other European countries (mainly in Central and Eastern Europe) earlier in the migration process which started in India and culminated in this population reaching the UK more than 500 years ago. ${ }^{4}$ Gypsies were welcomed by 'commoners' who had work that needed doing and who also wanted entertaining. ${ }^{5}$ The church objected to palmistry and fortune telling, and the authorities were concerned that was not easy to 'register' the travelling people for details such as name and date of birth. This lack of governmental control is possibly one of the 
reasons for the state's treatment of Gypsies and Travellers still today; it is one of the central tensions in the relationship between both the state and Gypsies, and between non-Gypsies (Gaujos) and Gypsies.

Appleby Fair was registered as a horse trading fair in 1685, and Gypsies from across the country continue to gather every June to trade horses and meet socially. In this aspect, Gypsy culture has been celebrated, but even in this context, to this day, there are debates on policing and crime which detract from this historic cultural event. In 1780, some of the anti-Gypsy laws, introduced in the mid-1500s by Henry VIII, started to be repealed, although not all. With the introduction of the Turnpike Act in 1822, Gypsies that camped on the roadside were fined. ${ }^{6}$ During the Victorian era Gypsies and Travellers were certainly 'othered' in discourse.7 The year 1908 saw the introduction of the Children's Act in England, which made education compulsory for Gypsy children for half of the year; this was continued in the 1944 Education Act. During the Second World War the Nazis drew up a list of Gypsies for internment, and the holocaust of the Gypsies in Europe is well documented. ${ }^{8}$

The post-war period witnessed major and often centrally driven programmes to create social housing, but these approaches were not applied to Traveller sites. In 1960, the Caravan Sites (Control of Development) Act caused the closure of many stopping-places used by Gypsies and Travellers as they moved around the country. The 1968 Caravan Sites Act required local authorities to provide sites for Gypsies in England. However, the Act was never fully enforced and the envisaged post-war network of sites did not come to fruition. Nevertheless, the Act later created the statutory duty of local authorities to provide accommodation on caravan sites for Gypsies residing in or resorting to their areas; this effectively created a duty for councils to design, build and manage sites. There was also recognition at this time that it might be necessary to accept the establishment of sites in protected areas, such as the green belt.

In 1993, the Conservative government announced its intention to introduce legislation to reform the Caravan Sites Act (1968) and it is from this period in recent history that the shortcomings in legislation and policies contribute particularly to the lack of suitable accommodation today. In 1994, the Criminal Justice and Public Order Act repealed many of the legal duties to provide sites. The shortage of Gypsy and Traveller sites in England increased following the abolition of the duty on local authorities to provide sites contained within the Act and the replacement of this duty with Planning Circular 1/94, which sought to privatise Traveller site provision; but the absence of a duty meant many local authorities chose to ignore this guidance. 
The subsequent Labour government, which came to power in 1997, placed a statutory duty on local authorities to assess the accommodation needs of Gypsies and Travellers in the Housing Act 2004. The assessment of need fed into regional spatial strategies and determined how many pitches were needed within each authority in the region. Planning Circular 1/06 obliged local authorities to identify land in their Development Plans appropriate for Traveller sites; but there was very little oversight of the implementation of strategic planning for sites and, although there were some successes in delivering Traveller site accommodation, to this day there are very many local authorities without sites located in their plans.

The turn to localism under the Conservative and Liberal Democrat coalition government from 2010 saw the abolition of regional planning bodies, and there were further changes in planning legislation and guidance under the National Planning Policy Guidance and more specifically the Planning Policy for Traveller Sites. The limited successes in site delivery starting to emerge from previous policies were slowed considerably by changes made by government policy in 2010 and again more recently in 2015 and 2016. Revised planning guidance published in 2015 made drastic amendments to the very definition of Gypsies and Travellers in planning law: not recognising those who had 'settled' in one place because of old age or of other reasons, even though they were recognised under equalities legislation as ethnic groups. The Housing and Planning Act in 2016 removed the duty to undertake separate Gypsy and Traveller accommodation needs assessments, and there has been concern registered subsequently that accommodation needs assessment figures are being revised downwards to reflect a reduction in the numbers of Gypsies and Travellers recognised under planning law, albeit not an actual reduction in real people needing site accommodation.

Today, Gypsies and Travellers live in bricks and mortar housing, on private sites, on local authority/housing association sites or on the roadside. Some Travellers are settled well in housing and prefer this mode of accommodation, but there are Travellers who tell researchers that they would move back onto a site if sufficient appropriate sites were available. The legislation related to planning defines Gypsies and Travellers now according to nomadic habit for work; but equalities legislation recognises the ethnic definition that means a Gypsy is still a Gypsy when living in a house. The conflict over accommodation and site is inextricably linked to conflict over definitions and identity. 


\section{Conflict, space and identity}

Different aspects of space are the source for conflict in the planning system on any planning applications whether for new homes, wind farms or indeed Gypsy and Traveller sites. Fragmented societies create challenges for planning and there is a need to recognise difference, understand past trauma and engage in participatory planning processes so that communities get to know each other better.9 Indeed, Forester makes the point that planning education and training have traditionally neglected skills to tackle conflict and tension in the planning process. ${ }^{10}$ Space is contested and it is represented and perceived in different ways the construction of 'green belt' in the mind's eye of people objecting to plans for new sites, for example, is particularly interesting in the examination and consideration of planning inspectors' language in their decision making.

Porter says:

the structures of meaning and authorities of truth that give planning agency in the world are drenched in the colonial historiographies, and so the colonial relations of domination and oppression are ever present. ... If planning is a producer of place, what does it claim is worth producing and how is this particular view of the world continually mediated and reconstituted? ${ }^{11}$

Additional consideration may be needed in planning, particularly in rural areas, because of romantic notions in discourse of the 'green belt' and the subsequent effect that this has on those who build homes in rural areas. Sturzaker and Shucksmith also examine planning for housing in rural areas and they argue that vested powers and interests can have an effect which increases exclusion:

[A]n 'unholy alliance' of rural elites and urban interests have wielded discursive power to define 'sustainability' on their own terms, which exacerbates the unaffordability of rural housing, leading to social injustice and spatial exclusion. ${ }^{12}$

Planning for 'affordable' housing is challenging enough in rural areas. When one considers Sturzaker and Shucksmith's comments in light of the difficulties in planning for Gypsy and Traveller sites in areas particularly where the only available land is in the green belt, it could be 
considered that Gypsies and Travellers are spatially segregated in liminal spaces on the edge of communities.

Conflict occurs in spaces where there isn't a common 'language'. Places where there is no shared understanding of different histories, cultures and races living within, or on the outskirts of such spaces, can exacerbate the feeling of strangeness and difference and lead to a lack of empathy which can in turn lead to further conflict. Zygmunt Bauman recognised how, when neighbours were made to seem 'other' and different, it was easier to acquiesce to discrimination and subsequent horror. ${ }^{13}$ Miles Hewstone also demonstrates the need for proximity in his study of 'contact theory' as a method to explore better relations between different ethnic groups in a school that was in an area where racial tension had been high. ${ }^{14}$

In the context of Gypsy and Traveller accommodation the problems of 'othering' and construction of strangeness are at their most stark where land, such as the green belt, is held by the wider community as 'sacred' and is seen as being under threat when it is used for stopping places or even for permanent sites. A particular 'them and us' scenario can take hold when there is a wider shortage of affordable housing and where general housing development particularly in urban areas is increasing in density. It can then feel like there is seen to be a fight over dwindling resources, which is exacerbated by the current financial crisis. ${ }^{15}$ Where communities are struggling to provide sufficient housing that can be accessed by people generally, anything that is seen to be different or provided in a special case can fuel feelings of resentment and further fuel latent conflict. Local authority councillors can feel trapped in these spaces of conflict, and are also, in some cases, concerned about the impact of residents' opinions on their ability to retain political power. Understanding the motivation behind 'no' to allowing an informal stopping arrangement, or 'no' to supporting a planning application for a new permanent site where it is needed, is important to unlocking a less conflicting approach to local planning debates for Gypsy/Traveller sites. 'No' may be explained through a lack of understanding of different groups' claims and aspirations for space and place; tensions in differing perceptions of place and links with cultural histories create an incoherent conversation in future planning.

Lefebvre examines perceived realms in space. ${ }^{16} \mathrm{He}$ discusses the need for interconnectedness between 'lived, real and perceived realms' and makes it very clear that this concept should not be viewed in the abstract, if its importance is to be retained: 
That the lived, conceived and perceived realms should be interconnected, so that the 'subject', the individual member of a given social group may move from one to another without confusion so much is a logical necessity. Whether they constitute a coherent whole is another matter. They probably do in favourable circumstances, when a common language, a consensus and a code can be established. ${ }^{17}$

Favourable circumstances for interconnectedness between these realms certainly do not exist in the process and debate surrounding planning policy for Gypsy and Traveller sites. One cannot see evidence of a common language, code or consensus between different groups and individuals living in a particular geographical area, and therefore it is unlikely that Lefebvre's conceptual triad can be anything but abstract in the realm of planning policy and decision making for the use of space in relation to Gypsy and Traveller site provision. Indeed, the language surrounding debate on providing sites is divided and divisive, as previous research on the use of discourse to control Gypsy and Traveller issues has shown. ${ }^{18}$

These different aspects of space are the source for conflict in the planning system on many planning applications whether for new homes, wind farms or indeed Gypsy and Traveller sites. Lefebvre's analysis of 'contradictory space' touches on the emotional connectedness with space as lived experience, rather than abstract planning policy. He says:

'Human beings' do not stand before, or amidst, social space; they do not relate to the space of society as they might to a picture, a show, or a mirror. They know that they have a space and that they are in this space. They do not merely enjoy a vision, a contemplation, a spectacle - for they act and situate themselves in space as active participants. ${ }^{19}$

If the lived, real and perceived realms of local residents, councillors and Gypsy/Travellers in an area could find a connected discourse, a shared language, then there is a greater possibility of sharing understandings of the history and culture of places and the people who live there or travel through on a habitual basis. Debates on location in space for Gypsy/Traveller sites can range from the blatantly hostile 'we don't want them anywhere - ever' to more reasoned arguments in 'fairness' of having a site in a particular area. However, 'fairness' of location rarely includes the preferences of Gypsies and Travellers, but rather focuses 
on discussion of locations that might cause least impact on the wider community. As a result, sites have typically been built in liminal spaces of least resistance, next to railway sidings and rubbish dumps, near sewerage works and under fly-overs - often on the edge of towns, reflecting the perceived otherness in the physical separation.

The perception of space itself is also an emotional consideration. Lefebvre's work shows the connection between human beings and space which prohibits the view of space in an abstract form, because it is lived experience. So, as important as it is to consider reasoning and objective criteria in conflict resolution approaches, as suggested by Fisher and Ury, ${ }^{20}$ it is also necessary to consider emotions such as fear, in the debate on planning for sites. Forester challenges, 'When interests clash, we bargain and negotiate. But when our values conflict, then what?'21

Deep conflict goes beyond a single issue such as planning accommodation in an area and starts to delve into strongly held values. Such values may be linked to, for example, the belief that the green belt is sacrosanct, or to perceptions of what other people (those for whom the accommodation is planned) represent. So, for Gypsies and Travellers, there are perceptions that they represent 'cost and mess' when in fact, this is not universally true. ${ }^{22}$ There can also be perceptions based on erroneous media representations of the character of Gypsy and Traveller people that fuels fears. There is a vicious circle at work here: because Gypsies and Travellers are seen to be different and strange they are at best afforded sites on the edge of communities and at worst moved on from place to place. Then, because of the exclusion and lack of contact, there is little opportunity for them to be seen as 'neighbours' and when new sites are proposed to meet need there is objection because 'they're not like us', and so the distance in space and perceived values grows.

Forester suggests that 'as we differ on basic beliefs ... we might still come to agree upon specific practical actions'. ${ }^{23}$ Healey adds that through mediation and discursive practices people come to understand different points of view, reflect on their own view, and that 'a store of mutual understanding is built up'. ${ }^{24}$ This mutual understanding has yet to manifest in many Gypsy/Traveller planning decisions, though, either at strategic or individual planning application level. Kaufman and Smith propose that, in conflict over land use, issues are framed and reframed as part of the reconciliation of differences. ${ }^{25}$ Reframing the debate, recognising differences in emotional attachment to place and identity, is vital if conflict is to be negotiated and site accommodation provided in the future where necessary. 


\section{From conflict to negotiation}

A research project, funded by the Joseph Rowntree Foundation, was undertaken by Richardson and Codona from 2014 to 2016 to look at site management and delivery and the negotiation of conflict inherent in this. ${ }^{26}$ The project included visits to 54 Traveller sites across the UK, and interviews with 122 Gypsies and Travellers and with 95 professionals including staff involved with housing, planning, health, education and the police. The project found that planning for and managing Gypsy and Traveller sites in the UK certainly constitute a complex challenge, as there are numerous interconnecting strands and multiple places of resistance. There were a number of examples of internal conflict - between different departments of the same council, or between agencies that would normally work together - and this impeded sound management and delivery of Gypsy and Traveller sites. In addition to this there was evidence in some areas of external conflict and objection to plans for new sites from wider community members, neighbours and politicians. The multiple layers of conflict needed identifying first before plans were put in place to communicate, negotiate and resolve management and delivery issues.

The need for communication and negotiation differs according to the type of conflict issue. The word 'conflict' was used in the research to encompass a range of actions and emotions - mostly low-level, everyday disagreement. During the course of the 18 months of data collection, the research team came to use the term 'everyday grind' for this lowlevel conflict, and indeed when this was reflected back to interviewees as part of the sense-making process there were nods and grumbles that this encapsulated the feeling very well. The research found a number of areas where conflict was evident, and the report includes examples related to management of social sites, ${ }^{27}$ but the key moments in terms of understanding the relationship between people and place, and the perceptions of identity and place discussed by Lefebvre, were planning for new sites and managing unauthorised encampments.

\section{Planning for new sites: a political and media battle zone}

There is negative media representation of Gypsies and Travellers, apparent not only in programmes like Big Fat Gypsy Weddings and articles in the popular press, but also in soft media hostility and marginalisation through 'under-the-line' comments on web-based news articles and social media web pages; viral vilification is rife. This exclusion and 
vilification has been compounded by poor access to services, a lack of political power and the exclusion of Gypsies and Travellers from decision-making processes. Alongside this is wider confusion in media and political debate on who Gypsies and Travellers are. This has not been helped by changes to definitions under the 2015 Planning Policy for Traveller Sites, which does not recognise Gypsies and Travellers who have ceased their nomadic life for health or educational reasons but who still define as Gypsy or Traveller as their ethnic status under equalities legislation. This confusion on definition is seen in planning debates amongst professionals, but is also reflected in wider media and public discourse on the issue, which can feed conflict and objection to new site proposals.

It takes determined political will to support site delivery in the face of hegemonic negative discourse, but there are strong leaders willing to show the way. In research interviews for the project, in an area in the south-west of England, Conservative and Liberal Democrat councillors, who helped to deliver a new site in their area, said of their councillor colleagues in the planning decision-making process, 'Members did what was right rather than what was easy.' The evidence of need was there, the imperative to provide for the residents on the long-standing unauthorised site was there, and the local politicians realised this was the right thing to do. There was a need though for a conflict to exist - in this area there was an unauthorised encampment which caused complaints from local people to councillors, so there was a 'problem' and a conflict that needed resolving and the provision of a new site, although the process itself was full of conflict and complaint, was a way of resolving the tension. It is harder to argue for a new site to be delivered when there is not a visible or tangible problem to resolve.

Planning for sites anywhere is challenging, but the objection to plans can be amplified when 'green belt' is mentioned, taking on mythical proportions. Communities see this as in need of 'protection', adding perceived moral weight to arguments. However, there is a need to untangle the emotional discussions of what green belt means to different parts of communities and to recognise that before abstract and structured designations of land in plans, Travellers have for centuries stopped on common land and green space as part of their nomadic culture. There are emotional connections to historic stopping places that if Gypsies and Travellers were able to safely share their ideas and memories of their conceived and lived space this would allow a more meaningful debate for the purposes of perceiving space and planning places for the future. ${ }^{28}$ 


\section{Policy-designed conflict: unauthorised encampments}

One of the most evident spaces of designed-in conflict is in policies on unauthorised encampments, and this was found in the JRF study. An insufficient number of sites, combined with a policy of walling off common land and deep verges that were traditional stopping places, leads to unauthorised encampments. Government policy puts a squeeze on more informal transitory stopping on traditional cultural or trade routes and there is an expectation to 'settle' whether on authorised sites or in houses. The objection to encampments in green belt areas takes on the feel of a battle for a mythical space which must be protected from settlement, even where this is on an informal and temporary basis, and where this may have been a traditional pattern of travel in an area of centuries.

The traditional model of dealing with unauthorised encampments sees enforcement, eviction and move-on as the norm, and this can create conflict between Gypsies, Travellers, police, local authorities and settled residents in a community.

There are different methods of responding to unauthorised encampments (UEs). One is an approach of 'toleration' or, better, 'negotiation' where encampments are in appropriate places and where they are only going to remain for a short period of time. Police guidance on unauthorised encampments sets out how powers should be used, and in her Preface to the guidance, in an echo of the idea that provision is the best way to reduce UEs, the lead author of the ACPO Gypsy and Traveller Portfolio wrote:

The purpose of the police is to protect people from harm. To this end, this Portfolio will encourage the provision of sufficient accommodation on small, properly managed sites, with access to health, education and all services, which we will police according to need. ${ }^{29}$

Much government guidance has made clear that the best way of preventing UEs and keeping costs down is by being proactive and providing accommodation for Gypsies and Travellers to reside in or stop on for a period of time; however, other polices on planning, for example on protecting the green belt, conflict with this and create a divisive context for decision making on delivery. Providing an appropriate mix of permanent and transit sites in an area is by far the most expedient method of preventing unauthorised encampments, and negotiation is a more agile and flexible approach to dealing with encampments that do arise in order to ease conflicts. 
Where there is not sufficient site accommodation, there will undoubtedly be higher costs associated with UEs - either in cost of clearing after a site if rubbish collection has not been made available, or in legal costs of bringing a case. In areas which engage with residents in UEs and where a period of 'toleration' is given, costs can be further reduced to the council if rubbish collection and toilet facilities can be arranged, with a fee payable by the UE residents by negotiation.

There are clearly costs associated with UEs - these are social costs (to the Gypsy and Traveller families themselves and to cohesion with the 'settled' community) and financial costs. Morris and Clements said:

It is probably safe to assume that the actual figure of $£ 6$ million derived from this research could be multiplied a number of times before the real annual cost of managing unauthorised encampments is reached. ${ }^{30}$

The JRF research project examined a policy of 'negotiated stopping' in one city, which - through using negotiation rather than eviction, where appropriate, on unauthorised encampments - means there are better social outcomes for Gypsies and Travellers and economic savings made for the public purse. This approach required a great deal of political will and engagement of council staff and Gypsy/Traveller advocates; however, more recently this will appears to have diminished due to a harsher political and ideological standpoint, which has interrupted the amplification of this approach both within and beyond the city. Negotiated stopping is basically an approach taken by police and the council that where an encampment arises there will be an assessment of whether, if it is in an area that is not hazardous or doing undue harm, there will be a short period of 'toleration' rather than eviction straight away. In adopting an approach that allows real listening and two-way communication there are social and economic benefits. The study team looked at this initiative further and asked for costs from the Traveller team and police; it found a clear business case for a negotiated approach. More importantly, there is a clear social benefit to providing a negotiated approach, offering accommodation in the broadest sense of the term to Travellers and stepping back from conflict to show the possibility of allowing informal use of spaces where it causes no harm. In not moving on and evicting, there is then opportunity for living alongside one another, hearing each other's connection with places in the locality, and accepting and accommodating difference. The potential for this approach to save local authorities money and improve community cohesion could go a long 
way to redressing some of the resulting conflict from the shortcomings in government policy.

\section{Necessary conditions, and tools for negotiation}

The identity of Gypsies and Travellers is wrapped up in the place where they live; accommodation on a site, rather than in a house, is inextricably linked to Traveller identity and this has been tested in planning decisions and in the courts. As Lawrence Susskind remarks on value conflicts, 'Compromise ... means abandoning deeply held beliefs, values or ideals. To negotiate away values is to risk giving up one's identity. ${ }^{\prime 11}$ So, if Gypsies and Travellers are no longer allowed to travel and use traditional informal stopping places along the way, and if developing an authorised site is blocked by public objection and planning constraints, conflict between travelling and settled people seems inevitable. John Forester suggested not mystifying value differences: 'even in the face of deep value differences, many practical resolutions may be possible, even if - or indeed because - asking parties to change their fundamental beliefs is often neither necessary nor relevant to settling the dispute at hand' ${ }^{32}$ Indeed, in previous research Richardson found that practical cases could be made to gain political support for site delivery through economic and legal arguments, rather than moral/social (more value-laden) arguments. ${ }^{33}$ Nevertheless, experience since that research, a better understanding of the literature and a reading of theorists like Lefebvre suggest that both practical issues and emotional values are important. Whilst many negotiation approaches suggest separating the issues and values to make practical progress, it is vital first to understand and listen to emotions and values that connect people, identity and place, before we can move on to working through the issues.

The research found a number of conditions present in areas where there was particularly noticeable conflict, two key amongst these were:

1. a crisis or 'tipping point'

2. residents collectively voicing and demonstrating dissatisfaction.

Looking at the first condition - the need for a tipping point - the widely reported story of local residents blocking access to a new temporary site for Travellers who had recently lost many members of their family in a fire on their site, is one particularly stark example which the research team followed up with a visit to the area and discussed with an advocacy 
group working with Travellers. The objection of neighbours to the proposed temporary site to house survivors of the Carrickmines site in Ireland horrified many observers. In addition to the human tragedy, this action seemed at odds with good neighbourliness and understanding from settled residents. It is suggested by those working in the area that part of the hostility stemmed from the fact that Carrickmines itself was supposed to be a temporary site to house the family following a previous tragedy, but that it had been in place for seven years. Therefore, when the council, following the fire, told neighbouring residents that the proposed site to house families would be a temporary measure, there was a sense of disbelief. Following the blockade of the first proposed temporary site, instead of forcing residents to move their vehicles and let the Travellers move there, the council found an alternative location, away from residential areas, 'near a dump, of course' as one person told the research team. The permanent site which will house the families is, according to the local Traveller Forum, due for completion towards the end of 2017.

In relation to the second condition - voiced dissatisfaction - residents demonstrating dissatisfaction, through anti-social behaviour or escalated disagreements manifesting in violence, were particularly prevalent in areas where lines of communication were not open between site managers and residents on existing sites. The 'everyday grind' can build up and dissatisfaction with a site can cause residents to argue with one another over scarce resources which may result in anti-social behaviour, or there can be disagreements and breakdown in working relationships between residents and site managers. In relation to the 'everyday grind' conflict resulting from poor design and process opacity, the tool of 'truth and reconciliation' resonated particularly with one senior officer in one of the case studies when it was mentioned as a conflict resolution method during an interview (perhaps because of the respondent's experience of working in South Africa previously) and he could see how it might be important in this research context of Gypsy and Traveller issues. This would require acknowledgement at least of previous grievances and issues. Where the second condition was particularly effective was in areas of collectively voiced dissatisfaction either through a constituted representative group, or through the sheer number of complaints on a single issue.

The research team also noted conditions then necessary to engage in negotiation to move out of conflict. Key amongst these, were:

1. Evidence that adversarial processes cost more than negotiation on unauthorised encampments, such as with the example of 
negotiated stopping where large annual savings are made. This must also be matched with elected members demonstrating political leadership and being open to evidence along with a willingness to resolve problems, as was seen in Leeds.

2. Strong resident voice, not only through advocacy organisations in an area, but residents on a site taking positive and co-operative action to voice dissatisfaction. But this must also be matched with site residents' willingness to work with councils and housing associations, talk with neighbours and offer to be part of a solution.

Conflict resolution and negotiation approaches are useful methods to make headway in the management of existing sites and the delivery of new sites. The methods employ real listening techniques, with an open mind, to all parties, based on issues rather than historic positions; this links to understanding people's perception of space and notions of their own identity. ${ }^{34}$ This process is not typical currently, with many debates, particularly on new site delivery, being position-based and with patchy consultation and communication.

\section{Conclusion}

This chapter has highlighted some of the key conflicts inherent in the public and political debate on land use, particularly problematic for 'outsider' groups such as Gypsies and Travellers. Through reflection on a theoretical framework focusing on key thinkers such as Lefebvre, it is argued that in order to move on from conflict, the emotional attachment to identity and place must be acknowledged: rational, criteriabased planning debates alone will not work. The key to approaching this is through listening and use of conflict resolution tools which could acknowledge the impact of existing planning policy shortcomings and set the stage for a more negotiated approach to relating people and places to one another in a more cohesive way. Challenges and conflicts tend to occur at all stages of Gypsy/Traveller-related policy, planning for sites, and site delivery and management. The study found that conflict can be 'designed in' through ill-conceived policy and legislation. There are particular conditions, found in the research, that need to be present for successful negotiation of conflict, and the chapter makes some recommendations for policy, planning, design and delivery of Gypsy/ Traveller sites; but it can be done. The example of 'negotiated stopping' is an approach ripe for adaptation across Britain; such new principles 
of listening and liaising should be integrated into existing policies and actions by local authorities in order to achieve lower costs, better negotiation procedures for talking with Gypsies and Travellers, and more cohesive communities. The theoretical framework suggests that before it can be successful and sustainable there must be local debates which recognise the emotional attachments to place and share the histories of people who have travelled through and settled in locations for better shared understanding which will accommodate different attachments to and uses of space. 
3

\section{Aceh post-tsunami housing reconstruction}

\section{A critical analysis of approaches, designs and socio-cultural implications}

Yenny Rahmayati

\section{Introduction}

Banda Aceh is the provincial capital and largest city of the Aceh region, a western part of the Indonesian archipelago. The city was formerly known as Bandar Aceh or City of Aceh but then it changed to Kutaraja or 'the king's fort' after the Dutch colonisation of the region in 1873. Following Indonesian independence, on 28 December 1962, it was changed again to Banda Aceh. As the provincial capital city, Banda Aceh become the centre of the provincial government's administration, as well as the centre of economic, political, social and cultural activities in the region.

Banda Aceh was among the most devastated areas affected by the December 2004 Indian Ocean earthquake and tsunami which struck the Aceh province, one of the largest natural disasters in Aceh's history. The disaster had a tremendous effect on the housing and settlement sector. Some Acehnese lost their land as the tsunami washed it away and even changed Aceh's coastline. Others found it hard to locate their lots in the ruined land; many of them had no proof that the lost land was theirs. ${ }^{1} \mathrm{Up}$ to 139,195 homes were destroyed or severely damaged, along with 73,869 hectares of land, which had provided varying degrees of productivity. ${ }^{2}$

The tsunami disaster triggered international aid for large-scale post-disaster housing reconstruction carried out by a combination of 
national and international organisations as well as Indonesian governmental agencies. That in turn led to noted changes in urban space.

In 2006, former US President Bill Clinton visited Aceh's disaster areas. He recommended several propositions to define the 'building back better' concept in Aceh's rehabilitation and reconstruction. They included recognising community-driven recovery, promoting fairness and equity, planning future disaster readiness, bringing local resources into action, using good planning and coordination, being clear about the roles of donor agencies, expanding the roles of NGOs, promoting the propensity to become an entrepreneur, making competition healthier and building resilience. ${ }^{3}$ This concept was planned to be achieved within a four-year period of Aceh reconstruction. However, Steinberg argued that the 'building back better' could not be adequately and fully realised in the given time frame and that it might take up to 10 years to complete. ${ }^{4}$ The rehabilitation and reconstruction phase was completed in 2009, by which time 147,000 new houses had been built. ${ }^{5}$

This chapter aims to increase understanding of the socio-cultural consequences of post-disaster housing reconstruction, and thus contribute to improvements in the planning and building of new housing for populations hit by natural disasters. It therefore argues for more careful attention to understanding the relationships between the tangible parameters of location, environmental configuration, and forms and sizes of housing on the one hand, and the intangible aspects of sociocultural phenomena informing people's sense of well-being and happiness on the other, in order to promote better practices in reconstructing communities over the long run in post-disaster contexts.

\section{Literature review}

Housing is one of the most important emergency provisions to be made in disaster-struck territory. ${ }^{6}$ More specifically Rodriguez, Quarantelly and Dynes add that in post-disaster responses all types and forms of affordable housing recovery are crucial. ${ }^{7}$ Permanent housing is the last stage of the housing reconstruction response. ${ }^{8}$ It is the core issue of postdisaster reconstruction study. Regrettably, post-disaster intervention sees the housing reconstruction process primarily as a macro issue of urban settlement and far less as a micro issue of comfortable living for individual families. Furthermore, most studies of post-disaster housing reconstruction focus on immediate actions and the policies, strategies, approaches, processes, technologies and costs involved, ${ }^{9}$ while less 
attention is given to the long-term socio-cultural impacts of the housing design in future. In addition, scholars also opt for macro approaches in studying the reconstruction of housing in post-disaster situations. This has resulted in significant macro knowledge and theory developments for post-disaster management. Only a few studies have analysed the socio-cultural consequences for society at large and for individual families. The essential social and cultural impact of plan layout and the outdoor-space design of housing, as well as the way these affect society, are often neglected in post-disaster processes. ${ }^{10}$

There are several common approaches used in post-disaster housing reconstruction: top-down, bottom-up or a combination of the two. Different terms are used for referring to the top-down approach, such as centralisation, governmental, contractor-driven and traditional donor approach. This approach is undoubtedly simpler and less time consuming. Davidson et al. argue that in this approach prompt decisions, quick processes and minimum delay are possible. ${ }^{11}$ The absence of owner/ tenant participation makes new houses available to survivors within a few months. However, this approach has several social and cultural drawbacks as it does not seem to be interested in the lifestyles, needs and wishes of individual survivors. Too often reconstruction authorities do not include traditional contexts and local values in their top-down approach. ${ }^{12}$ Many case studies of natural disasters around the world are approaching post-disaster rehabilitation and reconstruction in a top-down way.

Meanwhile, in bottom-up approaches, communities are involved in different roles in the process, which enable them to rebuild their houses. In this approach, communities build their new houses themselves, although further financial and technical external help may be needed. ${ }^{13}$ Non-governmental organisations, policy makers and scholars have encouraged the use of this approach. ${ }^{14}$ This type of bottom-up approach is popular because it empowers and offers the greatest possible success to communities. The beneficiaries of the house turn from being a passive 'victim' who has received humanitarian aid into an active participator. ${ }^{15}$ There are other advantages to this approach. It tends to be less costly due to fewer labour costs. People will be able to occupy their new home before building it is finalised and before it is furnished. ${ }^{16}$ It also builds community resilience and strengthens communal social bonds. Furthermore, Barenstein finds that bottom-up approaches help to re-establish confidence and pride among traumatised survivors, by encouraging them to be actively involved and participate in the building of their own new homes; in addition, seeing their needs and wants 
materialised makes people stronger. ${ }^{17}$ However, this approach does have some disadvantages and risks. It may take more time and mostly cannot be achieved without extensive facilitation. ${ }^{18}$ Community structures are often disrupted in a post-disaster situation as people are spread all over the place in emergency barracks and tented camps. ${ }^{19}$ This makes facilitation processes for the bottom-up building communities more difficult. There is also the risk that that technical quality is not always secured; in a number of cases traditionally built buildings have collapsed. ${ }^{20}$ Although participation planning may be more time consuming, better sustainability and satisfaction will be realised by individuals and communities, both in the short term and the long term.

On the other hand, the combined top-down and bottom-up approach claims to realise maximum results and to reduce building failures. Post-earthquake housing in Bam, Iran, is one example of a project using this approach. The co-operation of government agencies, communities and beneficiaries was managed by a special government agency, responsible for assuring the involvement of all government authorities as well as the integration of survivors' participation in the process. This project put survivors as the main actors of the reconstruction, and acknowledges that as one of the major principles in the master plan for sustainable reconstruction and development in Bam. ${ }^{21}$ However, this approach only covers the macro planning of reconstruction with little consideration for micro planning at the domestic level. Therefore, the success of the approach in ensuring housing satisfaction for beneficiaries still needs to be assessed.

Meanwhile, sponsors of post-disaster reconstruction often find it appropriate to implement the concept of 'building back better', which means that new post-disaster buildings should be better buildings in the broad sense of the word than the ones of pre-disaster times, offering survivors a better living environment, including their homes. 'Building better than before was the basic premise applied to housing and settlements held in the area. ${ }^{22}$ Building new houses and infrastructures was not only a technical affair. Above all, reconstruction and rehabilitation should help and develop new hopes and dreams for a better future. ${ }^{23}$ However, this concept needs to be reaffirmed. Who can assure that the new form, order, situation and condition of the building are better than the previous one, especially in terms of the appropriateness of culture, local context and values that have been formed, evolved and survived in society over a long time - hundreds of years in some cases. Moreover, the word 'better' can have multiple understandings; therefore, the tag line 'building back better' might cause further problems. ${ }^{24}$ 


\section{Methodology}

This chapter examines the socio-cultural transformation processes of the Acehnese communities in post-tsunami times and the expected longterm consequences of post-disaster new houses. These post-tsunami new houses gave survivors new homes. Often living space in these new homes was quite different the usual pre-disaster house space. It is important to find out which possible relationships exist between changing family practices and culture on the one hand and changing types of houses and space arrangements on the other. Research based upon one single methodology will not be sufficient. It should be complemented with studing the relevant documents, making observations on the spot and studying floor plans as well as evaluating constructions and former functions. ${ }^{25}$ In addition to observation and documentation, anthropology can also be of great help, asking how residents perceived and appreciated the spatial changes in their new home, and how they went about perceiving those changes, living a relating to others. An open-end in-depth interview technique was used for this purpose, with the aim of getting detailed qualitative information from micro-level respondents. The ownership/renter status (either of individual property rights, or as a renter, newcomer or inheritor), type of family (nuclear or extended), respondent status (gender, age, married/unmarried, occupation, level of education) and information about the donor agency were also recorded during the interview.

This study takes 18 post-tsunami new houses as case studies. These were selected from among 50 houses that had been surveyed during fieldwork in July-August 2010 and October 2011-January 2012 in four sub-districts in Banda Aceh and part of Aceh Besar: Meuraxa, Jaya Baru, Kutaraja and Peukan Bada. These four sub-districts were amongst the most badly devastated areas affected by the tsunami; in Meuraxa and Kutaraja out of tens of thousands of inhabitants only some 1,000 survived. Aceh's post-tsunami housing reconstruction projects concentrated on these four zones, ${ }^{26}$ and big donor agencies also concentrated their efforts there. The case studies were selected through observation in the locations, consultation with local leaders and studying donor agencies' report and documents. The 18 houses had been (re)built by different donor agencies between 2005 and 2007, and had been renovated and/or modified between 2006 and 2011. The agencies involved were: BRR (Badan Rehabilitasi dan Rekonstruksi Aceh-Nias; the AcehNias Rehabilitation and Reconstruction Agency), ADB (Development Bank), World Vision, Turkish Red Crescent, Muslim Aid, Lions Club, AlImdaad South Africa, Cooperative for Assistance and Relief Everywhere 
(CARE), United Emirates Arab Government (UEA), P2KP (Overcoming Urban Poorness Project: a Government of Indonesia development programme managed by the Department of Public Works), Peduli Bangsa ('Caring for the Nation') and Uplink.

The analysis of the transformation of the houses was focused on three time periods:

1. pre-tsunami houses

2. post-disaster aftermath of 2005 until 2008 (the phase of donorsponsored house building)

3. the years following the end of the rehabilitation and reconstruction process (living experience in post-disaster built new houses), 2009-11.

The important variables used for the analysis were total destruction or severe damage of pre-tsunami houses, major changes of house space (number and size of house rooms before and after the tsunami), important typology change (from traditional stilted/semi-stilted houses to ground-level houses), and permanent house structures versus semipermanent ones. The analysis also compared the newly built houses in 2005-08 with how some or many of them had been renovated or modified by 2009-12. These modifications and renovations were important because they show how the socio-cultural life of new house residents in the studied communities has been affected. They also show how physically changed houses were not culturally neutral phenomena as they have longer-term socio-cultural impacts on life in a community.

\section{Findings and discussion}

Through the 18 case studies, this study found that there were major, moderate or minor modifications, and some properties underwent no modification at all. This study also found that the kitchen was the most frequently modified space: it was changed in all of the houses that were modified. Other high-priority additions or modifications were the family room, living room, bedrooms and veranda. As to basic human needs, toilets ranked high. Meanwhile, in terms of future development plans, the most important spaces in the house to be improved in the future were the kitchen/dining room, the family room, the bedrooms, the veranda and the service area (including the toilet). Eating together as a family is an important practice for the Acehnese, so the top priority given to the kitchen/dining room is very understandable. As the beneficiary 
households were represented by men at planning meetings, women's views were not represented and the importance of the kitchen area was not expressed or appreciated.

\section{Housing reconstruction approaches}

Most of the houses in the case studies that were built following the top-down approach needed and received major improvements or had rooms/spaces added by the owner. Houses built following the bottomup approach had only minor additions or improvements. The combined top-down and bottom-up approach showed end results similar to the topdown approach; considerable changes or modifications were also made.

Uplink donated houses were built following a participatory bottomup approach: beneficiaries were involved in planning, constructing and monitoring. In this approach the beneficiaries' input started during the initial planning stage and continued all the way through construction. When the beneficiary was not capable of being involved in the construction process, for example when beneficiaries were women or young children, other professionals did that for them. Although the construction work was carried out by others, beneficiaries were still involved in planning and monitoring. When beneficiaries wanted to modify the plan/lay-out of the donated house beyond the terms and conditions set by the donor, for example by adding more rooms at their own expense, such a modification could be incorporated in the original plan of the donated house before construction began. Similar cases were found in other houses where the beneficiaries of the house could also incorporate their requested modifications in the original plan of their donated house before construction began. But in these cases, the donated houses were built first and modifications were carried out later, because the beneficiaries' financial funds became available later. In these conditions, the beneficiaries' needs for basic as well as socio-cultural spaces were better accommodated.

Combined top-down and bottom-up approaches did not ensure housing satisfaction either, as one of the case studies found, that of houses built by P2KP in Lambung Village. In that project, village planning was carried out through a community participatory approach (bottom-up) while construction of the houses was carried out in a topdown way (by contractors). At a macro level, housing reconstruction in that village had been successful through land consolidation planning (LCP). However, it was unsuccessful in the micro settings in terms of 
individual houses. As a result, the beneficiaries modified the houses to meet their socio-cultural needs. They also made future development plans to accommodate the specific needs and wants of their family.

\section{Transformation of construction typology}

Figure 3.1 shows how construction typologies of houses in Aceh have changed and developed historically before and after the tsunami. Before the 1950s stilted houses were popular. The space underneath the house could be used for various purposes. Then the typology changed into the semi-stilted house of the 1950s-1970s. From the 1980s up to 2004, right before the tsunami, most of the houses were ground-level style. During the period of post-tsunami rehabilitation and reconstruction all typologies of houses came back. Donor agencies did not adopt one single type of house only; they opted for all the types that had existed in Aceh before the tsunami. Aceh's post-tsunami rehabilitation and reconstruction officially ended in April 2009. This study found that all donated stilted and semi-stilted houses built in Aceh from 2004 to 2009 had been transformed into ground-level houses at the time this study was conducted between 2010 and 2012.

Muslim Aid has another reason for building their donated house in stilted house style. They believe that by reviving the old traditional style they help to preserve the local culture. However, in the end, most of the houses were transformed into ground-level houses, not only to meet the sociocultural needs of the occupants but also for technical and safety reasons. Responding to Aceh's culture does not and should not necessarily mean that old-fashioned styles should be copied. The response should be integrated into contemporary contexts, conditions, situations, needs and wants.

Resolving post-disaster housing reconstruction challenges by simply duplicating traditional forms can indeed accelerate the process. In addition, simplifying the designs of smaller-sized houses may lower construction costs. These also help to speed up the process of building a massive number of houses and getting numerous roofs over survivors'

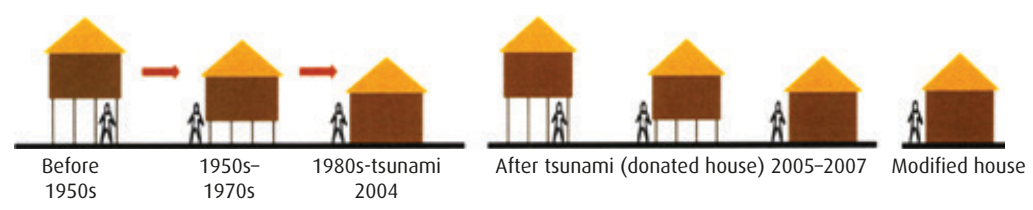

Figure 3.1 Historical transformation of housing typology. 
heads in short delivery terms. However, it does not guarantee that the beneficiaries' needs and wants will be fulfilled in their new houses, especially in terms of the socio-cultural context.

\section{Building back better}

This study also examines the 'building back better' phrase used as a common concept in post-disaster reconstruction, which can be interpreted building or creating something new that is better than what was there before. This concept is applied to both tangible and intangible aspects of reconstruction. How far can this concept be applied to Aceh post-tsunami housing reconstruction? This study found that building back better was not an effective concept for Aceh post-tsunami housing reconstruction. Almost all respondents who were interviewed wanted to bring back their house like it was before the tsunami and did not want something different or new. The respondents' unfamiliarity with the 'building back better' slogan indicates that it was an inner circle credo, understood by the financiers, builders, architects and sub-contractors but not by the recipients of the homes. It has benefited the facilitators - such as donors, builders, architects, planners and sub-contractors - has not reached the residents of Aceh, and the tsunami survivors specifically. This situation also implies that survivors have not really been integrated into the reconstruction processes of their own new housing. They were not fully involved in planning and building the new houses that were claimed to be better than ever before. If the new houses really fulfilled what was promised, why should the owners and their families have to modify and enlarge their donated house in the first place? Why have they reshaped their new houses and brought back their idealised pre-tsunami memory?

The donated houses of the case studies were too small, even smaller than the houses before the tsunami. The donor agencies did not adequately develop the design of 'an expandable house' as initiated by the BRR:

The minimum standard for new housing was the Type 36 Plus house, meaning that the structure of the house was based on an expandable house concept, with a core house measuring $36 \mathrm{~m}^{2}$ and consisting of two bedrooms, one living room/dining room, a kitchen, a bathroom and a terrace. ${ }^{27}$

The ADB, Uplink and Al-Imdaad South Africa only included one bedroom in their houses. Moreover, most of the donors did not provide for 
a proper kitchen and a veranda. Provided spaces were not at all better than before the tsunami. One house beneficiary (male, 45, fisherman) spoke about this question during an interview:

This house is not good enough for my family. We sent a request to the donor and asked for larger spaces, especially for a larger kitchen. But our wishes were not met, unfortunately. We did submit all required data and documents, an application letter, our family card, our identity card, but all in vain; our request was not approved.

Donated post-tsunami houses were not at all better than houses before the tsunami, either technically or socio-culturally, as the case studies suggest. Even when the owner had modified the family's house in such a way that it became similar to their pre-tsunami house, the atmosphere of the modified house had not become the same. One respondent expressed this feeling by saying, 'The modified new house could not bring back what we felt in our former house' (male, 62, entrepreneur). Another response came from a female, 42 years old who works as graveyard keeper. In terms of materials and construction, the shape of the house, the appearance and spaces provided were better than the former house. But the owner still felt that their previous house was better psychologically. When comparing cooking, for example, she said:

In the previous house, we cooked using fire wood. Now the donor has given us a clean kitchen with a gas burner, which looks better indeed; however, although our former kitchen was dirty, full of black dust and stain from the firewood, our food tasted better.

All respondents interviewed in this study clearly expressed the view that community togetherness was better before the tsunami than after. Neighbourhood contacts are fewer and intimacy is reduced. This is because there are fewer facilities for moderating contact and communication. There are no markets or Meunasah (small prayer houses), which serve important roles in communal society, such as the central religious institution of the community where meeting or community gatherings occur, amongst other times when matters of public interest have to be discussed. ${ }^{28}$ In addition, the donated new houses have a small veranda or none at all, which makes socialisation even more difficult. New residents from other cities or regions came to live in the neighbourhoods, which has also contributed to the decrease community togetherness. 
One respondent in this study found the new situation better as his house is built on a higher ground which provides better protection against floods. He is also satisfied with the rehabilitation of infrastructures; roads and drainage system in his neighbourhood are improved. But his satisfaction is limited to the macro level only, leaving aside his satisfaction or dissatisfaction with space provided in his new donated house as well as overall housing reconstruction aspects.

\section{Conclusion}

Results from this study show that donor agencies in most of the housebuilding projects in post-tsunami Aceh did not pay much attention to local concerns, socio-cultural family practices and the use of house space. Responding to a local culture does not necessarily mean that one should copy its original style. Housing styles must be made compatible with contemporary situations, conditions, needs and wants and how they are perceived. Just focusing only on physical house forms is not enough; local concepts around domestic space issues are much more important. Donor agencies have not shown that they understand these issues. They copied traditional Acehnese house forms into their donated new houses as that was thought to be the right thing to do, but they did not realise that traditional house forms had already been changing over the years, long before the tsunami, into more modern housing forms.

Reconstruction authorities and donor agencies in Aceh had not properly interpreted and included relevant local post-tsunami living values and norms. Ignoring socio-cultural family practices evidently led to unsatisfactory houses which failed to fulfil people's needs and wants. When unsatisfactory houses are built the unsatisfactory living conditions they engendered had an impact not only on socio-cultural family practices, but eventually on community welfare as well. And when the social practices of individuals and communities change, then this might also have an impact on the welfare of the larger society. This wider phenomenon has also been overlooked by the reconstruction authorities and donor agencies. Too many post-disaster housing interventions have been concerned with the statistical macro issue, neglecting the real needs and wants of survivors. Post-tsunami housing projects mostly focused on short-term goals, policies, strategies, actions, technologies and economic conditions that often did not make decision making easier. Meanwhile, the 'building back better' credo that was intended as guideline for posttsunami housing projects did not work out the way it should have. The 
survivors had never heard the term before. It is unfortunate that they were not informed about the concept that they should have been part of.

This study proposes new post-disaster housing reconstruction attitudes and a new type of action based upon real local down-to-earth contexts and concerns, by prioritising the housing needs and wants of stricken communities and traumatised individual survivors. It highlights the importance of integration of non-physical aspects of family practices - such as cultural living needs and wants, lifestyles and habits - into the physical design of housing. Contributing to architecture and planning disciplines, this study targets the architects, planners, builders, agencies and construction professionals as the main actors of post-disaster reconstruction. 

Section 2

Spatial politics of housing

Affordable housing, self-build, re-building and the economics/policies of housing 



\section{4 \\ Postproduced \\ How adaptive redesign and participatory approaches can transform ageing housing}

Sandra Karina Löschke and Hazel Easthope

\section{Introduction}

Ours is an urban century. For the first time in history, more people live in urban than rural areas, and cities around the world are struggling with the challenge of providing adequate housing for growing populations. Concurrently, the significant amount of housing stock built during the post-war housing boom (1950-80) is now ageing and in need of repair, which represents an equally formidable challenge to many cities. To date, the discussion surrounding both issues - growth and redevelopment - has primarily focused on the provision of new housing, predominantly multiunit apartments for medium- to high-density living. The redesign of the significant existing housing stock is rarely regarded as a viable option for providing high-quality living and additional habitable space. These ageing buildings are often seen as a failure of modernist architecture, technically outmoded and economically unviable, so demolition and rebuilding seems to be the preferred option for dealing with them. Contributing to the preference for demolition over renovation are the difficulties associated with multiple ownership and highly diversified resident profiles, which complicate decision-making processes and often obstruct development. As a result, residents are forced to live in deteriorating buildings or move away. However, much existing housing stock offers rich opportunities for creating more liveable, affordable and sustainable solutions, which 
remain largely underexplored. This chapter investigates the opportunities opened up by the 'adaptive redesign' of existing housing schemes and their potential to significantly contribute to the economic, social and environmental sustainability of cities. It highlights exemplary redevelopments that break with conventions, scrutinise regulations and utilise customised solutions to fundamentally rethink the architectural design of buildings, starting with the needs of their inhabitants. These offer vital alternatives to a mere renewal of the existing building fabric and the updating of the building's external appearance, and demonstrate that by thinking creatively it is possible to make advances that forge productive links between environmental, social and economic factors. In this way, the large amount of existing housing stock in cities around the world can be adapted to provide an immediate response to current concerns around building quality, while impacting positively on the lives of contemporary urban dwellers over the longer term. The chapter argues that what is needed is a meta-framework for 'adaptive redesign' approaches that can facilitate the transition from disparate ad hoc attempts towards mainstream housing solutions that influence policy and improve living experiences for large numbers of urban residents. Drawing on a broad church of research and examples from across the world, the chapter offers insights into fresh ways of thinking about design that are translatable to different scenarios and have potential to be developed further.

\section{Ageing apartment buildings: the need for management and decision making}

\section{Building maintenance and adequate property utilisation}

In many cities, a significant proportion of the apartment stock is ageing, poorly maintained and in need of upgrading. Dysfunctional lifts, deteriorating façades, mouldy walls, broken windows, defective lights, uninhabitable balconies, poor acoustics, lack of insulation and lockedup laundry rooms are just few examples in a long list of common deficiencies that have implications for the health, well-being and safety of apartment residents, and for the quality of the urban environment more generally. This challenge has received significant attention in Western European cities that have a long tradition of apartment living, ${ }^{1}$ in cities across North America and Australasia with more recent histories of apartment living, ${ }^{2}$ across Eastern Europe in the wake of the transfer of 
ownership from public to private control, ${ }^{3}$ in super-dense cities such as Hong Kong, ${ }^{4}$ and in cities with recent large-scale urbanisation and densification across Asia. ${ }^{5}$ In Hong Kong, Singapore and New York, for example, governments have responded to this challenge by instituting mandatory building inspections, ${ }^{6}$ and in Hong Kong the upgrade of apartment buildings is subsidised. ${ }^{7}$

In many cases, problems surrounding the maintenance of apartment blocks and the replacement of worn-out building elements are linked to particular forms of ownership and management. Where multiple owners are collectively responsible for the maintenance of their building, the problem of the 'tragedy of the anti-commons's can arise, namely a break-down of co-ordination that occurs when one or more owners frustrate collective efforts to come to an agreement on actions such as maintenance, repair and development. Ultimately, fragmented ownership structures can lead to a complete deadlock, ${ }^{9}$ and, as a study by Buchanan and Yoon demonstrates, can result in the erasure of potential economic value because of resource underutilisation. ${ }^{10}$ This scenario becomes more likely as the number of owners rises in higher-density developments or as the variety of socio-economic and cultural backgrounds increases as a result of global mobility and immigration. There have been calls for legislative and legal remedies to address these challenges around the world. ${ }^{11}$

While legislative and policy changes that prevent small minorities of owners from stalling repairs and development are no doubt a part of the solution, what is also needed are tools to enable residents to find solutions that provide a range of benefits for all and turn negotiations into positive collective exercises in conjunction with architects and other professionals.

\section{The challenges of decision making}

With owners and residents of apartment buildings assuming a more central role in the redesign process, there is an evident need to provide guidance with decision making, and more generally a clarification of responsibilities and collaborative processes. There are evident tensions that arise in transforming the architectural design process into a collective practice that successfully combines social needs and aesthetic aspirations. Participatory design approaches allow architects to reinvent their role as a resource for society and have the potential to turn mere refurbishment commissions into truly social enterprises that underscore 
the cultural significance of housing. Yet this is no easy task, and further investigation is needed.

Perhaps the greatest challenge in implementing an adaptive redesign approach that relies on the participation of multiple people is attaining consensus. Research undertaken in Australia ${ }^{12}$ and elsewhere ${ }^{13}$ has highlighted the difficulties of maintaining and upgrading apartment buildings under multiple ownership. For example, Easthope, Randolph and Judd found that disagreements relating to major expenditures, including major repairs, were quite common in strata schemes in New South Wales. They note:

A particular issue regarding decision-making in strata schemes ... is the length of time it can take to make a decision and take action on particular issues because of the difficulties that can be experienced in getting consensus within the executive committee or between owners. ${ }^{14}$

These challenges presented by neglected older apartment buildings have been recognised by government and industry in the Sydney context and formed part of the New South Wales government's justification for changing the legislation regarding the proportion of owners who must agree to terminate a strata scheme as the first stage towards knocking down and rebuilding apartment buildings. ${ }^{15}$ However, demolishing and rebuilding apartment buildings is both an expensive and a potentially very disruptive exercise. ${ }^{16}$ The demolition and redevelopment of ageing multi-owned properties will be insufficient to deal with the joint challenges of increasing housing needs and declining housing quality. It will be insufficient because it will be financially unfeasible to redevelop many of these ageing properties in a market-based housing system. ${ }^{17}$ It will also be disruptive to established residential communities who at best must be rehoused and at worst will be displaced. And it will be environmentally unsustainable to redevelop properties earlier than necessary because of the massive embodied energy in new buildings.

Yet, the challenge of multiple ownership has often seen apartment buildings left out of initiatives and programmes aimed at the upgrading of apartment buildings. Toronto's Tower and Neighbourhood Revitalization Program provides a good example. The Program, which started in 2008, is promoting the revitalisation of over 1,000 old apartment buildings through partnerships between the city council, local property owners, community organisations and donors. ${ }^{18}$ This is the council's response to the outcomes of the 'tower in the park' model, 
which was the city's main strategy for tackling housing shortages. More than 3,000 towers of five or more storeys were erected in Toronto's metropolitan area between 1950 and 1980, representing the second highest concentration of high-rise buildings in North America. ${ }^{19}$ Designed as affordable housing, the buildings are now increasingly dysfunctional and in disrepair. Amenities such as swimming pools, sports facilities and communal spaces have been largely closed; an influx of immigrants has changed the social mix, with more than 70 per cent of inhabitants living in poverty. However, the vast majority of the buildings that fall under the council's programme are private rental buildings with each building having one landlord owner; condominium buildings in the area that have multiple owners have been effectively excluded from the programme. This is most clearly seen in the requirement that all (100 per cent) of the owners in a condo building must sign their agreement before it becomes eligible for the city's High-rise Retrofit Improvement Support programme (Hi-RIS) to help fund energy and water efficiency improvements, effectively excluding multi-owned condo properties from this scheme because of the difficulty of obtaining 100 per cent votes, especially where some units are owned by absentee investors. ${ }^{20}$

\section{Ageing apartment buildings: the need to respond to demographic change}

\section{Changing resident profiles}

The renewal of the building fabric and services might resolve technical deficits, but it ignores additional social benefits that can be achieved with a fundamental rethink of the building occupation strategy. The issue is whether these ageing apartments continue to meet the needs of their current residents and prompts the questions who is living in them, and what are the socio-cultural sensibilities of current residents? Research has demonstrated that over time the resident profile of suburbs, and the apartment buildings within them, can change significantly, so that the people who live in these apartment 10 or 20 years after they are built may be quite different from the occupants envisaged by architects, developers and planners when the buildings were first constructed, as is the case in Sydney and Melbourne. ${ }^{21}$ Indeed, in older suburbs 'considerable restructuring of the local housing markets is likely to have taken place over time' with 'changing demand segments leading to up- or down-grading', as Randolph and 
Tice explain. ${ }^{22}$ Another study conducted by Easthope and Tice shows how, in one Sydney suburb, the resident profile of a new development made up of multiple apartment buildings changed rapidly to include increasing numbers of households with children and lower income households within just a few years. ${ }^{23}$

The changing resident demographics observed in Australia's major cities are a common occurrence in Europe as well. A recent housing project in the residential neighbourhood area of Ommoord in Rotterdam/Netherlands cited changes in resident profile as the main motivation for redesign. ${ }^{24}$ The Ommoord apartment blocks were constructed in the 1960s, and in 1999 the housing association commissioned biq architects to upgrade the buildings' technical performance and find an architectural solution to improve the increasingly tense relationships between different resident groups. In particular, younger families from varied socio-economic and ethnic backgrounds and older residents who had lived in Ommoord from the beginning presented conflicting needs and an ignorance of respective social codes. ${ }^{25}$ The architects noted that:

The departure of the stable population of pioneers and the influx of new tenants with different skin colours might be a completely normal manifestation of urbanisation, but for older residents it is a threat to their ways - new families parking their children's bicycles on the access gallery is their worst nightmare. ${ }^{26}$

The conflicts witnessed in Ommoord are a common occurrence in other developments too. In Slotervaart, a district in Amsterdam West, 50 per cent of the population were from a migrant background and, in surveys, 38 per cent of residents stated that they did not feel safe on the streets while 27 per cent indicated that they experienced friction with residents from other cultures. ${ }^{27}$ It is evident that the people living in older apartments may very well not be the types of people envisaged to live in them when they were built, and beyond that the demographic profiles of cities have also diversified as a result of increasing immigration and ageing of the population, which is likely to have led to a diversification of needs, or even conflicting needs. Add to that changing demands on space over time as home technologies, living practices and aspirations continually evolve, and one would expect that older apartment buildings might no longer meet the needs of their current residents.

At Ommoord, biq architects astutely recognised the positive impact that adaptive redesign could have on the lives of its residents. 
Negotiating the customised solutions to meet the diverse social and cultural needs represented a significant part of the architects' charge. In a nine-year participatory design process, biq developed an alternative occupation strategy by rethinking the spatial organisation of the scheme. The final design proposed a redistribution and sectionalisation of apartments according to social groups and, more specifically, the inclusion of aged care facilities and the reservation of two blocks for older residents.

\section{Aesthetic sensibilities}

Other successful approaches have focused on the aesthetic sensibilities of resident groups with different cultural backgrounds. In the Slotervaard neighbourhood of Staalmanplein on the outskirts of Amsterdam, half of the residents are Muslim, and alternative building aesthetics were explored in an intense participation process. Crystalline forms were developed with the intention to break with the traditional orthogonal patterns of the modernist post-war neighbourhood and create openness and access at ground level to increase communication. On another Slotervaard site, an apartment building received a screen to mitigate noise from an adjacent motorway. Here the architects' façade design drew on ornaments derived from Persian carpets and Moorish ornamentation, directly targeting the aesthetic preferences of the local Muslim community. ${ }^{28}$ Whether seen as cultural tokenism or meaningful references, these approaches recognise the increasing stratification of space, which is becoming more and more reliant on negotiating social cultural sensibilities rather than limited functional considerations to a degree that did not previously exist.

Aesthetic sensibilities come into play in the context of environmentally sustainable architecture, too: working with the givens of existing buildings constitutes an integral part of redesign approaches, and is often articulated as an interest in ethics over aesthetics. Lacaton \& Vassal, for example, have frequently cited their commitment to 'making do with what you have, working with the inherent qualities of the space or site', and being 'attentive to the situation you have in front of you' - tactics which show little interest in designing an architecture with a particular style, or using established design methods..$^{29}$ Leaving walls and floors unfinished, exposing services and signs of use, and deploying a limited range of off-the-shelf materials are integral to their 
adaptive redesign approach and evidenced in buildings such as La Tour Bois le Prêtre in Paris. Interestingly, they are frequently accused of an intentional anti-aesthetic that draws on imagery of dereliction and utilitarianism, a criticism that stands in opposition to their own emphasis on purely performative and economic criteria. Whether the repeated use of these design strategies does result in a certain aesthetic or style is not the main concern. More importantly, Lacaton \& Vassal's emphasis on a purely pragmatic, environmental approach downplays the cultural and aesthetic aspirations that have come to play a much more vital role in contemporary society since the late $1990 \mathrm{~s} .{ }^{30}$ German philosopher Gernot Böhme suggests that modern-day desires - the intensification of life, 'being seen' and outward presentation - all lead to an increased appreciation of aesthetics over functionality. ${ }^{31}$ If Karl Marx distinguished between use value and exchange value, today, as Böhme argues, the exchange value, namely the aesthetic appeal, increasingly assumes the role of a new use value. In architecture, this is evidenced in the extensive presentation of materials and settings that form the backdrop to everyday scenarios and form part of the commercial culture in our age of advanced capitalism. The implications for the redesign of apartment blocks are significant. Any form of participatory redesign would have to consider the importance of such consumer-driven aspirations that would have formed an additional stratum to the cultural occupation of space - both assuming a role that is equal to or even more important than the pragmatic consideration of everyday needs.

It highlights two important points that currently impede the transition of adaptive reuse and participatory modes of design into the mainstream: first, from the perspective of architectural critics, participatory and adaptive redesign approaches lack genuine creativity and an aesthetic dimension and this represents a vital deficit that positions them outside the accepted range of architectural endeavours - they are not architecture; second, from the perspective of architects engaged in such endeavours, the social, cultural and economic significance of aesthetic considerations is often downplayed or denied. The increasing aestheticisation of everyday life that has been embraced by contemporary mass society - the penchant for designer labels and buildings, the desire for self-representation and the staging of our everyday lives in social media - all points to the importance of design aesthetics, including the aesthetics of the apartment buildings in which we live. 
The challenge of rethinking occupation and design strategies in response to changing resident profiles assumes growing significance when looking at the future development of populations. Changes to the demographic profile of residents and the resultant diversification of habitation patterns can be attributed to various causes. In Australia, increasing immigration rates, including disproportionately more young adults, substantially add to demand for housing and lead to significant changes in resident profiles. ${ }^{32}$ Predictions highlight that, beyond 2040, as much as 80 per cent of population growth could be attributed to migration from overseas, and in Sydney this figure could reach 100 per cent. ${ }^{33}$

In contrast, European cities have to cope with considerably less predictable immigration scenarios. The European refugee crisis has seen EU countries grapple with housing unprecedented numbers of asylum seekers and immigrants. In Germany alone, 441,899 first applications for asylum were registered in 2015 alone, and the housing needs have rocketed to an estimated 350,000 new housing units per year, representing a 350 per cent increase on the current construction rate. ${ }^{34}$ These developments necessitate inventiveness beyond standard construction practices and have shifted focus onto the possibilities offered by the transformation of existing buildings for housing.

The ageing of long-term residents represents another significant issue in changing resident profiles. As recent demographic studies by the Australian Population Research Institute show immigration and the ageing of resident households are, together, the two most important aspects that shape resident profiles in Sydney and Melbourne. ${ }^{35}$ But there is a plethora of secondary causes, too: a recent report, for example, cites alternative habitation formats such as shared housing or children returning to live with their families in response to tightening rental markets as additional factors contributing to changing forms of habitation and resident demographics. ${ }^{36}$

These demographic changes and associated social and cultural needs are not prioritised in most modernist housing schemes, where standardised solutions are expected to fit the needs of an average resident. Even more radical modernist architects associated with the Neues Bauen (New Building) movement - which emerged in Europe in the 1920s and included well-known innovators such as Le Corbusier, Walter Gropius, Bruno Taut and Alvar Aalto - focused on what was regarded as basic universal requirements. This standardised thinking is equally 
engrained in building standards and architectural design approaches, and sits uneasily with the increasing socio-cultural diversity of populations which has become common rather than exceptional in an age of global mobility. These developments call for a fundamental rethinking of the ways we design based on contemporary needs and aspirations of a multiplicity of potential residents.

\section{The transformative potential of adaptive redesign: linking economic, social and environmental benefits}

The adaptive redesign of ageing buildings offers remarkable opportunities for reducing energy usage and greenhouse gas emissions and, in addition, is economically cheaper than demolition and rebuilding. Environmental strategies in adaptive redesign schemes are significant given that the built environment accounts for around 30 per cent of global annual GHG (greenhouse gas) emissions and consumes up to 40 per cent of all energy. ${ }^{37}$ The energy consumption and GHG emissions of a building can be divided into three phases of the wholebuilding life-cycle: construction, use and demolition. In most building projects, the use phase by far exceeds the other phases, with 80 per cent of GHG emissions occurring in this phase, compared to $10-20$ per cent produced for construction, maintenance and demolition. ${ }^{38}$ Technical upgrades to reduce energy usage and emissions during the use phase of buildings - which are the result of heating, cooling, ventilation, lighting and other applications - are an effective environmental performance measure that equally contributes to cost savings for inhabitants.

Because efforts have largely focused on improving environmental performance and fixing technical issues, architectural services have frequently not been involved. The lack of architectural consideration is one of the reasons why this model of renovation is highly reductive and ignores potentially important social outcomes. As was noted in a 2015 roundtable discussion hosted by the journal of the Royal Institute of British Architects:

In large-scale housing retrofit, clients generally regard the work as a mere technical fix that does not require an architect. In doing so, they potentially miss out on considerable value-adding opportunities that arise from the wider design vision that architects offer. $^{39}$ 
More recently, however, adaptive redesign approaches have become increasingly complex and often include an interplay between economic, environmental and social factors. More than simple renovations, they offer viable and holistic alternatives that are transformative rather than ameliorative.

\section{Social benefits of adaptive redesign in collaboration with residents}

Adaptive redesign of apartment buildings, especially if it involves the participation of residents and owners, has the potential to generate significant social benefits. First, it allows for the provision of amenities and facilities that fit the needs of current residents and enables a response to demographic shifts in the socio-cultural and age profile of apartment residents. Secondly, the participatory nature of the process itself has the potential to strengthen social ties and improve social capital. ${ }^{40}$

At the scale of the individual dwelling and the building, participation in the redesign process can also help residents to feel more in control over their properties. The importance of control over one's living environment for feeling at home in one's dwelling has been well documented, and similar relationships also exist at the scale of the building in the case of multi-owned housing. ${ }^{41}$

\section{Prefabrication and off-the shelf materials}

A milestone in the adaptive redesign of older apartment buildings is the acclaimed transformation by architects Druot, Lacaton \& Vassal of the 1960s apartment block La Tour Bois le Prêtre in Paris in $2011 .^{42}$ The 16-storey tower with 96 apartments underwent adaptive redesign using environmentally sustainable strategies such as minimising new building works, the intelligent use of materials, and performative upgrading to minimise operational costs such as heating and electricity, among others. The use of prefabricated elements permitted the residents to continue inhabiting the building during the construction phase, and thus avoided the considerable financial burden of rehousing them in other locations for the duration of the works. The use of prefabrication and offthe shelf materials also minimised construction cost and time, causing only minor disruption to residents: the addition of balconies and winter gardens, for example, had an installation time of one day per apartment. ${ }^{43}$ The architects demonstrated that the cost of adaptive redesign 
can be less than half the cost of demolition and rebuilding: the project cost came to $€ 15$ million instead of the $€ 26$ million initially envisaged for a new building. ${ }^{44}$

Leveraging land value for improved living experiences: activating communal space

Advanced prefabrication and the smart use of off-the-shelf materials are only one possibility for making adaptive redesign economically attractive. Graeme Stewart of ERA Architects, a practice that has been working on the renewal of tower blocks in Toronto, promotes the activation of land value to finance the redesign and upgrade of existing apartment towers. He proposes the construction of new high-density, mixed-use buildings, which are inserted into underutilised open spaces. These increase the economic viability of redevelopment and provide added social advantages: shops and restaurants provide missing amenities at ground-floor level and market housing on the upper levels increases the apartment mix and social diversity of the area (Figure 4.1). Stewart argues that the value of the land on which the towers sit can be leveraged to bring new investment to these neighbourhoods. By building new housing or commercial space on vacant land, Stewart believes, property owners could finance energy retrofits and building upgrades, while bringing in much-needed businesses and services. By combining new

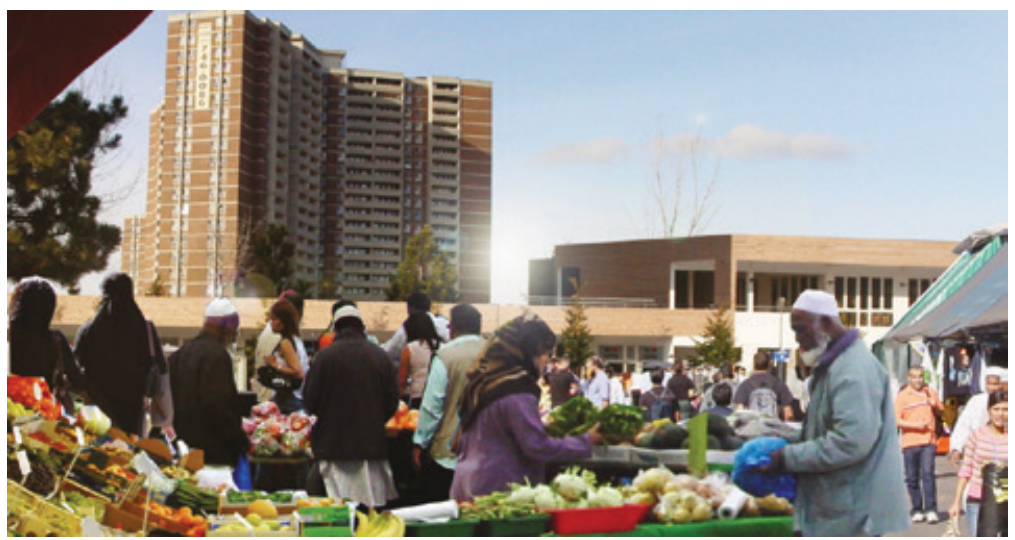

Figure 4.1 Once a middle-class status symbol, Toronto's 3,200 residential towers are ageing into overcrowded homes for the poor. Several efforts are under way to refurbish the towers and stitch them into the modern city. 
development with adaptive redesign, these developments aim to contribute to broader urban renewal processes.

\section{Leveraging property value for improved living experiences: customising home}

In Lacaton \& Vassal's La Tour Bois le Prêtre scheme, social sustainability was of equal importance to environmental and technical factors. Indeed, for the architects, consideration of the users acted as the main driver of the project. By developing customised measures in close collaboration with the residents, and looking at the adaptive potential of the building, the architects deployed a case-study approach that built upon the particulars of the project scenario. The residents' needs codetermined the adaptions of the individual apartments to provide simple comforts such as more space, light, views and social contact. Main improvements included extending habitable spaces through the addition of balcony spaces and winter gardens, providing generous views through the replacement of small windows with full-width glazing (the architects found that 'the building's windows were tiny, so [that] even the units on the upper levels of the building had no real view of Paris'), and rethinking communal areas to facilitate collective activities. ${ }^{45}$ Anne Lacaton explains that this approach is distinct from traditional renovation approaches, which reinstate rather than rethink, and often focus on external appearance. She insists that in La Tour Bois le Prêtre the design and aesthetics arose from decisions about the quality of the spaces: 'We could have done something playful and fashionable on the outside, to look better, if we had put just a few balconies here and there. But our priority was improving the living conditions for everyone. ${ }^{46}$ Conceived to improve the life experiences of inhabitants, the redesign represented a socially viable alternative to conventional renovation approaches, allowing residents to articulate their individual needs and appreciating the opportunities afforded by the customised housing design.

\section{Trialling new models of habitation to inform evidence-based policy change}

In Germany, the housing shortage has been exacerbated by rapidly rising immigration figures. Interestingly, the ensuing crisis has been seen as an opportunity to fundamentally rethink housing solutions by querying architectural typologies and standards. ${ }^{47}$ In 2015 , the German ministry 
in charge of urban development and environment (BMUB) called for inventiveness, providing $€ 120$ million for the development of so-called 'Vario Apartments' - small modular units intended for temporary living. ${ }^{48}$ These can be inserted into unutilised spaces such as vacant buildings or empty sites. Rather than permanently transforming these sites and buildings for residential use, the typology seeks to temporarily insert habitable space, proposing a provisional use. If successful, the initiative might influence the BMUB's review of a reduction of building standards and codes to facilitate alternative solutions for the present and make housing more diverse and affordable. As Stefan Rettich points out, 'not everyone needs the same standards', and 'people react differently to noise and have different heating requirements'. ${ }^{49}$ Yet a reduction in standards should not mean facilitating deregulation and substandard codes; rather, deregulation can offer scope for social innovation and agreater participation of residents in the design of their homes. Central elements of this idea can easily be translated in the context of redesign of ageing apartment blocks, where modular units can be attached to façades as in La Tour Bois le Prêtre, added to roof tops, or placed elsewhere to create additional living area and improve building performance and aesthetics.

\section{Participatory design processes: opportunities and limitations}

Participation is a word that is frequently used in architecture today but is understood in quite different ways, and often genuine participation of clients and users does not occur, for example when participants are offered only two options and no prior consultation has taken place - a standard practice in architects' presentations to user groups. Architectural historian Andres Lepik points out that genuine participation means 'listening to the community first, before starting a plan at all', and actively involving the community in the design and construction processes of projects. ${ }^{50}$ This has vital implications for the professional role and self-understanding of the architect. In his discussion of participatory processes, architect Markus Miessen has proposed the model of the 'cross-bencher' as a creative intervener, someone who belongs to no party, and stimulates argument and debate rather than consensus. ${ }^{51} \mathrm{In}$ this line of thought, the architect is no longer necessarily someone who designs buildings, but is more generally a creative producer or mediator who also aligns with art-inspired participatory practices proposed, for example, by practices such as muf, who does not see buildings as the only architectural outcome but also includes the making of relationships, the forging of dialogues and the staging of temporary interventions. ${ }^{52}$ 
Some forms of co-housing also provide important insights on the challenges and opportunities entailed in the collective engagement of architects and residents in the design process, although most multipleowned housing schemes do not form 'intentional communities' in the sense of co-housing projects. ${ }^{53}$ In a recent series of seminars, for example, the UK Cohousing Network seeks to tackle issues associated with knowledge transfer, particularly with respect to what they term 'the professionalization of the collaborative process between communities and expert partners' ${ }^{54}$ Expert partners would include architects who traditionally assume the role of the consultant team leaders. Asking whether 'collaboration between groups and professionals' can 'take place without undermining grassroots autonomy and creativity', the network points to the fact that client bodies see the involvement of professionals as a threat to their independence and participatory aspirations. ${ }^{55}$

\section{Concluding thoughts}

The examples of French, Dutch, Canadian and German housing schemes discussed in this chapter should be seen as pilot projects for trialling approaches to adaptive redesign based on user participation. It is important to note that in these projects the standard design processes used for architectural projects are no longer applicable. In both Ommoord (biq) and Paris (Lacaton \& Vassal), the design consultation phase was ongoing and extensive, whereas the construction phase was comparatively condensed due to processes such as prefab and strategies of minimising new-built interventions. While these case studies are exemplary in terms of their outcomes, they also suggest the need for improved guidance to streamline the participatory design approach. In Ommoord, the entire project involving 2,000 residents extended for nine years (1999-2009), of which the construction phase only took up two years (2007-2009).

Interestingly, few details are known about the methodological approaches and design processes used by Lacaton \& Vassal, biq or other architects involved these projects. The design guides of architect and planning institutes have equally little to say on the subject. In the absence of a clearly articulated methodological framework and the lack of evidence-based approaches, obvious problems come to the fore. If residents participate in the design process, how are design decisions made and who makes them? What then happens when parties such as residents make design decisions, which they are not professionally qualified 
and not best suited to make? And what does this mean for the role of the architect?

It is evident that standard design protocols for architectural projects do not effectively meet the needs of residents in existing properties nor of architectural professionals attempting to provide services for them. What is needed is a new design process for adaptive redesign that increases the efficiency of what to date have been case-by-case approaches and enables participatory design approaches to become a mainstream design approach. Where adaptive redesign has been employed, the design approaches have not been comprehensively recorded or disseminated and therefore there is a need for knowledge transfer. This would include (a) collecting the information that exists about what has been done internationally and (b) collecting new information through case studies. Building on the knowledge now available from these and other case studies, it should be feasible to develop a framework to support this type of participatory design process, thus opening up new solutions for multi-residential housing. 


\section{5}

\section{Integrated approaches and interventions for the regeneration of abandoned towns in southern Italy}

May East

Introduction

Where there is ruin, there is hope for a treasure.

Rumi, thirteenth century

The past century has been one of unprecedented change in terms of impact on the urban environment. Globalisation, rapid unrestrained development, demographic changes and economic pressures are the main factors driving change in the urban environment. ${ }^{1}$ In 2007, for the first time in history, the global urban population exceeded the global rural population. ${ }^{2}$ The world population has remained predominantly urban ever since. In 2014, Europe ranked the third most urbanised region of the world, with 73 per cent of its population living in urban areas. $^{3}$

The diverging trends of rapid urban expansion and decline, stagnation and even abandonment of smaller settlements and remote rural villages reflect larger social, economic and cultural changes that have shaped Europe in recent decades. ${ }^{4}$ One consequence of urbanisation is increasing numbers of so-called 'ghost towns': formerly thriving towns or villages now abandoned by their original inhabitants, whether due to natural disaster or for economic, demographic, environmental or infrastructural reasons. A large concentration of these abandoned small villages can be found in the southern regions of Italy. A combination of minimal maintenance and slow decay of fragile constructions, ${ }^{5}$ and national and regional governments' failure to protect historic settlements in accordance with the Code of Cultural and Landscape Heritage 
makes the conservation of uninhabited historic urban landscapes in southern Italy a complex cultural challenge. ${ }^{6}$

Concomitantly the availability of the depopulated historic settlements presents many opportunities, particularly when considered in conjunction with the emergence of community-led initiatives exploring resilient lifestyle choices, new ownership structures and livelihood strategies, ${ }^{7}$ and in concurrence with the upsurge in housing demand by significant influxes of migrants and refugees entering Europe via southern Italy.

Deprived of human presence the restoration of historical urban landscapes raises extremely complex challenges, where social and technical factors are intertwined with economic ones. ${ }^{8}$ For the anthropologist Vito Teti, contrary to all appearances, abandoned places never die. ${ }^{9}$ Recorded in their fragile fabric of place and absence there remain layers of meaning, waiting to be regenerated in new patterns of urban landscape.

\section{Ghost towns: causes of abandonment}

Filled with the presence of absences. What appears designates what is no more ... what can no longer be seen. ${ }^{10}$

Throughout history and across many countries thousands of towns have been abandoned for a variety of reasons. A town often becomes a ghost town because the natural resources and economic activity that supported its existence have failed to endure. Natural disasters such as earthquakes, landslides, floods and fires, government neglect, armed conflict, disease and environmental contamination are repeatedly the drivers for abandonment. Often it is a combination of factors that cause the town to lose its population, fading away in time and transforming itself into a place held only in the memory of those who lived there (Figure 5.1; Table 5.1).

There are multiple ways to define ghost towns. For Robert Brown, a true ghost town is a location where buildings still stand even though the population no longer exists. ${ }^{11}$ Lindsey Baker describes a ghost town as a town for which the reason for being no longer exists. ${ }^{12}$ Lambert Florin poetically defines a ghost town as 'a shadowy semblance of its former self'. ${ }^{13}$ Luca Di Figlia adds that 'the uninhabited village can be considered both as a discarded element of the modern consumer society and as a regional asset, reinterpreted from a qualifying perspective'. ${ }^{14}$ 


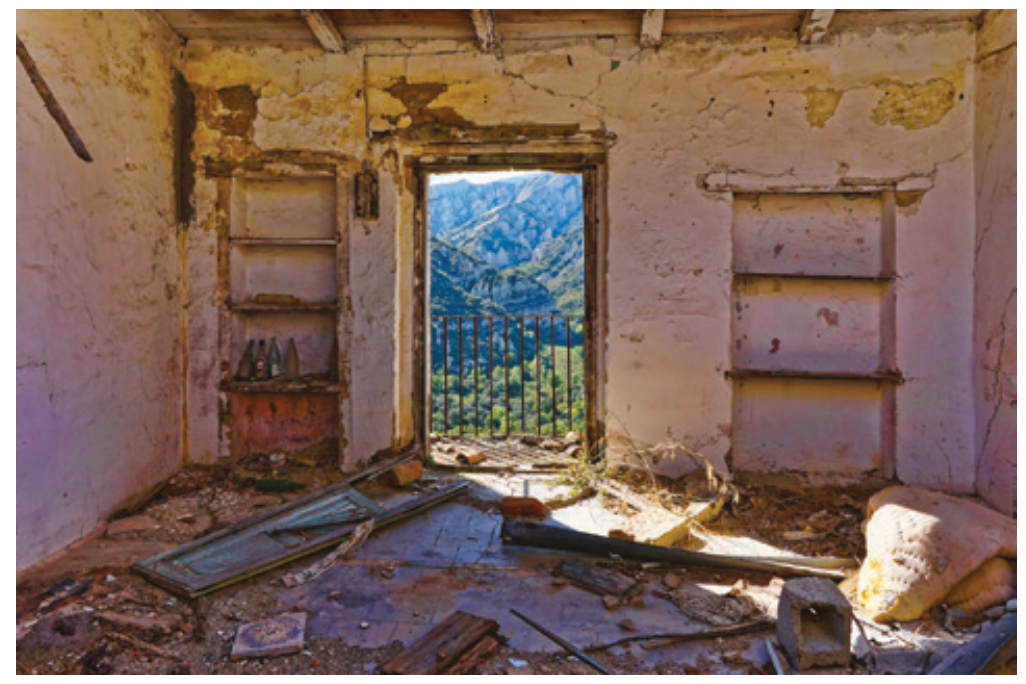

Figure 5.1 Ghost towns holding the tension between preserving the past and planning the future.

Table 5.1 Causes of abandonment of towns in the USA, UK, Australia and Italy

\begin{tabular}{|c|c|c|c|}
\hline Combined causes & & Country & Source \\
\hline \multicolumn{4}{|l|}{ Natural causes } \\
\hline \multirow[t]{2}{*}{ Landslide } & Thistle, 1983 & USA & US Geological Survey \\
\hline & Craco, 1963 & Italy & $\begin{array}{l}\text { Italian Statistical } \\
\text { Institute }\end{array}$ \\
\hline \multirow[t]{2}{*}{ Earthquake } & $\begin{array}{l}\text { Castelvetere sul } \\
\text { Calore (Irpinia), } \\
1980\end{array}$ & Italy & $\begin{array}{l}\text { Civil Protection } \\
\text { Department }\end{array}$ \\
\hline & $\begin{array}{l}\text { Pentedattilo, } \\
1783\end{array}$ & & $\begin{array}{l}\text { Province of Reggio } \\
\text { Calabria }\end{array}$ \\
\hline $\begin{array}{l}\text { Flood and dam } \\
\text { break }\end{array}$ & $\begin{array}{l}\text { Curon Venosta, } \\
1950\end{array}$ & Italy & $\begin{array}{l}\text { South Tyrol/Südtirol } \\
\text { Info }\end{array}$ \\
\hline Sand storm & $\begin{array}{l}\text { Kenfig, Bridgend, } \\
\text { thirteenth } \\
\text { century }\end{array}$ & UK & $\begin{array}{l}\text { The Official Kenfig } \\
\text { Community History } \\
\text { Project }\end{array}$ \\
\hline Fire & $\begin{array}{l}\text { Centralia, } \\
\text { 1962-ongoing }\end{array}$ & USA & $\begin{array}{l}\text { Smithsonian Magazine, } \\
2005\end{array}$ \\
\hline
\end{tabular}

(Continued) 
Table 5.1 (Continued)

\begin{tabular}{|c|c|c|c|}
\hline \multicolumn{2}{|l|}{ Combined causes } & Country & Source \\
\hline \multicolumn{4}{|c|}{ Depletion of natural resources and subsequent closure of industries } \\
\hline Toxic (asbestos) & Wittenoom, 1993 & Australia & $\begin{array}{l}\text { Western Australia } \\
\text { Department of Lands }\end{array}$ \\
\hline Potable water & Alton, 1856 & USA & $\begin{array}{l}\text { Handbook of Texas } \\
\text { Online }\end{array}$ \\
\hline Coal mines & $\begin{array}{l}\text { Bothwellhaugh, } \\
1960\end{array}$ & $\mathrm{UK}$ & $\begin{array}{l}\text { Scottish Mining } \\
\text { Website }\end{array}$ \\
\hline \multirow[t]{2}{*}{ Silver mines } & Argentiera, 1963 & Italy & $\begin{array}{l}\text { Regione Autonoma de } \\
\text { Sardigna }\end{array}$ \\
\hline & $\begin{array}{l}\text { Silverton, } \\
\text { 1960s-ongoing }\end{array}$ & Australia & $\begin{array}{l}\text { Australian Bureau of } \\
\text { Statistics }\end{array}$ \\
\hline Gold mines & Bannack, 1940 & USA & $\begin{array}{l}\text { Montana Ghost Town } \\
\text { Preservation Society }\end{array}$ \\
\hline Oil industries & Denoya, 1942 & USA & $\begin{array}{l}\text { Oklahoma History } \\
\text { Center }\end{array}$ \\
\hline Lumber & Singapore, 1875 & USA & $\begin{array}{l}\text { History of Manistee } \\
\text { County, Michigan }\end{array}$ \\
\hline $\begin{array}{l}\text { Poor agricultural } \\
\text { conditions }\end{array}$ & Schiro, 2000 & Italy & University of Catania \\
\hline \multicolumn{4}{|c|}{ Transport and accessibility } \\
\hline $\begin{array}{l}\text { Rail lines changes } \\
\text { and died off }\end{array}$ & Farina, 1930 & Australia & $\begin{array}{l}\text { Australian Geographic, } \\
\text { Issue } 97\end{array}$ \\
\hline $\begin{array}{l}\text { New roads bypass- } \\
\text { ing original town }\end{array}$ & Cook, 1997 & Australia & $\begin{array}{l}\text { Trans-Australian } \\
\text { Railway Melbourne: } \\
\text { Commonwealth } \\
\text { Railways }\end{array}$ \\
\hline \multicolumn{4}{|c|}{ Mutations of the economic and social conditions } \\
\hline Migration & $\begin{array}{l}\text { Torri Superiore, } \\
1910\end{array}$ & Italy & $\begin{array}{l}\text { Associazione Culturale } \\
\text { Torri Superiore }\end{array}$ \\
\hline Ageing & $\begin{array}{l}\text { Riace, } \\
\text { 1960s-ongoing }\end{array}$ & Italy & Comune di Riace \\
\hline Urbanisation & $\begin{array}{l}\text { Croce, } 1949 \\
\text { onwards }\end{array}$ & Italy & $\begin{array}{l}\text { Comune di Santa Croce } \\
\text { del Sanio }\end{array}$ \\
\hline
\end{tabular}


Table 5.1 (Continued)

\begin{tabular}{|c|c|c|c|}
\hline \multicolumn{2}{|l|}{ Combined causes } & Country & Source \\
\hline \multicolumn{4}{|c|}{ Government influence } \\
\hline $\begin{array}{l}\text { Infrastructure } \\
\text { construction }\end{array}$ & Tyneham, 1948 & UK & Ministry of Defence \\
\hline \multirow{2}{*}{$\begin{array}{l}\text { Geological insta- } \\
\text { bility and declara- } \\
\text { tion of unfitness }\end{array}$} & Balestrino, 1953 & Italy & Comune di Balestrino \\
\hline & $\begin{array}{l}\text { Toco Caudio, } \\
1980\end{array}$ & Italy & Quaderno It \\
\hline $\begin{array}{l}\text { Construction of } \\
\text { dams }\end{array}$ & $\begin{array}{l}\text { Mardale Green, } \\
1935\end{array}$ & UK & $\begin{array}{l}\text { Environment Agency of } \\
\text { England and Wales }\end{array}$ \\
\hline \multicolumn{4}{|l|}{ Disease outbreak } \\
\hline & Monterano, 1799 & Italy & Italy Traditions \\
\hline \multicolumn{4}{|l|}{ Armed conflicts } \\
\hline & $\begin{array}{l}\text { San Pietro Infine, } \\
1949\end{array}$ & Italy & Provincia di Caserta \\
\hline
\end{tabular}

\section{Ghosts towns in Italy}

In Italy the number of abandoned small villages is progressively increasing, with over 5,000 on Italian territory as a whole and a large concentration found in the impoverished and seismically active portions of the southern regions along the central-southern Apennines. ${ }^{15}$ Di Figlia has identified 135 towns abandoned during the twentieth and twenty-first centuries, ${ }^{16}$ while the Department of Agriculture, Food and Environment at the University of Catania confirms that, in Sicily alone, there are over 80 abandoned agricultural villages. ${ }^{17}$

Statistical research conducted in 2008 identified 1,650 municipalities at risk of becoming ghost towns by 2016, unable to reach the minimum threshold of 'survival' in the demographic, social, economic and services categories. ${ }^{18}$ These settlements represent one-fifth of Italian municipalities, one-sixth of the land area, 4.2 per cent of the population and 2.1 per cent of Italian workers.

Research findings provide striking evidence of the current fragility of rural economies in Italy. They also point out the need to find systemic solutions for the rehabilitation of historic urban centres that could be tested and scaled up to prevent a total rural exodus.

Southern Italy has suffered many earthquakes between the 1930s and the 1980s. The combination of such natural disasters and a weak 
economy provided villagers with an opportunity to radically reshape their way of life, with the prospect of switching from a largely rural and agricultural lifestyle to one based on a more modern urban life. ${ }^{19}$ In many instances the original town relocated to a nearby site and the abandoned settlement incorporated a new adjective 'Vecchio' or 'Old' to its name: Caianello Vecchia, Apice Vecchia and Alianenello Vecchio.

Poor farming, earthquakes, landslides and war all contributed to a mass migration of Craco's population to North America between 1892 and 1922. In 1963, a landslide caused the evacuation of the remaining 1,800 inhabitants to a nearby valley called Craco Peschiera, while the original Craco remained in a state of crumbling decay. In other cases the ruins of the ghost cities were given a second life as artist communities, or as refuges for migrants.

In 1998, the small village of Riace in Calabria welcomed 200 migrants fleeing the Turkish-Kurdish conflict, who settled in the village occupying empty buildings while changing the course of its demographic decline. Today a quarter of the population comprises migrants who have been given new homes and a new start in life.

Pentedattilo is a ghost town on the Monte Calvario, whose five pinnacles resemble five fingers. The town was founded as a colony of the Greek city of Chalcis, in 640 BC, and suffered successive invasions. After a series of natural events the village was evacuated in the mid-1960s due to the geological instability of the site. Today, it forms part of a network of trails for hiking, biking and trekking and serves as a tourist attraction because of its decadence. ${ }^{20}$

Apart from becoming film sets and a tourist attraction for ghost towns explorers, this growing number of settlements offers an, as yet, untapped potential to bridge the gap between decline and renewal, heritage and sustainability, localisation and resilience.

\section{Scenarios of revitalisation}

Numerous EU strategy documents highlight the need for far-reaching social innovation if Europe is to ensure employment and prosperity within planetary constraints. The EU Sustainable Development Strategy calls for cost-effective, integrated and interdisciplinary policies to ensure that future economic development is coherently rooted in social cohesion policies and environmental protection. ${ }^{21}$ The Europe 2020 Strategy for smart, inclusive economic growth also emphasises the crucial, overarching role of social, environmental and cultural dimensions of sustainability. ${ }^{22}$ 
Recent research conducted in 13 EU countries by the European Association for Information on Local Development (AEIDL) found there were in excess of 2,000 local, community-led initiatives that were directly engaged in practical activities to promote sustainable, resource-efficient, low-carbon and climate-resilient settlements. ${ }^{23}$ The AEIDL survey identified permaculture, ecovillages and transition towns as key movements of community-led initiatives with international reach in Europe testing new ideas, technologies and approaches and demonstrating how citizens and communities can live more sustainably.

Change is already happening, in the form of myriad local initiatives across Europe. Would any of these approaches, promoting socialeconomic experimentation in fast-changing environments, support the revitalisation of abandoned towns in southern Italy?

\section{Ecovillages in Europe: a pathway for rehabilitation of ghost towns?}

The Global Ecovillage Network (GEN) defines ecovillages as 'humanscale settlements, rural or urban, in the North or in the South, that strive to create models for sustainable living'. Ecovillages emerge according to the characteristics of their own bio-regions and typically embrace four dimensions of sustainability - social, ecological, economic and culturalcombined into a systemic, holistic approach that supports community development. ${ }^{24}$ Ecovillages often serve as research and demonstration sites aiming to address the quest for sustainability by increasing ecological literacy, ${ }^{25}$ developing processes that significantly reduce ecological footprints, and redesigning methods of production and patterns of consumption.

In Europe in 2016 there are 16 national ecovillage networks spread over 26 countries. With the mission of promoting the development of sustainable settlements that strengthen the capacity of individual ecovillages as well as the national ecovillage networks, GEN Europe disseminates the information on the ecovillage experience to wider society, professionals, government, the private sector and other nongovernmental organisations. ${ }^{26}$

Trainer believes the ecovillage movement is a remarkably theory-

less and apolitical movement. ${ }^{27}$ Fotopoulos adds that the northernoriented geographical distribution of the movement reflects its class structure, the concerns of most people taking part in it and the limitations of lifestyle strategies. ${ }^{28}$ Mare shares concerns on the prevailing 
public image of the 'ecovillage' as an entropic reiteration of the 'back to the land movement', or utopian rural outposts where people go to avoid society with an unfortunate tendency toward moral elitism. ${ }^{29}$ Garden considers the ecovillage 'movement' divorced from reality. ${ }^{30}$ Dawson counteracts by stating that since the late 1990s ecovillages, local communities which aim to minimise their ecological impact but maximise human well-being and happiness, have been springing up all over the world. For him they incorporate a wealth of radical ideas and approaches which can be traced back to Schumacher, Gandhi, the 1960s and the alternative education movement. ${ }^{31}$

\section{Torri Superiore ecovillage}

The origin of the medieval settlement Torri Superiore (Figure 5.2) is uncertain, though it may date from the late thirteenth century, a time of great social and religious unrest in the region. This would explain the village's compact architecture remarkable for its width and height, which would have offered good protection to its residents. ${ }^{32}$

The village is situated at the foothills of the Ligurian Alps, a few kilometres from both the Mediterranean Sea and the French-Italian border, close to the coastal town of Ventimiglia. Built completely in

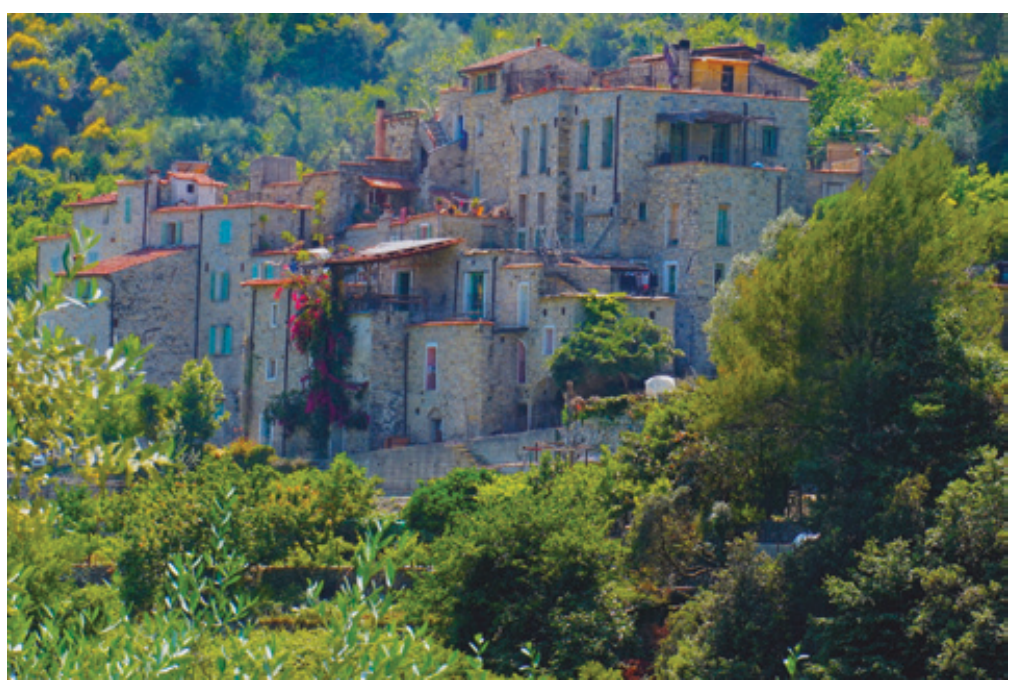

Figure 5.2 Built completely in local stone and lime over 700 years, Torri Superiore presents a unique urban layout with several five-storey buildings. 
local stone and lime over the course of many centuries, Torri Superiore presents a unique urban layout with several five-storey buildings, 162 rooms spread in an exceptionally intricate nature. ${ }^{33}$ Narrow passageways, stairways, terraces and alleys create a complex labyrinth, a web of rooms and corridors interwoven and spread with surprising connections. The total length of the village is $\mathbf{5 0}$ metres along the north-south axis, and 30 metres along the east-west axis. The total covered area is close to 3,000 square metres.

The buildings at Torri Superiore were added to over the centuries, with the last parts of the hamlet probably being built around the end of the eighteenth century. It was at this point that population levels peaked before the village gradually become abandoned as people began to leave Liguria due to lack of employment.

In the late 1980s a group of academics, professionals and enthusiasts initiated the process of negotiating the purchase of the abandoned village, and of setting up a cultural association and sustainable community. Early into the project the decision was made to renew the building following ecological principles and materials wherever possible, while respecting the original character. ${ }^{34}$ Torri Superiore was retrofitted over a period of 25 years in a comprehensive process of collective self-build utilising natural materials and appropriate technologies, compatibly with the limitations imposed by the local building codes and by the historical structure of the village. ${ }^{35}$

The renewal of settlement followed ecological principles wherever possible while respecting the original character of the medieval village. For instance, local stone was utilised on external and internal walls, which was considered an unlikely innovation in the region, 'since the local perception associated stone houses with a past of harshness and misery, something to be ashamed of, which must be hidden at all costs'. ${ }^{36}$ Furthermore, the community adopted lime plaster walls and washes, non-tropical wood for windows and doors, insulating cork and locally made terracotta floors. For one of the founders 'banning cement plaster, styro-foam panels, aluminum windows and synthetic paints made us look like foolish eco-idealists, but it paid off in the end'. ${ }^{37}$

The medieval village was given a new lease of life as an ecovillage, visitor attraction and cultural centre, with guest facilities and apartments for residents; a combined central solar, wood and gas heating system that functions at low temperature under the floor and on the walls; permaculture gardens and fruit orchards; and organically farmed olive groves.

Torri Superiore boasts a high level of social participation and inclusion, well structured under its cooperative and association frameworks, ensuring sharing of power and responsibility and modelling deep 
democracy practices, which members also teach to interested groups and individuals. Over the years the ecovillage residents have developed effective conflict-resolution mechanisms to ensure that all perspectives are heard once conflict emerges so that recourse to the legal system is the last resort.

With a solid social architecture built over time, a question remains whether community-led approaches such as Torri Superiore could support the rehabilitation of abandoned villages in southern Italy, creating a swift response to the increasing demand of housing amid record waves of refugees.

\section{Scenarios of revitalisation: the 'albergo diffuso' model}

To penetrate into Italy is like a most fascinating act of selfdiscovery - back, back down the old ways of time. Strange and wonderful chords awake in us, and vibrate again after many hundreds of years of complete forgetfulness. ${ }^{38}$

Tourism has become a global economic sector with a wide and significant impact on the socio-economic and ecological development of regions and nations. ${ }^{39}$ This global trend is apparent in Italy, where the tourism industry has become one of the main strategies for the recovery of abandoned settlements in the Southern region, ${ }^{40}$ with a direct impact on the identity and occupation of historic urban landscapes.

In the early 1980s, the hospitality concept of albergo diffuso (AD) was introduced to revive historic Italian villages and town centres by revitalising various historic buildings, thus attracting tourism to uncommon destinations. Translated as 'scattered hotel', AD offers guests the experience of living in historic sites in rooms scattered throughout different buildings within a village, overseen by a central management structure and hosted by a small community. Unlike a normal hotel, whose facilities are found in a single building, this model of hospitality consists of several units linked to each other within a range of not more than 200 metres.

The concept was developed by the Italian scholar Giancarlo Dall'Ara, who defined AD as both an original model of hospitality and an approach toward sustainability (Table 5.2). ${ }^{41}$ Scattered hotels, argues Dall'Ara, are healthy for the host villages, because they act as social, cultural and economic stimuli. He calls them 'drivers of development' because 
Table 5.2 Comparing and contrasting hospitality models

\begin{tabular}{ll}
\hline Albergo diffuso & Hotel \\
\hline Feeling at home & Feeling in a hotel \\
Courtesy and kindness & Provision of professional services \\
Authenticity & Efficiency \\
Non-standardised rooms & Variety of tariffs according to rooms \\
Attention to detail & Comfort \\
Link with territory & Wide range of services \\
Contacts with local residents & Contact with other guests \\
Informal environment & Privacy \\
\hline
\end{tabular}

everything is sourced in the region, involving the residents and local producers, thus preventing depopulation.

According to Bulgarelli, this unique model of tourism development for historic sites does not produce negative environmental impacts, since it grows with the demand, as rooms are 'regenerated' and added to the existing network as necessary. ${ }^{42}$ Russo, on the other hand, argues that the principle of capitalising on ruins' authenticity by transmuting ancient inhabited sites into 'slow' tourism places, mostly through foreign private investors, is questionable. ${ }^{43}$

To date, there are over 50 Italian ADs grouped under a national association, while 13 Italian regions have adopted legislation regulating the concept. The AD model has been used in villages in the process of depopulation with good results, though it seems less effective in completely abandoned villages. ${ }^{44}$ The first step toward establishing an $\mathrm{AD}$ is the development of a territorial analysis followed by a business plan. A SWOT (strengths, weaknesses, opportunities and threats) analysis of two AD business plans demonstrates the absence or frequent change in regulations, bureaucracy and long lead times to go through the process of authorisation, at both local and regional levels, as the main obstacles for establishing an AD. ${ }^{45}$

\section{Albergo diffuso Borgo de Castelvetere}

In 1996, Castelvetere sul Calore, a small rural municipality of Irpinia hit by an earthquake in 1980, embarked on the project The Villages of Tradition - Recovery and Rehabilitation of Four Medieval Villages. The project was part of a more complex strategy aimed at enhancing tourism in the whole mountain community of Irpinia, through 
a network of accommodation in traditional villages demonstrating valuable architectural and environmental profiles. ${ }^{46}$ Using the public-private partnership formula, the project 'acquired' abandoned buildings, which became public property, subsequently turning them into tourist accommodation, craft shops, museum and education spaces. ${ }^{47}$

Subsequently the AD model was adopted as the strategy for the rehabilitation of Castelvedere's historic centre, and since 2004 the Albergo Diffuso Borgo di Castelvetere (ADBC) has been promoting an integrated approach to socio-economic regeneration in the region.

The project of restoration that took place between 1996 and 2002 optimised the use of local materials by using wood from a chestnut forest grown at altitudes between 400 and 1,000 metres, stones and roof tiles reclaimed after the 1980 earthquake, and lime and sand plasters.

The use and reuse of local materials helped to contain the cycle of consumption and minimised construction waste. The reconstruction employed local builders' traditional knowledge in enhancing technical simplicity in the building and conservation processes.

Furthermore, the restoration included structural non-invasive techniques to improve the seismic response of the buildings and the use of ecologically compatible material. In terms of energy generation, ADBC has adopted a biomass wood-pellet system for commercial use with an automatic built-in hopper-fed fuel system. Originally imported from Scandinavia, the pellets have most recently been sourced regionally. Overall the architectonic rehabilitation of Castelvetere's historic centre has strengthened community identity, generated new jobs and promoted traditional workmanship.

Change and continuity, although they seem contradictory at first sight, are strongly interrelated factors that should be considered together when conserving places of cultural significance, ${ }^{48}$ such as the historic centre in Castelvetere. A key strategy under this principle is allowing changes to take place only to retain the significance and appropriate interpretation of the historic site. While the comprehensive restoration of the historic centre retained the original significance of the village, on the edge of the territory the original character was in some instances lost through unsolicited 'modernisation' interventions and alteration of building materials and techniques (Figure 5.3). 


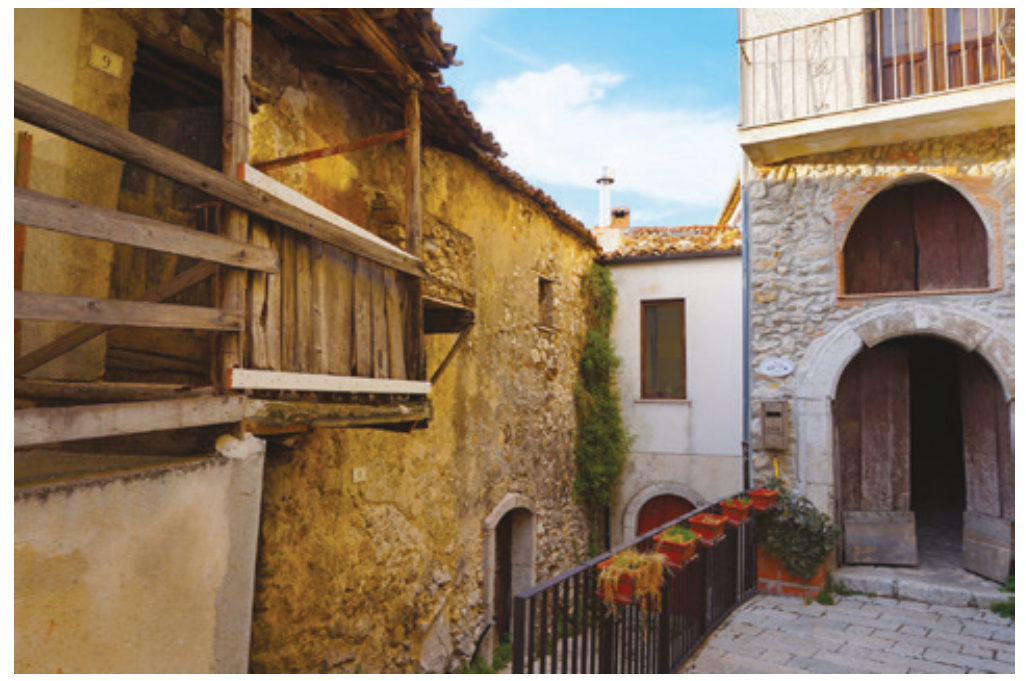

Figure 5.3 Architectural interventions and their effects on the character of the historic fabric.

As for the applicability of the AD strategy in the ghost towns context, their state of complete social abandonment does not offer the possibility of initiating a regeneration process via the scattered hospitality model. ${ }^{49}$ The main challenge of introducing AD as an approach for the revitalisation of abandoned villages is the need to reconcile the entrepreneurial project with the development strategies of the local territory while engaging the support of the deserted village's neighbouring communities.

A systemic way to address this challenge is by designing a multistaged regeneration strategy as exemplified by the ghost town Apice Vecchia. The project started with the regeneration of its medieval castle, and has now invited proposals for small businesses and B\&Bs to return to the area, with a view of establishing an economic base and gradually attracting new residents who, in turn, could provide a platform for the establishment of an albergo diffuso. ${ }^{50}$ Only time will tell if this designed strategy will bring life back to the ghost town, weaving the abandoned site back into the region via an EU-supported regeneration project that, at this stage, does not have community participation.

On the other hand, it may prove that a blended model of urban regeneration practice utilising $\mathrm{AD}$ as one of the elements, not as the driver strategy, may well balance the economic and conservation 
requirements of the historic site. However, this approach raises still unanswered questions concerning the impact of such a strategy in the identity and occupation of the historic landscape. Further research is needed to determine the nature of the real temporal, spatial and cultural impacts of an AD model of regeneration on the fragile social and natural balances that characterise the semi-abandoned towns and the ageing host communities.

\section{Scenarios of rehabilitation: the Riace humanitarian approach}

While every refugee's story is different and their anguish personal, they all share a common thread of uncommon courage - the courage not only to survive, but to persevere and rebuild their shattered lives. ${ }^{51}$

Each year thousands of men, women and children attempt a dangerous journey across the Mediterranean Sea to Europe. Many of them are trying to escape poverty, climate impact and war in their home countries. ${ }^{52}$ From January to December 2015, the total number of refugees and migrants arriving in Italy by sea was around 153,850 people. ${ }^{53}$ Key disembarkation points in 2016 remained Sicilian ports, which have been identified as hotspots, with 106,162 migrant arrivals during the first 10 months of the year. ${ }^{54}$

Despite all efforts, existing approaches to protection have proven singularly unable to find solutions for long-term displaced populations. Humanitarian responses in refugee situations have been criticised for focusing too heavily on the 'care and maintenance' of refugee populations, leaving refugees essentially 'warehoused' for years on end, their lives in limbo, with little focus on long-term, sustainable solutions. In particular over winter, families who have been forced to flee their counties and homes struggle in camps, poor housing and makeshift shelters. As temperatures drop they face icy winds, violent rainstorms and snow.

In the 1990s Riace was turning into a ghost town before 200 Kurds fleeing the Turkish-Kurdish conflict landed on a beach near the small village in Calabria. The village was in danger of becoming extinct as waves of residents migrated to northern Italy for jobs. Taking in refugees allowed the village to preserve basic public services, such as the school, and also commerce that had almost disappeared. ${ }^{55}$ The population of Riace has since more than tripled to 2,800 residents, among whom are migrants of more than 20 nationalities. Today portions of the abandoned 
town have been rehabilitated; a quarter of the population is composed of immigrants who have been given accommodation in the village's abandoned houses, as well as training to get them starting a new life. Riace is part of a national network of 376 municipalities called SPRAR (Sistema di Protezione per Richiedenti Asilo e Rifugiati; Protection System for Refugees and Asylum Seekers), created by the Italian Ministry of Home Affairs and funded by the Italian Government and the European Union. Riace is a model of what SPRAR calls an accoglienza integrata or 'integrated welcome'.

\section{Conclusion}

The number of ghost towns is increasing in Southern Italy. ${ }^{56}$ The progressive globalisation of our economies over the last century, orchestrated by 'the pyramid of power that contemporary financial capitalism imposes upon the world' combined with the speed of urbanisation have uprooted the viability of thousands of small communities, ${ }^{57}$ turning them in 'discarded elements of the modern consumer society'. ${ }^{58}$

Worldviews are formed to solve problems. ${ }^{59}$ They change when existing solutions no longer work and rising problems require new approaches. This chapter has argued that ghost towns are the result of a convergence of multiple crises, incorporating human, natural and economic factors. It has also suggested emerging innovative approaches, which could address the abandonment as an opportunity to implement integrated rehabilitation strategies of multi-stakeholder response creating pathways for addressing the increased demand of migrant housing.

Ghost towns tell of a time not far away, still present in the collective memory, ${ }^{60}$ where settlements were embedded in landscapes in a rich tapestry of cultural and natural values woven over time. Today they are the silent testimony of a time when culture and identity, geography and topography, diversity and exchange were eloquently expressed in a scale appropriate to the bioregion. Tomorrow they may become the living statements of a time when humanity re-ignited the locally adaptable, culturally rooted, energy conserving, technologically appropriate, inter-generationally balanced, place-based values and practices needed for historic rural settlements to thrive.

Could the approaches of Torri Superiore, Borgo de Castelvetere and Riace offer potential solutions to the increase of abandoned villages combined with the current shortage of housing engulfing Southern Italy? 
As a result of imaginative integrated planning practices, these initiatives have made significantly more progress than mainstream government approaches towards the realisation of sustainable communities by strengthening social cohesion, addressing environmental vulnerabilities, rethinking tourism, fostering local economies and improving housing status. By adopting integrated planning approaches, incoming migrants and asylum seekers could play an important role in repopulating and regenerating some of Southern Italy's neglected architectural treasures. 


\title{
6
}

\section{The role of community-driven finance in bridging formal and informal practices in housing}

\author{
Insights from Vinh, Vietnam
}

Johanna Brugman

\section{Introduction}

Informal practices play an important role in providing land, shelter and finance for the urban poor in cities of the global south. Despite this, informality continues to be perceived as an urban policy problem. ${ }^{1}$ The planning literature identifies the need to move forward from the current formal/informal dichotomy to a more comprehensive understanding of the role that informal practices play in urban development. ${ }^{2}$ This argument is especially relevant in the context of housing finance, where formal practices (e.g. from international, public and private institutions) have the ability to leverage funds to invest in housing at scale, while informal practices (e.g. community saving groups) have the ability to reach the poor. ${ }^{3}$ Despite linkages between formal and informal housing finance, most research has tended to concentrate on understanding these practices separately. ${ }^{4}$ From the starting point of a theoretical discussion on informality and planning in the urban global south and a sixmonth placement with the Asian Coalition for Housing Rights in 2013, this chapter discusses the potential of community-driven financial arrangements to bridge formal and informal practices and to provide access to affordable housing to the urban poor. This process is illustrated in the case of the redevelopment of collective housing in Huu Nghi community, Vinh, Vietnam. 


\section{Urban informality: a dilemma for planning in the urban global south}

In the global south urban informality is generally associated with human settlement and trade or exchange that occurs outside of formal legal structures and processes. ${ }^{5}$ However, the meaning of urban informality and what it represents is much broader and varies depending on the context in which it operates. In fact, urban informality is not just associated with informal settlements or street vending, but includes a variety of practices put forward by the various actors that operate in cities. ${ }^{6}$ Consequently, urban informality has been associated with ungovernable development practices, ${ }^{7}$ with the poor's autonomy and creativity, ${ }^{8}$ and with strategies that the poor use to survive in cities, ${ }^{9}$ and used to embody varying degrees of power and exclusion from the state. ${ }^{10}$ Thus urban informality is a complex and contested concept that is still subject to much academic debate.

Urban informality has traditionally been associated with poverty. In the debate, however, it is recognised that urban informality is not just the space of the poor but also of the state itself and other influential actors in cities. What this suggests is that, even when there is a direct relationship between poverty and informality, ${ }_{11}^{11}$ informality itself is much more complex as it is tangled up with complex structural power relationships that define which urban development practices are legitimate and illegitimate in cities. ${ }^{12}$ In this light, powerful actors use 'the state of exception' to move their development ideals forward and to purposely meet their individual interests, while powerless people and their 'illegal' practices are excluded from contributing to the development of the city. ${ }^{13}$ Thus planning responses to informality are important not only for successful pro-poor interventions, but also to progress social and spatial justice in cities of the global south.

Urban planning has traditionally viewed informality as a separate sector supporting a dichotomy between 'formal' and 'informal' sectors. In this light informality is seen as supporting illegal, uncontrolled and inefficient development, and is fundamentally different from the more ordered, regulated and efficient notions of planned land use and settlement. Thus, in the context of urban planning, informality is seen as 'the other' and thereby perceived as an urban policy problem. ${ }^{14}$ Most urban planning responses to informality have been informed by the formal/ informal dichotomy. In relation to housing, many of these responses are characterised by forced evictions of informal settlements, involuntary resettlement or an attempt to control informal settlements using land 
use regulations, zoning, building standards and the formalisation of land and property. ${ }^{15}$ Thus, planning's underlying assumption supporting the formal/informal dichotomy has been problematic and unable to solve the complexity associated with informal development in cities.

In this light, Vanessa Watson argues that the formal/informal dichotomy creates a significant gap between planning (institutions and practice) and the realities of those people that survive under conditions of informality ${ }^{16}$ This gap is conceptualised by the author as a conflict of 'rationalities' between the logic of governing and the logic of survival. ${ }^{17}$ The logic of governing is attributed to the notion of control and development held by most planners, government administrators and the private sector (grounded in the rationality of Western modernity). The notion of survival is referred to as the rationality which informs the strategies and tactics that the urban poor use to survive and make a living in cities. This gap is recognised as a central limitation of planning, and has brought to light an academic debate questioning the adequacy of current planning frameworks operating in cities of the global south. ${ }^{18}$ In this light the literature argues for the need to redefine planning practice in a way that engages with informality as a defining characteristic of rapidly growing cities. ${ }^{19}$ The next section illustrates how the formal/informal divide is manifested in the context of housing finance.

\section{The implications of the formal/informal divide in financing affordable housing}

In the urban global south, most approaches for financing housing have been informed by the formal/informal divide. The formal sources of housing finance include private banks, micro-finance institutions, governments and donors. The informal sources include individual (e.g. savings, loans from relatives and informal lenders) and/or collective practices (e.g. saving groups, co-operatives) used by the poor to finance housing. ${ }^{20}$ Despite this diversity most housing policies recognise the formal system as the only one with the capacity to finance affordable housing, and millions are spent in government and private sector social housing programmes. ${ }^{21}$ Despite the unquestionable importance of formal systems, many argue that informal sources of finance also play a role in financing housing, even when these are vulnerable and imperfect. ${ }^{22}$ These systems also reflect how poor people respond by themselves to vital housing needs with small resources, unrecognised status and in contexts where formal support is not available, a scenario which is common in many cities of the global south. ${ }^{23}$ 
The lack of engagement with informal financial mechanisms is part of the reason why housing interventions have been unable to appropriately respond to the needs of urban poor groups. For instance, government interventions sustain a highly centralised, hierarchical structure that leaves little room for the inclusion of the urban poor in investment decision making. Thus most public-funded housing has ended up being inappropriately fitted to the needs of the poor by being expensive, located in the peripheries of cities, and lacking appropriate design thus inhibiting it from adapting to the changing needs of families over time. ${ }^{24}$ Furthermore, research has demonstrated that in many cases government subsidies have been unable to reach poor groups because of the stringent conditions and rules placed on their access. ${ }^{25}$ Similarly, the literature acknowledges that finance from banks is not affordable to urban poor families and demand inflexible conditions such as stable incomes, and the need for land security for collateral which most of these groups lack. ${ }^{26} \mathrm{Also}$, most international aid rarely reaches the urban poor directly as funding is allocated to projects or sectoral reforms that are thought to contribute indirectly to housing provision. ${ }^{27}$ In addition, research has showed that those sources that manage to reach the poor, such as micro-finance institutions, are likely to create a debt burden as they target individuals who often cannot repay loans on their own. ${ }^{28}$

From the above it can be argued that the formal housing financial system is not as effective as it could be in working for the poor because it operates in disconnection from the way the poor use finance in their daily lives, usually aligned with their dynamic livelihood, survival strategies and social networks. ${ }^{29}$ This argues for the need for financial interventions to be tailored towards the particular circumstances of the poor, and develop new approaches in housing finance able to move forward from the formal/informal divide. In support, the planning literature argues for the need to develop new understandings of the interactions between formal and informal systems. Within this discussion, the concept of the 'interface' arises as a central concern for planning to understand the various and complex interactions between formal and informal urban development practices. ${ }^{30}$ In the context of financial practices for housing examples of community, public- and private-sector led initiatives supporting the interactions between formal and informal practices have appeared over the last decades. ${ }^{31}$

The interface is understood as a zone of encounter and contestation between the conflicting rationalities of the state and the poor, arising at the point where the state's attempts at modernisation and development (e.g. provision of formal services, housing and tenure 
systems) are met (or confronted) by the target populations. ${ }^{32}$ For the less powerful the interface is a zone of resistance, evasion and/or appropriation inherently shaped by power. Existing literature and research into the interface has highlighted the unpredictability of these interactions, having the potential to generate both transformative outcomes and at the same time exclusionary processes in planning practice. ${ }^{33}$ These arguments make research into the formal/ informal interface within different contexts and urban development practices important and relevant for informing planning knowledge. The next section describes the characteristics of community-driven finance in South-East Asia as an interface between formal and informal financial and housing development practices, and its potential for generating affordable housing solutions for urban poor groups in cities of the south.

\section{The role of community-driven finance in bridging formal and informal development practices}

Community-driven finance is a development process driven by organised poor communities seeking to secure access to land, housing, infrastructure and social development opportunities by accessing finance on their terms. ${ }^{34}$ This gradual process generally arises from the struggle and initiative of grassroots movements, and consolidates by linking individuals through saving activities, forming community saving groups, and evolving into neighbourhood, city-wide, national and international funds and networks. ${ }^{35}$ Despite this, these processes vary in their consolidation, mixing both bottom-up and top-down elements in different ways according to their specific context. Community-driven financial mechanisms function mainly as revolving funds used to give loans to organised poor communities. The literature has identified different names referring to community-driven finance mechanisms including urban community development funds, urban poor funds, urban poor development funds, community funds, community development funds, city-based community development funds, and city development funds. ${ }^{36}$

Today, community-driven finance is present in countries across Asia, Africa and Latin America and linked through global and regional networks of grassroots poor communities represented by two main umbrella organisations: Slum Dwellers International (SDI) and the Asian Coalition for Housing Rights (ACHR). In South-East Asia, ACHR and its network of local organisations provide funds, organise 
knowledge exchanges across countries, create partnerships with governments and key development agencies, and help consolidate grassroots networks as well as networks of committed professionals that provide technical support to communities on the ground. In this region community-driven funds are found in seven countries including Cambodia (23 funds), Indonesia (4 funds), Myanmar (4 funds), Philippines (15 funds), Vietnam (17 funds), Thailand (7 funds) and Lao PDR (26 funds), with a total capital of US\$22,192,646 in 2014, of which US $\$ 14,893,989$ come from urban poor community savings. ${ }^{37}$ The characteristics of each country's process are different, and only Thailand, Vietnam and Cambodia have experienced formal links with the government sector. ${ }^{38}$ Despite this diversity, there are common characteristics supported by community-driven finance allowing this approach to bridge formal and informal financial practices in housing development.

A defining characteristic of community-driven finance is collective action. This characteristic differentiates this approach to other housing financial interventions, which tend to target the individual family or household. Instead, community-driven funds provide collective loans to organised communities with established and functional saving groups. ${ }^{39}$ The saving groups act as communities' financial and governance systems, allowing collective investment decisions to be made according to the communities' needs, resources, capacities and conditions. Saving groups are community support systems that extend beyond the development of housing and infrastructure; these provide support for welfare and emergencies as well as the development of social and political capital among the poor. ${ }^{40}$ In this light, collective action ensures that when individual families experience difficult times affecting the repayment of loans (e.g. with their jobs or illness) the community system is available for support. Collective action also plays a role in increasing the decisionmaking power of poor communities by increasing their negotiating capacity and political support for their development plans, as well as opportunities to leverage external funds and resources..$^{41}$ This shows that the overall purpose of community-driven finance is to be not only a source of direct capital to the poor, but also a support system aiming to change the vertical governance relationships that are at play in urban and housing development.

Collective action is a learning process. In the community-driven approach collective action among poor individuals is facilitated by experienced community leaders and support professionals through collective mobilisation tools such as community-driven surveys and mapping 
and knowledge exchanges. ${ }^{42}$ These tools encourage poor communities to define and visualise their common development needs, as well as learn from the successes and challenges experienced by other communities facing similar situations, and envision how by working together they can address their needs in a more effective way. Collective action extends beyond the community level and reaches the institutions that manage housing and infrastructure development in cities. For this, the community-driven approach ensures that learning is also targeted towards key government officials of development agencies able to support and move forward the community-driven agenda within key institutions. In this light, key members of government and international institutions are invited to attend knowledge exchanges with communities as well as their respective institutions, and learn from successful examples where the community-driven approach has been successful. The learning component is essential for communities and institutions to learn from each other, bridge their knowledge and understanding, and work collectively towards addressing the needs of communities as well as cities as a whole.

Furthermore community-driven mechanisms and processes are designed to be flexible. ${ }^{43}$ Flexibility is reflected in the rules and conditions used to make finance available to poor communities, usually characterised by supporting loans with long repayment periods and low interest rates. Also, contrary to supporting large amounts of money, community-driven mechanisms support small budgets. These conditions make an effort to align the financial intervention to the livelihood dynamics of the poor, and make finance appropriate to the poor's management capacities. In addition, many of the housing and infrastructure projects supported by the community-driven finance approach strive for the relaxation of planning standards in order to make housing and infrastructure more affordable to the poor. Consequently, in most cases the development of housing and infrastructure encourage innovation in design and cost-reduction strategies. Flexibility is also reflected in the characteristics of the professionals supporting the communitydriven approach. These professionals believe in the capacity of the poor to provide solutions to their own problems, and act as facilitators of community-driven processes rather than direct implementers of housing and infrastructure projects. ${ }^{44}$

Community-driven finance is now recognised by many international organisations and the academic literature as an innovative approach to finance affordable housing for low-income and urban poor communities in the global south. ${ }^{45}$ As shown in this section the 
conditions supported by the community-driven approach - including collective action, flexibility and the their integral learning component have the potential to bridge formal and informal sectors together, not only by bridging formal and informal finance but also in terms of bridging knowledge systems and decision-making power. The following section introduces the community-driven finance approach in Vietnam, and describes the case of the redevelopment of old collective housing in Huu Nghi community through a city Community Development Fund (CDF) in the city of Vinh. The following draws from the characteristics of the community-driven approach described in this section, and illustrates how these conditions operate within the interface of formal and informal development practices, and progress the development of affordable housing for urban poor communities.

\section{The redevelopment of collective housing in Huu Nghi Community, Vinh}

The community-driven finance movement in Vietnam has been consolidating since 1989 through the support given to collective saving activities used by low-income groups. Key in the implementation of this process have been local organisations such as the National Women's Union, Enda Vietnam, the Association of Cities of Vietnam (ACVN) and local authorities, as well as international organisations including ACHR, UN-ESCAP, UNDP and Cities Alliance. ${ }^{46}$ The first breakthrough in the consolidation of this process was in 2001 with the establishment of citywide community development funds in five cities (Vie Tri, Hai Duong, Hue, Quy Nhon, Can Tho). The aim of this process was to strengthen and scale up existing community savings groups and link them with formal government institutions in different cities. The CDFs proliferated to a total of 17 cities, forming the National Network of Community Development Fund. ${ }^{47}$

In Vinh, a city on the north central coast of Vietnam with approximately 490,000 residents, the city-wide CDF was set up in 2006. The $\mathrm{CDF}$ is a revolving fund managed by a committee of members from the local government, and blends different sources of funding including the ACHR's former Asian Coalition for Community Action Programme (ACCA), the Latin American, African and Asian Social Housing Service (SELAVIP), UN-HABITAT, World Bank and the local government as shown in Figure 6.1. The National Network of Community Development Fund is the main deciding body on how the funds from the variety of sources are allocated to each individual city. 


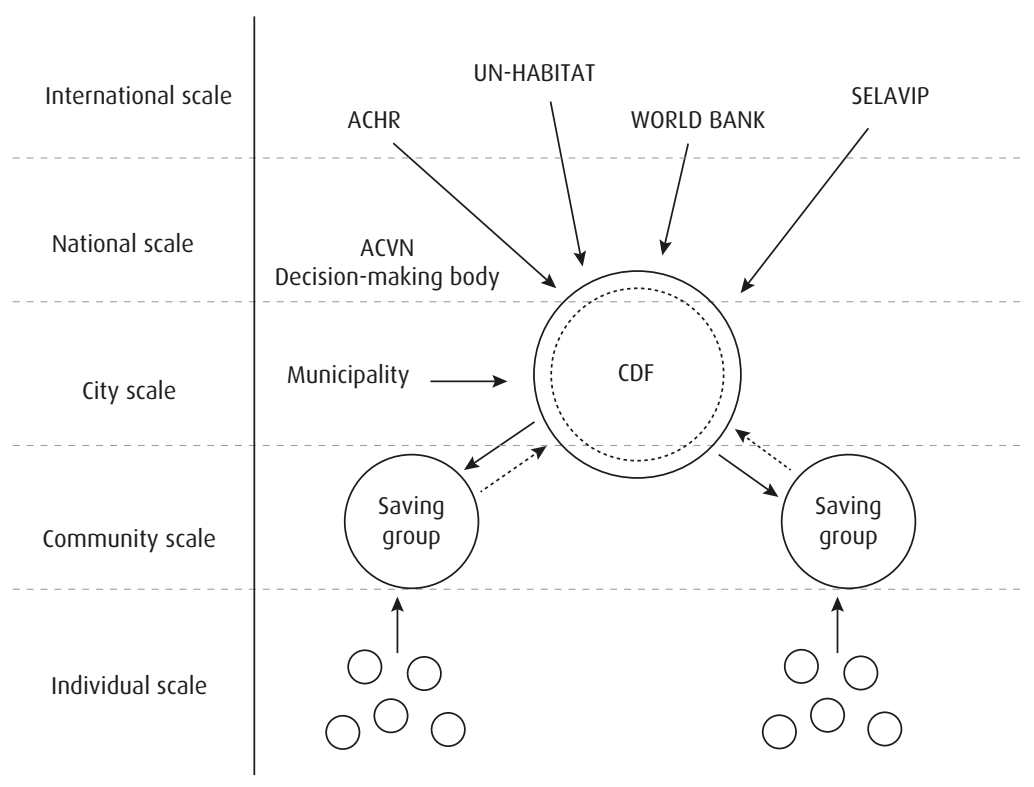

Figure 6.1 Operation of Vinh's community development fund (CDF).

Table 6.1 Conditions of loans supported by Vinh CDF in 2012

\begin{tabular}{lccc}
\hline Purpose & $\begin{array}{c}\text { Amount of loan } \\
\text { (USD) }\end{array}$ & $\begin{array}{c}\text { Repayment } \\
\text { period }\end{array}$ & $\begin{array}{c}\text { Annual interest } \\
\text { rate }\end{array}$ \\
\hline Infrastructure & 15,000 & 25 months & $0.8 \%$ \\
Housing & 40,000 & 42 months & $0.65 \%$ \\
Disaster relief & 20,000 & 25 months & $0.65 \%$ \\
\hline
\end{tabular}

The funds are used to give loans to communities with organised saving groups to manage infrastructure projects, housing projects and disaster recovery as well as support community exchanges, surveys, mapping and other activities. By December 2012 the CDF had funded a total of 34 small infrastructure projects, five housing projects and three disaster relief projects supporting the conditions seen in Table 6.1.48

Vinh is home to 99 old dilapidated collective housing blocks (both one-storey row houses and apartment flats) built for factory workers in the 1970s when the city was planned to become a new industrial centre. In 2007, the People's Committee of Nghe An province provided the legal basis for the redevelopment of old collective housing in Vinh. The redevelopment of old collective housing happens across Vietnam as part of 
the market-driven urbanisation aiming to 'renovate' and 'beautify' cities characterising South East Asia. In Vinh, this process initially supported the conventional top-down and state-driven practice, and proposed thereplacement of existing housing with lower-density social housing occupying plots of double the size of the existing ones. ${ }^{49}$ This made the houses very expensive and implied that some families would be relocated to new housing elsewhere. These plans triggered the members of Huu Nghi community to organise and discuss alternatives to upgrade their community. At that time Huu Nghi community comprised 29 households and 103 people living in old and dilapidated row houses, originally built by the Soviet-owned Huu Nghi Shareholding Company during 1974-78, and sold to the individual households in 1990. The community consisted of four single-storey housing rows that were seriously degraded, and had a lack of adequate infrastructure such as access roads, drainage and sewerage system.

In 2009, in the light of the political opportunity for the redevelopment of old collective housing, ACVN, ACHR and Vinh City's People Committee organised a workshop, 'Communities Collectively Build Low Cost Housing', and facilitated exchange visits to other cities in Vietnam and Thailand. These exchange visits aimed to give an opportunity to community members, as well as government officials, to learn from the initiatives of communities and governments facing the same challenges in other cities and countries. These exchange visits helped community members and local authorities to visualise and exchange knowledge and ideas on how they could work together in their own particular context. This sparked the interest and initiative of Huu Nghi community to start their saving group and save the required deposit to borrow the CDF's US $\$ 40,000$ housing loan.

With the money in hand and the help of a retired architect, the community developed the design plan for their new houses and infrastructure. This plan proposed the development of two-storey houses within plots of 45 square metres each. This plan made houses more affordable by proposing smaller plots than the provincial government's minimal social housing standard. Thanks to securing the loan through the CDF, the good organisation of the community, and support from ACVN and ACHR, negotiations with city and provincial authorities were successful in relaxing the housing standards. This is recognised as an important breakthrough in the provision of affordable housing for low-income families in Vietnam's socialist regime. Community leaders recognise that obtaining this permission was the hardest step in their redevelopment process but it was possible thanks to the good relationship between the community and the Mayor of Vinh. 
In addition, the design proposed sharing the houses' foundations and walls, reducing costs by about 40 per cent. The community reduced additional costs by collectively purchasing materials in bulk, making effective use of new materials, recycling materials from their old houses, and having one contractor for the whole community. In the end, the project cost VND1,248,000 per square metre, a reduction of 43 per cent of the estimated cost of VND2,200,000 per square metre. In 2010, just six months after the project began, the whole development was complete, taking away the one-storey dilapidated houses with leaking roofs and bad-quality infrastructure, and replacing it with two rows of two-three storeys with a five-metre-wide alley, street lighting, complete drainage and available basic services to all households. With the remaining money the community leader bought Vietnamese flags for all households, which are displayed by all households together in the community on special occasions. ${ }^{50}$

Interviews with community members attribute the success of the project to different key factors. Most important was the collaboration and solidarity between community members, which was achieved by the community working towards a common goal and setting up a saving group and a system to make their collective decisions. In this case community collaboration went further; it also involved sharing land plots of equal size in the new development even when some households had previously had bigger plots of about 90 square metres. Also, two better-off households agreed for a 72-year-old single and poor woman to 'borrow' the walls of their houses, meaning she only had to pay for a roof and front and back walls. Solidarity and collaboration were also reflected in the initiative of all community members to volunteer their labour in the construction of the houses and infrastructure, the supervision of construction quality and use of materials, and the constant sharing of information about the use of the money, development plans, obstacles and progress.

Furthermore, good leadership, the support of government and their decision to allow the relaxation of planning standards, and the support from national and international organisations are attributed as important factors for the success of this project. At time of writing the community has been able to pay back the complete loan to the city CDF and continue to enjoy their new houses and life together. Community members feel proud of their houses and community, have received recognition from wealthier sections of society and have secured material assets for themselves and future generations. The case of Huu Nghi community helps to demonstrate how the community-driven approach can 
work in Vietnam, and the community's leaders and members, as well as the local government, have shared their experience across the nation as well as internationally with communities, governments and development agencies, including at the World Urban Forum in Naples in 2012.

\section{Lessons from a community-driven financial approach to planning theory and practice}

The case of the Huu Nghi community shows the capacity of communitydriven finance to move forward from the formal/informal divide and finance affordable housing in cities of the global south. This case provides an example of the 'conflicting rationalities' that are at play at the interface between formality and informality in housing development processes, which as the literature suggests is a zone of contestation between different actors operating in cities. The case of the Huu Nghi community shows how the city's community development fund acted as a bridge between the market-driven ideology of the state, and the rationality of a low-income community seeking to collectively improve their living conditions and community through the development of housing. The community development fund in this case not only bridged formal and informal systems to finance housing, but importantly bridged knowledge systems and decision-making power between poor communities and government institutions. In this case collective action, flexibility and the learning component that gives rise to these conditions were essential in facilitating the bridge between informal and formal development practices.

Collective action was manifested in the collective organisation of the community, including setting up a saving group allowing poor families to access finance provided by government and international development institutions. The saving group allowed the community to create a support system and a collective governance structure. These organisation systems ensured the community's control over their decisions, collective investments and development process. Working collectively also contributed towards all members' having access to housing and infrastructure. Collective action also involved actors such as ACVN, ACHR and the Mayor of Vinh, who pushed forward the community-driven development agenda within a complex top-down political culture and a market-driven ideology driving the development of Vietnam. This support and their collective organisation gave bargaining power to the community and helped them negotiate with provincial authorities for the 
relaxation of building standards. Learning through national and international examples was a key incentive to collective action within the community and with key development actors. Learning through community exchanges helped to bridge knowledge systems and enhance understanding of how poor communities and local authorities could work together not only for the development of a particular community but for the city overall.

Flexibility in this case provided a necessary space for the organised community to play a key role in their development process. In this case flexibility was manifested in the terms, conditions and small amount of the loan provided by the $\mathrm{CDF}$, allowing finance to be more aligned to the livelihood and dynamics of the poor community. The conditions supported in the loan provided space for the community to plan the housing development according to their needs, resources and capacities. In addition, flexibility allowed the generation of an adequate and affordable housing design with the technical support from a retired architect equipped to facilitate (rather than enforce) a community-driven design process. The design process showed innovation in ensuring that room was made for all 29 households living in the community to continue to live together (in contrast to the standards of public housing set up by government authorities), and using recycling materials for the development of each individual house. Flexibility in this case reflects the belief that poor communities can play an important role in their own development.

The case of the Huu Nghi community shows how informality, in this case reflected in the savings group and the development practices of a poor community, can play an important part in planning and development of affordable housing in the urban global south. The communitydriven approach allowed poor communities not only to participate in the process but to appropriate it and play a key role in their own development. In addition, community-driven mechanisms such as the Vinh's community development fund and the conditions and processes that these systems support help to bridge knowledge systems and decisionmaking power between communities and local authorities. This process enhances understanding of how governments and communities are able to work together moving forward from the scenario of 'conflicting rationalities' which usually characterises their encounter.

Furthermore, the case of Huu Nghi provides important lessons on how housing finance can act as an enabler (rather than a constraint) for the urban poor's development, and for progressing more inclusive approaches in the development of housing in cities of the urban global south. Despite the important lessons from this case different questions 
remain, including: How can this process be replicated on a city-wide scale? How can community members be involved in the management and decision making of the city CDF? How can the mobilisation and networking of urban poor groups in the city be continuously maintained? Research into community-driven mechanisms would benefit not only from in-depth case-studies into these processes but also from contextualising these cases within the political and socio-economic complexities experienced in cities of the global south, as well as more practice-oriented research into how these mechanisms could be scaled up and sustained by linking with private sources of finance. 


\section{7}

\section{Clearing stock of the invisible \\ Effects of cosmopolitan power on the supply of affordable housing}

Kane Pham

\section{Introduction}

The geopolitical landscape of the Sydney Global City Region is caught in an entanglement of competing interests framed within the conflict of state and local governments, council borders and changing leadership affecting how these edges are drawn, quartered and sold. Sydney's transformation is typical of the shift to a post-industrial city with flight of heavy industries to the suburban fringe and concentration of service and information industries in the central business district (CBD) and surrounding area. ${ }^{1}$ The effects of these structural changes have homogenised the diversity of its residents and their requirement for amenities, furthering the transformation to a post-industrial landscape. Through a case-study analysis of the Barangaroo precinct development, this chapter examines how issues of policy provision affect the development of city regions and their impacts on the development and supply of affordable housing. This chapter concludes with a comparison to both local and global projects identifying guidance for changing the way affordable housing might be delivered within the larger scope of iconic developments and the 'right to the city'.

It is not just the tourist gaze but also the gaze of its residents that allow cosmopolitan developments to proceed as planned. The drive for 'Sydney Global City' leaves the more quotidian requirements of 
affordable and social housing supply to claim the little attention left in our schizophrenic lives. Urban densification and intensification in the context of Sydney's housing bubble places considerable stress on innercity brownfield development, ${ }^{2}$ where quantitative measures such as economics and yield dominate the agenda and passively implicate further social inequality through spatially determined outcomes. ${ }^{3}$

Issues of housing supply and affordability are not a new phenomenon, with plans and policy provisions existing since the post-war era. Leonie Sandercock provides an account of planning in Australia for the period from its Federation in 1901 to $1975,{ }^{4}$ but more intensively in the post-war period from 1945 to 1975, beginning by rather nihilistically stating that 'this is a book about failure'. In nearby Pyrmont, during the 1980s and 1990s, we witnessed the impacts of cosmopolitan development on existing residential neighbourhoods at the city's edge. ${ }^{5}$ An increasingly transitory and foot-loose citizenship is also affecting the quality of communities, with temporary tenure and empty residences that have contributed to a lack of cohesion in the quality of social relationships. One could argue that a tourist and commercial precinct like Darling Harbour might not require the same level of cohesion as a more residential suburb at the edge of the Sydney Global City Region. But for want of progress and development, Millers Point has gradually seen a loss of its historically working-class residents, forced out as the agglomeration of the image of Sydney Global City expands its spatial catchment further, claiming more casualties in the efforts of consolidation.

The state government has recently released a public paper providing a 10-year plan for housing reform and addressing a backlog of over 60,000 residents waiting for placement. ${ }^{6}$ As we consider the contents of this document and the trend for divestment onto the community and private sector we truly see this shift from managerialism to entrepreneurialism that David Harvey identified in the late 1980s and which has grown increasingly visible in the urban cityscapes as they take shape. ${ }^{7}$

\section{Sydney's context}

City development since the 1970s has been unashamedly outward looking. The internationalisation of Sydney's identity and urban form has been the subject of myriad conflicts and controversies, striking a dividing line between citizen and business interests. Foreshore development within the City of Sydney's (CoS) Local Government Area (LGA) has been a particularly tenuous affair. Developments do not only need to navigate the needs of economic development, social cohesion and 
technological innovation, but because most larger developments fall under the category of 'major projects's and designated State Significant Developments (SSDs) there is tension between the agendas and remit of both local and state governments that determines the outcomes of these projects. Following Madanipour, ${ }^{9}$ the importance of urban planning and design is such that it must consider the tensions between 'producers, regulators and users' and, in the case of Sydney and many other cities, the developer, the state, and a mix of residents and visitors. ${ }^{10}$

The working-class heritage of Sydney's foreshore - grounded in shipping, goods handling and associated industries - is kept by such monikers as 'The Hungry Mile' lining East Darling Harbour and in the public housing tenancies within the adjacent suburb of Millers Point. These ties are tested with both historical anchors pushed to the edge, and even sold to remove their physical and memorial connection. These strategies align to the ideology of perceived efficiencies and blanket urban renewal, transforming Sydney into a homogenised spatial agglomeration for the transnational citizen (Figure 7.1).

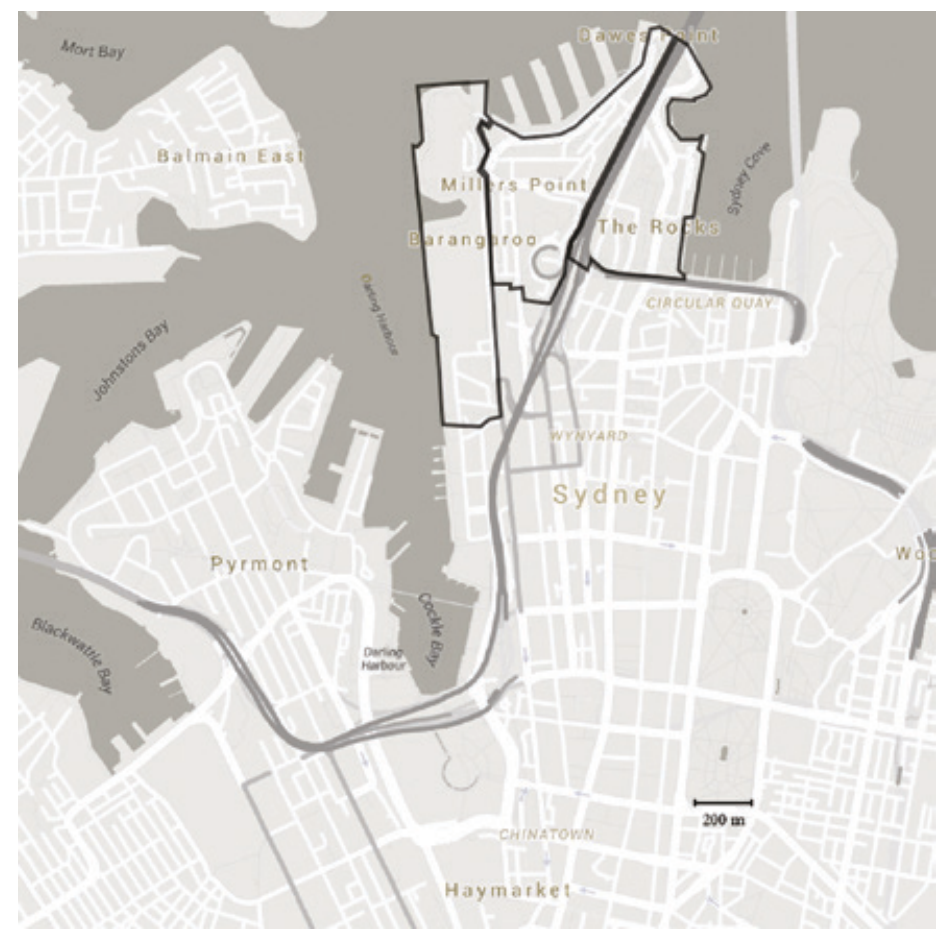

Figure 7.1 Barangaroo and the adjacent suburbs of Millers Point and The Rocks holding significant stock of affordable housing in the Sydney CBD. 
The development of social housing in Sydney has had a history of addressing challenging conditions of high-value sites, whereby innovative pragmatism advanced the building of social housing in the innercity suburbs of Redfern and Surry Hills in the 1950s. ${ }^{11}$ At the time, these areas were laden with slums and urban upgrades, seen as a way to alleviate these sites of poverty. This advancement progressed until the early 1980s, when neoliberal governance strategies saw a shift in the development and replenishment of housing stock accentuating the government's push to inspire a society of homeowners. ${ }^{12}$ This ideological shift contributed to a rapidly expanding Sydney that embraced globalisation and the attraction of open markets, shifting the developmental focus back into the city.

Contemporary renewal and the development of Sydney's industrial heritage along its foreshore dates from the 1960s and 1970s, coinciding with the shift of Sydney's major shipping needs to Botany Bay. ${ }^{13}$ As the shipping requirements in Sydney began rolling back, the docklands in Darling Harbour became available for redevelopment, and urgent action to meet the Bicentennial celebration deadline in 1988 led to a mixed-use tourist precinct conceived in tenuous terms, which is currently undergoing a new stage of redevelopment in the face of regional competition. $^{14}$ The conditions surrounding the Bangaroo Precinct development, an area in proximal adjacency to Darling Harbour, have been equally tenuous and conflicted since its inception and during the competition phase, with light cast on the politics, design and process of development. ${ }^{15}$ Notwithstanding this, Lend Lease, the developers of Barangaroo South, are also redeveloping the southern flank of Darling Harbour, raising concerns about ownership of what is considered public space. ${ }^{16}$ As this development takes shape with expansive massing and floorplates, the adjacent suburb of Millers Point continues with the sale and therefore depletion of public housing because it stands in the way of densification and capital gain. ${ }^{17}$

Figure 7.1 locates the Barangaroo precinct development, and the surrounding public and community housing developments. These concentrated sites identify with the historical development of Sydney's foreshore and maritime heritage, maintaining a connection to that variegated history with both diverse building typologies and socially heterogeneous communities. This ecology of variegated residential 
tenancies, however, is under threat as the value of their sites is emphasised and amplified through the renewal process, both to extract that potential value and to contribute to the state strategy of becoming a more global city.

What ties these developments together is the drive to deliver iconic buildings and 'world-class' facilities as a magnet to attract global capital, serving double duty as post-modern capitalist monuments. ${ }^{18}$ This ocular bias leads to a 'contrived depthlessness' that reinforces the existing condition of social exclusion, ${ }^{19}$ and also raises questions of how we can balance economic growth with the need to provide for social sustainability that results in inclusionary interfaces between public and private spaces. The complex assemblage of the city as a nexus between global competition and local (and social) sustainability requires a shift in the locus of observation of this dialectical struggle. Instead, forming a relational analysis of the historically and contextually specific development of the city that mediates between preservation and progression chances the opportunity given to cities of the past to generate instead of prescribe their culture and identity. The importance of Sydney as an economic centre is problematised as its jurisdictional remit is held between state and local governance strategies. More attention should be paid to the outcomes of their shared role in the construction and promotion of Sydney Global City.

Previous scholars have identified the importance and direction of policy towards home ownership in the New South Wales (NSW) government's divestment of public housing stock and shifting its focus from housing supply towards subsidies like the Commonwealth Rental Assistance (CRA) ${ }^{20}$ The generational call for and promotion of home ownership may attempt to remedy the issue of housing supply and affordability, but recent research by Jacobs identifies that subsidies to homeowners total AU $\$ 45$ billion annually while the CRA to low-income renters totals just AU $\$ 3.6$ billion per year. ${ }^{21}$ This incongruence of support is evidently disproportionate to those in need of assistance, and these regressive policies that have been put in place only exacerbate the conditions of inequality. In the shift from managerialism to entrepreneurialism there is a need to consider the not immediately read social capital and value of the ecology of heterogeneous communities, and also to have a wider consideration of the political economy of housing as a complex asset and instrument of basic human need. ${ }^{22}$ 


\section{Barangaroo}

Located on Sydney's foreshore, the Barangaroo precinct development is a landmark megaproject and urban regeneration proposal that was initiated through an open international design competition in 2005. Lofty rhetoric promoted by its organisers, the NSW government, claimed a once-in-a-century opportunity and attracted 137 entries from both local and international firms. ${ }^{23}$ In 2006, an Australian team formed by Hill Thalis Architecture + Urban Projects, Paul Berkemeier Architects and Jane Irwin Landscape Architecture (HTBI) were unanimously selected as the winners with a scheme that exceeded the target gross floor area (GFA) while also satisfying the brief by providing a complying scheme and a stretch scheme, a scenario that is common among contemporary developments. Although HTBI were selected as the winners, the competition jury suggested a series of recommendations that were mostly isolated from the Richard Rogers team competition scheme. The structure of the competition brief gave no guarantee of the winning team's entry to be used as the final design, but hedged through the guise of an 'ideas competition'; indeterminacy, politics and secretive processes have plagued this mixed-use development on public land, and have revived the conflicts inherent in the process surrounding the Darling Harbour precinct development in the 1980s. The first concept plan was approved in 2007 under the now-repealed Part 3A of the Environmental Planning and Assessment Act, which allowed the state government (rather than local government) power to grant approvals. ${ }^{24}$

Global city competition and economic-driven development continue to drive urban renewal projects. These principles overwhelm and overpower the potential fine-grain development within these megaprojects as they are divided and sculptured through high-level spatial planning principles that align with the strategic positioning of the global city discourse. The maintenance and retention of any semblance of socially planned development was always going to be under strain as it attempted to balance the needs of a growing Sydney Global City. ${ }^{25}$ The now defunct Sydney Harbour Foreshore Authority (SHFA) ${ }^{26}$ had commissioned a report by a well-known Sydney-based academic ${ }^{27}$ considering the social sustainability of the precinct and had provided a case for the retention of the existing affordable housing properties by considering the site in relation to the neighbouring suburb of Millers Point, and by international benchmarking against comparable cities 
of London and New York on the feasibility and necessity of planning a socially diverse community in this new suburb on East Darling Harbour. However, the economic developmental potential preceded any detailed planning or attempt to consider the social sustainability of the site and any confirmed documentation of the allocation of affordable housing, which didn't appear until 2011 with the approval of Modification 4 (MOD4). ${ }^{28}$ Although there is some indication that connection to the social and historical grounding of the site and its surrounds will be retained, the competition brief makes no mention of affordable housing or its provision.

In 2008, the CoS introduced a new vision for 2030, the subtitle of which reads 'Green, Global, Connected'. ${ }^{29}$ Among the mandate to plan for a sustainable future, equity in the housing market was also challenged retrospectively because the proportion of social and affordable housing had declined from 15 per cent in 1996 to 7 per cent in $2006 .{ }^{30}$ In response to these declining figures, the CoS target for 2030 indicates an aim for 7.5 per cent social housing and 7.5 per cent affordable housing. Fast forward to 2011 and the first public commitment for affordable housing within the Barangaroo precinct development fills a meagre 2.3 per cent of its residential GFA. An analysis of the modifications of the masterplans, supporting documentation and their reviews, the inclusion of affordable housing appears to have been predicated against the existing supply of public housing within Millers Point as part of a greater assemblage within the spatial boundary of East Darling Harbour. ${ }^{31}$ This predication belies the NSW government offering a rolling sell-off of these public housing properties with the intention of using the proceeds to fund additional public housing stock elsewhere in the state.

The result of these co-isolated developments is that far greater emphasis is placed on housing as a commodity over the social and historical capital that is and has been generated by their tenants, many of which have multi-generational ties to the area through the working harbour and its associated employment catchment. These state-led strategies ignore the spatial live-work assemblage that housing offers and the condition of their tenants, who lack the ability to choose other alternative forms of shelter. The selective dissemination strategy employed by the NSW government refers to housing as 'assets' or 'stock', and by these terms highlights the reference to housing as a product of exchange rather than use, constructing the argument for offloading these properties to the highest bidder. ${ }^{32}$ 
Because of the public reaction to the veiled secrecy that continued through the development, and the repeal of the Part 3A laws under which the development had been approved, the legitimacy of the project was increasingly put under scrutiny. A significant change to the way information was disseminated and to oversight of the modification process was signalled with the commissioning of the Sussex-Penn Review in 2011. Meredith Sussex and Shelley Penn conducted the first major, and only, review of the Barangaroo precinct development to date, with a mandate to provide a review of the development thus far. The SussexPenn Review expressed that, however high the potential worth of development, the current provision of 2.3 per cent community housing was very low by global standards and suggested finding opportunities to double this amount. There was a reciprocal lack of information regarding the provision of affordable housing, which is mirrored in the report.

Although the Barangaroo precinct development has had approval to deliver 2.3 per cent of its residential GFA as affordable housing, it has been revealed that even this is at risk. ${ }^{33}$ Considering this modest proposal, it has been reported that Lend Lease may be shifting their contribution off site. ${ }^{34}$ Once again we see the developmental field of view cast much wider than the pursuit for social cohesion. This inequitable distribution of rights disadvantages those who lack opportunity to afford themselves the choice of alternative private tenure, and who require at least the facilities to furnish themselves a liveable environment. And as these tenants are given a 'choice' elsewhere there is little regard given to the communities they have been living as part of. ${ }^{35}$

Considering the CoS targets of 7.5 per cent social housing and 7.5 per cent affordable housing, in 2014 the stock of social housing in the CoS LGA was at 8.6 per cent (8.1 per cent after the sale of Millers Point) and 1 per cent affordable housing, ${ }^{36}$ which will make achieving the City of Sydney 2030 goals inherently difficult. ${ }^{37}$ The parallels of isolated development within existing urban assemblages reinforce the existing polarisation of development to manage the increasing inequality amongst the denizens of the city. As a showpiece and exemplar urban regeneration project within the city, on public land no less, the state and local governments and the proponent of the Barangaroo precinct development have a responsibility to become the pivot that shifts the direction of social sustainability within inner-city precincts to better advocate for inclusive communities.

Since the most recent modifications were approved on 28 June 2016, there have been surreptitious changes to the provision of affordable housing on site. There are two points to clarify from the approved 
modifications. Firstly, the increased provision should be commended, however minimal the inclusions in Modification 8 (MOD 8). In terms of approval Part B11, there are modifications that allow 2.3 per cent residential GFA on site for key worker housing and an additional 0.7 per cent off site (within 5 kilometres of the site or within the City of Sydney LGA). In conflict with these requirements, within Schedule 3, Statement of Commitments, Condition 34 allows Lend Lease (the proponent) to shift all of the community housing off site under the following provisions: ${ }^{38}$

- 2.3 per cent of the total 3 per cent may be located in Barangaroo South, or at another location outside Barangaroo South and within the City of Sydney LGA area. Selection of any location outside Barangaroo South is to be at the discretion of the community housing provider that has been allocated to own and manage the development, with Lend Lease's agreement.

- Should the existing 2.3 per cent key worker housing provision be located outside of Barangaroo South, Lend Lease will transfer a monetary contribution to the community housing provider equivalent to the difference of the independently verified value offered by the provider, and the independently verified cost of providing the required floor space for key worker housing at Barangaroo South, at a time to coincide with practical completion of 75 per cent of Barangaroo South residential floor space.

The strategy to separate these important and interrelated pieces of information continues the poor legibility of this documentation intended to subvert the effects of the successive modifications. This approval now allows the entire Barangaroo precinct to be sanitised of lower-income residents and fulfil its role as the new cosmopolitan and economic centre of Sydney. Also approved in MOD 8 was the Crown Casino Resort occupying prime space, with the foreshore edge as its frontyard and Hickson Park as its backyard.

The lack of overarching public housing strategy across state and federal policy certainly limits what can be achieved within the Barangaroo development. The development itself has already been viewed as a benchmark development for the cosmetic resolution of the Headland Park. These accolades ignore the more insidious issues of right of access, surveillance and limitations to habitation within the park. Much like the provision of affordable housing, these issues are rarely considered from a regional let alone international perspective. 
In addition to the housing stock deficit, the conflictual nature of housing itself must also be recognised. The 'right to the city'39 has long been advocated, especially with shifting governance structures and transfer of responsibility to quasi-state and community sectors in delivering housing solutions. ${ }^{40}$ The problems they inherit stem largely from the fixed assets of housing, the scarcity of resources to develop them, and the changing demographics of both their tenancy and society as a whole. It is beyond the scope of this chapter to develop these issues but perhaps we can consider the relationship between demographic and the built form of public housing in the inner-city suburb of Millers Point.

\section{Millers Point}

The adjacent suburb of Millers Point was historically working class, housing men and families involved in the nearby docks. ${ }^{41}$ This rather tight-knit community held together until about the $1950 \mathrm{~s},{ }^{42}$ when technological innovation and manufacturing efficiencies produced the affordable automobile, which allowed workers an easier commute from the then more desirable suburban lifestyle. This gradual locational dissociation of work and home has today seen the reverse, whereby not only is city and coastal property more valuable and desired, but also changing societal mores desire a lifestyle where we may live and work in close proximity and near the city. Recent demographic studies have illustrated how the figures between the City of Sydney LGA and Millers Point differ greatly. Figure 7.2 illustrates the

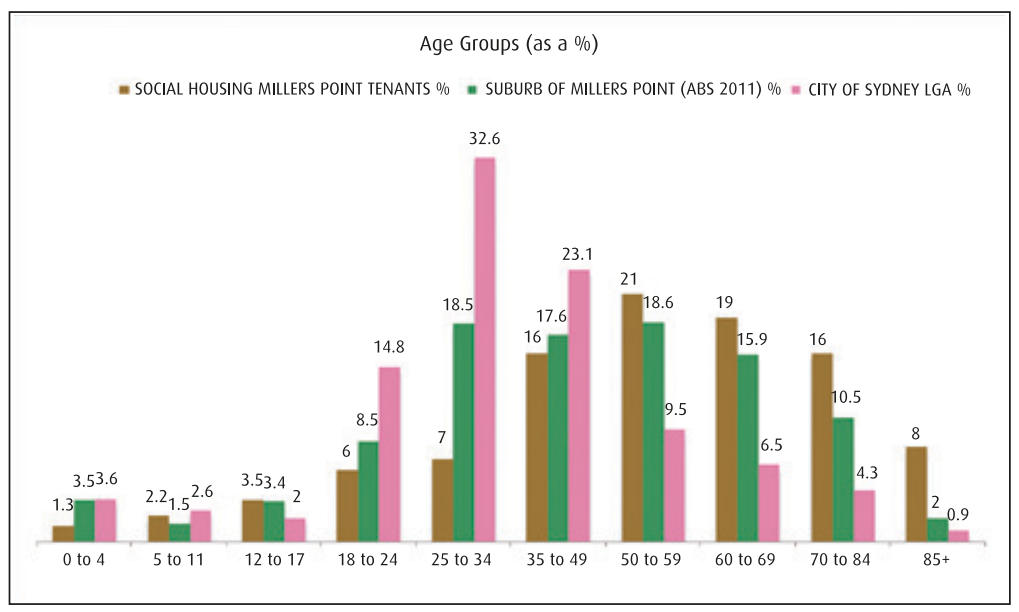

Figure 7.2 Age comparisons: age groups as a percentage of total. 
sharp demographic differences between those in social housing in Millers Point, and that of the CoS average, seeing a heavily skewed population imbalance.

There is a far greater proportion of social housing tenants in Millers Point from the older age brackets, with nearly 43 per cent aged 60 or older: 28.4 per cent in all of Millers Point, and 11.7 per cent in the CoS LGA. This heterogeneity in and between resident groups in the CoS LGA identifies a clear dichotomy of identity that exists. To clear these residents out in one fell swoop resembles the colonisation strategies that took place on this land 200 years prior. As the Barangaroo precinct development also lacks the requisite affordable housing provisions, the entire foreshore from Darling Harbour to The Rocks will now be sanitised of subsidised tenancies.

\section{International benchmarks}

Together the ageing and less mobile tenants, as well as the ageing housing stock, compound the issues of supply and funding of social and affordable housing as a whole in the CoS with upkeep, repairs and rental subsidies costing significantly more than the state average. ${ }^{43}$ In addition, the high value of inner-city land prices leads to convincing cases to pursue consolidation, but not at the expense of shifting the current residents and so completely removing any historical connection to the suburb through the violence of gentrification. Recent European perspectives have seen the benefit and success of hybrid, mixed-tenure developments and alternative development models. ${ }^{44}$ Looking at the UK context, London is considered to be one of the most connected global cities, alongside New York. ${ }^{45}$ The Peabody Group has successfully delivered numerous social housing projects, ${ }^{46}$ and has also incorporated welldesigned buildings that successfully cater for mixed-tenure residences on challenging sites. ${ }^{47}$ Their development of the Mint Street building in Bethnal Green, East London, successfully delivers a well-designed mixed-tenure apartment block. Peabody manages 67 homes that comprise 27 social rent, 17 shared ownership and 23 market-rent properties, totalling roughly a 34 percent market / 66 per cent affordable split, with common entrances. ${ }^{48}$ This project won a number of awards, including a RIBA London Regional Award in 2015. The architects working with Peabody highlighted the 'longer time horizon' of the developer; ${ }^{49}$ being around for 150 years has allowed their culture to consider the sustainability of their projects. A second insightful component of their strategy is the funding of affordable housing. Initially planning a 35 per cent 
affordable/65 per cent market split, due to improved market conditions they were able to reverse that reaching the 34 per cent market/66 per cent affordable proportion. ${ }^{50}$

As a corollary to this successful mixed-tenure project, there have been well-fought struggles to innovate within the political impasse of federal and state housing policy development in Australia. In 2013, Nightingale was initiated by a group of Melbourne architects who sought to challenge the speculative form of housing development to place a greater emphasis on the lived quality of housing. ${ }^{51}$ Their strategy to introduce co-housing within a dominant trend of development, to maximise yield and actively attempt to exploit the value of tightly held land, follows a similar ideal to the London example, to balance the outcomes through innovative strategies delivering high-quality housing that is able to be sold for a significant margin below what is currently market rate. Significant cost reductions were achieved through strategies to remove non-essential amenities such as underground car spaces, air conditioning through passive design, additional bathrooms and individual laundry services, as well as bypassing the need for real estate agents, lowered marketing costs, and developer margins capped at 15 per cent. Currently these projects experience significant conflict at the planning stages, as their building typologies do not meet standards; for example, smaller car-parking provision elicits opposition suggesting there will be a pronounced impact on street parking from new tenants and their visitors. Although these are reasonable concerns, as cities become increasingly dense spatial assemblages, and there is a reduced uptake of driving from a younger generation that also prefers living in capital cities, there is a converse argument to shift back from an automobile-centric city design, reclaiming space for pedestrians to inhabit, as the case of Copenhagen has proven.

Collectively, these two projects demonstrate the possibility of good design and innovative planning strategies to become successful components that allow for the growth of equitable and cohesive communities. The stigma of subsidised tenancies adjoining private freehold properties is dispelled in the Mint Street development, with the ideology of equality presiding over maximising economic gain. The ability to design, from the start, a development that ignores the relative layering of social strata separating different forms of tenure may be related to Peabody's foundations in a philanthropic agenda, which have allowed for this mandate to support the social agenda of diverse communities. Nevertheless, the goal to achieve equity of tenure can be adopted by developers and championed by governments. Similarly, with regard to market-rate housing, the strategy 
to adopt the co-housing framework and integrate it to fit the incoming tenants, allows for tangible efficiencies to be translated into cost savings that will enable a variegated tenancy to not be dominated by the market.

Adapting these strategies and frameworks would acknowledge the greater assemblage of social capital within the dominant frame of economic development. The requisition of innovative housing solutions would be most effective embedded in the competition brief as a central tenet that would ground the precinct, recognising the historicism of the site and thereby responding to its spatial context. As the competition was run by the state, a shift in ideology of the state will be required to recognise this complex and essential assemblage that situates housing both in and within the 'right to the city'.

\section{Iconicity and its effects}

The image of subsidised housing in Sydney differs markedly from these two examples. With a lack of affordable housing provision in the last two decades or longer, it remains to be seen if development of affordable housing will become available in Sydney in the face of economically driven development. The Barangaroo Precinct has towers more than 200 metres tall abutting the water's edge, an unprecedented condition that is in breach of planning controls requiring that buildings step down towards the waterfront. ${ }^{52}$ As Lend Lease successfully argued their case to reduce and/or negate entirely their contribution to 'key-worker' housing on site, the neoliberal turn has yet to come about face as the desire for iconicity, ${ }^{53}$ and cosmopolitan development envelops any socially cohesive outcome with even the heavily curated and managed parkland capped on the north of the precinct, ${ }^{54}$ challenging our perception of the success of privately owned public space (POPS) outcomes. ${ }^{55}$ The role of architecture as a social good faces serious challenges under capitalism, ${ }^{56}$ and brings us to the question of who controls the architectural agenda. ${ }^{57}$

This controlled urban narrative carefully guides the eye from icon and spectacle, back and forth, creating a false ontology of the urban experience. This curation of a depoliticised urban environment mirrors the construction of visual images, following Rancière: 'Politics and art, like forms of knowledge, construct "fictions", that is to say material rearrangements of signs and images, relationships between what is seen and what is said, between what is done and what can be done. ${ }^{58}$ This urban semiotic relationship allows the privatisation of public resources projecting this sanitised image of the city to continue breaching the agenda 
of homogeneous urban development. But fortunately, within the larger spatial assemblage of Sydney's global city region, the naturally endowed resources balance these constructed visions.

The agglomerative imagery of Sydney incorporates the natural features of its surrounds (Bondi Beach and the Blue Mountains) and the built icons accumulated through means of infrastructure provision (Harbour Bridge), cultural amenities (Opera House), mega sporting events (Olympic stadia) and now through the showpiece of the proposed casino resort. The site is prescripted and, to borrow from Maria Kaika, becomes a form of 'autistic' architecture that does not respond to its environs, neither the built form nor social structures. ${ }^{59}$

\section{Rights to the city}

To commit to being part of the global network of cities, this mobility affects the definition of spaces both public and private shifting from a strictly dialectical positivist structure to one that can be politicised and its outcome deliberated in public. The gradual erosion of the democratic political process and the socio-spatial reformation at the water's edge eats away at structuring an equitable sustainable development of the city in what David Harvey terms 'accumulation by dispossession', ${ }^{60}$ as the structural framework that urban policy sets on the design and construction of urban form allows insidious modes of encroachment on the liberties of a wider public. These restrictions dictate the determinates of the public but does not allow them to be involved in the construction of the city themselves. ${ }^{61}$

In the fifth of his 'Theses on the City, the Urban and Planning', Lefebvre suggests the

realization of urban society calls for a planning oriented towards social needs, those of urban society. It necessitates a science of the city (of relations and correlations in urban life). Although necessary, these conditions are not sufficient. A social and political force capable of putting these means into oeuvres is equally indispensable. ${ }^{62}$

This urgent call for a greater emphasis on the social in the urban has attracted responses to the 'right to the city', with Purcell suggesting the idea of the 'right to the city' as a response to neoliberal urbanisation. ${ }^{63}$ As governments are shifting towards governance and public-private partnerships are proliferating, there is a genuine fear that these new 
institutions and arrangements will monopolise power and control the shape of the city, leaving inhabitants disenfranchised and eventually taking away their 'right to the city'.

The embedded position of government continues to shift the responsibility of providing affordable housing to non-government and community sectors as a marketised commodity, rather than innovating policy that aligns with the rhetoric of housing as a basic good. ${ }^{64}$ This realised marketisation focuses its gaze on the well-heeled mobile 'communities' as the agglomerated region of Sydney continues to expand, reimaging all the remaining high-value sites and re-colonialising these sites of conflict to pacified depoliticised spaces. ${ }^{65}$ This gesture of 'revitalising' the last significant portion of public land, and indeed as the whole of Darling Harbour is apportioned to a single developer, sings praise of the condition of urban design and governance of iconic development in Sydney. ${ }^{66}$

Seen through the case study of Barangaroo, the provision of social housing is a poor fit with the ideology of cosmopolitan development on such a significant high-value site. The state governance strategies that favour economic development completely overpower the softer, more implicit function of social capital that provides the baseline for nurturing cohesive and inclusive communities. Even at this stage of development there is no clear indication of where the 'key-worker' housing is to be located. Indeed, examining how this development has unfolded in relation to the developments in inner Sydney since the 1980s, one can be pessimistic of the outcome.

\section{Conclusion}

In a competitive global environment there are certain prerogatives that cities must attend to maintain relevance in terms of influence, connectivity and attractiveness. Iconic developments are desirable cosmetic attachments to city agglomerations that easily serve to both promote externally and regenerate internally. The unfortunate casualties of this process are those on the edge, on the fringe of maintaining a foothold in, or even a tangible connection to, identifiable citizenship, defined in terms of the quotidian activities taken for granted by the bourgeoisie or even petit bourgeoisie.

As a non-liquid asset, housing, and even more so affordable housing, faces the challenges of a rapidly changing demographic, and the cost consequences of establishing, maintaining and replacing housing 
stock clash with the aims of the private sector, as their business model even more strongly opposes the risks that accompany these types of development. The inherent risk associated with provision of affordable housing is a poor fit with development and supply by the private sector without the structural support of policy advancement or leadership from state and federal government. Although these restrictions pose challenges to the supply of affordable housing, there are hybrid forms of tenure through the aforementioned Peabody Group case and emerging innovative typologies of housing in the Nightingale model in Melbourne that tackle affordability and demographic issues by reducing overheads and optimising spatial allocation. These innovations are slowly emerging, although planning instruments and zoning restrictions hinder their implementation.

Aside from the structural issues of provision, there are further geographical restrictions and responsibilities that must be considered. A recent City of Sydney Housing Issues Paper identifies these challenges of housing provision and supply in the context of balanced economic growth and housing affordability. ${ }^{67}$ Reinvigoration of interest within the federal government and progressive policy provisions as anticipated by the Greater Sydney Commission could work to guide balanced growth that collates social cohesion into the sustainability framework.

Important landmark developments like the Barangaroo precinct development should consider the gaze of iconic status not just speculatively on the grounds of perceived design quality, but as inherent in the quality of its urban condition, which includes the social equity of its catchment. Introspection towards the long-term demographic changes and needs of its users should assist in the provision of equitable housing models that are adaptive to guide future sustainable development. 
Section 3

Non-standard practices of housing

Art practice and alternative forms of

engagement with housing 

8

\section{Art does matter}

\section{Creating interventions in our thinking about housing}

Keely Macarow

\section{Introduction}

The story of my formative years is a typical tale of twentieth-century Australian housing. I was born in the mid-1960s and brought up in the Melbourne suburb of Moorabbin in a brick veneer house on a quarteracre block. My parents were keen to bring up their young family in this south-eastern suburb, which is around 15 minutes' drive from Port Philip Bay, and 40 minutes from the central business district. My mother and father were brought up in working-class Victorian cottages in inner-city Melbourne and pleased to move into the suburbs with larger houses, and front and back gardens. My early housing narrative is like that of many of my Melbourne peers. The irony is that many of my contemporaries have moved back into the inner-city areas my parents' generation were pleased to leave. Inner-city Melbourne, like many inner regions of populous cities, has been increasingly gentrified since the 1980s and it has now become very expensive to purchase housing there.

\section{Art and housing}

The artworks of the late artist Howard Arkley (1951-99) provide a glimpse of Australia's obsession with home ownership through his iconic 
paintings of the suburban homes that are found in many Australian cities. Howard Arkley used the bright and fluorescent colours of Pop Art to embellish his depiction of these post-war houses and to celebrate the Australian dream of home ownership and suburban life. ${ }^{1}$ These cream, tan and orange brick veneer houses were predominantly constructed on quarter-acre blocks during the 1950s-70s. Typical of these holdings were the two- to three-bedroom house (with kitchen, lounge room, bathroom and laundry). A driveway down one side of the property led to the garage, which usually contained the family car. Contoured grass, shrubs and bushes adorned the front and back gardens. A Hills Hoist clothes-line was usually located at the rear of the back garden.

However, Arkley's airbrushed paintings also managed to transform the uniformity of the brick veneer house by presenting the suburban homes in a post-modernist, cartoon-like sheen through his stark use of pointillism, line and colour. In Australian Home (Hamilton Art Gallery 1993, $175 \times 255),{ }^{2}$ Arkley depicted an orange brick veneer house with a pink and black slate roof, blue and purple striped blinds and a brown wooden fence and mailbox. Light green grass decorated the grey concrete driveway, and red, green and brown shrubs were artfully woven around the front of the home. A dark blue sky and large puffy white clouds completed the suburban vista.

Howard Arkley transformed the Australian brick veneer suburban house into a vibrant site of colour, aplomb and difference. For Arkley, and indeed many Australians, it is the suburbs where the great Australian dream is played out. Australia, like many developed countries, has based the country, and indeed its cities, around the narrative and fulfilment of home ownership. For many Australians, life follows a symbolic cycle in which one is schooled and housed in the family home until they have permanent employment and can afford to buy their own home through a family inheritance and/or the rewards of their labour. Of course, there are many people who sit outside this highly simplistic narrative, and it is for those people that it is particularly important to create new models and options in housing.

Australia currently has a rapidly growing population but little investment in social and affordable housing, preferring a marketled economy approach to housing. However, this approach has led to Australian cities, such as Melbourne, currently ranking as some of the least affordable cities in the world for housing. Very few options in housing have been developed for people that cannot afford to buy, or who want (and need) other modes of accommodation. 
Not surprisingly, the suburban home is the major financial asset of many Australian families and the site of the family residence and wealth. This trajectory is of course fraught with challenges, which sit behind the façade of the brick veneer, for many residents are faced with high mortgages (or rent) and require decades of income security to pay for their house (or to offset their landlord's mortgage).

Australian artist Kate Breakey provides another view of Australian houses in her photograph Untitled (House no. 10) (Australia, 1981). Breakey used a pallette of pale blues, greys, greens and red to illustrate a black-and-white photograph of a house. Indeed, the house is very plain compared to Arkley's bright synthetic homes and represents another side to the lived experience of Australian housing. A wire fence denotes the boundary between the house and the asphalt of the street. Dry shrubs surround the front and side of the pale white house. The neighbouring house is also an ashen colour. Both houses are marked by their dull uniformity and their grey veneers. So, where Arkley's paintings gave a pop sheen to middle-class housing, Breakey's photograph revealed a working-class suburb where the veneer is not as glossy.

The price of brick veneer houses such as those portrayed in Howard Arkley's paintings and Kate Breakey's photography has risen dramatically since the 1950s and 1960s when these forms of housing emerged in the suburbs of Australian cities such as Melbourne and Sydney. Interestingly, my parents purchased their Moorabbin home for AU\$5,000 in the 1960s and it is now worth approximately AU\$650,000700,000 . Whilst this steep hike is a result of five decades of rising housing prices, wages and costs of living, the current value of the house ensures that my family has the safety net of a key asset.

However, for many Australians, this spike in housing prices has proven to be highly problematic. The high prices of contemporary Australian housing make it somewhat difficult for many people to enter the private housing market. This means that anyone not living in their own privately owned house has to rent other people's houses, if they are not eligible for social and public housing.

Australian artist Elvis Richardson has explored housing affordability and privilege through a number of exhibition projects. In 2012, Richardson demonstrated her creative research into unaffordable housing by exhibiting Growth Growth Growth \& The Bedroom at the Margaret Lawrence Gallery, Melbourne. For this installation, a double bed draped in an orange bedspread resided underneath bamboo scaffolding. A laptop computer was installed in the bamboo and positioned so that visitors 
could lie on the bed and view images of bedrooms which were represented in real estate search engines. Richardson embedded the installation with a voyeuristic narrative by encouraging visitors to lie on the bed and view photographs of bedrooms from properties for sale which the artist cannot actually afford to buy herself. ${ }^{3}$ This mixed-media installation illustrated the threshold between those that can afford to purchase property and those who cannot.

Richardson's installation reveals traces of intimacy amongst a wider agenda of housing affordability and availability. The artist reveals the interiors of other people's homes and lives through her use of images of bedrooms taken from real estate websites. Whilst no one is currently living in the houses she represents, other people's lives (which could be our lives) are suggested. As a result of this, the artist and the viewer are outside the margins of housing.

\section{Residential capitalism}

Political economy researchers Herman Schwartz and Leonard Seabrooke have written how the family home is the major asset that flows through generations and provides leverage for the further purchase of property. However, Schwartz and Seabrooke view this intergenerational exchange of housing finance as somewhat problematic. ${ }^{4}$ Schwartz and Seabrooke pay caution to the problems that might ensue when rapidly rising housing prices prevent people from acquiring housing because they are priced out of the market by those that have more extensive housing wealth and financial portfolios. Schwartz and Seabrooke argue that the intergenerational transfer of housing ensures a culture of 'residential capitalism', where houses are used as financial assets at the expense of those that have lower or no commodities. Residential capitalism pivots housing as liquid assets and is at odds with those that cannot enter the housing market due to a lack of affordable housing and housing capital.

This critique of residential capitalism aptly summarises the housing markets of many OECD countries. For instance, the escalating prices of Australian housing makes it difficult for low income earners and younger people to enter the housing market when mortgages are significantly greater than 30 per cent of the household wage. The Australian market is also over-reliant on buyers who purchase investment properties to let at high rents and receive tax breaks through negative gearing. This scenario establishes a housing market which precludes many 
renters from saving a deposit to enter the market themselves, making them vulnerable to housing stress and precarious housing. Housing policy, as the authors of the Demographia International Housing Affordability Housing Survey have written, 'requires a strong focusing on affordable housing, but it also requires a broader focus relating to the entire population. The consequences, among others are slower economic growth, less job creation and greater poverty. ${ }^{5}$

Artworks by Howard Arkley and Kate Breakey reveal examples of late twentieth-century Australian suburban housing, which people continue to inhabit in the early decades of the twenty-first century. Although the focus by Arkley was on colourful Pop Art housing exteriors and interiors, Breakey's home appeared to be languid in comparison: depictions of the actual people that inhabited these houses were not represented by these artists in the cited works. We do not know whether people who owned the properties inhabited these houses. Today, as in the twentieth century, Australian housing is still constructed around the dominant ideology of home ownership at the expense of pursuing multiple options in social, public, co-operative and shared housing to cater for the lives of people with varying social, economic, cultural and family needs. Quite simply, Australia, as with many developed nations, has a growing population with diverse backgrounds, faiths and households, which requires us to take stock and rethink our housing needs so we can accommodate our growing diverse populations in a range of housing options. For this, we should glean inspiration from countries such as Sweden that have invested heavily in affordable and social housing to develop varied models of housing for future generations.

\section{Swedish and Australian housing}

Whilst privately owned brick veneer homes were constructed throughout Australian suburbs and 45 public housing concrete tower blocks were developed for 21 Housing Commission (public housing) estates in inner city Melbourne in the 1960s and 1970s, ${ }^{6}$ a million homes were built for the Swedish Miljonprogrammet from 1965 to 1974, by tenant associations, construction companies, housing co-operatives and municipal housing associations. ${ }^{7}$ The sheer scale of the project was enormous and proof that governments can attack housing crises if they have the political will to gather resources and providers. These functionalist multi-family apartments and single-family houses were developed because of the government's concern about the demand for housing, and 
designed specifically to meet the needs of Swedish nuclear families. ${ }^{8}$ The Miljonprogrammet of large-scale housing estates, low-level apartment blocks and houses solved the Swedish housing shortage of the time and led to a surplus in housing. Since the Miljonprogrammet was first established many of the houses and apartments have been refurbished and adapted to include sustainable energy and garden features, and some dwellings have been demolished. ${ }^{9}$ The scale of the Miljonprogrammet was audacious given the ambition of the Swedes to provide housing 'for all home-seekers regardless of their income'. ${ }^{10}$ However, this concern for social equity may now be viewed as rather nostalgic; housing researchers Emma Holmqvist and Lena Magnussen Turner have noted that

Swedish housing policy has over the last decades lost many of its traditional characteristics.

The main approach in Sweden nowadays is to follow the mainstream market-orientated housing policy in Europe, which is marked by reduced tax benefits, reduced housing subsides, reduced housing allowances and an emphasis on housing as an individual responsibility. ${ }^{11}$

Whilst this example of mass social housing demonstrates Sweden's vision for social housing initiatives in the mid-1960s and 1970s, the country subsequently moved into a market-led model, characteristic of countries such as Australia, where the housing ethos revolves around residential capitalism. ${ }^{12}$

The contemporary Swedish housing policy that housing and social researchers Emma Holmqvist and Lena Magnussen Turner describes is similar to Australia, where housing has been modelled around the responsibility of individuals and families whether they reside in private rental or their own properties.

Australian governments have been concerned with the drivers of the private housing market, and see rapid growth in housing prices as indicative of a buoyant Australian economy. However, in the 11th Annual Demographia International Housing Affordability Housing Survey in 2014, five of Australia's major metropolitan housing markets including Sydney and Melbourne were found to be 'severely unaffordable..$^{13}$ In addition, the Australian Bureau of Statistics has documented that around 67 per cent of Australian households own their own homes and 25 per cent rent privately owned houses. ${ }^{14}$ Of $8,630,428$ households, 339,197 householders rented homes from a state housing authority, 2,164,482 from a private landlord and 11,540 from an 'other 
landlord'. ${ }^{15}$ In addition, National Shelter (Australia) has noted that there were 404,289 dwellings in Australia's social housing stock in 2013. ${ }^{16}$ Interestingly, the Australian Federal Government's Social Housing Initiative (2009-12) built 19,740 dwellings throughout Australia to provide social housing for people that were 'homeless or at risk of becoming homeless, Indigenous Australians, people with disability, aged over 55 years, or escaping family violence'. ${ }^{17}$ In comparison, around one-third of '9.5 million Swedes live in rental housing', and 'half of this is public housing' ${ }^{18}$

Holmqvist and Magnussen Turner have written that Swedish affordable housing is the responsibility of the municipal housing sector, where housing is available to all but 'the allocation principle is waiting time not need'. ${ }^{19}$ In comparison, Australian public housing tends to have large waiting lists, only available to those that fit requirements around low incomes and assets. ${ }^{20}$ To their credit, Sweden has invested in largescale social housing initiatives since the mid-1960s.

Whilst Swedish housing policy may have changed somewhat from the time that the Miljonprogrammet was conceived, the development of large-scale social housing programmes is sorely needed in cities where investment in sustainable affordable housing is minimal and housing demand outweighs supply. This is especially so in cities such as Melbourne where housing prices continue to spike as a result of the upward growth of residential capitalism.

\section{Knitting houses and community}

The enormous scale and political will of the Miljonprogrammet is a reminder of what governments can initiate for their citizens if they deem it necessary and find the resources. But what of the actual housing built for Swedes, and how have contemporary artists responded to the Miljonprogrammet? I turn now to the work of artists who have investigated responses to housing crises and developments in Australia, Sweden and the USA to discern how art and creative interventions can contribute to current debates about housing. I commence with a discussion of the work of artists who were inspired by the Swedish Miljonprogrammet and represented the large-scale housing initiative in installations exhibited in Stockholm and Melbourne.

In 2010, Elin Strand Ruin, Annika Enqvist and The New Beauty Council created the Knitting House to resemble the layout of a flat typical of those built for the Miljonprogrammet. ${ }^{21}$ Originally 
exhibited at Husby Konsthall, the work was re-presented at Stockholm's Arkitekturmuseet from 24 January to 3 March 2013. The installation was knitted by a group of women from diverse cultural and ethnic backgrounds who used twelve knitting machines over eight weeks to make the work. The large-scale installation was a fullplan impression of a Miljonprogrammet flat with doorways, windows, a bathroom, towels, heaters, kitchen, drawers, bedrooms, living room, cupboards and floor. Whilst Knitting House was a conceptual textile piece that referenced the history and architectural plans of Husby social housing, it also represented the homes of many of the knitters of the project who live in the outer Stockholm area. Thus, the knitted installation also celebrated the social fabric and lived experience of the women who created the work. 'The aim was to use textile as the tool to produce an exact reproduction of the private area of a flat like an enormous thin dress with sewn-in traces of care and wear.' ${ }^{22}$ Here, the traces of wear in the fabric of the Knitting House resemble the intimate marks that frame the women's lives and the homes they inhabit. The artwork, installation and architectural plan provide a spatial and haptic response to the lived experience of the Miljonprogrammet. It is 'a three-dimensional drapery, a large-scale model, a garment you could walk into, explore and experience'. ${ }^{23}$

Knitting House is an extraordinary work of tenacity, imagination and skill. It reveals the domestic layout of many of the apartments built for the Miljonprogrammet. With this in mind, the installation is also a monument to the lives of the women who constructed and knitted the work, and to the Swedish housing project that provided shelter and a home to Swedish families and newcomers to the country.

A large-scale floor drawing of the one-to-one plan of a kitchen common to the Miljonprogrammet was also included in the Untitled Collective's exhibition Open for Inspection (West Space Gallery, Melbourne, June-July 2014). In this Melbourne representation of the Miljonprogrammet, the floor drawing of a common Swedish kitchen afforded a domestic site for political and economic discussions about housing, hence making the personal political and the political personal. The drawing of the kitchen on the parquet floor of the Gallery provided space for informal and public meetings held during the exhibition and welcomed visitors to discuss their views and experiences of housing (Figure 8.1). Like the Knitting House, Open for Inspection was conceived as a communal enterprise, where visitors could pass through, inhabit the work and be drawn into discussions about housing. 


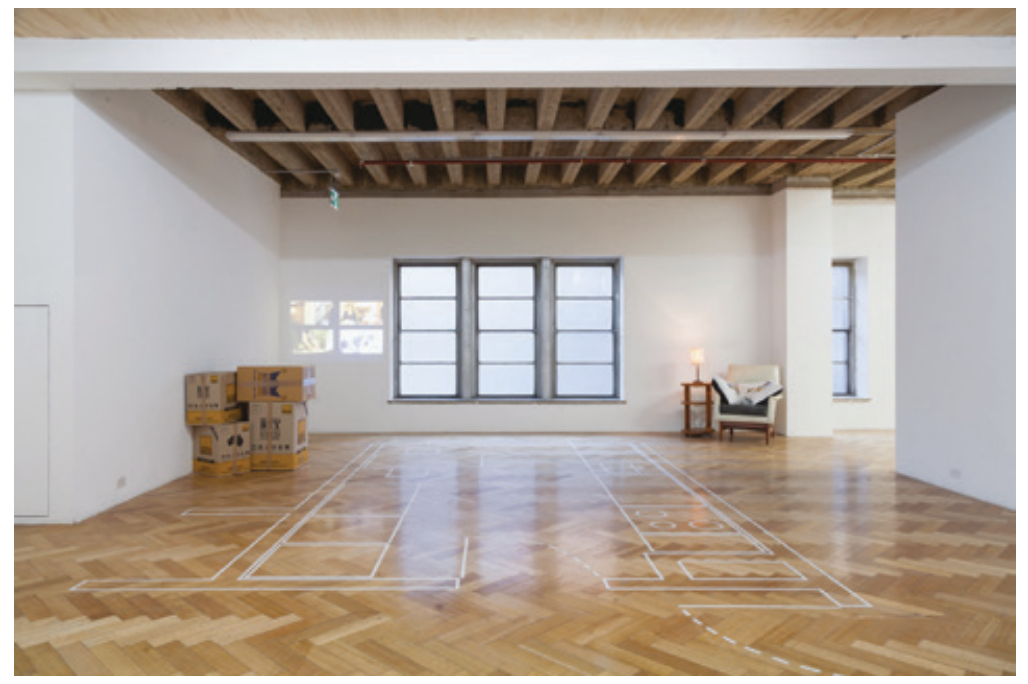

Figure 8.1 Untitled Collective, 2014, Open for Inspection, West Space Gallery, Melbourne, mixed-media installation.

The Melbourne members of the Untitled Collective (Keely Macarow, Neal Haslem, Margie McKay, Mim Whiting and Mick Douglas) exhibited Open for Inspection to explore the linkages between housing unaffordability, housing stress and homelessness in Australia and Sweden. ${ }^{24}$ The Untitled Collective's ongoing project Homefullness advocates for housing for all (or homefullness rather than homelessness) and investigates the commonalities and differences between Swedish and Australian housing issues through writing, conference, exhibition and housing projects. Open for Inspection featured a mixed-media installation (which included a domestic lounge setting, video, the floor drawing and a clothes line of specially illustrated tea towels) and four participatory events. ${ }^{25}$ The events were designed for the Collective to engage in conversations with gallery visitors and invited guests about the differences between a house and a home, housing stress, homelessness, and affordable and sustainable housing. These discussions inspired the production of new tea towels in situ, which were added to the installation over the duration of the exhibition. The Collective's installation explored the juncture between the domestic interior and lived experience of homes and the overarching stress for those that live in unaffordable and precarious rental housing. Whilst the Knitting House project drew on the daily experience of women who had lived in Miljonprogrammet housing, Open for Inspection was designed to present an example of large-scale affordable housing 
schemes to an Australian audience who had not experienced this level of investment in social housing.

Interestingly, it is estimated that the population in Melbourne (currently 4.25 million) will grow to 7.7 million by $2051 .{ }^{26}$ It is therefore important that artists, designers, architects and housing activists contribute to questions and debates around housing, and more significantly to work within communities to develop and produce sustainable and affordable housing on a mass scale.

Put simply, housing affordability will continue to be a major concern for developed countries such as Australia that base their housing policies around the growth of the market place. Whether the rise of populations and citizens without permanent housing will see the development of informal settlements on the edges of Australian cities such as Melbourne remains to be seen. Whilst I have focused much of this chapter on housing narratives that have marked Australian and Sweden, concerns about housing affordability and availability are certainly common to many other countries. For these reasons, governments must address the inequities that drive housing markets and prices, and they must regulate growth, cap sale and rental prices, and remove the taxes and financial incentives that assist investors and multiple home owners at the expense of lower-income and new home owners trying to purchase their own home. Governments must also invest in large-scale social and affordable housing programmes such as the Swedish Miljonprogrammet to provide decent housing for people that are homeless or affected by housing stress, and for those who need permanent homes instead of precarious and temporary rental or emergency accommodation.

We must also go beyond only discussing housing solutions for a few constituencies. By only committing to developing affordable housing for certain groups, we will continue to see housing prices and supply predominantly being available to those that can afford and access it. By insisting on sustainable and affordable housing for all, we will shift our housing policies, plans, developments and programmes from the snare of residential capitalism to the engagement of communities.

\section{Interventions in housing}

Whilst the work of the artists examined this far has raised observations and tensions about privatised housing markets and social and affordable housing, none of the discussed projects have actually provided interventions in housing or created housing solutions for communities. Instead, 
the artists have explored Swedish and Australian housing through visual media and conceptual installations of one-to-one plans or visual representations of actual homes. Although there is much to learn from artists' representations of housing, it is also important to discover how artists can work directly with people to extend our understanding of contemporary housing. I move now from artists who have depicted representations of housing programmes and homes to the work of artists who have developed new possibilities for and interventions in housing.

In 1993, US artist Rick Lowe took a proactive approach to extending opportunities in housing by acquiring a row of houses in a deprived area in Huston through private and public funds. ${ }^{27}$ Lowe's Project Row demonstrates how an artist can be the enabling force behind housing projects and community engagement. The houses were refurbished by Lowe and architectural students and now provide artist residencies, galleries, gardens and support services to the local community. The project has since been established into a housing organisation which has 40 houses.$^{28}$ Project Row reveals how dilapidated houses can be transformed into a thriving communal asset through collaboration between an artist and the adjacent community. Interestingly, the writer Nato Thompson has speculated: 'as art enters life, the question that will motivate people far more than What is art? Is the much more metaphorically relevant and pressing What is Life? ${ }^{29}$ This question could apply to Project Row but one could also ask, what is housing? What is a home, and can it reflect and nurture life? After all, human beings are social creatures that need communal relationships for a meaningful existence. Our sense of community may extend from the family unit and local neighborhood, to religious, cultural, leisure, recreation, education, work, urban, rural, political and artistic communities over the course of our lives. People need safe and enabling housing to facilitate, support and strengthen the social ecology and culture of their communities. However, housing should not just be a physical structure: it should be a home where our sense of well-being and potential thrives.

Rick Lowe has achieved this by his engagement with a Huston community through his embedding of cultural and social services into the Project Row housing. Lowe's socially engaged housing project is a model for creativity, social inclusion and capability building through the integration of art, social services and gardens. This infrastructure could certainly be combined in housing projects in cities such as Melbourne and Stockholm.

Marjetica Potrč is a Slovenian artist and architect whose locationbased works blur distinctions between art, architecture and community 
development. Although Potrč is based in Berlin and Ljubljana, her practice is international. Like Rick Lowe, Potrč collaborates with communities to create outcomes for their neighbourhood and domestic needs. For instance, she has worked on site with communities in Europe, Asia, and North and South America to develop ecological gardens, dry toilets, sustainable energy technologies and devices, and temporary shelters for refugees. ${ }^{30}$ Here Potrč combines architecture and art to build capacity and sustainability within formal and informal city settings. Her site-specific projects demonstrate how different modes of building and living can coalesce. They also recall the strategies of international non-government organisations, who work with communities to develop capability and resources. This form of social practice is not without discussion. Saara Liinamaa has written of artists who have

become renowned for a practice, a brand that has achieved the success and recognition that appeals to institutions and funding bodies. When paired with the successful of internationalization of certain practices, we must contend with the implications of contemporary art that mimics the operations of an eclectic NGO. ${ }^{31}$

It would be easy to dismiss Potrč's work with communities as an exercise in self-aggrandisement. However, Liinamaa's critique of artists who have transient social practice could also be levelled at the work of international aid organisations.

Interestingly, Potrč also has an exhibition practice in which she presents installations and wall-based works in galleries to interrogate the concerns and reflections of her socially engaged practice. As a result of this, Potrč has constructed buildings in galleries including the STUK Arts Centre (2013, Leuven, Belgium) and The Eli and Edythe Broad Art Museum (2012, Michigan, USA) as architectural case studies of informal housing from Caracas, (Venezuela) and Soweto, Johannesburg (South Africa) respectively. These exhibitions provide snapshots of the built environment and housing of informal cities and townships. ${ }^{32}$

In the 2001 wall-based installation, Urban (2015, National Gallery of Victoria, Melbourne), Potrč combined an assemblage of text, photography, a folded cotton garment, remote control and a vase that was made from the shell of a bomb to depict urban lived experiences of housing. The artist/architect included framed pieces of images and text within the installation to provide wry observations of 'Illegal Façades' on Hong Kong high-rise buildings, the organic and unplanned growth of 'Shantytowns', the mobility of moving prefabricated housing to new 
sites in 'Travelling House' and the mass squatting of the 'Occupied Towers' of the vacant Hotel São Paulo amongst others. These graphics were installed in a formation which encouraged the viewer's gaze to traverse across the framed works as if they were travelling across nations and borders. Enclosed in the midst of the visual works were two low ledges which contained the vase, and the jacket and remote control. These domestic objects are both irregular and normative artefacts for many people, although it must be noted that a vase constructed from a bomb is somewhat unusual. However, this may not be as unusual for people who have lived in conflict zones such as Sarajevo, where the item was originally from. Urban documents housing experiences that sit outside formal cities such as Melbourne and Stockolm. This strategy reveals Potrč's interest in informal housing, settlements and cities, which is also evident in the representation of Caracas informal housing that she has re-constructed for gallery-based exhibitions. ${ }^{33}$

Marjetica Potrč's interest in informal housing and settlements links to her interest in participatory design whereby artists, designers and architects work with communities to design, create and construct sitespecific garden, housing and energy projects. However, with informal housing, it is the autonomy of the builder/owner from state-run structures that is a major point of difference. Self-built housing and informal townships have grown exponentially in countries such as Venezuela and South Africa because people have had to live outside state infrastructure and city boundaries as a result of political structures, regulations and poverty. Rick Lowe and Marjetica Potrč's collaborations demonstrate how artists can work with communities to produce housing, and domestic and cultural infrastructure. Lowe's project is noteworthy for using arts funding to develop a housing association with cultural and community services. Potrč's social practice is of interest due to her commitment to working on location-specific community projects, some of which are then re-presented and explored in exhibitions for wider dialogue with gallery audiences.

The work of the artists discussed in this chapter reveal the scope for interdisciplinary collaboration across the creative, planning, construction, design and health sectors to develop housing which is socially engaged and facilitates cultural, horticultural, creative, social, environmental and health benefits. Rick Lowe's Project Row is an interesting model where home is not just lodging in a line of houses, but a community in which people share and gain from gardens, artists residencies and galleries. This is instructive for communities in and outside the Huston neighborhood in which Lowe's housing association is located. 
There is nothing to prevent housing providers, architects and artists in Melbourne, Stockholm or Houston combining expertise and developing housing which sustains the resources, energy needs, creativity, sociability and well-being of communities. It is important that we move from a dominant ideology of residential capitalism to a more holistic system for housing, which contains and eclipses our well-being and our personal, cultural, social, artistic and environmental potential. 


\section{Uncanny home}

\section{Considering race and American housing policy in Mike Kelley's Mobile Homestead}

Lee Azus

The treasured past is now the albatross around your neck. ${ }^{1}$

\section{Introduction}

Mike Kelley's Mobile Homestead is a full-scale sculptural replica of the artist's childhood home in Westland, a suburb of Detroit. This public artwork, occupying a lot adjacent to the Museum of Contemporary Art Detroit (MOCAD), is an architectural anomaly in a district of brick-faced buildings, medical complexes, universities and museums - as well as the empty lots emblematic of contemporary Detroit. Kelley's 'house' suggests a kind of reverse displacement, potent symbol of the vast sprawl that rings Detroit. The 60 per cent decline in Detroit's population since 1950, together with the decentralisation of the city's manufacturing, has made the suburbs a foil for Detroit's economic problems. In particular, 'white flight', the movement of white Americans away from the cities to new suburban subdivisions, has become synonymous with the suburbs' growth. In this sense, the Homestead's appearance in Detroit can be considered uncanny, a return of repressed, or the city's submerged histories. The racial history undergirding suburbia continues to shape American spaces. While Kelley's work does not overtly interrogate race, it is nonetheless ingrained within Homestead, which takes up residency in the city that most white residents fled. 
Both the uncanny and the repressed are ideas that Mike Kelley (1954-2012) explored throughout his career. He referenced these concepts in various projects that used institutions and landscapes of his native suburban Detroit as themes. These works offer a dystopian aura around a mythologised mid-century idyll that romanticised the American home and school. Kelley's works are not diatribes against suburban mores, but rather sly hints at the psychic and collective (de)formations borne from America's naturalised institutions. Kelley described his art's 'joyfulness' but then went on to qualify, 'it's a black humour. It has a mean humour. So, it's a critical joy ... it's negative joy.' Aligning art's negativity as its social function, Kelley's work evokes an uncomfortable familiarity. ${ }^{2}$ Across his work, Kelley referenced personal history as if it were collectively familiar. Home, school, the suburb and industry's detritus have become shorthand for America's post-war landscape, a Disneyland Main Street for generations of white Americans. But this familiarity has an unfamiliar aura, not only because of the specificity of Kelley's deeply personal material drawn from suburban and educational contexts, but because of what that specificity excluded. For those whom the suburbs excluded racially or culturally, Kelley's landscape is only recognisable at a distance through media and pop references. For example, in works like Notebook Sketch for Entry Way (Genealogical Chart) (Welcome to Wasteland) (1995), Kelley created an imaginary Westland community road sign, with medallions representing local chapters of civic clubs such as the National Rifle Association (NRA), Children of God, North American Man Boy Love Association (NAMBLA), the White Panther Party and the National Trailer Park Association. He lampooned white American suburban values, as well as some of its worst fears, and in the process subverted community pride. In other works, he defamiliarised an architecture of suburban banality, suggesting hidden social dynamics in seemingly neutral spaces. He continued this in the Mobile Homestead, which the Mike Kelley Foundation and MOCAD saw to completion a year after Kelley's death in 2012.

Funded by the British arts commission group Artangel, as well as the Mike Kelley Foundation, the Mobile Homestead is set back from Detroit's Woodward Avenue, beside neighbouring parking lots and an expansive lawn; it is almost as if the structure were following spatial requirements mandated by suburban covenants and legal restrictions (Figure 9.1). The replica is cordoned off by a chain-link and barbed-wire fence from MOCAD and the surface parking lots; its rear butts up against a sky-blue blank wall of a neighbouring brick building (Figure 9.2). Despite the setting, the Mobile Homestead is an oddly unremarkable 


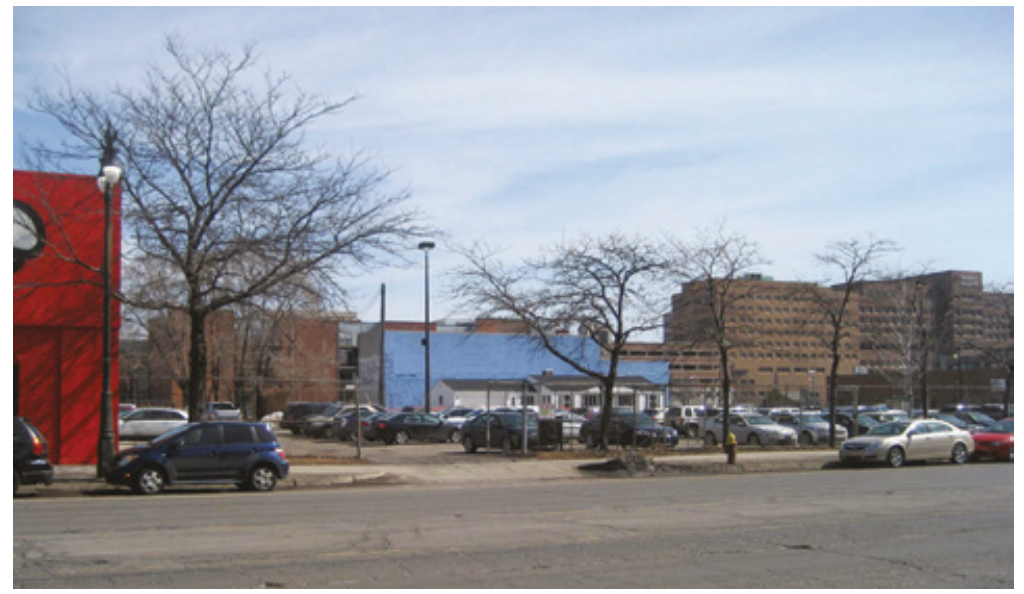

Figure 9.1 The Mobile Homestead looking east from Woodward Avenue. MOCAD at left.

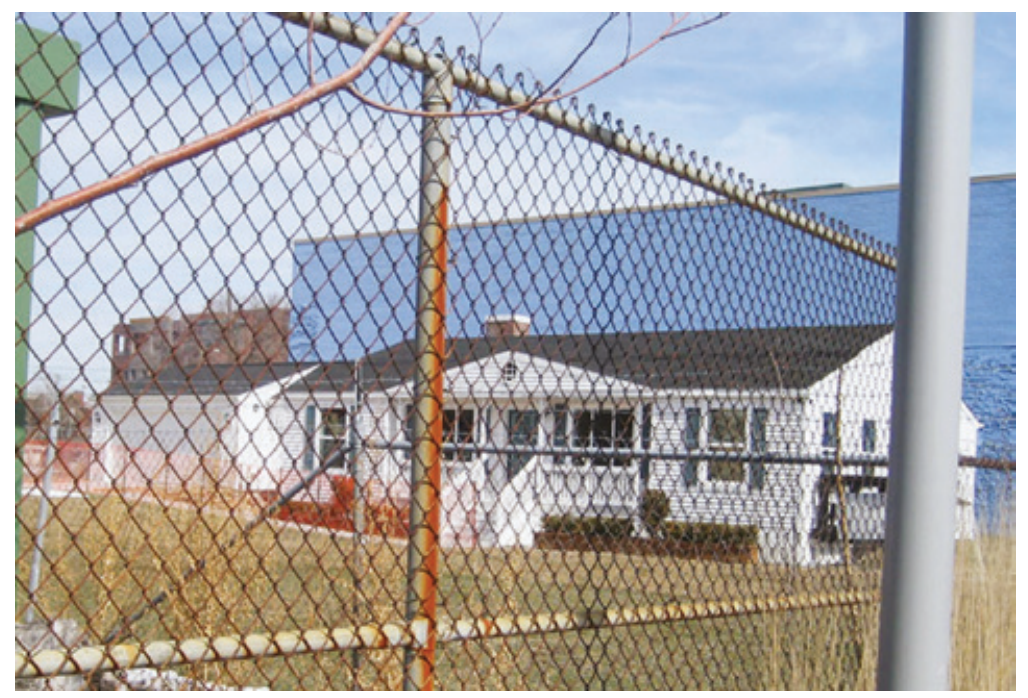

Figure 9.2 The Mobile Homestead looking north-east from Canfield Street.

suburban vernacular structure amid a landscape that vaguely recalls the city's automobile history, its scrap economy, and its medical/educational institution neighbours.

Kelley conceived of a fully mobile reproduction of his family's house to be based on MOCAD's property. The mobility of the house proved problematic due to its size, which exceeded maximum loads 
permissible on public roadways. Reconceived, the Mobile Homestead's façade was designed to be detachable, and transportable on a flatbed truck, with the intention of having it travel through metropolitan Detroit performing 'useful public service' such as 'a blood mobile, food drop-off site, etc. ${ }^{3}$ The façade, completed in 2010, was inaugurated on a trip between MOCAD and the actual house (the former Kelley home) in Westland. Kelley completed two videos of the journey, Going West on Michigan Avenue from Westland to Downtown Detroit and Going East on Michigan Avenue from Downtown Detroit to Westland. Here the sociospatial relationship between the urban and suburban is on view as the 'homestead' glides past residents, businesses and institutions.

Kelley imagined the ground-floor space of the Homestead at MOCAD as performing 'various sorts of public services'. ${ }^{4}$ Since opening, it has hosted a free library, children's art classes, art exhibits and public lectures. In a poignant realisation of the work's mobile function, a homeless advocacy group used the space to collect donations and present artwork by Skid Row neighbourhood residents when the façade travelled for the first time outside Michigan to be part of the Mike Kelley art retrospective at the Museum of Contemporary Art in Los Angeles. The juxtaposition between 'art' and 'community service' challenges the participant's expectations about the space. One reacts simultaneously to Kelley's piece as its own autonomous artwork, and the community-based art that might be curated in it, while also feeling empathy or discomfort with the local charity using the structure on the grounds of a major art institution. The Homestead provokes a collision of feelings and attitudes that are often contradictory, recalling the defamiliarisation of familiar suburban architecture, a feeling of being 'not-at-home' when at home, or vice versa.

The uncanniness of Kelley's Mobile Homestead is informed by the history of its architecture. From the exterior, this vaguely Cape Cod Ranch style of the Mobile Homestead is a version of the low-density, racially exclusive type of suburban housing that government-guaranteed mortgages and army veteran housing benefits (the 'GI Bill of Rights') made available to predominately white Americans in the decades after 1945. But, located within a seven-square-mile area in central Detroit that has become the site of private and publically subsidised investment in the city, the Mobile Homestead is a dislocated symbol of the city's mid-twentiethcentury suburbanisation. At the same time, it materialises the flow of 'creative capital' into formerly devalued urban space, a national phenomenon that seems to have bypassed Detroit until now, as the movement of neoliberal investment becomes legible in public artworks. As demographics continue to shift following the movement of capital, institutions like the 
Detroit Institute of Arts (DIA), MOCAD and the Homestead contribute to the cultural legitimacy of the area, where the educational and medical institutions co-constitute economic anchors in the neighbourhood, encouraging upscale restaurants, a publically subsidised Whole Foods Market, and the repurposing of old buildings into apartments and condominiums. The Homestead is haunted by a spectral presence of Detroit's history, namely its migratory demographics and economic instability. The work's literal mobility offers a reminder of capital's unrootedness as investors are now returning from where manufacturers and investors of a generation past had decamped in search of better returns on investments. In short, although the Homestead might serve as an uncanny monument to the effect of housing and economic policies over the past century on Detroit, this is not what is immediately perceived.

Like the cartographers in Jorge Luis Borges' short story On Exactitude in Science who design a map 'whose size was that of the Empire, and which coincided point for point with it', Kelley's reproduction of a 1950s-era suburban tract home on a site in the Midtown neighbourhood of Detroit differs materially and historically from an actual house. ${ }^{5}$ Were a house situated on a lot behind MOCAD, its presence would raise a set of questions not applicable to its facsimile: Is the home the sole remainder of an urban renewal project? Was it inhabited or abandoned? Is it a model home for an unrealised subdivision? Was it built by a local builder or was it prefabricated? Has it been put into the service of 'art' by being moved from a site outside Detroit? The sculptural reproduction and its association with Mike Kelley, on the other hand, is clearly endowed with cultural capital, and deracinated from the historical or cultural contexts assigned to the home. But as Kelley himself was aware, it would be impossible for the Homestead and its social services to be autonomous works of art or of charity. Presenting the project at the 2012 Whitney Biennial, Kelley wrote:

It will not be designated as the 'Kelley family home.' It is simply a house typical of the area where I grew up. Yet even this aspect of the project is far from neutral. A replica of a typical house of the suburbs, it will look quite out of place in downtown Detroit. This fact itself points toward the complex racial and class-based issues that are representative of the Detroit area - for example, the 'white flight' from the city after the Detroit race riots of 1967, which resulted in a city with a primarily African American population surrounded by white suburbs. ${ }^{6}$ 
Extending Kelley's logic, the contrast between the Homestead and its neighbourhood would have been even more pronounced in Detroit's economically devastated areas, or along the walls and cul-de-sacs separating the city from its wealthy Grosse Pointe suburbs to the east. Ensconced behinds fences on the grounds of MOCAD privileges the piece as a work of art, and diminishes its potential to suggest Detroit's racial and economic history. Instead, Kelley does manage to suggest this in his Michigan Avenue videos where the Mobile Homestead appears in its larger metropolitan context. In tracking the Mobile Homestead's journeys to and from Westland, the videos are full of personal and collective narratives that document the transformation of the west side of Detroit and its suburbs since the 1960s. The ruins along Michigan Avenue have a time-lapsed, entropic quality that recall photographer Camilo José Vergara's multiple images of individual Detroit buildings taken over a period of years and published in The New American Ghetto (1995) and American Ruins (1999). By the time the Mobile Homestead has arrived in front of Henry Ford's Greenfield Village and the former Kelley family home in Westland, the videos diverge from Vergara's seemingly apolitical temporal inevitability. The roles of public and government policies are largely absent from the visual and personal narratives, but the effects of those racialised policies on the urban and suburban landscape are unmistakable. Within the larger body of Kelley's work, an aura forms around a submerged narrative that extends from the personal and encompasses the political.

\section{Mike Kelley's hidden spaces}

Beneath the Homestead's ground floor, Kelley designed two underground levels, a double-level basement intended for use by invited artists or Kelley himself. Sublevels, hidden spaces and tunnels appear in several of Kelley's works, but none at the scale of the Homestead's. A ladder descends from a space on the ground floor that corresponds spatially to a bedroom closet while a second ladder descends from a hatch located outside the house by the porch stairs. Within this first basement, a hatch in the floor leads to the second sublevel composed of tunnels. The first basement space is a mirror image of the house's floor plan, except for the absence of most doorways. Instead, a set of tunnel-like hallways links some of the rooms via their 'closet' spaces, while for other rooms one must descend to the second sublevel by ladder, move through the tunnel and ascend another ladder to the chosen space. The ladders 
and two hatches connecting the underground ceiling to the closet and 'front yard' provide orientation in an otherwise isolated and destabilised domestic plan.

While Kelley typically avoids explicit politics in his art, there is nevertheless an implicit political dimension in his work involving the construction of hidden desires, latent trauma and subject formation, which can be subsumed by his works' formal qualities. His piece Educational Complex (1995), for example, is an agglomeration of white, smooth, featureless models of his childhood schools and Westland home beneath a Plexiglas cover and mounted on a table top base supported by sawhorses. Onto this 'built' environment - as subjectively informed as architecturally 'objective' - Kelley has constructed memory maps of the interiors of these structures. Solids and voids within each extruded model indicate remembered, forgotten, or unknown spaces: the voids are articulated floor plans recalled from memory, while the solid spaces have escaped from Kelley's consciousness. Enhancing the work's subjective dimension, Kelly has placed a mattress on the floor between the sawhorse legs, providing a space - conceptually, not in practice - to view the underside of the plywood base, where he has attached a replica of the basement of CalArts, the Los Angeles-area art school that he attended. The basement beneath an institution is likely the mechanical heart or storage area of the school. But for Kelley, who became interested in the 1980s scandal regarding children's tales of abuse in hidden tunnels under the McMartin Preschool in Los Angeles, it suggested a potentially ominous site. Writing about repressed memory, fantasy and the futile search for tunnels at the site, Kelley said that the McMartin Preschool 'is no longer a real building but a symbolic architecture. It is more akin to an amusement park, like Disneyland, built as a ritual site to reveal the political and moral convictions of its users. ${ }^{77}$ Placement of a mattress on the floor, rather than a mirror as in Kelley's Antiqued (Prematurely Aged) piece (1987), suggests a ritual site or a site of leisure, play, sexual activity or homelessness just below what is intended to be visible.

The Mobile Homestead and its sublevels thematise the personal and familial within a larger metropolitan context, but Educational Complex suggests that personal trauma - real or imagined - has a familial and institutional basis. George Baker has written of the relationship between repression as a deviant product of 'structures of power and of the law' and Kelley's repeated use of sublevels in his work: 'Repression would now literally create the sublevel, the underside or underground, the missing and the forgotten, as if the sublevel could only arise through a dynamic of dominance and of masochism, the sublevel as truly 
"sub" - below, but also subjected, subservient, submissive, potentially subversive.'8 The hidden spaces imply that the effects of 'structures of power' create a repression that is both psychic as well as social.

As an architectural agglomeration of social space, Educational Complex is not so much Bauhaus as it is Chicago's 1893 World's Columbian Exposition, an ironic commentary on the optimism embodied in architecture; here the work is a narrative of post-war faith in American institutions at the apex of the country's economic and international power. At the same time, Kelley wanted his compact collection of buildings to counter any hints of utopia. He has acknowledged that unlike utopian projects, where 'moral and aesthetic dimensions are presented, often openly and dramatically, as mirrors of each other ... my project is a perversion of such an attitude: I present an obviously dystopian architecture, reflecting our true, chaotic social conditions, rather than some idealized dream of wholeness.' ${ }^{9}$ His Westland home makes an appearance in this work, implicating the suburban idyll that frames this educational arrangement.

In yet another work entitled John Glenn Memorial Detroit River Reclamation Project (Including the Local Culture Pictorial Guide, 1968-1972, Wayne/Westland Eagle), Kelley and his assistants dredged ceramic and glass detritus from the Detroit River, separating the shards by colour into a wooden ramp placed around a ceramic encrusted larger-than-life statue of astronaut John Glenn. The first American in space, Glenn was treated as a 1960s hero, and was the namesake of Kelley's high school. Here, the Detroit River has become a figurative sublevel where prosperity's detritus is externalised and collectivised. Framed copies of Westland's local newspapers accompany the statue and ramp of broken ceramics. The news stories and images contain a metaphorical void. Like the schools, home, and space-age hero, they share an uncanny feeling that the suburban homes and institutions were neutral, ahistorical spaces. In their assumption of collective whiteness, race is absent, even as it shaped urban planning and access to particular neighbourhoods, schools, homes or types of finance. Like the Mobile Homestead and Educational Complex, Kelley's focus on local narratives assumes a white identity formation at the apex of American power. The absence of race is an effect of the work, unlike the work of other artists like Kerry James Marshall, whose paintings Visible Means of Support: Mount Vernon and Visible Means of Support: Monticello explicitly recuperate an absent racialised history in the national celebration of America's first heroes. 
If the Mobile Homestead truly raises 'complex racial and class-based issues' - as Kelley himself acknowledges - the racial history undergirding suburbia needs interrogation. The construction of racially segregated subdivisions had juridical and governmental support, and was concurrent with racially restricted access to public accommodations, such as shops, hotels and restaurants. New subdivisions were encircling Detroit in the 1950s, while corporate decentralisation of manufacturing began a slow exodus from the city in search of abundant undeveloped land and lower labour costs. In this decade, Detroit's population peaked at just over 1.8 million residents, then began its decline as 362,877 white Detroiters migrated out of the city by $1960 .{ }^{10}$ Mike Kelley's family home in the Northlawn subdivision of Westland can thereby serve both as a sculptural model and as a study of racialised US urban policy in the twentieth century. But before examining that history, it is worth recalling the Mobile Homestead's nomenclature, the 'homestead' as it was used in federal land policy in the nineteenth century. Under the Homestead Act of 1862 the Federal government gave 160-acre parcels of formerly Native American land to individual European-Americans for productive settlement. This creation of private property displaced Native Americans, while introducing use-value onto land, the basis for the American economy since its settlement in the seventeenth century. In Detroit, the Mobile Homestead 'settled' on a parcel of land in a city with thousands of acres of property that, in an inverse process, have become valueless within the logic of the market. Under the aegis of Artangel and MOCAD, the Homestead has contributed to value creation in Midtown, making land culturally, and by extension economically, productive.

\section{The federal housing administration and the minimum house}

Suburbia can never be understood solely in its own terms. It must always be defined in relation to its rejected opposite: the metropolis.

Robert Fishman ${ }^{11}$

The large lots and detached single-family homes of Northlawn subdivision in Westland (which was known as Nankin Township, before its citizens voted to adopt the name of the new Westland Shopping Centre upon incorporation in 1966) seem typical of post-war suburban development. However, Northlawn was legally registered in 1925, the peak year of an 
American home building boom that would soon crash. It was a typical pre-Depression-era subdivision in which a developer typically divided farmland into blocks, which were further divided into building lots that were sold piecemeal to individuals or speculative builders, who were responsible for the construction of their own homes. ${ }^{12}$ Northlawn subdivision was laid out in an economical gridiron, lacking the curving streets, parks and cul-de-sacs found in affluent late nineteenth-century suburbs such as Vaux and Olmsted's Riverside development west of Chicago.

New housing starts and building investments in the USA began to decline in 1926, three years before the Great Depression. By the time Franklin Roosevelt was inaugurated in March 1933, half of all US mortgages were in default and new housing starts were down 90 per cent from their peak in 1925. Pre-New Deal-era mortgages had a higher level of risk even in good times. Home loans before the Roosevelt era typically required a 50 per cent down-payment and monthly interest-only payments, with the full principal amount due upon maturity, which was 10 years or less. ${ }^{13}$ The Roosevelt administration sought to manage loan defaults and foreclosures on existing properties by establishing the Home Owners Loan Corporation (HOLC) in 1933. The government issued bonds to lenders in exchange for distressed home loans, which were then renegotiated with borrowers at a lower interest rate, amortised over 15 years. Although formally dissolved in 1951, HOLC issued the bulk of its one million loans by $1935 .^{14}$

The administration then established the Federal Housing Administration (FHA) in 1934 with the aim of encouraging new home building, lending and home ownership. It did so by insuring private lenders' loans to homebuilders. In addition, it insured up to 90 per cent of a homebuyer's mortgage value. ${ }^{15}$ The FHA helped stabilise the banking and housing industries by underwriting credit to a large demographic of American consumers. As an underwriter, the FHA promulgated standards for rating properties, locations and borrowers. Using loan guarantees as financial incentives, the housing and banking sectors adopted the agency's guidelines, which thus became de facto national housing standards.

The first standards were published in 1934 in the FHA's Underwriting Manual, and were based on years of studies and reports by trades' organisations and non-profit foundations. The rules endorsed racial segregation and specific house types to assure that homes underwritten by the FHA would retain their value over time. Specifically, the recommendations concerning minimum lot size $(50 \times 100$ feet $)$ and dwelling square footage, room sizes and layout, ventilation and natural light, plumbing and electrical standards, and landscaping were written 
to favour newer, detached, single-family homes. Multi-family housing was discouraged 'through unpopular terms', and loans to repair existing housing tended to be small and short term. ${ }^{16}$

The Underwriting Manual guidelines also expressed a preference for traditional house design. Flat roofs, as one example, did not conform with Part II, Section 1, Part 126 (1) (a), which asked underwriters, 'Is the roof correctly pitched and are the slope and angles of the roof of such a nature as to afford proper drainage and to avoid "snow pockets"?' 'Non-conformity' was considered detrimental, to both the future value of the home and its neighbours. The manual stated, 'It is universally recognized that a structure, though conforming in every respect except exterior design, may clash so violently with that which is typical that the marketability of the property is largely destroyed.' ${ }^{17}$

No rules had more of an impact on racial housing patterns and access to credit than the Underwriting Manual's endorsement of racial covenants and racially separated neighbourhoods. The Manual followed the practice of the real-estate industry and 'recommended ... [p]rohibition of the occupancy of properties except by the race for which they are intended'. ${ }^{18}$ The use of racial covenants did not begin with FHA mandates, or the series of 239 colour-coded risk-assessment maps issued by the HOLC. Racially restrictive housing covenants became common in new subdivisions after the United States Supreme Court in the Buchanan v. Warley case (1917) struck down city ordinances that had prohibited the sale of property to African Americans as a violation of the 14th Amendment to the Constitution. A decade later, however, the court affirmed the constitutionality of the racial covenants in the Corrigan v. Buckley case (1926) and determined that the 14th Amendment did not 'prohibit private individuals from entering into contracts respecting the control and disposition of their own property. ${ }^{19}$ The FHA affirmed African-American exclusion as necessary to maintain property value for white homeowners due to realestate industry practices based on those precedents.

As a companion to the Underwriting Manual, another FHA publication, Principles of Planning Small Houses, served as a pattern book for acceptable home design. In its 44 pages, it provided variations on a single floor plan, elevations and site plans. The house style that illustrated the FHA's brochure was the Cape Cod Revival (Figure 9.3). By illustrating a particular house style in a Federal Housing Administration publication, the federal government as underwriter of mortgages implicitly endorsed that style. ${ }^{20}$ It is among the most common styles found in American subdivisions and is particularly well known as the house type for the first 6,000 homes built in the Levittown, New York, development in 1948. 


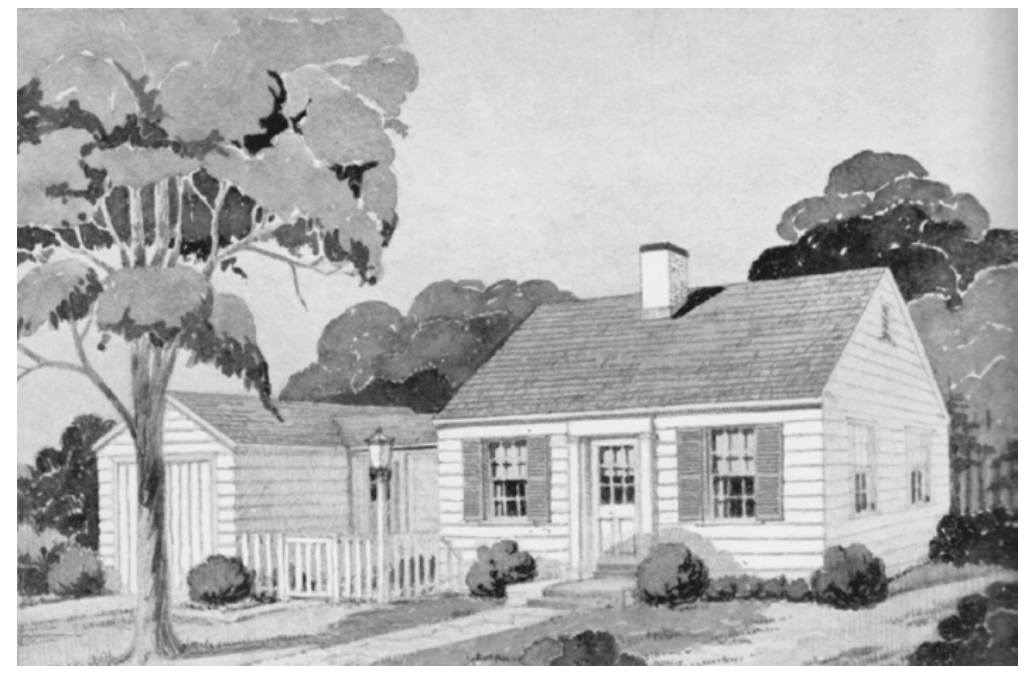

Figure 9.3 Cape Cod Revival style illustration in Principles of Planning Small Houses, 1940 edition, page 2.

Seeking to create reproducible housing models that eliminated all costly and unnecessary construction, Principles of Planning Small Houses incorporated recommendations by trade and advocacy groups with the purpose of financially underwriting a mass-produced 'minimum house' at an affordable price. ${ }^{21}$ From the foundation to the attic, to its siting on a lot, the house was reimagined as an efficient commodity. The Cape Cod Revival, as well as the Ranch style, a popular style based on the American South-west ranch house, and the Midwest Prairie school design, were traditional styles that functioned as skins over the modern, minimum house floor plan.

The basic FHA house type was between 625 and 900 square feet in size, wood-framed, square-shaped and one storey tall. It excluded an attic and basement. A concrete slab served as the foundation, and a wall or floor-heater was installed in place of a furnace. The front entry opened directly into the living room. The kitchen was next to the living room and had a side-entry door. The four-room floor plan minimised hallways and excluded a dining room, which was combined into the kitchen or living room. There were two bedrooms and a bathroom, the latter positioned behind the kitchen to minimise plumbing costs. Principles of Planning Small Houses recommended locating the kitchen in the northeast portion of the house, where the heat from the stove would have the least effect on the comfort of the house (Figure 9.4). 


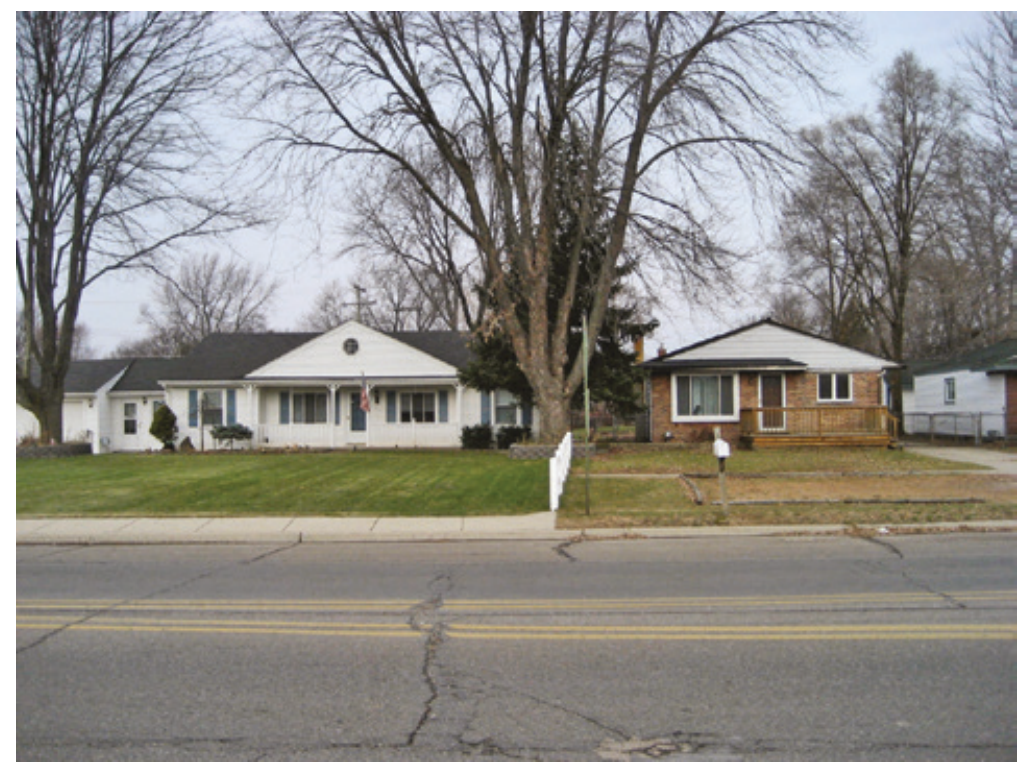

Figure 9.4 'Basic Plan, One-Story, Two-Bedrooms', from Principles of Planning Small Houses, 1940 edition, page 16.

Variations of the basic floor plan included additional square footage for a dining alcove, or for rooms along one side of the house, resulting in a rectangular floor plan; the creation of a small basement for a heating unit; or the construction of a one-and-a-half-storey dwelling with an unfinished attic large enough for two bedrooms. Other FHA floor plans included a garage, a third bedroom or full basement, all sharing similar floor plans with the basic version. ${ }^{22}$ Through promotion of the minimum house in FHA publications and travelling displays of model homes (at the 1939 New York World's Fair, for example), along with mortgage insurance underwriting standards, the average American house size was reduced from 5.8 rooms in 1936 to 5.1 rooms in $1940 .^{23}$

The Kelley family house is the descendant of the FHA's Underwriting Manual's codes and the minimum house template. Constructed a generation after the first edition of Principles of Planning Small Houses, its Cape Cod-Ranch style and size reflected the increasing prosperity of post-war working-class America and the Detroit suburb in which it was located. The Kelley family house met the criteria of the FHA's construction recommendations, but was built specifically for its double lot in an older subdivision, not as part of a new housing development. In this sense, the house differed from the typology of the post-war house. In fact, because 
the Northlawn subdivision was legally registered in 1925 and built out over a period of almost 40 years, it should have fared poorly according to the Underwriting Manual guidelines.

Where the Northlawn subdivision in Westland would be in accord with FHA standards was its housing restrictions, which predated the Roosevelt administration and the FHA. As early as 1928, the subdivision's restrictions specified that the 'property not ... be sold, exchanged, or occupied by any but the Caucasian race'. ${ }^{24}$ According to the 1940 US census, white, mostly native-born Americans inhabited all homes in the Northlawn subdivision and in the surrounding communities in Nankin Township. The US Supreme Court eventually reversed the Corrigan v. Buckley decision and declared racial covenants unconstitutional in the Shelley v. Kraemer case (1948). This made little difference to the practice of the local real-estate industry, which in nearby Ann Arbor, for example, believed 'that all private owners of property have the right to determine with whom they are to do business and that the owner has an unqualified moral and legal right to define without limitation the persons with who the broker may deal in consummating the transaction with which the broker is involved as agent'. ${ }^{25}$ It was only the Fair Housing Act of 1968 (Title VIII of the Civil Rights Act of 1968) that codified a national prohibition against racial discrimination in housing.

\section{Post-war housing developments}

At the end of the Second World War, small-scale subdivision developments were inadequate to deal with the housing shortage and high demand due to the zero down-payment, government-guaranteed home loans offered to returning veterans under the Servicemen's Readjustment Act, also known as the GI Bill of Rights. Builder-developers, many with wartime experience building worker housing quickly and inexpensively, levelled hundreds of acres, obtained building permits, and constructed and outfitted thousands of similar homes. The efficiencies of vertical integration allowed them to build faster and at less cost per house than an individual who might purchase and build on a single parcel in older subdivisions such as Northlawn.

For the massive post-war development in Levittown, for example, the Cape Cod Revival, the Ranch, and the Cape Cod-Ranch became a common skin over the minimum house floor plan. Levittown's first 6,000 
homes, identical 'Cape Codders', were complete in 1948 along strongly curving streets and cul-de-sacs. By 1951, 11,500 Ranch style houses, 50 square feet larger than the Cape Codders, were complete. In Panorama City, in suburban Los Angeles, the 'Suburban', 'Rancho', 'Colonial' and 'Palm Springs' models were West Coast variations on an 800-900 square foot, stucco-clad minimum house floor plan.

The Kelley family house is indebted to the minimum house design, as well as private and government policies that sought to assure stable home values for all but African Americans and other marginalised communities. Racial covenants continued to be enforced in Levittown long after the Shelley v. Kraemer case invalidated them. African-American families were not permitted to live in Levittown, New York, or Levittown, Pennsylvania, until a family in Levittown, Pennsylvania, sold their house in July 1957 to Bill and Daisy Myers, an African-American couple. A lawsuit that ended at the United States Supreme Court eventually gave the Myers family the right to live in their home. ${ }^{26}$

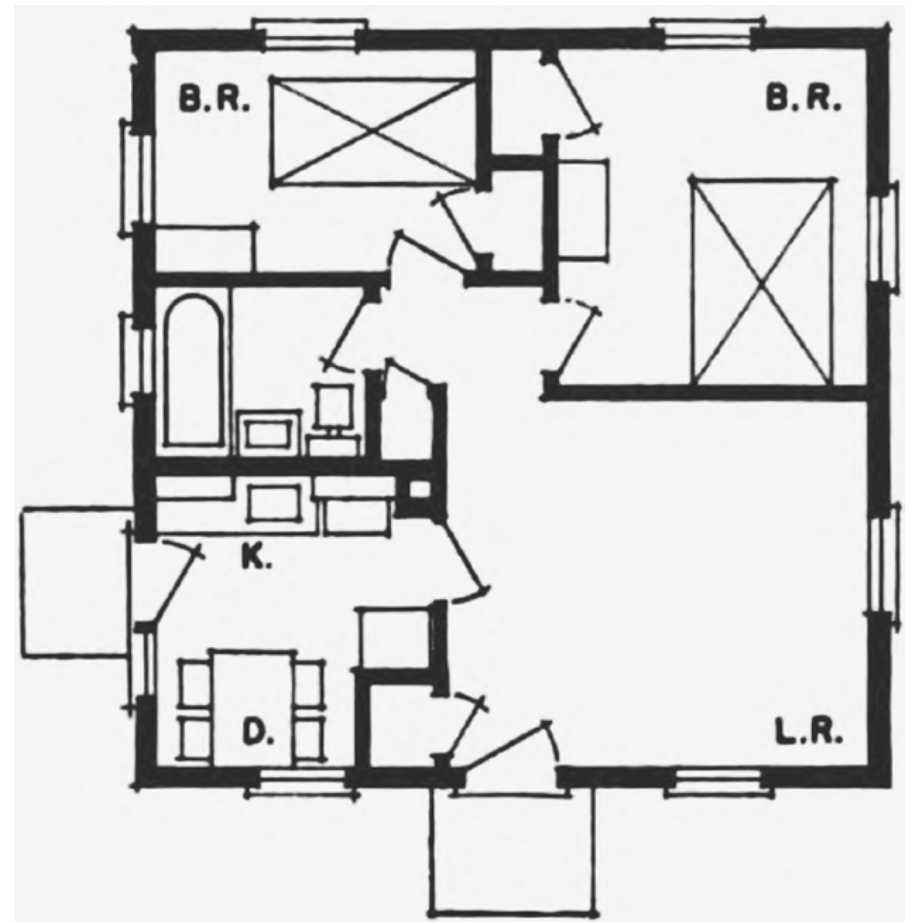

Figure 9.5 The Kelley Family House (left), Northlawn Subdivision, Westland, Michigan. 
While the design and building of suburban Detroit was left to private developers backed by financial guarantees from the Federal Housing Administration and the Federal National Mortgage Association, a similar symbiotic relationship developed between private developers and public subsidies within urban areas due to the US Housing Acts of 1949 and 1954, which addressed overcrowding and substandard structures in the United States. In Detroit, the Acts financed the condemnation and clearance of hundreds of parcels to provide public housing for thousands of residents, mostly within the informal borders of the African-American neighbourhoods. There was a local antecedent in the Brewster Homes and Frederick Douglass Homes completed in 1938 and 1941, respectively, in the Paradise Valley neighbourhood. Title III of the Housing Act of 1954, however, turned Federal policy away from its 1949 mission of providing 810,000 new units of publically owned housing throughout the United States to 35,000 units per year over four years for the sole benefit of relocating families displaced by urban renewal projects. ${ }^{27}$

The Housing Act of 1949 privileged 'private enterprise' in its 'Declaration of National Housing Policy' preamble and as part of its mission financed the acquisition and clearance of parcels by local public entities to sell them to the private sector for new, market-rate housing. The dual nature of the law meant that additional public housing units, as well as market-rate housing, were added to the black neighbourhoods of Detroit. Public housing for African-American families was added to the Paradise Valley neighbourhood, north of Gratiot Avenue, while to the south, affluent and largely white residents moved in to the Lafayette Park development, the largest collection of Mies van der Rohe buildings in the world, displacing 7,000 African-American, Black Bottom neighbourhood residents. ${ }^{28}$

Would a mobile Mies' townhouse in Midtown Detroit be less of a curiosity than the Mobile Homestead? Although it is a representation of an earlier generation of gentrification, its presence at MOCAD could be easily confused with a new condominium development rising in the neighbourhood. The Mobile Homestead, on the other hand, functions as an urban totem, what Freud, writing on the uncanny, calls a 'frightening element ... that has been repressed and now returns'. ${ }^{29} \mathrm{In}$ Detroit, a city that Fred Moten calls a 'kind of anti-capital of white flight', ${ }^{30}$ the Homestead recalls Mike Kelley's own paraphrase of Freud's theory of the uncanny, which Kelley refers to as 'the class of the terrifying which leads us back to something long known and once very 
familiar, yet now concealed and kept out of sight. It is the unfamiliar familiar, the conventional made suspect. ${ }^{31}$ But it's not simply the arrival of any familiar yet atypical house type that warrants the conceptual quality of 'the uncanny'. We do not experience the uncanny in the federal government attempt to normalise a literally toxic mobile house type in New Orleans after Hurricane Katrina, for example. Nor do we experience it in new 'Tuscan Villa Revival' subdivisions next to Spanish Colonial Revival homes in suburban San Diego. In Detroit, the unfamiliarly familiar Cape Cod-Ranch house type might become even more unremarkable if a change in American housing policy led to distribution of prefabricated copies on the thousands of empty parcels of land. Even the Homestead itself - as a mobile structure moving through the city, "perform[ing] various types of "social services" along the way - to function as a blood mobile for example', in accord with Kelley's vision might appear as banal as a mobile library, if the sight of freely available public services in most neighbourhoods would be considered common and conventional. ${ }^{32}$

What makes the 'conventional' suburban home uncanny in Detroit? Putting aside its being the domestic site of Kelley's personal adolescence and subjectivity, it is the synecdoche for the subject formation of the post-war white working class that once flourished outside the city. This nostalgic representation of white aspiration has returned to Detroit, wheeling up Michigan Avenue in what Fred Moten has called a 'fugitive reversal of white flight's chain ganged mobilization'. ${ }^{33}$ As an object, this aligns with Freud's quotation of Schelling's definition of the uncanny as 'something that should have remained hidden and has come into the open'. ${ }^{34}$ But, when considering the entire Mobile Homestead project, including the sublevels, Kelley's opposing paraphrase of Freud's definition of the uncanny is equally apt: 'Something long known and once very familiar, yet now concealed and kept out of sight.' As it assimilates over time into the landscape of Midtown, the Homestead risks becoming another work of public art, which Kelley feared would be 'forced upon a public that, in most cases, finds no pleasure in it'. ${ }^{35}$ But within the sublevels, 'concealed and kept out of sight', the uncanny double of the floor plan of the Kelley house and the Mobile Homestead acts as the political unconscious of US housing policy. The Homestead in all its parts, then, realises a site-specific monument to a specific form of domesticity. The suppression of a racist history has transformed the American house following the Second World War into an object that has come to signify qualities such as individual success or consumer 
preference over its origins in deliberated American housing policies. What persists, however, is the unhomely home, that collective history which remains unfamiliar even as its effects are lived out on both sides of Detroit's border with its suburbs at Eight Mile Road, Grosse Pointe, Dearborn and beyond. 


\section{0 \\ The real 'housos'}

\section{Reclaiming identity and place}

Michael Darcy and Dallas Rogers

\section{Introduction}

Public - or, as we are now more likely to refer to it, social housing ${ }^{1}$ - represents a very small and indeed falling proportion of Australia's housing stock, especially when compared to most European countries. From a peak of just under 6 per cent of dwellings nationally in the 1980s (10 per cent in South Australia), by 2006 social housing represented around 4 per cent of housing stock. ${ }^{2}$ Government subsidies for low-income rental housing have been politically contested since the earliest federal government intervention following the Second World War, but at least until the early 1990s public housing provided affordable and secure housing for those households who could not afford to house themselves appropriately through owner occupation or private rental. Some 70 years beyond its inception and despite a similar situation of chronic undersupply of housing in major cities, and with the least affordable housing internationally, public housing is now perceived by many as a highly problematic form of tenure which exacerbates or even produces social problems rather than ameliorating them. As in the UK and USA, mass-produced estates containing concentrations of public housing are frequently characterised as incubators for crime and anti-social behaviour, residents' unemployment and poor educational outcomes. State-owned housing not only the policy of providing assistance, but its actual physical form and location ${ }^{3}$ - is now widely described as a 'failed experiment' and has 
emerged as the target of a concerted campaign of reform and redevelopment. ${ }^{4}$ A striking illustration of the public perception of public housing neighbourhoods in Australia can be seen in the popular television comedy Housos, which is discussed below. ${ }^{5}$

The roots of the social housing problem are described as both economic and cultural. Economic causes are understood to relate to work disincentives and poverty traps directly arising from the structure of housing assistance, while perceived cultural factors include the reproduction of poverty brought about by lack of sufficient role models of 'good citizens' and the predominance of inward-looking social networks amongst residents of discrete public housing neighbourhoods. These factors are reinforced by popular prejudice against, and stigmatisation of, public housing tenants.

In housing policy discourse, the urban form and geography of public housing, especially in large estates, ${ }^{6}$ have thus come to be depicted as destroying its ability to assist tenants to improve their lives, while in the media public housing tenants are frequently portrayed as irresponsible and ungrateful receivers of public beneficence. However, historical analysis shows that key contributors to the problems experienced in public housing are not its design or specific geography but increasingly restricted eligibility associated with progressive reductions in funding over many years. Initially, public housing was targeted to assist lowincome working families but gradually over time the demography of the tenant population has transformed through the increasing targeting of higher and more complex need groups such as ex-prisoners and people experiencing homelessness and substance abuse issues. As such, public housing is now a residualised tenure of last resort targeted at the most complex needs, so that low income alone does not guarantee access.

Nonetheless, the net effect of this process has been to reinforce the perception of failure - not just of policy, but of whole communities - and thus to instil a profound sense of public tenants as 'failed citizens' who are unable to produce the conditions for a standard of everyday life such as that enjoyed by owner occupiers.

Goffman's seminal work on stigma identified three categories of the phenomenon which were: abominations of the body, blemishes of individual character, and tribal stigma (race, nation and religion). For Goffman, stigma arises through negative labelling and stereotyping of people that are depicted as possessing discrediting attributes, which leads to a 'spoiled identity'. Wacquant argues that a key omission in Goffman's thesis is a link to 'blemish of place' or a discredited neighbourhood reputation, which leads to what he terms 
as 'territorial stigma'.7 Territorial stigma can project a virtual social identity onto families and individuals living in particular neighbourhoods and thus deprive them of acceptance from others. Place and person become intertwined in negative representations although these may well conflict with lived experience. Consequently 'blemish of place' can add an additional layer of disadvantage to any existing stigma that is associated with poverty, ethnicity, disability or physical appearance. Community identity is thus constructed by outsiders to the territory, and stigma is associated with not only the neighbourhood but also the individuals who live there.

The consequences of experiencing 'territorial stigma' include: discrimination by employers and others on the basis of one's address or other spatial markers; impacts on health and well-being, and mental health in particular; differences in the nature and quality of local service provision; and threats to housing security associated with attempts to deconcentrate poor households, which may result in reductions in overall stock of social housing. Together these impacts become new factors regenerating stigma in a self-perpetuating cycle. In Australia, Warr draws particular attention to the role of television and other media whose "negative ... attention amplifies and cements the quotidian prejudices that are experienced by people living in "discredited" neighbourhoods', ${ }^{8}$ and concludes that while global economic forces and government policy intervention are important mediators of territorial stigma, the 'unwarranted and unsympathetic attitudes and actions of outsiders ... are key contributors to the difficulties of those living in stigmatised neighbourhoods. ${ }^{9}$

The media is a key channel through which distinctions of class and territorial stigma are shaped, imposed and reproduced. Electronic media is easily accessible with 24-hour internet and television availability, so its realm is pervasive. In Australia and elsewhere Arthurson and others have shown that:

The media has played an active role in supporting and embellishing pathological depictions of social housing estates as sites of disorder and crime, drawing on explanations that cite individual agency and behaviour as the problems. ${ }^{10}$

Stressed urban communities are frequently sought out by the media as settings for nightmarish portrayals of urban life that may serve or extend negative stereotypes. In the end it matters little if these localities in fact are, or are not, run down and dangerous places, and their populations 
composed essentially of minorities and poor people, 'the prejudicial belief that they are suffices to set off socially noxious consequences'. ${ }^{11}$

Research from Australia and internationally also explores the disjuncture that often exists between media representations of estates and the lived experience of residents. Lapeyronnie, for instance, identified the tension between internal self-perceptions of the French banlieue experience and external images. ${ }^{12}$ Residents of stigmatised places bemoan the fact that others and the media, in particular news and current affairs programmes, stigmatise their neighbourhoods and occupants, often without even having visited there or knowing the people. An alternative standpoint is that mainstream media needs to be recruited to challenge negative perceptions of estates, but in a time of sensationalist and xenophobic media discourse this seems unlikely to happen. ${ }^{13}$

Acceptance of the negative stereotype invalidates the legitimacy of any claims upon place making in urban areas by poor public tenants and, as a corollary, legitimises redevelopment through forced relocation and disposal of public assets through public-private partnerships. For affected tenants, 'voice' has usually taken the form of reactive consultation on details only after major decisions concerning redevelopment, relocation and population mix have been taken. ${ }^{14}$ As suggested by Imbroscio, free residential choice 'often conceives the expansion of residential choice for the urban poor as involving merely the ability to exit their current neighbourhoods and enter others'. ${ }^{15}$

The 'social exclusion' of public tenants thus extends beyond the housing management arena to their exclusion from the research processes through which disadvantaged places have been defined as problems, and in which policy solutions are framed. Current urban studies debate offers limited engagement with micro-scale analyses of creative destruction cycles and consequences and particularly with the creative potential of local communities and public tenants themselves who are typically viewed as either passive beneficiaries or victims of redevelopment.

\section{Situated knowledge and the production of culture}

Bourdieu has shown how social order is inscribed through 'cultural products'. ${ }^{16}$ These products include education, language and the media. Cultural products work through framing and reworking alliances over culture both symbolically and materially. This leads to an unconscious sense of acceptance of social differences and one's place in society both 
in a social and geographical/spatial sense. In other words, through these cultural products meanings are attached to certain practices, places and events and these meanings are internalised even by those who themselves are being culturally defined.

Faced with threats of demolition and redevelopment of their dwellings, dispersal of tenants and communities, ${ }^{17}$ and with persistent stigmatisation and demonisation in mainstream media, ${ }^{18}$ some residents of public housing in Australia have used video and other creative media to create alternative cultural products.

Three examples are outlined below which emerged during a fouryear project (funded by the Australian Research Council, St Vincent de Paul Society, UWS and Loyola University Chicago) entitled Residents' Voices: Advantage, Disadvantage, Community and Place. The aim of the project was to collaborate with residents to challenge conventional outsider approaches to understanding place and disadvantage by facilitating the emergence and validation of situated knowledge and 'insider' theorising about this relationship. Each is a response to stereotyping and stigma, and can be understood as a limited attempt to reclaim the identity of specific neighbourhoods or of public housing tenants collectively. Importantly, as will be shown, the residents involved in these projects do not set out primarily to change the views or actions of policy makers or other outsiders - although such an outcome might be welcomed. In each case, the primary audiences for their efforts were the participants themselves, their neighbours and other tenants.

The examples discussed below are, firstly, digital storytelling disseminated through a website; secondly, tenant-driven media analysis of the popular Australian television parody Housos; and, finally, a short dramatic film written and directed by tenants entitled Into the Woods. In each of these examples, public housing residents speak back to popular stereotypes, yet in each case their main purpose was not primarily to influence public perceptions or the policy agenda, but rather to reclaim and reinforce their own identity and connection to place.

\section{Digital storytelling}

Digital storytelling is a narrative-driven form of digital media production that allows people to share aspects of their life by making a short film, or audio or photographic essay. While digital storytelling is a relatively new visual methodology within academia, it has a much longer history in the media and the corporate spheres. With the addition of 
increasingly affordable high-quality digital media tools - such as photography equipment, video cameras and voice recorders - digital storytelling is a performative practice that can be undertaken by almost anyone. As a practice, digital storytelling is very diverse and might produce short radio documentaries, photographic essays, participant-directed autobiographical films or stop-animation stories.

For the Residents' Voices Project we commissioned Information and Cultural Exchange, ${ }^{19}$ a community arts organisation, to run our digital storytelling workshop as a capacity-building process for the university researchers and tenant collaborators. Lundby argues that increasing access to the Internet, low-cost or free software and the rise of social media rise have allowed some marginalised groups to redeploy 'the ageold practices of storytelling' to self-represent their own social experience. ${ }^{20}$ Therefore, we wanted the residents not only to create a digital story through the workshops but, more importantly, to acquire the skills and knowledge to create and teach others how to create additional digital stories in the future. This workshop involved five residents and three university researchers. We conducted two technical sessions in a studio space and four content development sessions in a computer room at the local library near the residents' homes. In the first two sessions, the digital storytelling facilitators conducted classes on 'talking about personal stories', 'storyboarding for narrative development', 'using digital recording equipment' and 'using digital editing software'. In the four content development sessions, the residents drafted a narrative and recorded it on a voice recorder. They also collected a suite of photographs to match their verbal narrative. With help from the digital storytelling facilitators, the residents produced their digital story by building a photographic essay over the top of their oral narrative using movie-editing software. The stories covered topics including living in social housing with a mental illness, criminal activity and violence, interactions with law enforcement agencies, experiencing and addressing both personal and geographical stigma, and living in social housing with family members with complex needs.

Guillemin and Drew describe the academic digital storytelling process as follows: 'participants are asked by the researcher to produce photographs, video, drawings and other types of visual images as research data'. ${ }^{21}$ However, we set out to challenge the relationship between the researcher and the researched. In our first digital storytelling project, we found that the production and consumption of the digital cultural products was more dynamic and contested than Guillemin and Drew suggest. Participant-generated visual methodologies are not bound 
by the constraints of positivist empirical research frameworks, which define clear roles for the researcher and the researched. Indeed, one of the (student) researchers from the Residents' Voices team participating in this workshop was at the time a social housing tenant living in the neighbourhood alongside the other participants. Thus our digital storytelling project involved multiple stakeholders with complex identities that very clearly called into question the researcher/researched dichotomy. At the request of residents, in our project we exposed the 'researchers' to the same digital storytelling process as the residents, and the 'researchers' created digital stories alongside the residents about their experiences with social housing. Our project became a collective process of knowledge creation whereby all the participants became autobiographical researchers. ${ }^{22}$

Much of the literature on digital storytelling is focused on the way the participants have sought to deploy their stories to talk back to, or to talk up to, audiences of power. Others show how the storytellers have used their narratives to pursue 'transformations' of the social, cultural or political 'context in which it operates'. The case studies presented in this chapter outline a different suite of audience target groups and more nuanced forms of political action. They show that the storytellers have complex motivations for using digital storytelling and when freed from the constraints of external mediators, including researchers, the stories that they choose to tell can challenge our assumptions about their political motives.

In many cases, the people making digital stories do so with the aim of sharing their story with a particular audience. In the Residents' Voices digital storytelling project participants were offered the chance to share their stories with other residents, in locations around Australia and in the USA through publication on a website. The communicative aim was focused on horizontal connections between tenants rather than, at this stage of the project, of speaking directly to the powerful. However, participants did not all share the same understanding of the purpose or impact of their products.

Anita chose to tell a very shocking story about being consistently harassed and frightened by a regular visitor to her housing block, leading to her applying for an ultimately unsuccessful court order and eventually for a transfer to another location. ${ }^{23}$ She did not appear in the video, and the images which she chose are not dissimilar to many tabloid images of public housing. However, at the public launch of the video stories Anita recounted the way in which telling the story had reinforced her belief in her own strengths and ability to deal with what life throws at her. 
Lachlan was very enthusiastic about the project and produced a digital story but didn't want anyone to see the film, which was never released on the website, while Linda was happy to tell her story of moving out of the home she had lived in happily for decades as a sound recording, but provided no pictures. Peter's story was explicitly political and directly criticised the common stereotypes of public housing. He wanted policymakers to see it and hear the story.

\section{Housos}

Housos is a satirical parody about the daily life of social housing tenants in the fictitious 'Sunnyvale' social housing estate which appeared on Australian free-to-air television from 2011, and has since produced a second series, a live stage production and a feature film. It is a highly embellished representation of Australian social housing estates where characters act outside of the law and common norms of society. The depictions of the social housing tenants draw on overdrawn but common caricatures and stereotypes - with characters such as Dazza, Shazza and Franky, portrayed as feckless individuals who shun work, survive on welfare benefits, indulge in substance abuse, routinely commit crimes and cause generalised disorder, along with highly dysfunctional families and relationships. Each episode is slapstick in tone and addresses a different theme. These include the housos' attempts to defraud the welfare system through feigning injuries that might qualify them for disability pensions, and drug-dealing activities involving transporting illegal steroids to Asia. (This story contains references to a real high-profile case which are unmistakeable to Australian audiences.) The final episode for the first series concerns plans for redeveloping Sunnyvale estate whereby the social housing tenants, facing relocation to other neighbourhoods, organise various forms of resistance.

Recent research on cultural representations of class draws on cultural capital ${ }^{24}$ to identify the dominant contemporary depictions of the working class in the media as based on ridicule, disgust ${ }^{25}$ and mockery, ${ }^{26}$ claiming that disgust is winning out. ${ }^{27}$ These representations of the working class are used as part of the processes of maintaining middleclass distinction, authority and security. ${ }^{28}$

Promotional materials provided by the producers of Housos include a satirical 'dictionary definition' of a houso that points towards 
similar class distinctions and derogatory representations of social housing tenants.

houso [how-zō], Informal: Often Disparaging.

noun: 1. an uneducated person who lives in social housing.

2. a bigot or reactionary, especially from the urban working class. Adjective: 3. Also, Housoish, narrow, prejudiced, or reactionary: a Houso attitude.

The term 'houso' has long been in common use amongst Australian social housing tenants, signifying identification with a common community experience. While it doubtless has wider currency and forms part of stigmatising language used by non-housos, in the above 'definition' it appears unequivocally pejorative, albeit used satirically. In the Australian context, the use of this term as the title of the programme immediately identifies a subject associated with very specific and welldefined urban spatial localities, evoking well-rehearsed and exaggerated stereotypes and popular perceptions concerning a jobless underclass.

As the programme commenced, a group of social housing tenants approached the Residents' Voices team to collaborate on a research project focused on perceptions of, and reactions to, the programme. Over the nine-week first season of the show participants watched the current episode and responded to key research themes and questions in a creative medium of their choice, such as mobile phone video diary recordings.

The project was designed to create opportunities for social housing residents ('real housos') to develop and express their own knowledge and understanding of the links between place and disadvantage as represented in Housos. A screening of the first episode of Housos was organised at the community centre in an inner-city social housing estate for an audience consisting of social housing tenants and community workers from across the city. The screening was followed by a panel discussion and question and answer (Q\&A) session with audience members and a panel of 'experts' consisting of social housing tenants. The focus was on generating 'community knowledge' through collaboration, discussion and reflection of the television programme. Audience responses to the programme varied on a continuum, with some 'enjoying the show' and others expressing the viewpoint that the stereotypes drawn on in the programme would 'reinforce the stigma attached to social housing'.

In the course of this discussion tenants expressed interest in understanding how different people extrapolate meaning from a programme such as Housos. A second stage of the project thus focused on how tenant 
and non-tenant viewers interpreted Housos, and how their understandings related to the tenants' lived experience.

Participants watched each week's episode in their own time and were asked to respond to the research questions by keeping an informal audio, video or written diary. The videos also captured participants' physical responses and other audio or visual clues - such as facial expressions - when they were discussing an episode of Housos. A final focus group consisting of the two tenant-researchers, a tenant community worker and tenant participant from the study reviewed and interpreted the study data. These data included the tenant and non-tenant audio, video and email diaries and a video recording of the initial expert panel discussion and the Q\&A session. ${ }^{29}$

All of the participant groups used the show as a reference point to discuss real political and social issues around territorial stigmatisation and media representations of class based on their own experiences. They moved between discussing the imaginary characters and events in Housos to real-life social housing communities and policies.

People do assume, simply because I'm on a pension and I live in social housing; I'm a drug addict, I'm a dole bludger, and I'm just the worst that can be. And this [Housos], I think, gives them the right to say they're right, and I'm no good because of where I live and what income I have [in the 'real world']. (Discussant).

I used to be very shy about saying I live in Redfern and I'm not any more. I'm not, because I'm looking at it as a challenge to these other people. (Tenant F2)

...why I got involved in this - was to challenge those public stereotypes. For a lot of reasons, but one is that it's like a chain around people's lives that pulls them back, because you've got all this public stigma that you're battling against when you step outside your designated zone. So that's one part of what this is about. So in this programme that's put on TV, it just heightened all of those public images...(Tenant F1)

However, Housos is clearly fictional, and police and housing managers are targeted by its satire along with tenants. Thus, we were open to the possibility that such a satirical and lampooning representation might have the effect of highlighting the processes of stereotyping and stigma themselves, and thus produce a more reflexive, even self-critical, response in the audience. We also sought to better understand the meaning that residents attached to media stereotypes of themselves and 
their stigmatised neighbourhoods. The deliberately highly exaggerated characters and scenarios in Housos provided an excellent vehicle for resident researchers on the team to explore their own reactions to being represented in this way. Perhaps one of the most telling contributions to the tenant discussion of Housos came in response to a call from one participant for the producers to show more respect for the situation of tenants and to involve and consult them, from a tenant leader who said:

Yes, and we could have given them so much better material than that.

\section{Lost in the woods}

The third example of resident cultural production has its roots in the earlier digital storytelling project, but the transfer of knowledge in this case was by no means direct. Rather, this project provides new insights about the emancipatory power of participant-driven visual methodologies, especially when these practices are freed from the disciplinary constraints of academia and the discursive constrains of talking back to the powerful with policy discourse.

The Residents' Voices team asked Information and Cultural Exchange to run the workshop as a digital storytelling capacity-building project for the academic and resident researchers. Throughout the workshop the university researchers took detailed notes about the structure and content of the workshop. The university researchers wrote this information up in easy-to-read fact sheets and placed these on the Residents' Voices website, largely as a resource for the residents who were completing the workshop. The assumption of the Residents' Voices team, at this point, was that the residents could come back to and use these resources in the future if they decided to create further stories or to train other residents in digital storytelling techniques. However, the residents of one particular street in the Villawood East estate, 25 kilometres west of central Sydney, took up these fact sheets in a different way.

After watching the Residents' Voices digital stories and reading the fact sheets, residents and community workers from the Woodville Community Centre contacted Information and Cultural Exchange to run a similar project in Villawood. Woodville Community Services funded the project. In this project residents took a leading role in all aspects of the production process, and, importantly, this included deciding to produce a film in an entirely different genre. 
Information and Cultural Exchange employed film director Vanna Seang $^{30}$ and creative producer and dramaturg Nicholas Lathouris to work with the residents through the digital storytelling process. The residents worked with these professionals to brainstorm their individual and collective stories, and workshopped and improvised the script. They completed training in locational filming, film directing and film production and acting. Then they directed, shot and produced three films, which they released under the collective titled Lost in the Woods. The centrepiece is a naturalistic fictional drama set in the Villawood estate. The films were showcased as part of 2014 Indi Gems emerging filmmaker festival held in Western Sydney. ${ }^{31}$

The fictional film covers topics that clearly reflect the trope of discourses about public housing, such as domestic violence, community violence and drug dealing. However, the film moves well beyond the commonly deployed narratives about social housing to present lived experiences in a new light. The public tenant filmmakers also address issues of asylum-seeker settlement and detention in Western Sydney, which are largely absent from mainstream media. They challenge the boundary between fiction and experience, with one of the filmmaker residents stating in the film The Making of 'Lost in the Woods', 'Some people could look at it as fiction, but for some people it could touch home'. ${ }^{32}$

\section{Conclusion}

Sociologists have been analysing and exposing the role that the media has played in shaping and reproducing territorialised notions of class and disadvantage for well over a decade. It is clear 'the media' is a key technology through which embellished depictions of class and disadvantage are mediated. These familiar narratives often focus on both interpersonal and neighbourhood-level disorder and crime.

The three resident-led media projects described above did not set out to provide new answers to the questions that might be raised in consultation exercises by housing managers or policy makers, but rather to facilitate the framing of new questions based on the powerful collaboration of local residents in the project design. The cultural analysis and cultural products produced by residents in these projects reconceptualised the media methods and tools that they could access and use to talk back to housing managers or policy makers, and indeed more importantly, to talk back to other housing research methodologies and knowledge systems. Central to this approach to knowledge creation 
is the reconceptualisation of the social actors who design and participate in these media projects. The media products that are produced by the resident groups have the power to directly challenge conventional approaches to understanding place stigma and disadvantage.

On a number of occasions, during these three projects, participants made clear that they needed to talk to other tenants first, and did not feel comfortable or free to discuss their experiences or ideas with housing managers or researchers - especially while redevelopment and relocation was proceeding. A central concern is that tenants in areas targeted for redevelopment have severely limited choice, or voice, in key debates and decisions affecting their living environments, and, furthermore, that conventional policy-driven research on neighbourhood social conditions has effectively devalued the situated knowledge of public housing tenants, compounding their relative powerlessness. These projects aimed to create a space where tenants are able to express, exchange and theorise about the impact of the places they live on their lives, to validate their own knowledge, and to use it in ways which best suit their interests.

As Wacquant shows, the 'social exclusion' of public tenants extends well beyond the individual tenant and the housing management arena. ${ }^{33}$ Residents have long been excluded from the research processes that define the 'problems' with disadvantaged people and places. They have been excluded from producing counter-narratives about these people and places, and they are excluded from the policy discussions about how solutions should be framed and implemented. 


\section{1 \\ Sharing the domestic through 'residential performance'}

Jonathan Orlek

\section{Introduction}

This chapter investigates how performance practice collaboratively reimagines and reconfigures domestic space. In doing so it considers the home beyond private concerns. Stealth and performance art practices explore housing relationally and critically, without losing tools and approaches to act architecturally. In response to privatised and atomised living, many 'residential performances' are identified which use the intersections of architecture and performance art to collectively perform alternative shared domestic realities.

Ethnography is used as a method for commenting on the quality of these temporary domestic spaces and relationships, by finding meaning in architectural processes, negotiations and dialogues. Collective documentation and self-narratives produced by, and through, the identified residential performances are investigated. This leads to the development of autoethnography as an appropriate research method for residential performance projects. The chapter concludes with a work-in-progress autoethnographic study of OPERA: Open Public Experimental Residential Activity, ${ }^{1}$ a residential performance I have initiated with Studio Polpo. ${ }^{2}$ OPERA is a programme of sleepover performances to introduce and test sociable residential uses within vacant city-centre locations. 


\section{Domestic space and the public sphere}

The dominance of the neoliberal world view poses a threat to the idea that society, through collective actions, can shape the way we live. Instead technical procedures tend to ensure that consensus, dictated by the laws of supply and demand, dominates. ${ }^{3}$ This concern, rooted within the 'Right to the City' movement, ${ }^{4}$ views the homogenisation and atomisation of cities as a mechanism for abstracting spaces so that they can be speculated, exchanged and 'policed' by capital. ${ }^{5}$

Individuals, whose conditions for living constrict them to consume, also become isolated and atomised. Henri Lefebvre connects this isolation with the production of an 'abstract space', extending the Marxist understanding that capitalism abstracts social relations to produce abstract labour. 'Abstract space' denies individuals the ability to contribute to the creation of the environment around them by dictating behaviour and spatial organisation according to the laws of supply and demand. Lefebvre points to the 'lived spaces' of everyday life - 'concrete' social relations - as holding the potential to resist its homogenising logic. ${ }^{7}$

Contemporary articulations of democracy have shifted from a single complete "public sphere's towards a negotiation of multiple competing publics, and a struggle between dominant and counter behaviours. ${ }^{9}$ Nancy Fraser suggests that descriptions of a single, rationally articulated and 'public' sphere have always been predicated on exclusions, and argues that the domestic is an example of this:

The rhetoric of domestic privacy seeks to exclude some issues and interests from public debate by personalizing and/or familializing them; it casts these as private-domestic or personal-familial matters in contradistinction to public, political matters. ${ }^{10}$

Fraser points to several 'counterpublics', including women-only voluntary associations, who have historically used the domestic as a 'springboard for public activity'. ${ }^{11}$ This research draws on Fraser's reconceptualisation of the public sphere, to ask the questions: Can domestic spaces address collective and civic concerns? Can the production of spaces for eating, sleeping, washing and so on, create forms of living that are not predicated on isolated consumption? 


\section{Housing as a 'matter of concern'}

Placing domestic spaces within a contested public sphere requires it to be understood through collective and contingent concerns. The work of Bruno Latour can be used to describe this approach as a shift from private 'matters of fact' to collective 'matters of concern'. ${ }^{12}$ For Latour, 'matters of fact' emerged from a modern desire to separate objects from subjects, in order to create static incontrovertible material facts. Latour argues that this endeavour has always been an illusion; 'we have never been modern'. ${ }^{13}$ Reconnected with their complicated entanglements, objects have the ability to gather social and material actants around hybrid 'matters of concern'. Doing so reveals hidden political and spatial geographies:

Each object gathers around itself a different assembly of relevant parties. Each object triggers new occasions to passionately differ and dispute. ... In other words, objects - taken as so many issues - bind all of us in ways that map out a public space profoundly different from what is usually recognized under the label of 'the political'. ${ }^{14}$

Space, therefore, embodies social relations; by creating, conforming to and contesting social relations the objects of architecture are continually made and remade. This demands an understanding that rejects space as an empty container within which the social world can exist and understands it as being inhabited, and performed, by both Cartesian and semiotic objects. ${ }^{15}$

Architectural 'matters of concern', such as housing, can no longer be described in their own static, abstracted worlds alone. Defined instead by their complicated entanglements, they must be performed by humans and non-humans, the material and the social, the technical and the symbolic. Architecture, now understood through is consequences, ${ }^{16}$ has the ability to assemble concrete social relations, rather than represent abstract constituents, providing an ability to act through everyday spaces, in an otherwise imprisoned Cartesian world. Directed towards the domestic, it transforms a fixed private space, isolated from political life, into something which can connect to public concerns.

\section{Stealth practices}

But if the static, abstracted territory of architecture explodes into relational space (if, returning to Latour, 'matter itself is up for grabs'17) how 
is architecture best practised, and how do we direct our tools, skills, technical knowledge, representation techniques and so forth towards the making of housing?

The art critic Stephen Wright has pointed to an emergence of practices which use art-related activities rather than art-specific ones. ${ }^{18}$ Described as 'stealth-art', they exist for specific means and competencies rather than a specific end as an artwork. The practice 'crops up in the everyday not to aestheticize it, but to inform it. ${ }^{19}$ Doina Petrescu suggests that these stealth practices might provide a vantage point for architects interested in relational dimensions to spaces. ${ }^{20}$

[M] aybe a 'stealth architecture' could also exist: an architecture which would deal with architecture-related activities, rather than architecture-specific ones, which would consider architecture in terms of its specific means (tools, competences, processes), rather than its specific ends (constructions and buildings). What would it be, this architecture which 'crops up in the everyday' not to give it a form, but to inform it? ${ }^{21}$

\section{Performance as 'stealth architecture'}

'Performance architecture' is an example of how familiar architectural tools and competencies can be used to unfamiliar ends, to inform the spaces of everyday life. The introduction of the term - used to describe practices which connect performance art with architecture - is credited to both Pedro Gadanho and Alex Schweder, two architects who began using it independently of one another in 2007.22 A growing interest in performance architecture has prompted MoMA to acquire its first 'Architectural Performance' (Ikea Disobedients) in 2011 and Tate Britain to host an event titled Performing Architecture in 2013.

Alex Schweder uses performance art to consider architecture in terms of an evolving relationship between subjects and objects, and through open-ended scripts. He argues that 'through performance and performativity, traditional conceptualisations of architecture can be unpacked, altered, and reconfigured to produce environments where the distinction between the life of the subject and the architectural object becomes productively unclear. ${ }^{23}$ Although architecture can be understood as a sequence of performances, ${ }^{24}$ Schweder suggests that the habit of prescribing fixed programmes prevents this trajectory from being explored. 'We have to dislodge our habits of thinking about the 
way architecture works with the subjectivities that occupy it, from proscriptive (program) to exploratory (performance). ${ }^{25}$ Doing so reveals a transformatory potential:

[C]onstructing architecture around the way we 'perform' it offers its occupants agency in determining who they become in relation to a space and having that space facilitate their desires, hopes, anxieties and needs. Carried out to this concept's ideal extreme, occupants of buildings become partial authors of their environments as well as producers of their meanings. ${ }^{26}$

\section{Residential performances}

There are several projects which use performativity and performance art practices to reinterpret and reconstruct domestic spaces. These 'residential performances', defined here, use familiar architectural tools within an expanded relational space to question conventional distinctions between the domestic and the urban, or the private and the public. They use live, immediate and durational events to perform alternative ways of living alongside one another, and create alternative sites of debate. Three residential performances are presented here. The alternative domestic relations that are performed have all been temporary, or 'micro-utopian', ${ }^{27}$ but they all contribute and respond to long-standing personal, familial or collective projects.

\section{Ikeo Disobedients}

Ikea Disobedients is an architectural performance by Andrés Jaque Arquitectos. It builds on research based in New York City which identified a number of households who transformed their home into social and political spaces, by inhabiting unusual spaces, constructing alternative economies or living in atypical families. ${ }^{28}$ For Andrés Jaque Arquitectos, these households demonstrate how disobedient domestic behaviour can accommodate unique political activity:

Disobeying IKEA's injunction to certain social interactions within sunny apolitical home enclaves is what we propose as an urban counter-notion to the domestic. Not a neutral space but one installing controversy and disagreement precisely at the site where affections may also emerge. ${ }^{29}$ 
During gallery-bound performances, these disobedient households act out some of their everyday activities within an elaborate stage made from improperly assembled and stacked Ikea furniture. Fixed separations between spectators and performers are avoided and the disobedient households invite the audience into their regular domestic experiences, opening them up to frictions and discussions. ${ }^{30}$ The disobedient's 'unconventional domestic approaches challenged the apolitical ideal of "the independent republic of your home", as well as demonstrating the richness of social interactions that straddle the public-private divide'. ${ }^{31}$

\section{EXYZT}

EXYZT initiates temporary architecture projects by socialising, working and sleeping in empty and unusual sites. Formed in 2003 by five architects including Nicolas Henninger, it now operates as a collective of regular collaborators including graphic designers, cooks, DJs and pyrotechnicians. EXYZT's projects bring together collectives and friends to construct ambitious living spaces (often including swimming pools, saunas and nightclubs) for themselves, before opening the temporary spaces up to a broader public - who share what they have made and suggest further contributions. Henninger describes this process as an extension of hosting guests:

Where is the place you can host people the best - it is your place. When you want to invite your friends for dinner and you want to please them you host them. It is an extension of that feeling; where it meets with the public. ... We are making a private space where we host the public. Where is the border? ${ }^{32}$

EXYZT played with this domestic border during the 2006 Venice Biennale, where they worked with Patrick Bouchain to inhabit the French pavilion. To satisfy Biennale rules they placed a clear yellow line between the public and private areas but transgressed this by hosting parties, meals and inviting people to use their sauna and plunge pool. Henninger describes how the private-public divide was carefully staged. '[Patrick Bouchain] was 60 years old and he tricked them all! We said this is the line; this is private, this is public. [The commissioner] could see the yellow line. ... But who can really tell you that you can't invite someone from the public into your private space?'33 
The Institute for the Art and Practice of Dissent at Home is a family of six: Gary Anderson, Lena Simic and their four children. ${ }^{34}$ They have all agreed to use their family unit to find ways of acting against capitalist culture. 'We have decided to ask questions around art and culture, money and capitalism, private and public, familiar and civic life. We have decided to disobey. We as a family have decided to be naughty. 35

With the goal of 'a workable model for cultural dissent based in a family ${ }^{36}$ they have made their spare bedroom into a meeting place for artists, activists and cultural dissenters, turning conversations and actions that would normally be carried out in private into public behaviours, analysed and interrogated as performance art events. "Through the simple act of placing the family within the frame by designating the spare bedroom the institute and documenting family activities as assiduously and seriously as any art event, the day to day activities of the family are reframed as ritualised public performances that are denaturalised and laid open to scrutiny. ${ }^{37}$

The Hazardous Family is a picnic performance by the Institute, which took place in Parsonage Park in Manchester as part of the HAZARD Festival in 2008. During the performance, Gary and Lena took it in turns to recite excerpts from Marx and Engels' writing on the family, while the children ran around in the background, eating picnic food. The event fulfilled a familiar practical requirement (finding a space to feed the family when away from home), whilst concurrently critiquing the Institute's heteronormative actions in front of an audience.

\section{Interpreting residential performances}

\section{Commenting on the quality of residential performances}

The residential performances described here demonstrate in different ways that alternative, collective forms of living can crop up in everyday spaces. They have all opened prototypical domestic realities to new audiences and participants to trigger action and debate. A question which remains is how initial claims for the creation of 'counter publics', however small or fleeting, might be critiqued or commented on. How does the public behaviour of the Ikea Disobedients change the day-to-day experiences of MoMA's visitors when they leave the 
gallery? Do EXYZT's transgressing guests behave differently when they leave the inhabited pavilion, on the right side of the yellow line? Do audiences or passers-by viewing the Institute's family performances return to normal family life?

To develop responses to these questions, the social and material relationships that are performed through these experimental residential projects need be followed, allowing personal processes of participation, invitation and transformation to be articulated. Albena Yaneva has explored how ethnography can be used to find meaning in the processes and controversies of architecture. ${ }^{38}$ For her, this methodological approach has been adopted to directly confront the dominance of critical theory, and its obligation to find meaning in architecture by applying symbolic social meaning to abstracted technical matter. In order to undertake 'an ethnography of design', Yaneva situated herself within the Office for Metropolitan Architecture (OMA), an architecture practice set up by Rem Koolhaas. ${ }^{39}$ Between 2002 and 2004 she 'lived' in the Rotterdam office, following the architects as they made and communicated tentative decisions and assembled around foam 'design objects'. She found meaning in the everyday, tentative practice and performance of architecture and recognised that architecture was a collective and co-operative activity performed by many actors including architects and non-architects, humans and non-humans. Yaneva embedded herself within OMA and commented on the routinised actions and objects of architecture from the position of participant observer. She maintained a clear divide between herself, producing research, and the OMA, producing architecture.

\section{Self-narratives}

Many of the live events that have been discussed are accompanied by selfmade films, scripts and photographs that follow the life of the project. The Ikea Disobedients performance is accompanied by a short film, made with stop-motion footage and a voiceover. It introduces the domestic lives of a number of disobedient subjects and critiques the Ikea catalogue for its dominance of white and blonde protagonists and fixed notions of family. This remains a publically accessible, archived work on the MoMA website..$^{40}$ EXYZT also use films, made by members of the collective, and shared via YouTube. ${ }^{41}$ During the inhabitation of the French Pavilion five short films - the Metavilla Sessions - were made that reveal some of the more hidden activities, including the construction process, the bed spaces and the sauna parties. Stop-motion, time-lapse and amateur footage is set to music, and participants directly perform to the camera. 
For The Institute for the Art and Practice of Dissent at Home, selfproduced documentation is used as a mechanism for framing everyday family rituals as artworks, elevating them to the status of a scripted performance event. This confuses conventional boundaries between domestic activities and shared activities that are opened to public scrutiny. Scripts, instructions and transactions of the Institute's performances are recorded and have been subsequently published. ${ }^{42}$ Unedited DIY/audience footage of performances is also made available through YouTube. ${ }^{43}$

The close relationship between the live durational performances and multi-format documentation could provide a rich space for architectural ethnographic research, if a reflexive ethnographic position is adopted. Since the live residential performances and accompanying 'field notes' are produced by the same authors (both individual and collective), autoethnography is explored as a method for researching residential performances. Autoethnography allows the researching and making of residential performances to be undertaken together, recognising a role within architectural research and practice for a knowing subject.

\section{Autoethnography as a research method for residential performances}

Reflexive ethnographic positions, such as autoethnography, ${ }^{44}$ allow researchers to understand and write about residential performances as an active co-producer and collaborator, rather than an embedded participant observer.

[Reflexive accounts] have the effect of transforming the 'cultural' text into a speaking subject, ... who sees as well as is seen, who evades, argues, probes back. ... It obliges writers to find diverse ways of rendering negotiated realities as multisubjective, power-laden, and incongruent. In this view 'culture' is always relational. ${ }^{45}$

Autoethnography has been developed primarily within communication and education studies, ${ }^{46}$ and describes writing that 'tells about a culture at the same time as it tells about a life'. ${ }^{47}$ Autoethnographies can include ethnographers studying their own culture, the use of personal narratives by ethnic minority groups and the creative use of personal experiences within ethnographic writing. ${ }^{48}$ 
Carolyn Ellis suggests that it can be used as 'an avenue for helping us understand narratively and conceptually a larger relational, communal and political world of which we are part and that speaks to critical engagement, social action and change'. ${ }^{49}$ Since the relationship between the production of a community and the self is a dialectical one, through describing a personal transformation as an active participant autoethnographers are not only describing an individual experience but also the wider relational community that they have actively co-produced. 'If culture circulates through all of us, then how can autoethnography not connect to a world beyond the self?'50

Storytelling becomes an important communication tool in autoethnographic research. By describing a personal process of negotiation, vulnerability and transformation, autoethnographic stories provide the ability to offer one of many voices that have been transformed through residential performances, whilst also commenting on wider cultural experiences. Deborah Reed-Danahay argues that autoethnographic writers can 'assert alternative forms of meaning and power from those associated with the dominant, metropolitan culture'. ${ }^{51}$ Autoethnographic storytelling could therefore provide a critical framework for researching collective housing projects attempting to seek alternatives to dominant forces of atomisation and privatisation.

\section{OPERA: a work-in-progress architectural autoethnography}

Within Studio Polpo I have started to develop an autoethnographic study of one of our ongoing shared living projects: Open Public Experimental Residential Activity (OPERA). OPERA is a series of sleepover performances that we have initiated within vacant citycentre locations. Initially conceived as a way to test shared living in an immediate, live and prototypical way, the OPERA programme has developed into a longer-term programme of events, writing and prototyping.

The autoethnographic research method developed for OPERA draws on a study by Emma Gieben-Gamal and Juliette MacDonald, two female academics who have researched their personal use of laptops. ${ }^{52}$ They use autoethnography as a stimulus for examining how their laptops, as mobile offices, transform public and domestic spaces. Using diary entries, written over a three-month period, they describe how domestic spaces can become "more than "home"' through specific, 
gendered, negotiations and transformations. ${ }^{53}$ They combine firstperson storytelling with academic writing to connect lived experiences with theoretical analysis, and use this approach to open a wider discussion about the boundaries of private space and the desirability of embedded technologies for interior architectural design. ${ }^{54}$

About OPERA: open public experimental residential activity

In 2014 Studio Polpo responded to an open call for artists to exhibit work in an empty former department store in Sheffield city centre. Our accepted proposal, framed as a durational performance, led to the

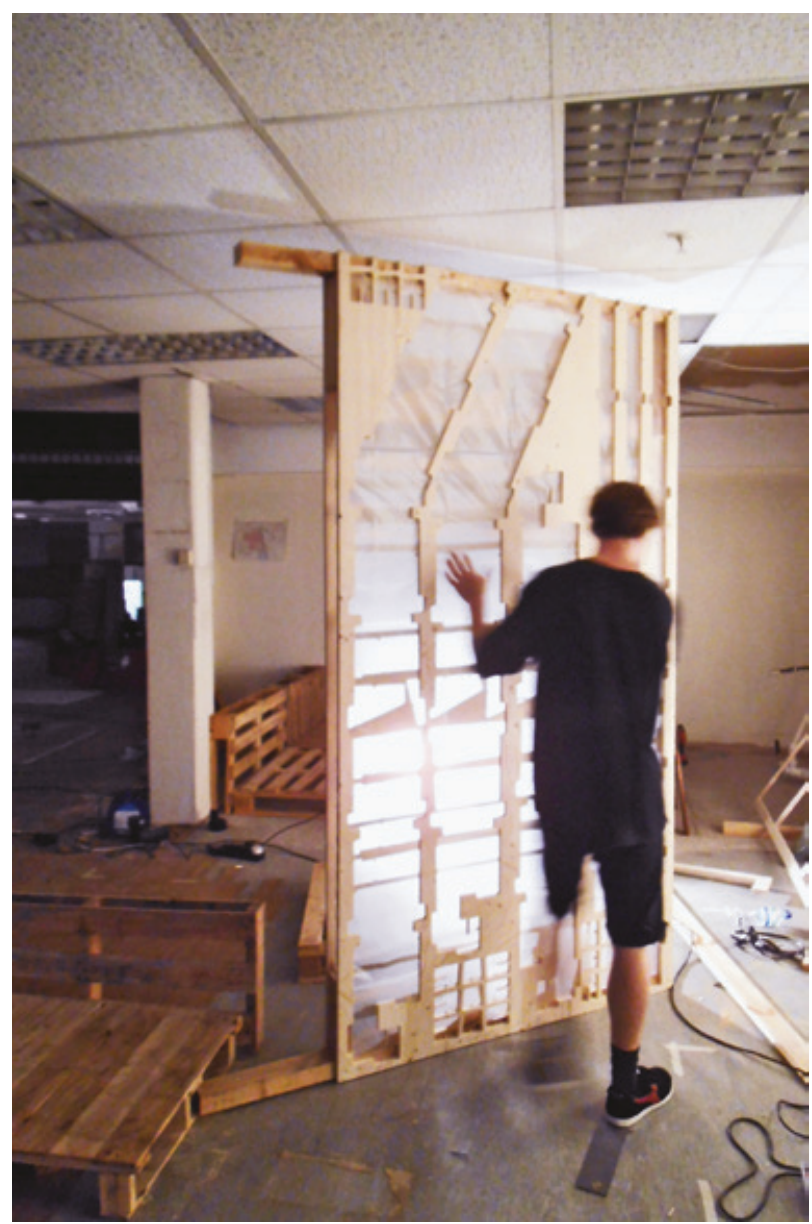

Figure 11.1 Building OPERA 1 partitions using plywood reclaimed from $\mathrm{CNC}$ manufacturing process. 


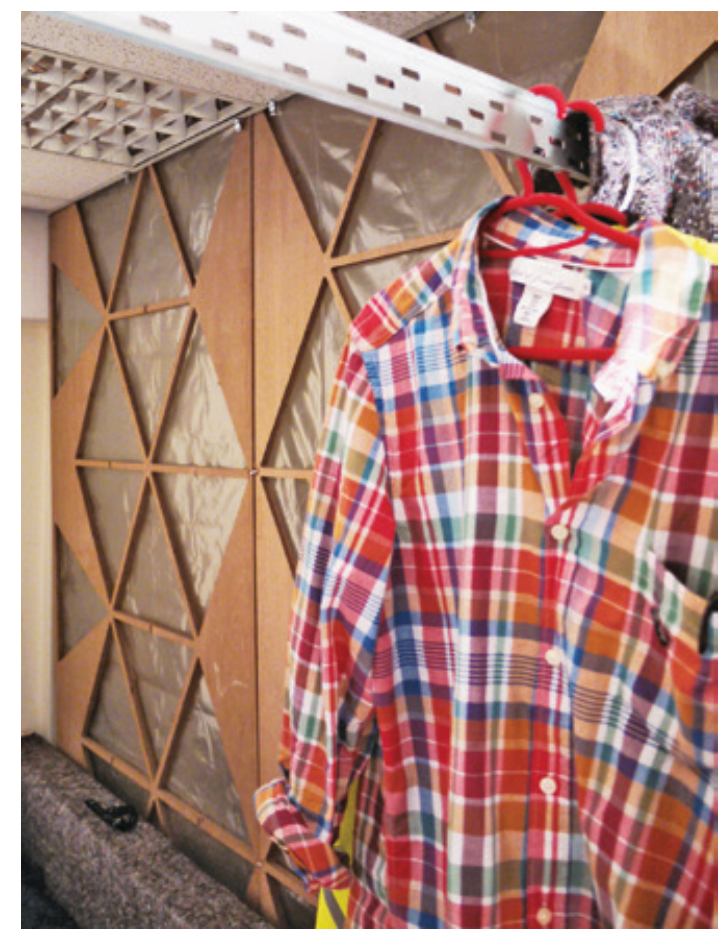

Figure 11.2 A private bed-space in OPERA 1.

installation of eating, sleeping, cooking and eating facilities into part of the vacant building (Figures 11.1-11.5). OPERA 1 was open for 10 days (the duration of a curated group exhibition) and each evening Studio Polpo invited guests to share a meal, host domestic activities and stay the night. Up to six residents shared the house overnight, including Studio Polpo directors, our friends and members of the public. The evening meal usually prompted discussions about shared forms of living, empty spaces, and city-centre living. Some evenings residents arrived with specific activities to share, including a screening of short films about alternative living arrangements, screen printing, haiku poetry writing, impromptu music making, and a workshop about accessible toilet design in relation to LGBTQ (lesbian, gay, bisexual, transgender and queer) issues. In addition to the residents who contributed in the evening and overnight, a large number people visited the exhibition during the day. This created two types of interaction with the project: a quick, usually unexpected, visit and a longer arranged evening and overnight event. 


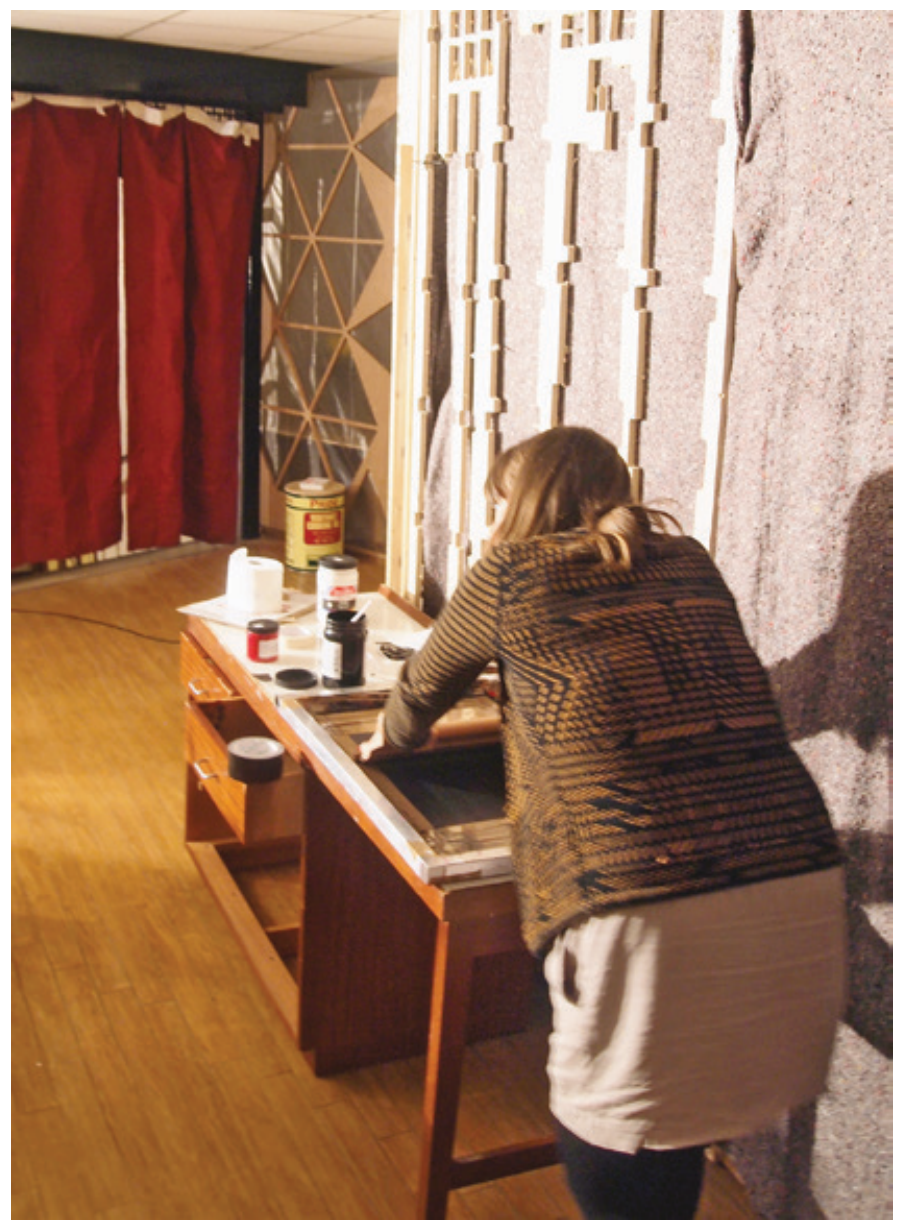

Figure 11.3 Screen printing evening event during OPERA 1.

After the intensity of the 10-day round-the-clock performance, Studio Polpo developed OPERA into a continued and more sustainable performance programme. We adopted an alternative format, a one-day-a-month sleepover event, so that the overnight performances were compatible with other work and family commitments and, generally, life outside the performance. The infrastructure of OPERA 2 (the kitchen, bedrooms, dining area, sink, room dividers etc.) was physically nestled within a larger creative arts space, ${ }^{55}$ occupying a substantial empty retail unit through a meanwhile use agreement with the landlord. This time OPERA also began to develop a life outside of 


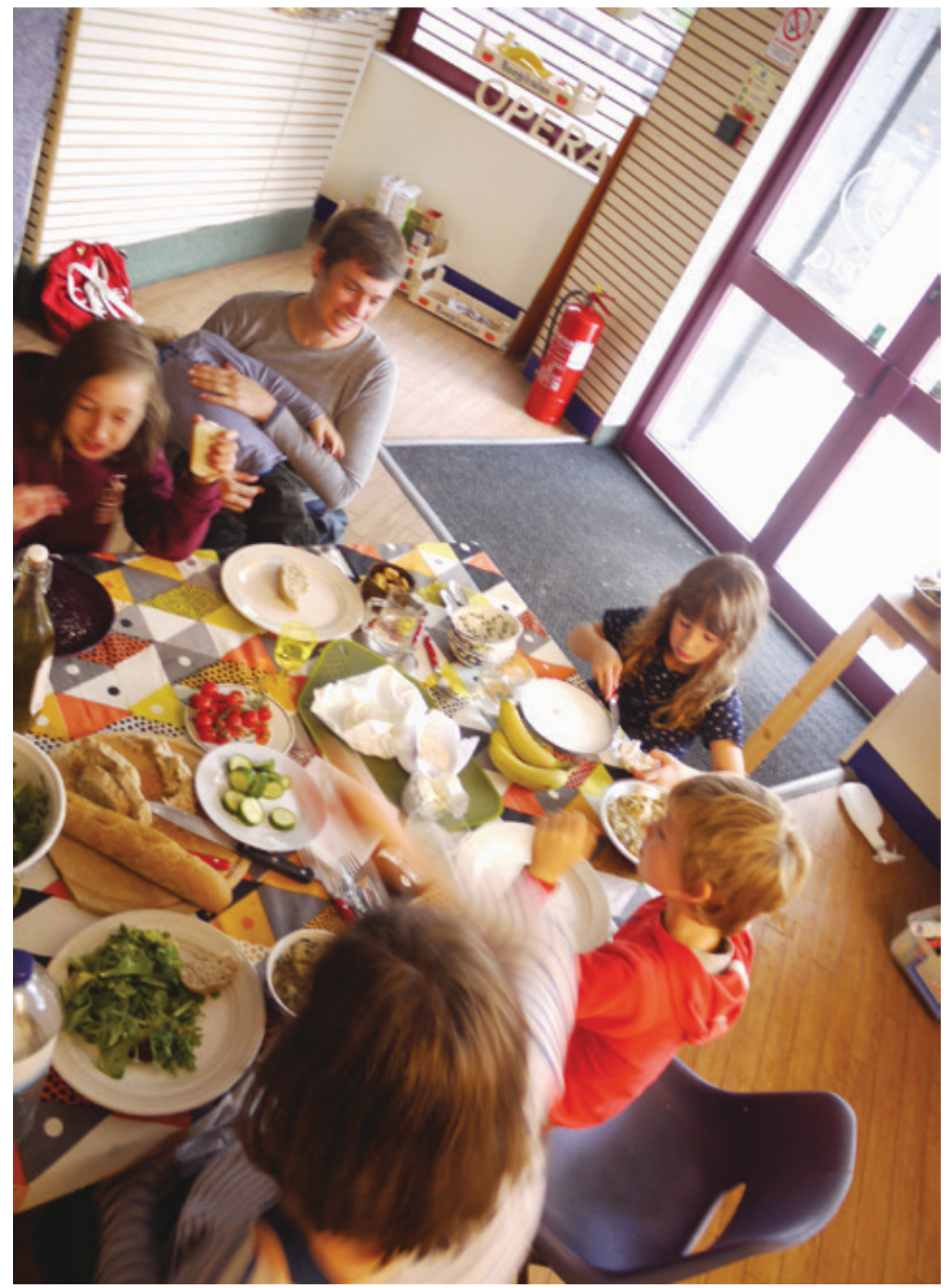

Figure 11.4 One of many shared meals during OPERA 1.

the performance: although the event was curated and performed by Studio Polpo once a month, other groups borrowed the infrastructure to host activities, including intimate theatre performances and spoken-word events.

Starting out as an experimental shared living space, OPERA has developed into a broader programme of performances, writing and research (Figure 11.6). We anticipate that future OPERA activity will 


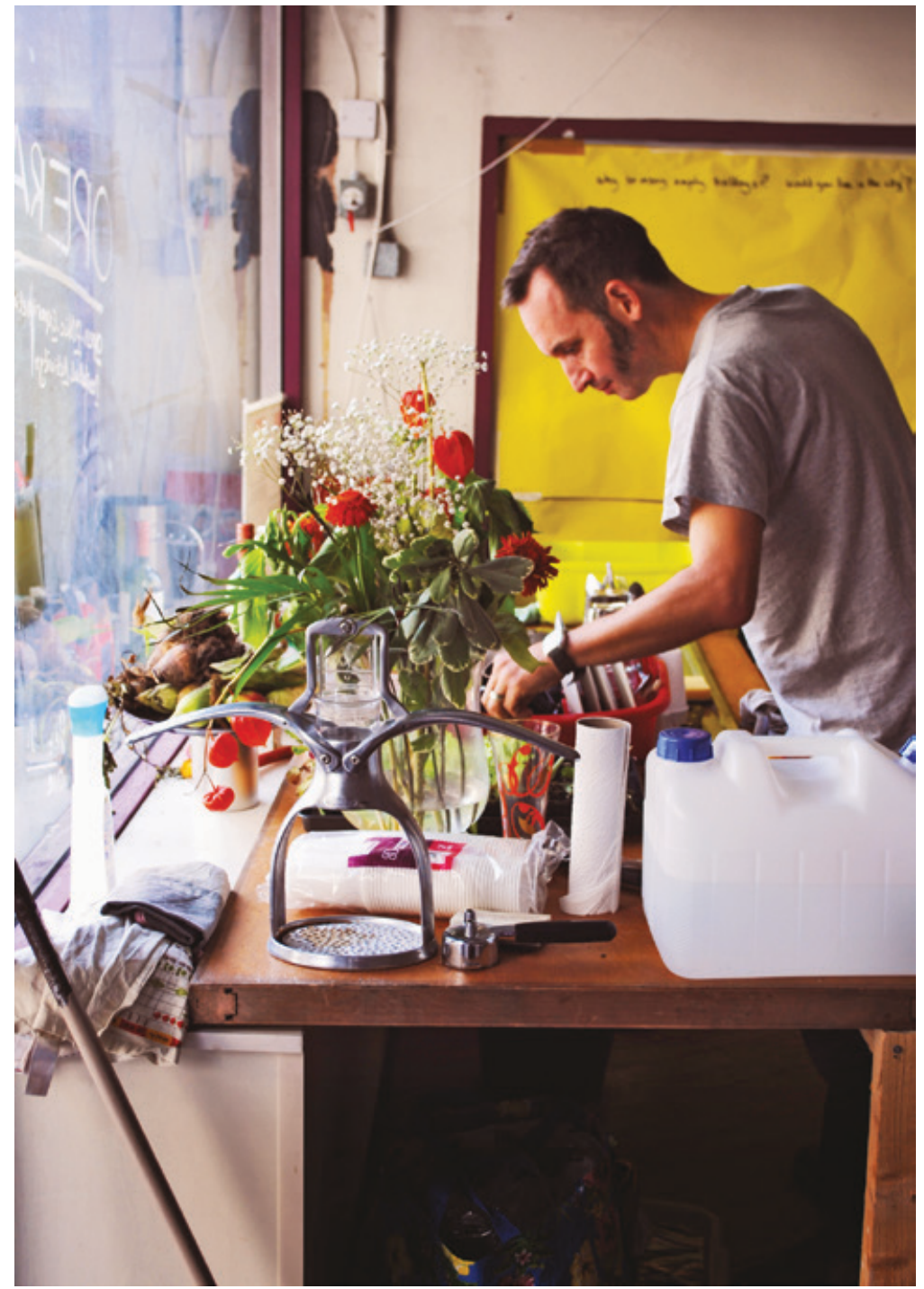

Figure 11.5 Doing the washing up at OPERA 1, with a view to the street.

continue to activate vacant buildings, testing different locations and performance formats. In addition, members of Studio Polpo are also exploring an OPERA model which would incorporate elements of the performance into a longer-term and financially independent hosting facility. 


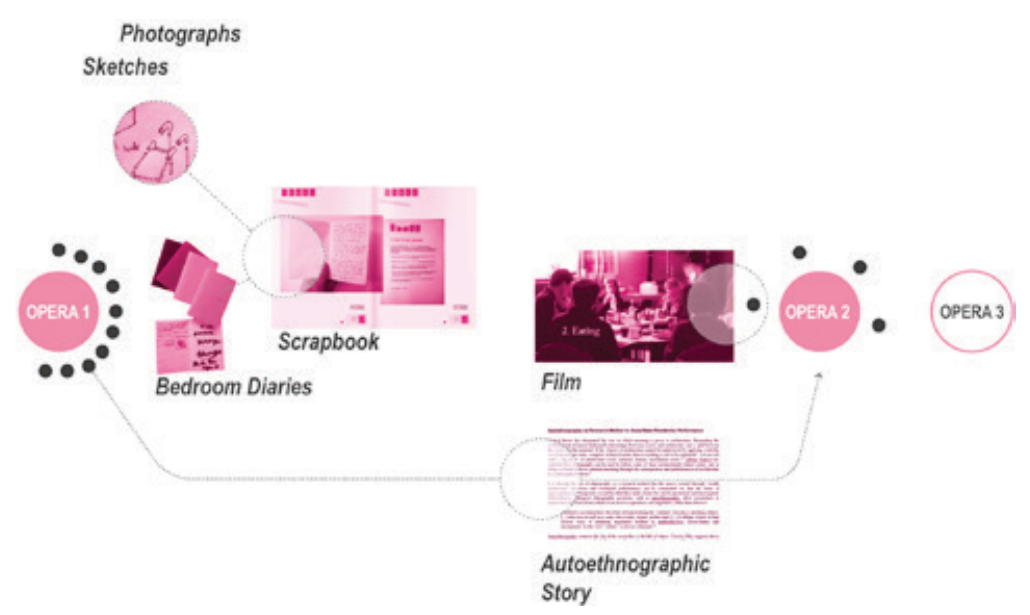

Figure 11.6 Mapping showing how writing and documentation have become an integral part of the OPERA prototyping practice.

\section{An autoethnographic study of OPERA}

During OPERA 1, Studio Polpo decided not to record much of the performance. This was motivated by a desire not to alter the dynamics of the participant interactions as well as practical limitations on our time due to demands of delivering the performance itself. The documentation was limited to occasional photographs and blog writing. ${ }^{56} \mathrm{~A}$ journal was left in each bedroom and guests were encouraged to write about the evening before going to sleep. Many of the guests wrote brief reflections on their experience of taking part in OPERA, revealing their apprehensions, concerns and pleasures. In many cases participants found ways to relate and compare experiences to their everyday life and to wider society. On completing OPERA 1 Studio Polpo published a scrapbook of notes, sketches, ephemera and diagrams which had been collected, left or found throughout the performance..$^{57}$

Between completing OPERA 1 and starting OPERA 2 I reviewed the diary entries and scrapbook; recollected from memory several regular rituals, conversations and thoughts; and made note of specific one-off events and interactions. These captured aspects of the project that were valuable to me and provided field notes from verbatim diary entries, memories and scratch notes, leading to the writing of an autoethnographic short story.

My field notes, collected and related to the whole of the 10-day OPERA 1 performance, were condensed into a story that was narratively 
structured around one 24-hour performance cycle. The use of creative writing, and the augmentation of time, was used to create an engaging account without diverging from the conventions of creative non-fiction. ${ }^{58}$ An extract from this autoethnographic short story, presented at the Housing: A Critical Perspective Conference, Liverpool, 8-9 April 2015, is reproduced below:

I have finished serving up the vegetable dahl, slow cooking since lunchtime, and we quickly begin exchanging our day to day experiences at home and the potential benefits and annoyances of living collectively. 'I absolutely can't stand it when the neighbours burn plastic in their garden.' Jo energetically announces.

Familiar architectural conversations - about meanwhile use, co-housing, relational space making - seem to find resonance with Rats' experiences. 'Communardism has never had a better time for growth with the depletion of affordable housing stock.' But his anecdotes and ideas quickly change the dynamic of the conversation, preventing academic discussions from dominating and forcing them to become, I don't know, more creative? I am pleased that the project resonates with his experiences; it offers some reassurance that the project can accommodate multiple overlapping needs, interests, and desires. Rats wouldn't come if this was a twee pop up! I think to myself...

I start to clear the plates from the table. 'Leave it to us' jokes Adam 'If you take too much responsibility this will become your house!' I smiled, retreating from the makeshift sink and towards one of the bed spaces. It's a nice quote, I think, stopping my train of thought to consider the relationship between hosting and losing control. There seems to be a continual friction between the two. I want people to have a good time, I want people to enjoy the meal, I want discussions to be stimulating and diverse. But I realise that the structure of the OPERA residencies should not afford me the ability to control this. It is great that conversation and drink are flowing tonight, but the possibility for this not to be the case should always remain open.

Tonight, Ian has arrived with some short films for us to watch and two of the bed spaces have been adapted to make a mini cinema. It feels cosy; people are sat on beds and stools, filling the full length of the private area. After four or five films we all agree to go to bed, and head upstairs, as a group, through the expansive empty exhibition to the toilets where we can brush our teeth. ${ }^{59}$ 
Writing has provided a method of inquiry as well as way to communicate the project both individually and collectively with a view to shape future OPERA events and shared living projects. ${ }^{60}$ Reflective, personal and collective writing styles have been used to find meaning in the convivial, sociable and mundane exchanges facilitated through the sleepover performances. Writing was also used to communicate the material performance set, without isolating it from the production of a social and relational project.

With other members of Studio Polpo, different styles of writing have been used (autobiographical, diary notes, academic) to develop accounts of OPERA which connect theoretical motivations and contexts with personal experiences and actions. Storytelling and the creation of alternative housing narratives have become an intertwined part of OPERA, viewed as part of a wider prototyping practice within the studio. ${ }^{61}$

\section{Reflections on residential performance}

\section{Practising residential performances}

The residential performances, including OPERA, stealthily nestled themselves within prominent spaces in the city, challenging boundaries and borders, sometimes by playfully altering physical thresholds, sometimes by diligently complying with organisational rules as part of the performance. Hosting, curated invitations and unpredictable encounters became a way to bring audiences across conventional institutional borders and into prototypical domestic spaces.

Performance practices can be adopted by architects to peek into a world beyond the protection of Cartesian representation, and open the making of domestic spaces to collective concerns. Framing OPERA as a performance allowed Studio Polpo to use familiar architectural tools and skills (designing room layouts, working with fabricators, communicating with stakeholders) but deploy them to unfamiliar and open ends. We were not interested in fixing and prescribing spaces or uses, instead motivated to create an open framework for testing, playing and experimenting with others. In order to adopt this position, we framed the project as an art commission, testing the accepted boundaries of our discipline.

OPERA has provided a relatively low threshold for participation in collective living; the performances have fitted within existing living and 
working patterns, taking individuals out of these for one night to act and imagine otherwise. However, it connects into a wider practice of shared living within Studio Polpo, which includes art commissions, newspaper publications, feasibility studies and co-housing design. OPERA has, in some instances, functioned as a taster for further commitment that our longer-term projects have supported.

\section{Researching residential performances}

As the city becomes increasingly controlled by supply and demand, and conventional sites of counter-public representation (such as the coffeehouse or city square) allow no ability to act outside of marketised consensus, perhaps the home is a good place to begin constructing social, lived space? Although revisionist understandings of public spacemaking reveal hidden political roles for the home, domestic settings are usually used to address specific inequalities and gender struggles. ${ }^{62}$ The intention of this research has been to demonstrate how shared domestic experiences can also be used to confront wider social, economic and cultural questions.

This research also contributes to a wider discussion about the cultural value of artistic practices and an established need for deeper understandings of 'the processes (rather than outcomes) of arts engagement', especially within policy making. ${ }^{63}$ Autoethnographic storytelling has opened the possibility of researching and articulating the processes of OPERA rigorously and reflexively, as both a project co-producer and researcher. The use of theory, peer practices and personal storytelling has allowed Studio Polpo to construct invitations, boundaries and physical interventions within our work with raised awareness; it is hoped that collaborative ethnographic approaches could be used in the future to inform longer-term shared living projects and housing narratives as well as to capture participant experiences and engagements with emerging contemporary art practices directed towards domestic space. 


\section{2}

\section{Contesting 'dilapidated dwelling'}

Matthew Thompson

\section{Introduction}

In this chapter I take off from where others have landed; first from psychogeographer Patrick Keiller's essay, and film of the same name, 'The Dilapidated Dwelling, ${ }^{1}$ in which he presents the remarkable insight that

Under advanced capitalism it is increasingly difficult to produce and maintain the dwelling ... Modernity, it seems, is exemplified not so much by the business park or the airport, but by the dilapidated dwelling. ${ }^{2}$

By this Keiller means the ageing building stock that constitutes our domestic property, what he calls 'old space', which in the UK is the oldest and most underinvested housing in Europe, at an average age of 60 years. This he distinguishes from the 'new space' of mostly corporate economic activity - shiny sheds, retail units, offices, business parks and transport infrastructure - mostly built in the last few decades and replaced at a rate befitting the hyper-mobility and flexibility of late modernity. Such a discrepancy in investment between domestic and commercial property, Keiller argues,

Is especially odd given that dwellings constitute the greater part of the built environment, that they are the spaces where most people spend most of their time, and where what is arguably the 'real' work of society is done. ${ }^{3}$ 
This last point alerts us to the idea that dwelling is not simply a material or physical object, but also a setting for the 'work' of society, and indeed the activity of living itself. The question for this paper is how to resolve dilapidated dwelling(s) - in both a material and social sense. It draws on the insights of John F.C. Turner - that dwelling is not simply a noun, but also a verb; a social activity, defining the active dynamic process of social reproduction as much as the relatively static material building that facilitates it. ${ }^{4}$ On this reading, Keiller's 'dilapidated dwelling' becomes an expansive metaphor for urban life in general: the relative dilapidation of 'old space' compared to 'new' is just the physical manifestation - the symptomatic expression - of a much deeper dilapidation in the collective activity of dwelling; the dialectical flipside of over-accumulation of capital.

The 'dilapidation' of dwelling - in these multiple senses - takes on greater weight in those deindustrialising shrinking cities, the old heartlands of global industrial production, long suffering from capital flight and urban decline. Many cities around the world are now facing the 'wicked' problems of mass unemployment, deprivation, depopulation, housing market failure, neighbourhood abandonment, crime and social unrest. ${ }^{5}$ This is particularly salient for one city in particular, Liverpool, whose severe economic decline - its fall from grace - has left it dealing with such tricky problems since the late 1960s. At its height as a world city, Liverpool was one of the biggest global seaports, the logistical nerve-centre of the British Empire at its apex. The seeds of decline were sown in the early twentieth century as the British Empire began to retract, and Britain's trading partners shifted away from Atlantic-facing colonies thereby leaving Liverpool, in Tony Lane's oft-quoted maritime metaphor, 'marooned on the wrong side of the country'. ${ }^{6}$ This longterm structural shift slowly destroyed the port-based economy upon which Liverpool's wealth and purpose was built. ${ }^{7}$ The consequences for the inner-city neighbourhoods reliant on port-related work were catastrophic. Unemployment followed by rapid population loss was exacerbated by the council's post-war slum clearance programme and comprehensive redevelopment policies, which rehoused much of the population in outer estates and new towns. Around three-quarters of the docklands population were lost, with up to 60 per cent unemployment rates for those left behind. ${ }^{8}$ Many neighbourhoods were tipped into a spiral of decline, in which unemployment and depopulation conspired to create deprivation, housing vacancy and dereliction, whilst the council was left with diminishing tax income to pay for rising public improvements and regeneration costs (Figure 12.1). 
(a)

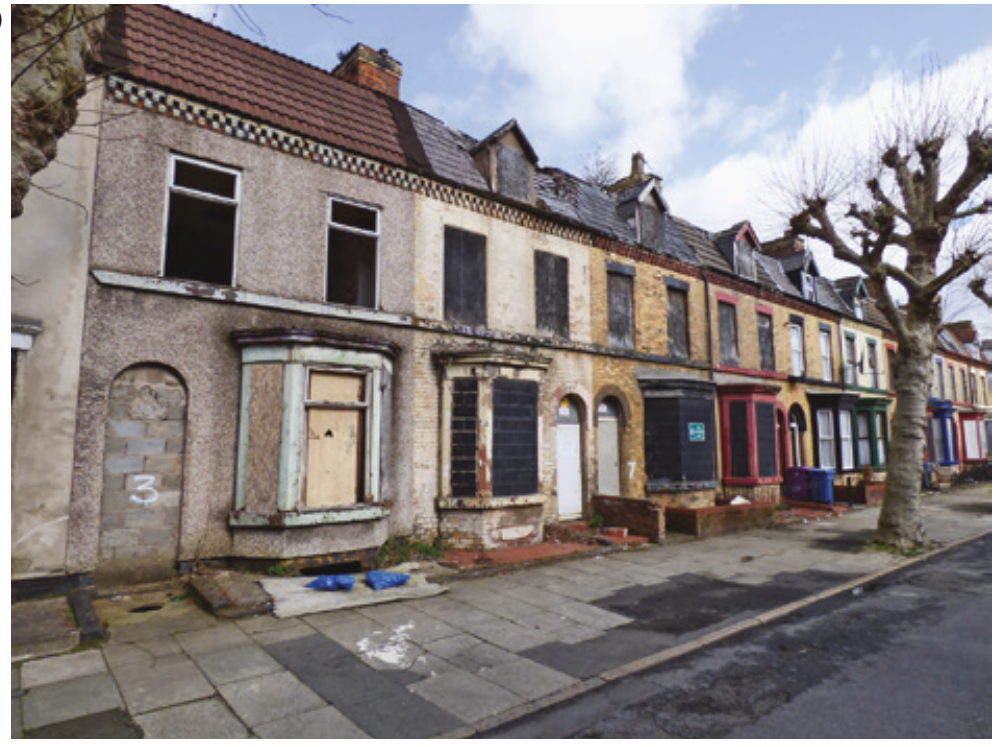

(b)

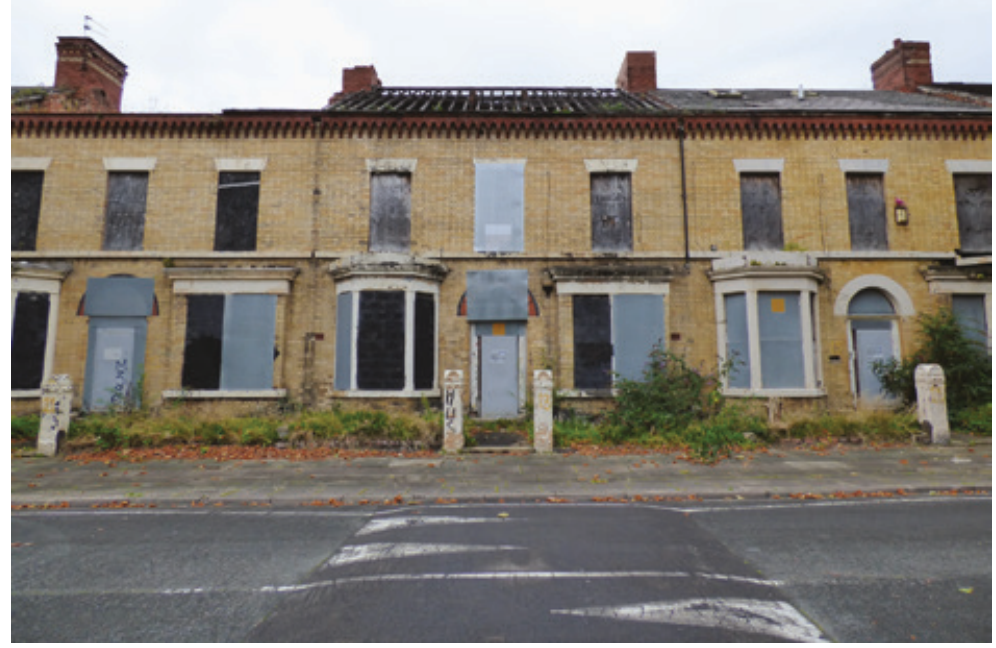

Figure 12.1 A familiar image of dilapidated dwelling in Liverpool's inner-city neighbourhoods. 
Such 'wicked' problems spurred Liverpool City Council to commission, design and lobby for the government funding of Housing Market Renewal (HMR) Pathfinders, the controversial $£ 2.3$ billion programme rolled out across de-industrialised inner-city areas in nine English cities from 2003 to $2011 .^{9}$ The HMR programme was designed to intervene in failing local housing markets to reverse neighbourhood decline and attract new residents by refurbishing dilapidated housing and replacing 'obsolete' terraces with new desirable housing products. However, in the wake of austerity, it was prematurely cut short, leaving swathes of vacant land and empty homes without the funds for redevelopment. It is now increasingly clear that conventional large-scale housing-led redevelopment has failed to address the problem of dilapidated dwelling - and in many cases only exacerbated it. Liverpool's recent history puts a new spin on Keiller's conundrum as one of the dilapidated neighbourhood or even the dilapidated city. The question now becomes: how to resolve the problem of dilapidated neighbourhoods?

Keiller's insight would be of no surprise to Engels, who in his seminal text on the housing question, saw 'the housing shortage from which the workers and part of the petty bourgeoisie suffer in our modem big cities' - including all other forms of deprivation and dilapidation in housing provision - as just 'one of the numerous smaller, secondary evils which result from the present-day capitalist mode of production'. ${ }^{10}$ Engels derides Proudhon and his anarchist disciples as 'bourgeois reformists', criticising as simply untrue their claim that 'as the wage worker in relation to the capitalist, so is the tenant in relation to the house owner';11 arguing that their 'practical solutions' - self-help housing and common ownership - are futile spatial displacements or mere manifestations of a structural problem, which without total revolution would simply reappear elsewhere. It is not difficult to see how Engels' observations of Liverpool informed The Housing Question. Here, in a passage from The Condition of the Working Class in England, written in 1844, Engels meticulously records the scale of the squalor:

Liverpool, with all its commerce, wealth, and grandeur ... treats its workers with the same barbarity. A full fifth of the population, more than 45,000 human beings, live in narrow, dark, damp, badly-ventilated cellar dwellings, of which there are 7,862 in the city. Besides these cellar dwellings there are 2,270 courts, small spaces built up on all four sides and having but one entrance, a narrow, covered passage-way, the whole ordinarily very dirty and inhabited exclusively by proletarians. ${ }^{12}$ 
Conditions have clearly improved over a century on from the darkest days of industrialisation, but in many respects this is the original problem of dilapidated dwelling with which Liverpool has been struggling to contend ever since. Successive municipal modernist projects to improve such appalling conditions first targeted the dockside slums, replacing them with tenements and tower blocks, which themselves quickly became slums, requiring further redevelopment, whilst the inner-ring of speculatively built Victorian terraces were deteriorating and in need of attention. These council programmes were of a diverse ideological bent: Labour's post-war policies of modernist comprehensive urban renewal; the far-left municipal socialist strategy of the Trotskyist Militant Tendency controlling the Labour council in the mid-1980s; and, in the twenty-first century, what might be described as a neoliberal public-private partnership approach, the HMR Pathfinder programme. Yet all succumbed to the same fallacy.

Throughout his writings, Keiller is fond of citing Henri Lefebvre, whose theory of the (social) production of (social) space is clearly a major influence. ${ }^{13}$ Indeed, it is no great leap to see how the relative dilapidation of dwelling, compared to corporate new space, is an expression of the relative power of exchange value over use value in the sociospatial production of urban space. The domination of 'abstract space' over 'lived space' is what Japhy Wilson has emphasised in Lefebvre's work as the 'devastating conquest of the lived by the conceived'. ${ }^{14}$ To help unpick the politics and prospects of resolving dilapidated dwelling - as both material setting and social activity - I draw on the theoretical insights of Lefebvre, to argue that 'housing-led' regeneration, focusing narrowly on built structure, erroneously treats the symptom rather than the root condition: locating the problem at the door of the housing 'product' itself rather than the myriad socio-economic relations and cultural processes flowing through it and materialising in dilapidation. I sketch out an alternative vision that attempts to reconnect the ends and means of dwelling - building on Turner's insight - in alternative collective housing practices, such as cooperatives and Community Land Trusts (CLTs). This chapter draws on recent critical interpretations of the concept of abstract space, ${ }^{15}$ as well as my own doctoral research on Liverpool's recent alternative public housing history, to suggest how successive housing-led regeneration approaches have failed to resolve persistent dilapidated dwelling in Liverpool.

My second point of departure is Robert MacDonald's essay 'The City as a Laboratory of Shadows: Exposing Secret Histories While Thinking of the Future', in which he draws our attention to Liverpool as a city of shadows: ${ }^{16}$ an urban laboratory of experiments, ideas, images, 'absent 
presences', inconvenient truths, contradictions, hidden myths, radical ideas and possibilities. Closely related is Lefebvre's notion of 'experimental utopia': ${ }^{17}$ testing out in the present through concrete material forms and social practices the utopian visions and conceptual horizons of radical urban transformation. Liverpool has a hidden or 'shadow' history of experimentation in housing, in which two moments of utopian possibility are significant. First, in the late 1970s Liverpool produced one of the largest, most concentrated and most innovative working-class movements in co-operative housing in British history. The first new-build co-op to be campaigned for, designed, owned and managed by its working-class resident-members, the Weller Streets, was the pioneer in a new form of co-operative housing incorporating radical new ideas around dweller control and design democracy - and inspiring successive groups of council tenants to develop a new wave of new-build co-ops across Liverpool. ${ }^{18}$ The democratic moment of the 1960s that spawned the movement soon faded - and political changes in urban governance and deeper structural shifts conspired to arrest their further development - but the movement nonetheless left a legacy of some 50 co-ops still functioning today, providing a vision of how dilapidated dwelling could be approached differently.

Fast forward to the twenty-first century, and a second democratic moment, following the 2008 financial crisis, has inspired a new generation of mutual alternatives to public housing and neighbourhood management. In 2011 - the 'year of dreaming dangerously' as Žižek puts $\mathrm{it}^{19}$ - some of the country's first urban CLTs were established in Liverpool as legal entities, the first step towards successfully applying the CLT model to a disinvested urban context. ${ }^{20}$ Granby Four Streets CLT and Homebaked CLT are innovative projects aiming at acquiring and rehabilitating for community use the terraced housing and local assets left vacant and derelict by successive large-scale state-led urban renewal programmes, notably HMR. ${ }^{21}$ These CLTs mirror the co-ops that went before them, emerging out of grassroots campaigns against the demolition and displacement of communities wrought by top-down modernist urban renewal programmes. They share an antipathy towards the monolithic, universalistic, technocratic, bureaucratic, alienating - and commodity fetishising - approach of the latter, tending to be more spatially piecemeal, temporally incremental, socially inclusive and politically experimental. Although different in institutional design, co-ops and CLTs are united by a shared aim of reconnecting the producer and user of housing (the means and end of dwelling), aspects which propertyled regeneration serves to keep apart, to be achieved through participatory design and development methods and the democratic collective 
ownership of land and housing. The final part of this chapter draws comparisons between Homebaked CLT and the 1970s co-op movement; by way of conclusion, I offer some reflections on the nature of 'experimental utopia' in the context of abstract space.

\section{Lefebvre's theory of abstract space}

In this theoretical section, I build on Lefebvre's concepts of 'abstract space', 'concrete abstraction' and 'commodity fetishism' to construct an explanation as to why state projects of comprehensive urban renewal have focused on the condition of housing stock rather than the social relations of production that produce it. I suggest that their failure lies not simply in the scale, complexity and severity of the problem, which should not be underestimated, but also in a tendency of planners and policymakers to fetishise the dilapidated dwelling itself as a 'product' rather than see it as the final result of fluid social processes - the surface symptom of a vast hidden hinterland of structural shifts, social relations of production, cultural practices and historical layers - just as commodity fetishism obscures the relationships of exploitation in the production of the final product.

Repudiating Engel's uncompromisingly structuralist Marxism, the housing question is for Lefebvre not simply that working-class housing is marked by material deprivation, as a secondary consequence of worker exploitation, but that this reveals a deeper dilapidation in the activity of dwelling, arising from cultural and political alienation as much as economic. With bureaucratic state management of housing and other basic needs came new forms of deprivation, located in cultural and political spheres. Lefebvre like many on the New Left criticised Marx and Engels for limiting their analysis of alienation to the economic sphere and the commodity form: for not seeing the effects of abstraction in the political and cultural spheres of bureaucratic state power and the quantification, calculability and managed spectacle creeping into everyday life. ${ }^{22}$ In post-war attempts to resolve the housing question, Lefebvre identifies the increasing incursion of what he calls 'abstract space' in the discursive shift from 'residence' to 'housing':

It was at this juncture that the idea of housing began to take on definition, along with its corollaries: minimal living-space, as quantified in terms of modular units and speed of access; likewise minimal facilities and a programmed environment. What was actually being defined here ... was the lowest possible threshold of tolerability. Later, in the present century, slums began to disappear. ${ }^{23}$ 
As the post-war welfare state began to eliminate the worst conditions brought about by capitalist urbanisation, through the construction of council estates, new towns and the subsidisation of suburban housing, this was however paid for through the imposition of standardised units measured according to the bare minimum of acceptable standards, both in terms of material tolerability and the 'lowest possible threshold of sociability - the point beyond which survival would be impossible because all social life would have disappeared.'

Central to this perspective is the idea that housing delivered through impersonal state bureaucracies and profit-making corporations alienates dwellers from their immediate living environments, thereby failing to instil any real sense of ownership or pride, removing all obvious incentives to care and maintain the property and, crucially, severing the psychologically health-giving and spiritually fulfilling direct connection with the home. Among the most articulate proponents of this position during the twentieth century were 'anarchist architect' John F.C. Turner and 'anarchist planner' Colin Ward, who famously argued that the bureaucratic alienation of public landlordism - the treatment of tenants as 'inert objects' rather than active subjects - was largely responsible for the swift physical dilapidation of council housing estates, which in turn contributed to the rationale for their residualisation and replacement with marketised social housing. ${ }^{24}$

Likewise, Lefebvre's is above all a critique of the disconnection of ends from means and the instrumentality brought about by the abstraction inherent in capitalist and technocratic rationalities. This is the root of alienation in urban modernity, which Lefebvre perhaps sees as the paramount experience of late capitalism, as opposed to the exploitation in the workplace as Marxists before him saw it. For Marx, like Engels, the production process - founded on the labour-capital relation - was the primary source of exploitation and alienation, and all other relations were merely secondary reflections of this primary contradiction:

The capital-relation presupposes a complete separation between the workers and the ownership of the conditions for the realisation of their labour ... So-called primitive accumulation, therefore, is nothing else than the historical process of divorcing the producer from the means of production. ${ }^{25}$

The abstraction and alienation that Marx had identified at the core of production was, for Lefebvre, emerging in more and more aspects of late twentieth-century everyday life. The common conceptual thread tying 
this all together was 'abstract space' - the spatial dimension of global capitalism and state technocracy. This is a purely instrumental, partitioned, rational space in which the embodied, sensual, emotional 'lived space' of localised everyday life is overlain, controlled and channelled by the plans, classifications, abstract divisions and orderings of 'conceived space' - that of planners, architects, scientists and bureaucrats. The ideological and structural dominance of abstract space over everyday life is shored up by the visual-objective illusion of transparency, which suggests to the perceiver that space is merely a product, an object, visible to the eye, thereby obscuring from view the complex reality of social relations and historical processes that goes into creating it and infusing with meaning. In this way, abstract space obfuscates from the dual dialectical nature of socio-spatial reality - in being at once thing and flow, object and process - leaving us with a conception of space as homogeneous, material and container-like, composed of separable units. When we are led to believe space is an empty transparent container, it becomes easily abstracted from its socially produced and embedded context, detachable for exchange on the world market. Space also appears as objective, given, unchangeable, and therefore not amenable to change through collective action, proving politically disempowering. In sum, abstract space obscures social reality from view in an analogous spatial process to that which Marx called commodity fetishism. Lefebvre offers a striking description of this enigma:

What is a commodity? A concrete abstraction. An abstraction, certainly - but not an abstraction in spite of its status as a thing; an abstraction, on the contrary, on account of its status as a social 'thing', divorced, during its existence, from its materiality, from the use to which it is put, from productive activity, and from the need that it satisfies ... Self-exhibition is its forte ... And yet, once it has appeared, its mystery only deepens. Who has produced it? Who will buy it? ... Who, or what purpose, will it serve? ... The commodity does not answer these questions; it is simply there, exposed to the gaze of passers-by ... be it in a nondescript small shop or in a glittering department store. ${ }^{26}$

Thus, Lefebvre's theory of the production of space has been described by Andy Merrifield as a 'spatialised rendition' of Marx's commodity fetishism concept; ${ }^{27}$ and likewise by Lukasz Stanek as analogous to Marx's concept of 'concrete abstraction': labour as an 'abstraction which became true in practice'. ${ }^{28}$ First, it abstracts from the qualitative 
difference of diverse lived experience a general homogeneous form that is common to all instances. For instance, the diverse actions of labourers in all sorts of industries are abstracted into quantitative labour-time, made equivalent as units of abstract labour-time, represented by money. Similarly, in space, as Lefebvre shows, abstract space divides urban space up into particular parcels or plots abstracted from lived context, and made available as commodities with exchange value on the global market. Second, it produces 'concrete abstractions' in the real world, making materially and socially concrete the abstract concept in question, which in turn then has real power to affect people's behaviours and social practices. For instance, money is for Marx a concrete abstraction of the abstract 'commodity form' - the social relation that transforms a use value into a commodity - in that money has a real material existence that people can physically hold and act in relation to. Likewise, in space, Lefebvre reveals how property plots, distribution channels, communication networks and other physical spaces of circulation and exchange are the concrete abstractions of abstract space. Concrete abstraction, then, describes the transformation of material space in the image of abstract representations, such as those of modernist planning, and the infusion of social space with the strange immaterial objectivity of exchange value.

To get a firmer grasp on the concrete power of abstract space over urban life, Liverpool provides a good example. In another essay in The View from the Train, ${ }^{29}$ Keiller discusses the destruction of Liverpool's raison d'être as a maritime hub, which has virtually eliminated its main source of employment and global importance. This is the abstraction of global capital, moving elsewhere according to the logics of efficiency and profitability, being made concrete through technological change - the rationalisation, containerisation and general abstraction of port activities - which meant that Liverpool's port economy shed its workforce at a rate far outweighing the loss of its economic value. Keiller surprises us with the fact that 'Liverpool can still be described as the UK's largest conventional port, with more traffic today than even at its peak', and that

The dereliction of the Liverpool waterfront is a result not of the port's disappearance, but of its new insubstantiality. The warehouses that used to line both sides of the river have been superseded by a fragmented, mobile space: goods vehicles moving or parked on the UK's roads - the road system as a publicly-funded warehouse. ${ }^{30}$

Most port traffic passes through via complex mechanised processes without generating local jobs. This mechanised 'new insubstantiality' 
is a specific process of 'concrete abstraction': the abstraction of global trade made concrete in material and economic infrastructures - containers, cranes, lorries, motorways and car parks - as the fetishised objects obscuring from view the real scale and scope of the social relations that make up the vast chain of logistics stretched out, as Keiller implies, along the road network.

\section{Towards a spatialised conception of commodity fetishism}

Applied to space, then, abstraction conceals the social reality of urban space in the same way that the commodity form obscures in the final product the multiple geographically and historically layered social relations of production and exploitations of labour. In terms of buildings themselves, Lefebvre points to the tendency of 'productive operations' in general to 'cover their tracks', sometimes with 'this as their prime goal: polishing, staining, facing, plastering, and so on' ${ }^{31}$ It is these tendencies of abstract space in the production of buildings and urban space more generally that led Lefebvre to identify a dangerous forgetfulness:

When construction is completed, the scaffolding is taken down; likewise, the fate of an author's rough draft is to be torn up and tossed away ... products, and even works, are further characterized by their tendency to detach themselves from productive labour. So much so, in fact, that productive labour is sometimes forgotten altogether, and it is this 'forgetfulness' - or, as a philosopher might say, this mystification - that makes possible the fetishism of commodities: the fact that commodities imply certain social relationships whose misapprehension they also ensure. ${ }^{32}$

This 'forgetfulness' works in two ways: to obscure from casual view the full productive process that went into making a dwelling what it is; and to mystify the critical faculties from recognising the power of users to change it. First, all traces of the labour that produced it are made invisible by the rendered, polished, homogenised - fetishised - end-product. This is tantamount to Lefebvre's insight that modernity is marked by the 'manifest expulsion of time' by fetishised space; that 'with the advent of modernity time has vanished from social space. ${ }^{33} \mathrm{~A}$ building produced as a commodity conceals the myriad historical layers, social relations, imaginaries, plans, skills, construction techniques, sweat and toil that went into making the building. Moreover, this also hides from common sense the inhabitants 
themselves, who infuse material structure with life and project their subjective experiences, memories, dreams, fears and hopes into buildings in ways which actually produce it as a social space rather than abstract product. Abstract space helps us forget that it is the users of dwellings that truly 'perform' dwelling - that dwelling is a verb as well as a noun.

Second, a fog of abstraction descends over our critical faculties, preventing us from seeing buildings in any other way than abstracted and exchangeable products; a tendency which Lefebvre identifies as affecting both users and critics - but which just as easily applies to policymakers and practitioners:

Fetishized abstract space thus gives rise to two practical abstractions: 'users' who cannot recognize themselves within it, and a thought which cannot conceive of adopting a critical stance towards it. ${ }^{34}$

In this chapter, I want to trace how this forgetfulness has informed attempts in Liverpool to resolve the problem of dilapidated dwelling. The dilapidated dwelling itself becomes a fetishised object for planners and policy makers, who treat the material building as the target of their intervention rather than the social relations that produce it. This is evident in increasingly property-led attempts at regeneration in which policymakers locate the problem at the door of the end 'product' itself rather than the complex background process that produces space. In response to such commodity fetishism, I posit an alternative that seeks to reconnect the user and producer of housing, in ways that attempt to resolve the alienation at the root of a production process founded on abstract divisions of labour. In Liverpool there are two movements that define such an alternative method: the 1970s co-op movement and the contemporary CLT projects. I address each in turn below.

\section{Liverpool's housing question reconsidered}

In the 1970s and 1980s, Liverpool once again found itself at the centre of the housing question. Just as Engels had attacked Proudhon, the latter's self-help heirs, John F.C. Turner and Colin Ward, were likewise critiqued by Marxist structuralists such as Rod Burgess for misunderstanding the commodity nature of housing. ${ }^{35}$ They responded by highlighting the failure of the structuralists, going back to Engels, to usefully distinguish between ends and means in answering the housing question. 
Turner draws our attention back to the insight that 'dwelling' is a verb as well as a noun - an active lived process of doing, as well as a static material resource, the building itself. Liverpool found itself caught up in this debate when Ward's ideas - strongly influenced by Turner's - were to find their expression in Liverpool's 1970s housing co-operative movement, which Ward retrospectively explains:

The book had a salutary effect in Liverpool during a brief period when the Liberals controlled the city's housing policy. It inspired several instances ... of newly-built housing where the tenants of old slum houses were enabled to find a site, and commission an architect to design their own new housing ... The proudest moment of my housing advocacy was when the Weller Street Coop chairman, Billy Floyd, introduced me at a meeting by waving a tattered copy of Tenants Take Over and saying: 'Here's the man who wrote the Old Testament ... But we built the New Jerusalem!'36

Here, the Old Testament referred to is Colin Ward's book Tenants Take Over, his radical manifesto for 'collective dweller control', whilst the New Jerusalem is the Weller Streets Co-op, the country's first newbuild co-op to be designed, owned and managed by its working-class residents (Figure 12.2). The Weller Streets in turn ignited what some have dubbed the 'new-build cooperative revolution'37 - and Liverpool's 'Co-op Spring'38 - fuelling what became the country's largest housing co-operative movement, at least outside of London. It was an extraordinary shift from a situation in which most of Liverpool's working-class residents were housed by the council, or the 'Corpy' as it was known, without any control over the type, design or location of their home, to one in which residents had for the first time a genuine choice over these aspects and a real sense of ownership. It heralded a radical new model, the 'Weller way' of doing things. This put residents in the driving seat of a development machine funded and legislated for centrally by the state but deploying resources through an unprecedentedly decentralised programme of design and construction by a range of local professional services organisations, all chosen and commissioned by residents themselves. This new form of cooperative housing incorporated radical new ideas around dweller control, design democracy and participatory techniques - then being experimented with in what became known as the 'community architecture' movement - and which inspired successive groups of council tenants to develop a new wave of new build co-ops across Liverpool. ${ }^{39}$ 
(a)

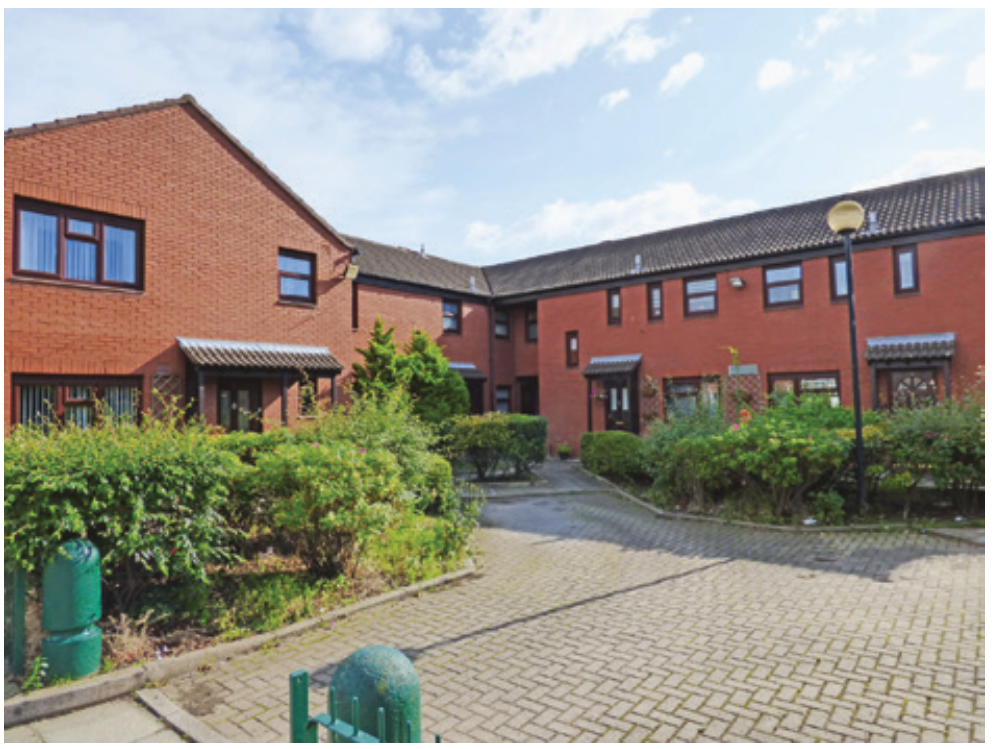

(b)

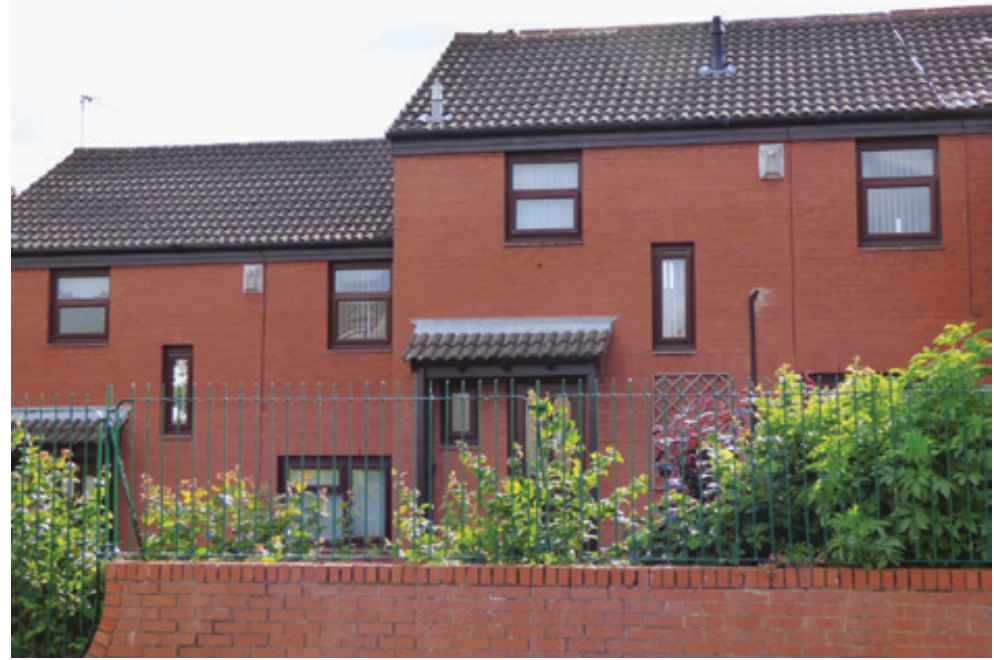

Figure 12.2 Weller Street Co-op resident-led design, well managed and in better condition today compared with surrounding housing built afterwards. 
The leading secondary co-op agency, Cooperative Development Services (CDS), played a crucial role in the movement's development initially suggesting a co-op as an idea for groups of residents campaigning to be rehoused together, as a solution to the problem of displacement posed by the 'slum clearances' then demolishing much of inner-city Liverpool's terraces. The work of CDS with the Weller Streets Co-op was to set the trend for the rest. First, CDS suggested architects, developers and agents for the co-op committee to shortlist and then interview; the Weller Streets' committee insisted that 'the architects act as advisers and scribes' ${ }^{40}$ Their selected scribe was a local newly trained architect, Bill Halsall-another key figure in the movement, who went on to design many other co-ops, notably the Eldonians, the most famous of the Liverpool co-ops and the largest and possibly most successful community-owned housing trust today. ${ }^{41}$ Halsall worked with the Weller Streets Co-op to pioneer a radically democratic design process that would put the flesh on the theoretical bones of Ward's 'dweller control' concept. Participatory techniques and 'planning for real' exercises were innovated to traverse the wall separating technical architectural knowledge practices from the lived experience of inhabitants. These included questionnaires of residents' needs and preferences; exhibitions to illustrate design ideas; factfinding trips and site visits to schemes designed by bidding architects and to brief architects on design ideals; and group modelling methods, such as moveable blocks rearranged on cork boards to find desired layouts. ${ }^{42}$

Spin-off benefits of such intensive involvement included individual empowerment through teaching new skills; tackling socio-economic needs by producing more responsive designs; lowering long-term maintenance costs; and building better communities, in developing community confidence and sense of ownership, thereby instilling responsibility for housing, helping deter vandalism, crime and neglect, and giving people a political voice in local decision making. Indeed, such skills were often life-changing. Working-class people otherwise without access to the professional knowledge and mores of architects and planners were suddenly immersed in that world and picked up new know-how that would help them in their own lives. What might have initially seemed alienating and intimidating jargon, such as housing 'cost yardsticks', was absorbed and put to good use in negotiations with professionals. This not only turned power relations on their head but, crucially, gave individual members the tools to expand their aptitudes and open opportunities to new areas of employment, often in local architectural practices.

Empowerment was not simply a matter of education and skills, but also one of power, confidence, self-belief and identity. Prior to the design 
stage, members cut their teeth on intensive political campaigning and collective negotiation with key gatekeepers to secure the legal support funding and development for their co-op. Co-op campaigns were like a kind of 'political school' for many members, who were inspired and empowered to go into politics full time, representing their communities and often becoming councillors. Phil Hughes, treasurer of the Weller Streets Co-op, became a Labour councillor and eventually Chair of Housing following the fall of the Militant Tendency. Other men from Weller Streets and the Eldonians also became Labour councillors, and women too were radically empowered: Jackie Harris, a single parent leading the Kirkby co-ops, is now a Labour councillor for Knowsley Council; and Jane Corbett, an activist in the Langrove Co-op, is now a Labour councillor and Cabinet Member for Education and Children's Services on Liverpool City Council. In these various ways, therefore, the intensive campaign and design process through which co-op residents empowered themselves and their communities was a vital move in making their new co-op neighbourhoods more than just a collection of better-quality material dwellings: it also strengthened their capacity to take collective control over the social activity of dwelling. Community self-government was in turn buttressed by individual empowerment to find employment and a political voice.

In providing the resources and skills for people to make significant steps towards housing themselves, the co-op movement in many ways bridged the growing chasm between the ends and means of dwelling, bringing the user and the producer of housing into closer synergy. The movement embedded the seeds of an alternative model of neighbourhood regeneration which would later inspire the growth of a new generation of grassroots action in the community land trust movement, and made real steps towards resolving the alienation at the root of the problem of dilapidation dwelling(s). However, we will never really know the true regeneration potential of co-ops, for the life of the movement was dramatically cut short by subsequent political events, which I now turn to.

\section{Militant mono-mania for housing}

Within less than half a decade of the completion of Weller Streets, following the election in 1983 of a far-left municipal socialist administration led by a Trotskyist sect within the Labour Party, the new-build co-operative revolution was dissipated by an agenda of centralised local 
state control over the means of social reproduction. ${ }^{43}$ Militant saw co-ops as a bourgeois conspiracy and a threat to municipal housing - much like Engels saw Proudhon's self-help reformism - and forcefully quashed coop development through a programme of 'municipalisation'. Gestating co-ops were either aborted or taken into municipal ownership, as part of a bold and ambitious $£ 350$ million housing renewal programme, the Urban Regeneration Strategy (URS) - which met targets of 1,000 new homes built per year up to 1988: a remarkable achievement for a time when, nationally, council housebuilding had come to a standstill. ${ }^{44}$

Militant believed that large-scale municipal house-building would revitalise Liverpool's economy and environment by providing jobs and decent homes for all, but became seduced by a form of design determinism - blinded, perhaps, by the power of commodity fetishism which sat awkwardly next to socialist beliefs in collectively controlling the means of production. Their assessment of council house designs revealed 'one bright spot' of 'problem-free' semi-detached housing built in the inter-war period, and concluded that this was the pinnacle of British council housing design: this 'insight was the germ of the URS housing programme'. ${ }^{45}$ At around the same time, the geographer Alice Coleman was popularising her ideas on the 'design disadvantagement' of modernist council housing estates, which she had borrowed and adapted from Oscar Newman's theory of defensible space from across the Atlantic. ${ }^{46}$ Ironically, despite the clear influence of Coleman's ideas on Militant's most despised ideological opponent - Thatcherism - Tony Byrne, the brains behind the programme, had come to the same conclusions as Coleman. In a strange twist, Coleman gave her seal of approval to Militant housing policy, publicly stating that 'Liverpool has got it right', which leading Militant members are proud to report: 'she completely concurred with the main thrust of the URS and of the council's conviction that the majority of people preferred to live in traditional houses. ${ }^{47}$ The URS development principles that she praised were published as new guidelines which prescribed that only houses and bungalows, semi-detached where possible, were to be built. No cul-de-sacs, clusters or inward-facing dwellings; no shared surfaces, common areas or play spaces; only conventional road layouts with private gardens. ${ }^{48}$ This was bad news for uncompleted co-ops. Many of the more interesting courtyard designs with built-in communal space, community centres and focal points for collective gathering - essential to the social life of a co-op - were now in contravention of the new guidelines. Not only did Militant take co-op developments under council control - if they had 
(a)

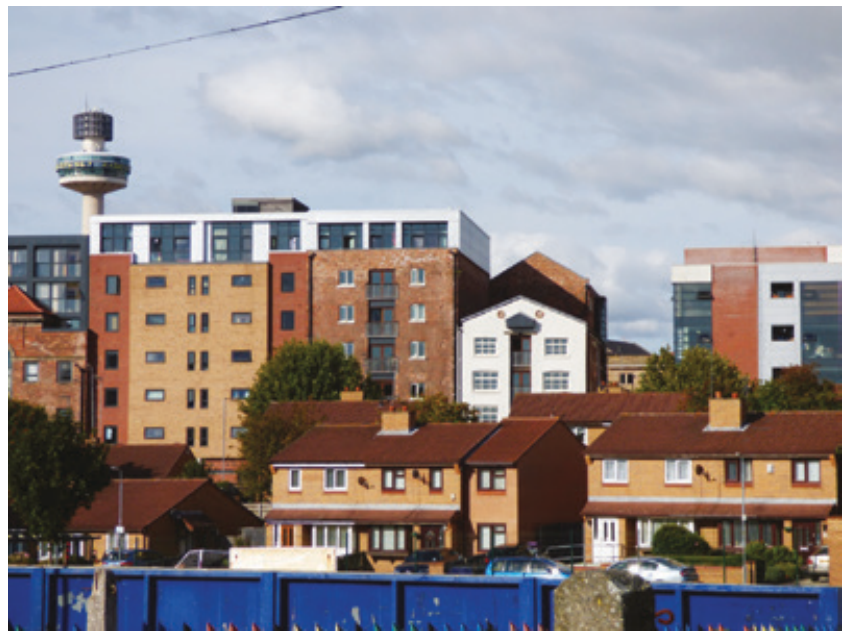

(b)

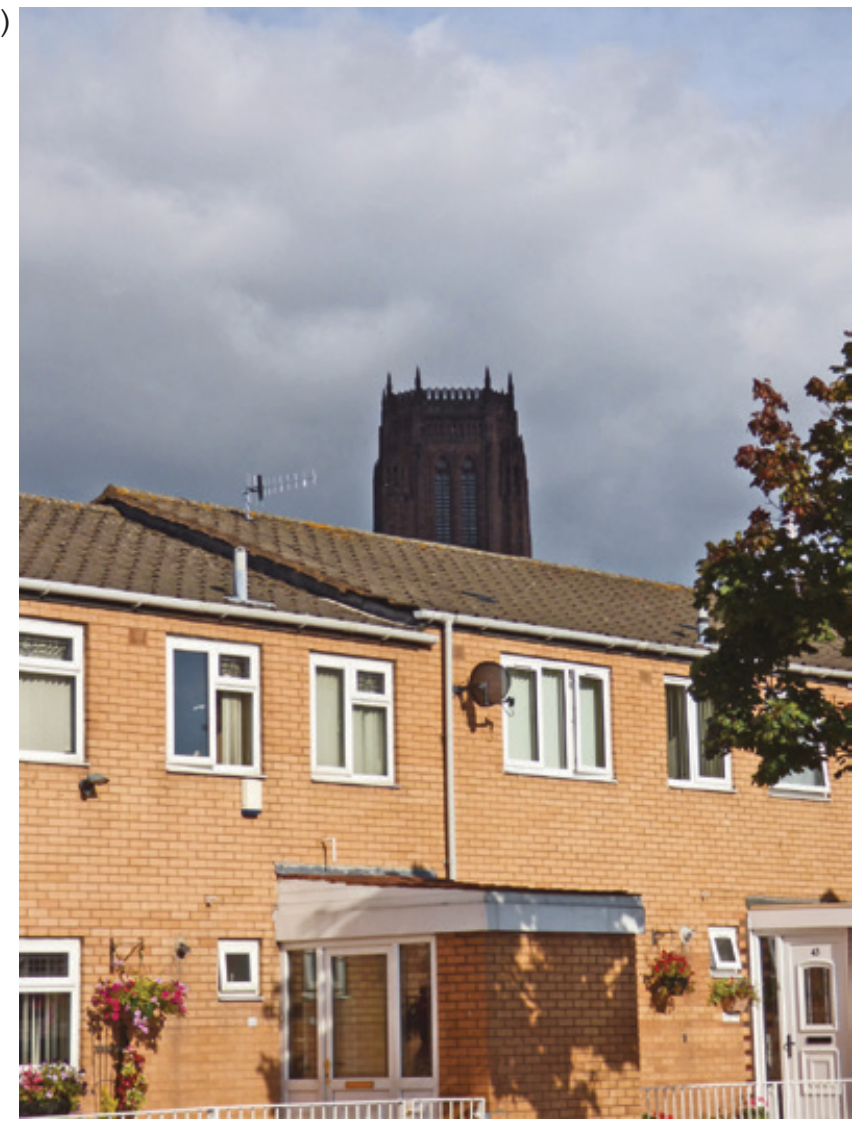

Figure 12.3 Hatton houses in Liverpool's urban core, overshadowed by Radio City tower and the Anglican Cathedral. 
yet to sign a council agreement - they also radically altered their design to reflect their belief in plain suburban housing, thereby threatening the social existence of these co-ops.

In many respects, however, Militant had accurately captured the mood of many tenants, alienated by several decades of living in dysfunctional and decaying council flats. In his architectural review of Liverpool, Owen Hatherley concurs that 'Militant's policy was perhaps the widest-scale attempt to give people what most (if not all) always said they wanted - a house and garden, close to their place of work. ${ }^{49}$ However, the result was perhaps less desirable. An ex-manager of council housing regales a common observation: "Hatton houses" we called them, because they were directly controlled by Derek Hatton', ${ }^{50}$ leading Militant member and deputy leader of the council. He continues: 'so they built the sort of "story book" look of what a house was supposed to look like, in a way entirely wrong for a hundred yards from here [Liverpool city-centre]' (Figure 12.3). Owing to fiscal constraints on the URS from the ongoing struggle to find financial sources amidst an illegal budget deficit, the housing was often of a lower design quality than the council housing it replaced, often not big enough for new tenants to fit the furniture from their old house.

Militant's mono-mania for housing, reflected in the stringent URS design prescriptions, was found guilty of spatial determinism by critics, including co-op agency CDS Chief Executive, Catherine Meredith, who accused Militant of a 'megalomaniac belief in housing type', ${ }^{51}$ for failing to recognise the importance of dweller control in the management and maintenance of housing. Militant ultimately fell victim to a kind of housing fetishism, in which the design and type of housing were seen as the key to resolving dilapidated dwelling. The Coleman/ Militant 'design modification' approach worked on the assumption that people wanted semi-detached Hatton houses, overlooking the fact that working-class co-op tenants had opted for terraces, enclosed courtyards, cul-de-sacs and communal features in the participatory design processes at the heart of the new build co-op movement. The URS made the very same mistake as the post-war modernist council designs it critiqued: a narrow focus on providing the right design over any consideration of tenant participation in the design, management and ownership of their housing. Supposedly alienating high-rise flats and council estates may have been replaced by more popular, humanscale traditional houses; but the distant paternalistic bureaucratic structure remained unmoved. 


\section{History repeats itself: first as tragedy then as farce}

We see history repeating itself with Housing Market Renewal (HMR) in the twenty-first century. The primary objective of HMR was to restructure failing housing markets by improving and replacing dilapidated housing to attract new residents back into the inner city, after decades of depopulation in the wake of economic decline. Much like Militant's URS, HMR focused too much of its energy on treating the surface symptom of a deeper structural problem, but upgrading the materiality of housing by itself is not enough. This is acknowledged even by leading figures in HMR policy making and management, captured in this quote from a Liverpool regeneration manager and former executive of another HMR Pathfinder:

You have to try and make sure that housing is linked into other forms of socio-economic regeneration ... And if I think a mistake was made in the work that ... led to Housing Market Renewal ... [it] should have been called 'Market Renewal'; because housing in a sense in itself may stabilise, may stop decline, but in itself it will not be enough to promote economic well-being, you have to have other things that go alongside it. That's where the Eldonians were clever. $^{52}$

Initially, HMR was quite a forward-thinking and radical approach which took as its object the wider systemic structure of markets, and attempted to resolve the 'wicked' problems of vacancy, dereliction, unemployment and so on, by reconnecting failing neighbourhoods with more stable regional markets. However, this expansive market restructuring rationale was soon distilled to the narrow issue of housing type and design. The reasons for this mission drift are complex and highly political, as documented in David Webb's research. ${ }^{53}$ In very basic terms, because HMR followed an abstract logic of markets and exchange, the problem was increasingly reformulated and framed as one of housing 'products' competing for the attention of upwardly mobile consumers in a residential 'market of positions'. ${ }^{54}$ Terraced housing was deemed to be unpopular and therefore unviable by researchers owing to its low market price, and so a solution was found in replacing it with a new product, reflecting consumer choice, rather than improving wider systemic factors, such as employment, education, health and environment. 
The terraced house itself was thereby vilified as the enemy, deemed 'obsolete' because it was assumed to be unpopular among potential residents who were subjectified as rational consumers competing for the best 'product' on the open market. This internalised the responsibility for the problem of housing vacancy and dilapidation into the terraced house - not in its concrete context, as particular buildings with place-based economic dependencies and social relations, but rather in its abstract form as the general concept of the terrace, interchangeable with like type anywhere else. Dilapidated dwelling is fetishised as a commodity to be easily replaced with a better model, simplifying its complex reality as a spatial constellation of fluid social processes - just as commodity fetishism obscures the relationships of exploitation in the production of the final product on the shelf.

To get 'objective' evidence on what type of houses to build, HMR policy makers conducted surveys with their target population - those middle-class residents currently living in the affluent suburbs - whose responses were unsurprisingly in favour of the kind of suburban housing they currently lived in: neo-traditional semi-detached homes arranged in cul-de-sacs with gardens and garage space for a car to commute into the city. But this was not the suburbs, and the resulting (sub)urban design was a 'bizarre' abstraction from Liverpool's unique urban context. In an uncanny reflection of Militant's housing policy - though from a very different political angle - HMR has built what many regard as the next generation of 'Hatton houses ${ }^{55}$ (Figure 12.4). Owen Hatherley's scathing description of the inner-city suburban housing built by Militant in the 1980s could equally apply to the decontextualised housing estates built by HMR since the 2000s:

It's not dignified for the city centre to mimic the 'burbs. It leads to depressing juxtapositions ... the scale is preposterous, with the houses seeming to desperately want to be somewhere less dramatic, a murmur of discontent with the idea of getting above your station ... it becomes a tragicomedy. ${ }^{56}$

By singling out the terraced house for extinction, and building offthe-shelf housing in its place, HMR alienated the inner-city neighbourhoods from their urban context, but also the existing residents from their surroundings. Campaigns against demolition thus gathered momentum to confront HMR. An anti-demolition campaigner laments 
(a)

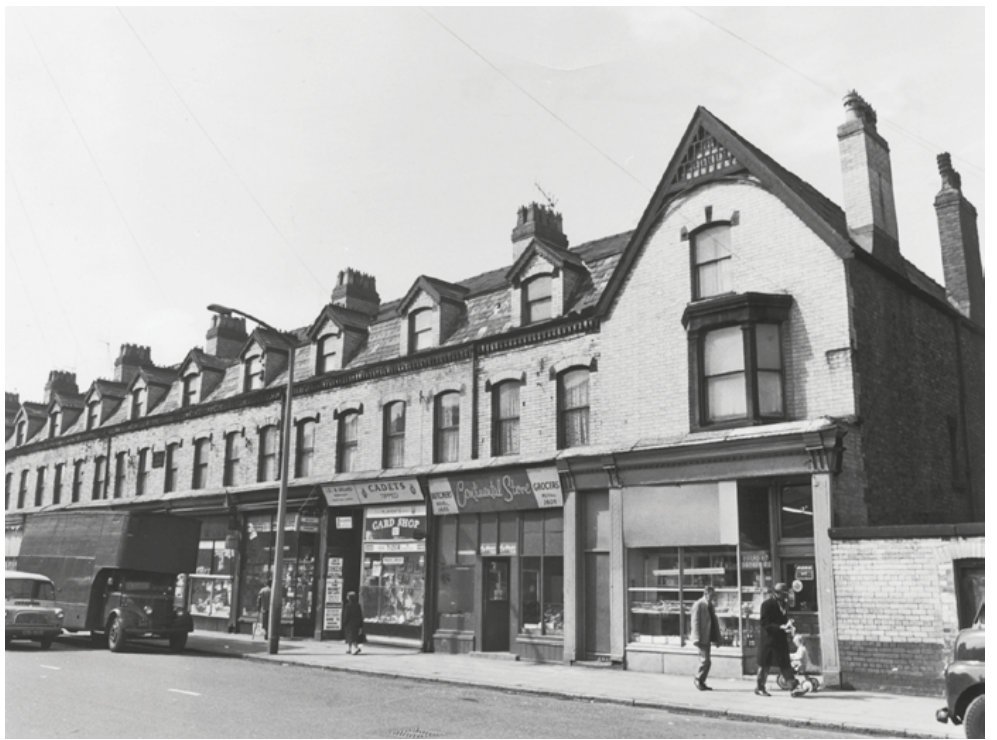

(b)

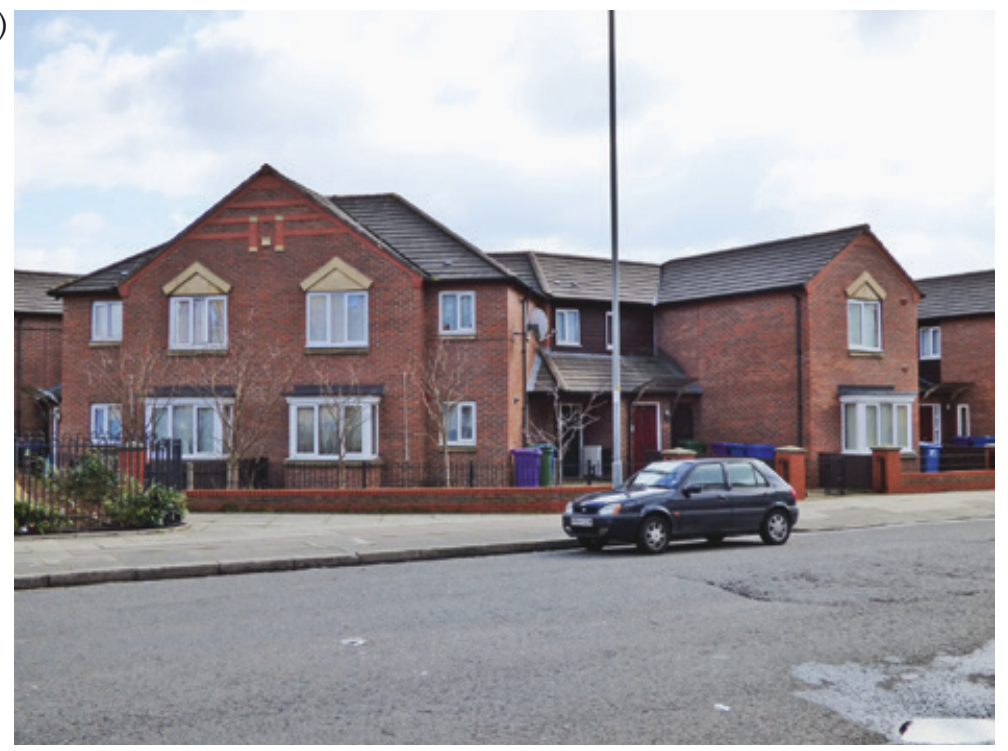

Figure 12.4 Granby Street in the late 1960s, a once-bustling shopping street before decline and demolition, compared to the replacement housing built by HMR.

the proclivity for homogeneous suburban-style housing in the HMR clearance zone surrounding her terraced home, which she helped save from demolition: 
It's kind of despising of working-class terraced housing ... and giving people these poor shoddy imitations of sort of suburban living as if that is the pinnacle of human aspiration ... it's a kind of despising of any public or communal space ... the idea that you huddle so that you see as little of your neighbours as possible and there's no through movement anywhere; it's always like dead-ends. ${ }^{57}$

Some of these campaigns channelled their anti-HMR sentiments into more proactive projects for alternatives, culminating in two CLTs one in Granby and one in Anfield, on opposite sides of the city centre - amongst the first urban CLTs to rehabilitate empty homes. The campaign process for Granby Four Streets CLT - its emergence out of guerrilla gardening activism and ongoing development through innovations in 'community homesteading' - has a complex social history and political context, which I have documented elsewhere. ${ }^{58}$ Most recently, Granby CLT has recently received a great deal of media attention following the nomination of the project for the 2015 Turner Prize. The architecture collective working with Granby residents, Assemble, are the first architectural and design studio to be nominated for the Turner Prize - suggesting how art, traditionally focused on aesthetic objects, can be reimagined as a lived, collective process and dynamic socio-material practice. The other CLT project so far to be established in Liverpool, Homebaked CLT, across the other side of the city in Anfield, has emerged more directly from radical artistic intervention. For the remainder of this chapter, I consider the process-driven philosophy of Homebaked CLT as an alternative to the abstract space of HMR.

\section{Homebaked: 'brick by brick, loaf by loaf, we build ourselves'}

Right from the outset Homebaked had a powerful political agenda, beginning as a public art project commissioned by the 2010 Liverpool Biennial, whose organisers invited Dutch artist Jeanne van Heeswijk to visit Anfield and work with local residents on an art initiative to address the effects of HMR on lived experience. Out of her initial interactions with local residents and artists, Jeanne created '2Up2Down', a community-led participatory design project to reimagine the future of the area as constructed through small-scale community-led alternatives to top-down policies; or, as their website suggests, 'a way for local people to "take matters into their own hands" and make real social and physical change in their neighbourhood. ${ }^{59} 2 \mathrm{Up} 2$ Down takes public arts funding 
and pursues something more akin to political activism, aiming for radical redistribution of land and power to traditionally marginalised communities. Discourses on the urban commons, co-production and participatory democracy are central to the design philosophy of Jeanne van Heeswijk, who believes 'communities should co-produce their own futures' in an art-action-research method she calls 'radicalising the local', which works 'by empowering communities to become their own antidote'. ${ }^{60}$

Active participation, performance, and community storytelling were at the heart of the project, which gained momentum through a participatory design process with 40 young people from the area, gradually expanding to include local adults who were affected by HMR and whose housing needs and desires were expressed in the evolution of the project. ${ }^{61}$ The process was facilitated by a young architect from URBED, who adapted URBED's 'Building for Change' modelling toolkit, used to get adults to remodel their neighbourhoods - a contemporary equivalent of the 'Planning for Real' exercises developed by CDS in the new-build co-op designs. The architect also explains that 'for my previous diploma thesis I did a case study on the Eldonians, and the design process ... and community architecture, just doing a comparison between that and Byker, and Homes for Change in Hulme'.62 There is thus a direct lineage from the design democracy infusing the 1970s co-op movement, and community architecture more broadly, to the resident engagement that helped create Homebaked.

The slogan at this time was: 'Housing is the battlefield of our time and the house is its monument. ${ }^{.63}$ By acknowledging the terraced house as the 'monument' of Liverpool's present conjuncture - but just that: only a monument, the symbolic edifice of a deep-rooted condition - the aptly named '2Up2Down' recognises the commodity fetishism at the heart of the HMR's strategy in the 'battlefield'. It seeks to reveal this illusion for what it is by turning the prevailing wisdom on its head, proposing a sustainable rehabilitation approach to breathe life back into the much-maligned twoup, two-down terraced house through new community uses. Just as the dilapidation of dwelling signifies that of the activity of living in place as well as the physical place itself, so too does rehabilitation taken in its most expansive sense. The project thus aims to revitalise the community as well as the buildings, by restoring the local bakery as a community anchor and co-operative, providing social space and jobs, and eventually new affordable housing in the terraced row - all to be owned and managed by a CLT governed democratically by and for the interests of local people.

2Up2Down eventually became grounded in the neighbourhood in 2011 when they took over the lease of a newly vacant bakery in the heart of Anfield, whose custodians had been forced to accept the council's compulsory purchase offer after the loss of most of their customers, emptied out 
from the surrounding streets by HMR. The Mitchell's Bakery was founded in 1903 and known as 'The Pie Shop' by football fans from all over the world located opposite the stadium main entrance (Figure 12.5). ${ }^{64}$ Symbolically the bakery is a cornerstone of the community, and 2Up2Down has

(a)

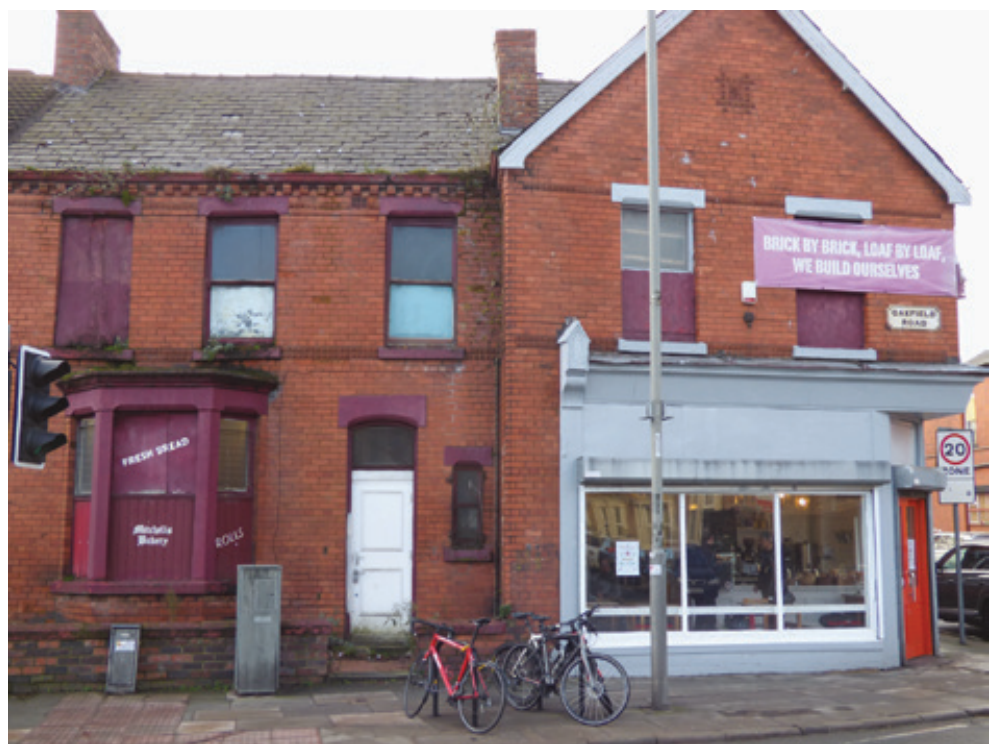

(b)

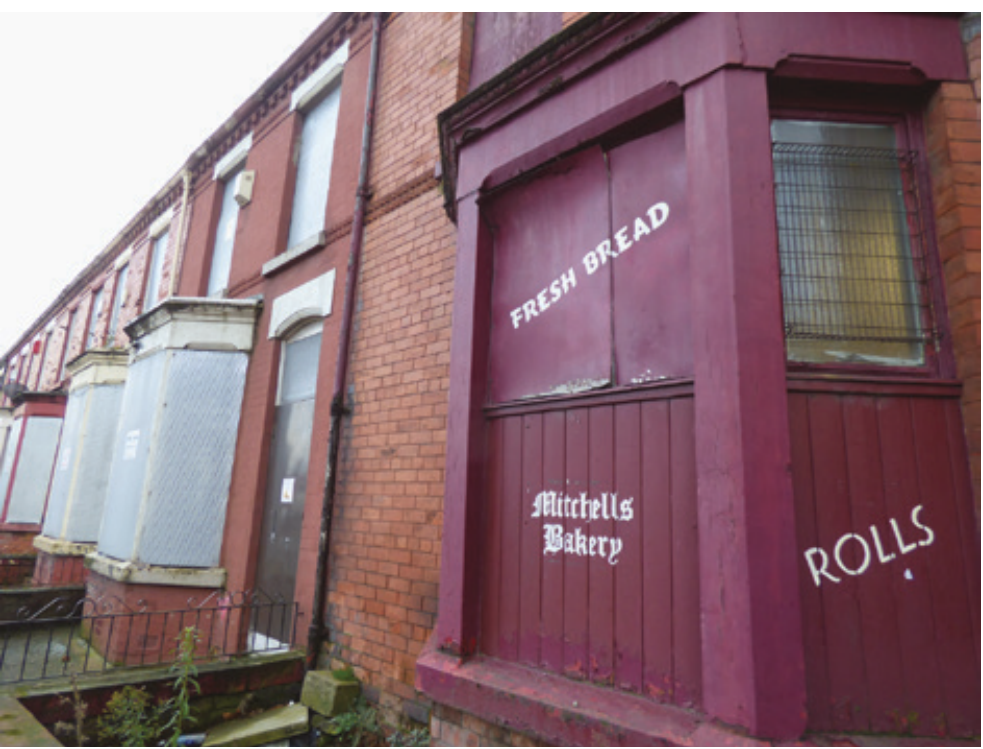

Figure 12.5 Homebaked bakery emblazoned with its slogan, and the terraced row the CLT is hoping to acquire from the council for affordable housing. 
capitalised on this cultural history by renaming the bakery 'Homebaked'. This clever piece of branding conjured up new slogans that would prove to be very marketable: 'Brick by brick, loaf by loaf, we build ourselves.'

Artists and activists involved in the project see in Homebaked an alternative vision for social change through slow cumulative learning, analogous to home cooking, 'denoting the slow building of collective resilience within the face of the "tyranny of emergency" ... that characterises the everyday lives of the residents of Anfield' ${ }^{65}$ Homebaked's incremental, experimental, immersive and hands-on process stands in stark contrast to the abstract time horizons and monolithic operation of HMR, in which current users are simply cut out of the picture.${ }^{66}$ On the other hand, there are many on the Left who would deride Homebaked's performative art techniques and cutesy branding as a kind of bourgeois reformism - sharing as much with trendy pop-up entrepreneurialism of creative-class politics as any serious political resistance. Indeed, some observers refer to Homebaked's campaign strategy as 'half-baked'. ${ }^{67}$ This is a contradiction that likewise we can see in Patrick Keiller's project, as Will Self suggests:

Keiller's dilemma - and the source of a fruitful tension in his work - is whether to see his films as part of a strategy of resistance to the spatial forms of late capitalism, or only as incorporations of the everyday into a bourgeois calculus of the arty-factual. ${ }^{68}$

Homebaked's approach, like Keiller's work, occupies ambivalent ground, positioned self-consciously within prevailing cultural trends, exploiting connections, media attention and marketing to gain a wide audience and win over both public and political support, whilst simultaneously pursuing a slow-burn strategy of transforming capitalist property dynamics and neoliberal regeneration policy through demonstration of an extraordinary alternative. After decades of failed state solutions to dilapidated dwelling, Homebaked is a vital injection of creative energies, skills, expertise, publicity and funding into an otherwise deprived neighbourhood that had been brought close to social extinction by the violence of abstraction, both through economic decline and state-led displacement. Yet Homebaked is taking into CLT ownership only one terraced row within a large area in need of rehabilitation, as part of the council's broader Anfield Village masterplan. ${ }^{69}$ Their ability to contest the conventional large-scale demolition-and-rebuild approach was ultimately constrained by their reliance on local government support and acquisition of public land. Experimental activist-art projects like 
Homebaked are especially time-consuming, labour-intensive and piecemeal endeavours, which remain highly vulnerable to the whims of both participants themselves and those external stakeholders, not least local politicians, who are important gatekeepers in the transfer of public land and assets into community hands. Moreover, their ability to make headway with structural change on any significant scale appears intrinsically limited. The flipside of the coin of the huge potential social benefits accruing through democratic, intensive and immersive methods is the inherent difficulty to replicate or scale up such schemes without attenuating the spontaneous energies at their source.

\section{Conclusion: towards experimental utopias?}

The commodity fetishism and concrete abstraction that Lefebvre saw as a fundamental facet of abstract space - and which I have sought to show as permeating the logic of diverse state projects from the Trotskyist municipalisation of Militant to neoliberal market restructuring of HMR - is essentially a failure to see the importance of means in achieving ends. The ends themselves no doubt differ radically between these state projects. For Militant, the end was state socialist control over the means of social reproduction - notably housing - and eventually the means of production. They were so fixated on this substantive political goal - as a first step towards the revolutionary overthrow of capitalism - that they forgot how important the process of getting there was for its full fruition. They overlooked the tiny incremental steps in between that must connect and channel the everyday life of working class Liverpudlians into the radical political change they sought. Such a misapprehension of ends and means reflects that of Engels' Housing Question. It is also evident - though in a very different, neoliberal form - in HMR's misidentification of the terraced house as an obsolete product and the root problem of inner-city neighbourhood decline, when in fact it was just the tip of the iceberg.

To truly effect change, then, Militant's URS and HMR alike needed to bring residents along with them, through a participatory process that would instil legitimacy and, crucially, develop their skills, capacities and values in co-operation to eventually realise collective selfmanagement. Co-ops and CLTs - as microcosms of democratic or even utopian socialist states, operating at the street or neighbourhood scaleare the natural muscle tissue or organs required to grow the socialist body. Tragically, Militant mistook them as a threatening bourgeois 
virus. Lefebvre's dialectical insight - the production of (urban) space as both determined by and in turn determining of social relations and cultural practices, through constant iterative co-evolution - offers a way out of this impasse. It is this dialectical tension inhering in projects like Homebaked that gives them so much dynamic potential and creative energy to sow the seeds for future transformation - straddling the delicate dialectic between reform and revolution. Homebaked does indeed embody a distinctly Lefebvrean vision of experimental utopianism, seeking out urban change in concrete ways bit by bit in the here and now, whilst staying present to its own limitations and contradictions:

The idea of a new life is at once realistic and illusory ... The fact is that the space which contains the realized preconditions of another life is the same one as prohibits what those preconditions make possible ... A total revolution - material, economic, social, political, psychic, cultural, erotic, etc. - seems to be in the offing, as though already immanent to the present. To change life, however, we must first change space. ${ }^{70}$

Homebaked CLT - like the co-ops that went before it - attempts to change life by first changing the space - material, architectural, ideological and social - in which we live out our daily lives. This alternative model - first pioneered in the dweller control of the 1970s co-operative movement and evolving through the contemporary CLT campaigns does not alienate the users of the final product from the process of getting there; it designs in their needs and desires from the outset, in a way that ensures social use is valued over market exchange. It is a simple and humble ambition of incremental and piecemeal urban transformation that gradually draws in more people, building on their strengths and providing additional resources, in an inspiring and empowering process, breathing life and hope back into both buildings and minds that have long been neglected by economic and political forces. In contrast to the kind of spatial and temporal abstractions imposed by large-scale state-led comprehensive redevelopment programmes, experimental projects like Homebaked have the potential to reconnect the ends and means of dwelling - as self-sustaining and democratic attempts to heal dilapidation, both material and social. 


\section{Notes}

\section{Editorial commentary}

1. Kenneth Frampton, Modern Architecture: A Critical History (London: Thames \& Hudson, 2007), 272.

2. Sigfried Giedion, CIAM: Die Wohnung für das Existenzminimum (Frankfurt: Englert \& Schlosser, 1930).

3. See Alastair Fuad-Luke, Design Activism: Beautiful Strangeness for a Sustainable World (Abingdon: Taylor \& Francis, 2013), 38.

4. Royal Institute of British Architects, Town Planning Conference London, 10-15 October 1910, Transactions (London: The Royal Institute of British Architects, 1911).

5. See Jamileh Manoochehri, The Politics of Social Housing in Britain (Oxford: Peter Lang, 2012).

6. The Barbican Estate is an exemplary case of promoting variation through design typology, as it consists of 140 different types of flats; see Elain Harwood, Chamberlin, Powell and Bon: The Barbican and Beyond (London: RIBA Publishing, 2011).

7. Here the word 'fitness' is defined as the appropriateness of the space with regards to the opportunities for occupation that are offered to different users at different times during the life of the building.

8. See Ian Colquhoun, RIBA Book of 20th Century British Housing (Oxford: ButterfieldHeinemann, 1999), 64-7; Miles Glendinning and Stefan Muthesius, Tower Block (New Haven: Yale University Press, 1994), 39, 62, 105, 120-2.

9. Sofia Balters, 'AD Classics: Robin Hood Gardens / Alison and Peter Smithson', Arch Daily (18 August 2011), accessed 29 May 2017, www.archdaily.com/150629/ ad-classics-robin-hood-gardens-alison-and-peter-smithson.

10. Stefi Orazi, Modernist Estates: The Buildings and the People Who Live in Them Today (London: Frances Lincoln, 2015), 109.

11. Yona Friedman, Manuel Orazi and Nader Seraj, eds, Yona Friedman: The Dilution of Architecture (Zurich: Park Books, 2015).

12. Yona Friedman, Architecture Mobile (1960), quoted in Ruth Eaton, Ideal Cities: Utopianism and the (Un)built Environment (London: Thames \& Hudson, 2002).

13. See Takis Zenetos, 'City Planning and Electronics', Arxitectonika Themata, 3 (1969).

14. Joke Brouwer and Arjen Mulder, eds, The Art of the Accident (Rotterdam: V2 Publishing, 1998).

15. Bernard Cache, 'Architectural Shooters', Hunch 6/7 (2003), 123.

16. R\&Sie.(n), François Roche, Stephanie Lavaux, Jean Navarro and Benoît Durandin, I've heard about (Paris: Paris-Musee, 2005).

17. R\&Sie.(n) et al., I've heard about, 7 .

18. Marjorie Grene, 'Evolution, "Typology" and "Population Thinking"', American Philosophical Quarterly 27, no. 3 (1990). 


\section{Chapter 1}

1. Nadia Somekh, A Cidade Vertical E O Urbanismo Modernizar (São Paulo: Editora Mackenzie, 2014).

2. Nabil Bonduki, Origens Da Habitação Social No Brasil: Arquitetura Moderna, Lei Do Inquiliniato E Difusão Da Casa Própria, 6th ed. (São Paulo: Estacão liberdade, 2006); Nadia Somekh and Candido Malta Campos, A Cidade Que Não Pode Parar: Planos Urbanisticos de São Paulo No Século XX (São Paulo: Editora Mackenzo, 2002).

3. Candido Malta Campos, Os Rumos Da Cidade: Urbanismo E Modernização Em São Paulo (São Paulo: Editora Senac, 2002).

4. Suzana Pasternack Tascher, 'Squatter Settlements and Slums in Brazil: Twenty Years of Research and Policy', in Housing the Urban Poor: Policy and Practice in Developing Countries, ed. Brian C. Aldrich and Ravinder Sandhu (London: Zed Books, 1995); James Holston, Insurgent Citizenship: Disjunctions of Democracy and Modernity in Brazil (Princeton: Princeton University Press, 2008).

5. Bonduki, Origens Da Habitação.

6. Somekh, A Cidade Vertical.

7. Kazuo Nakano, Candida Malta Campos and Raquel Rolnik, 'Dinâmicas Dos Subespaços Da Área Central de São Paulo', in Caminhos Para O Centro: Estratégias de Desenvolvimento Para a Região Central de São Paulo, ed. Alvaro Comin and Nadia Somekh (São Paulo: EMURB, Prefeitura de São Paulo, 2004).

8. Heitor Frugoli Jr, Centralidade Em São Paulo: Trajetórias, Conflitos E Negociações Na Metrópole (São Paulo: Editora da Universidade de São Paulo, 2000).

9. Helena Menna Barreto Silva, Habitação No Centro de São Paulo: Como Viabilizar Essa Idéia? Documento Preparatório (São Paulo: LABHAB/FAUUSP, 2000).

10. Instituto Brasileiro de Geografia e Estatística (IBGE), 'Censon Demográficos'.

11. IBGE, 'Censon Demográficos'.

12. Fundação João Pinheiro, Déficit Habitacional No Brasil: 2011-2012 (Belo Horizonte: Fundação João Pinheiro, 2015).

13. Anon., 'Bar de Hotel Mantém Charme dos anos 50', Estadão (3 March 1996), Z10.

14. Jeroen Stevens, Bruno De Meulder and Débora Sanches, 'Cortiços: Interstitial Urbanization in Central São Paulo', in The Political Meaning of Informal Urbanization, ed. Roberto Rocco and Jan Van Ballegooien (Abingdon: Routledge, forthcoming).

15. Anon., 'Bar d'Hotel, Bar do Noite', Estadão (6 October 2000), Z10.

16. E.g. Folha de São Paulo, 16 May 1975 and 1 February 1979.

17. Nakano, Campos and Rolnik, 'Dinâmicas'.

18. Jean Remy and Liliane Voyé, Ville, Ordre et Violence: Formes Spatiales et Transaction Sociale. Espace et Liberté vol. 4 (Paris: Presses Universitaires de France, 1981).

19. Nakano, Campos and Rolnik, 'Dinâmicas'.

20. Anon., 'Festar para Cairn a Gaudaia', Estado do São Paulo (7 March 2003), 19.

21. Charmaine Levy, 'Brazilian Urban Popular Movements: The 1997 Mobilization of the InnerCity Slum Movement in São Paulo', Studies in Political Economy 85 (2010): 35-68.

22. Colin Ward, Housing: An Anarchist Approach (London: Freedom Press, 1976).

23. Débora Sanches, 'Processo Participativo Como Instrumento de Moradia Digna: Uma Avialiação Dos Projetos Da Área Central de São Paulo - 1990 a 2012'. Doctoral thesis, Universidade Presbiteriana Mackenzie, 2015.

24. Helena Menna Barreto Silva, Adriano Henrique Rebelo Biava and Letícua Nireura Sígolo, 'Tributos Imobiliários E Imóveis Vazios No Centro de São Paulo: Relatório Final' (São Paulo: FAU-USP, 2009).

25. Fábio Mariz Gonçalves, Anna Gabriela Hoverter Callejas and Rodrigo Minoru Hayakawa Tanaka, Estudo Para Implantação de Unidades Habitacionais No Centro de São Paulo (São Paulo: FUPAM Fundação para Pesquisa Ambiental, 2009).

26. Paolo Freire, A Pedagogia Do Oprimido (Rio de Janeiro: Paz e Terra, 1968).

27. Victor Turner, Dramas, Fields and Metaphors: Symbolic Action in Human Society (Ithaca and London: Cornell University Press, 1974).

28. Arantes, Arquitetura Nova. Sérgio Ferro, Flávio Império E Rodrigo Lefèvre, de Artigas Aos Mutirões.

29. Rebecca Solnit, A Paradise Built in Hell: The Extraordinary Communities That Arise in Disaster (New York: Viking Adult, 2010). 
30. Turner, Dramas.

31. John F. C. Turner and Robert Fichter, Freedom to Build: Dweller Control of the Housing Process (New York: Macmillan, 1972).

32. Harms, 'Historical Perspectives on the Practice and Purpose of Self-Help Housing', in SelfHelp Housing: A Critique, ed. Peter Ward (London: Mansell Publishing, 1982), 18.

33. Pedro Fiori Arantes, Arquitetura Nova: Sérgio Ferro, Flávio Império E Rodrigo Lefèvre, de Artigas Aos Mutirões (São Paulo: EDITORA 34, 2002).

34. Raul Zibechi, Territories in Resistance: A Cartography of Latin American Social Movements (Oakland: AK Press, 2012), 71.

35. Claude Lévi-Strauss, The Savage Mind (Chicago: University of Chicago Press, 1962), 17-19.

36. Raul Mehrotra and Felipe Vera, Kumbh Mela: Mapping the Ephemeral Megacity (New Delhi: Niyogi Books, 2015).

37. Colin Ward, Cotters and Squatters: Housing's Hidden History (Nottingham: Five Leaves, 2002); Harms, 'Historical Perspectives'.

38. Andrej Holm and Armin Kuhn, 'Squatting and Urban Renewal: The Interaction of the Squatters' Movements and the Strategies of Urban Restructuring in Berlin', in Squatting in Europe: Radical Spaces, Urban Struggles, ed. SwEK Squatting Europe Kollective (New York: Autonomedia, 2013).

39. Bart van der Steen, Ask Katzeff and Leendert van Hoogenhuijze, eds, The City Is Ours: Squatting and Autonomous Movements in Europe (Oakland: PM Press, 2014); SqEK Squatting Europe Kollective, Squatting in Europe: Radical Spaces, Urban Struggles (New York: Autonomedia, 2013).

40. Alfredo Brillembourg and Hubert Klumpner, Torre David: Informal Vertical Communities (Zurich: Lars Müller Publishers, 2012).

\section{Chapter 2}

1. Henri Lefebvre, The Production of Space (Oxford: Blackwell, 1991).

2. J.-P. Liégeois, Roma in Europe (Strasbourg: Council of Europe Publishing, 2007).

3. Angus Bancroft, Roma and Gypsy-Travellers in Europe: Modernity, Race, Space and Exclusion (Aldershot: Ashgate Press, 2005).

4. Donald Kenrick, Gypsies: From the Ganges to the Thames (Hatfield: University of Hertfordshire Press, 2004).

5. Donald Kenrick and Colin Clark, Moving On: The Gypsies and Travellers of Britain (Hatfield: University of Hertfordshire Press, 1999).

6. Kenrick and Clark, Moving On.

7. Sarah Holloway, 'Outsiders in Rural Society? Constructions of Rurality and Nature-Social Relations in the Racialisation of English Gypsy-Travellers, 1869-1934', Environment and Planning D: Society and Space 21 (2002): 695-715.

8. Donald Kenrick, The Gypsies During the Second World War: In the Shadow of the Swastika (Hatfield: University of Hertfordshire Press, 1999).

9. Patsy Healey, Collaborative Planning: Shaping Places in Fragmented Societies (Basingstoke: Palgrave Macmillan, 2006).

10. John Forester, Dealing with Differences: Dramas of Mediating Disputes (Oxford: Oxford University Press, 2009), 59.

11. Libby Porter, Unlearning the Colonial Cultures of Planning (Farnham: Ashgate, 2010), 16.

12. John Sturzaker and Mark Shucksmith, 'Planning for Housing in Rural England: Discursive Power and Spatial Exclusion', Town Planning Review 82, no. 2 (2011), 169.

13. Zygmunt Bauman, Modernity and the Holocaust (Cambridge: Polity Press, 1989).

14. R. Turner, M. Hewstone and A. Voci, 'Reducing Explicit and Implicit Outgroup Prejudice via Direct and Extended Contact: The Mediating Role of Self-Disclosure and Intergroup Anxiety', Journal of Personality and Social Psychology 93, no. 3 (2007), 369.

15. Jo Richardson, The Impact of Planning Circular 1/06 on Gypsies and Travellers in England (Leicester: De Montfort University, 2011).

16. Henri Lefebvre, The Production of Space (Oxford: Blackwell, 1991).

17. Lefebvre, Production of Space, 40.

18. Jo Richardson, The Gypsy Debate: Can Discourse Control? (Exeter: Imprint Academic, 2006). 
19. Lefebvre, Production of Space, 294.

20. Roger Fisher and William Ury, Getting to Yes: Negotiating an Agreement Without Giving In (London: Random House, 1999).

21. Forester, Dealing with Differences, 59.

22. Richardson, Gypsy Debate.

23. Forester, Dealing with Differences, 91.

24. Healey, Collaborative Planning, 33.

25. Sanda Kaufman and Janet Smith, 'Framing and Reframing in Land Use Change Conflicts', Journal of Architectural and Planning Research 16, no. 2 (1999), 165.

26. Jo Richardson and Janie Codona, Managing and Delivering Gypsy and Traveller Sites: Negotiating Conflict (York: JRF, 2016).

27. Richardson and Codona, Managing and Delivering.

28. Lefebvre, Production of Space.

29. Association of Chief Police Officers of England, Wales and Northern Ireland (ACPO), ACPO Guidance on Unauthorised Encampments, version 13 (June 2011), 4.

30. Rachel Morris and Luke Clements At What Cost? The Economics of Gypsy and Traveller Encampments (Bristol: Policy Press, 2002), 50.

31. Lawrence Susskind, Dealing with an Angry Public: The Mutual Gains Approach to Resolving Disputes (New York: The Free Press, 1996), 155.

32. Forester, Dealing with Differences, 79.

33. Jo Richardson, Contentious Spaces: The Gypsy/Traveller Site Issue (York/Coventry: JRF/ $\mathrm{CIH}, 2007)$.

34. Lefebvre, Production of Space.

\section{Chapter 3}

1. DTE, 'Community-Centred Reconstruction Needed', Down to Earth 64 (2005).

2. BRR, Housing: Roofing the Pillars of Hope (Jakarta: The Executing Agency of Rehabilitation and Reconstruction for Aceh and Nias, 2009).

3. Jim Kennedy, Joseph Ashmore, Elizabeth Babister and Ilan Kelman, 'The Meaning of "Build Back Better": Evidence From Post-Tsunami Aceh and Sri Lanka', Journal of Contingencies and Crisis Management 16, no. 1 (2008).

4. Florian Steinberg, 'Housing Reconstruction and Rehabilitation in Aceh and Nias, Indonesia: Rebuilding Lives', Habitat International 31 (2007).

5. BRR, Housing.

6. R. Hirschon and S. Thakurdesai, 'Housing and Cultural Priorities: The Asia Minor Greek Refugees of 1922', Disaster 2, no. 4 (1979).

7. Havidán Rodríguez,Enrico L. Quarantelly and Russell R. Dynes, Handbook of Disaster Research (New York: Springer, 2006).

8. Gonzalo Lizarralde, 'Post-Disaster Low-Cost Housing Solutions, Learning from the Poor', in Rebuilding after Disaster: From Emergency to Sustainability, ed. Gonzalo Lizarralde, Cassidy Johnson and Colin Davidson (New York: Spon Press, 2010).

9. Anthony Oliver-Smith, 'Anthropological Research on Hazards and Disasters', Annual Review of Anthropology 25 (1996).

10. Roger Zetter and Camillo Boano, 'Space and Place after Natural Disaster and Forced Displacement', in Rebuilding after Disaster, ed. Lizarralde, Johnson and Davidson.

11. Colin Davidson, Cassidy Johnson, Gonzalo Lizarralde, Alicia Sliwinski and Nese Dikmen, 'Truth and Myths about Community Participation in Post-Disaster Housing Projects', Habitat International 31 (2007).

12. Jennifer Duyne Barenstein, People-Driven Reconstruction and Rehabilitation in Aceh: A review of Uplink's Concepts, Strategies and Achievements (Aachen: Misereor, 2008).

13. Jennifer Duyne Barenstein and Sushma Iyengar, 'Towards Owner-Driven Housing Reconstruction in India', Paper presented at the Conference on Development from Disaster Scaling up Owner-Driven Reconstruction, IFRC, Practical Action and London South Bank University, London, 2009.

14. Davidson et al., 'Truth and myths'.

15. Davidson et al., 'Truth and myths'. 
16. Jennifer Duyne Barenstein, A Comparative Analysis of Six Housing Reconstruction Approaches in Post-Earthquake Gujarat (SUPSI, 2005), accessed on 3 July 2017, http:// humanitarianlibrary.org/sites/default/files/2014/02/SUPSI.pdf.

17. Barenstein, Post-Earthquake Gujarat.

18. Steinberg, 'Housing Reconstruction and Rehabilitation'.

19. Steinberg, 'Housing Reconstruction and Rehabilitation'.

20. Barenstein, Post-Earthquake Gujarat.

21. Alireza Fallahi, 'Lessons Learned from the Housing Reconstruction Following the Bam Earthquake in Iran', The Australian Journal of Emergency Management 22, no. 1 (2007).

22. BRR, Housing, 29.

23. BRR, Housing.

24. Kennedy et al., 'Meaning of "Build Back Better"'.

25. Roderick J. Lawrence, 'Integrating Architectural, Social and Housing History', Urban History 19, no. 1 (1992).

26. DTE, 'Community-Centred Reproduction Needed'.

27. BRR, Housing, 13.

28. C. Snouck Hurgronje, The Acehnese, 2 vols (Leiden: Brill, 1906).

\section{Chapter 4}

1. Glasgow and West of Scotland Forum of Housing Associations, Our Crumbling Tenements: A New Approach for the 21st Century (Glasgow: Glasgow and West of Scotland Forum of Housing Associations, 2015).

2. Hazel Easthope, Jan Warnken, Cathy Sherry, Eddo John Coiacetto, Dianne Dredge, Christopher John Guilding, Nicole Johnston, Dawne Martha Lamminmaki and Sacha Reid, 'How Property Title Impacts Urban Consolidation: A Lifecycle Examination of Multi-Title Developments', Urban Policy and Research 32, no. 3 (2014); Michael McClelland, Graeme Stewart and Asrai Ord, 'Reassessing the Recent Past: Tower Neighbourhood Renewal in Toronto', Journal of Preservation Technology 42, nos. 2-3 (2011).

3. Adriana Mihaela Soaita, 'Strategies for In Situ Home Improvement in Romanian Large Housing Estates', Housing Studies 27, no. 7 (2012); Justina Muliuolyte, 'Rediscovering Large Scale Social Housing Estates in Post Socialist Cities', Journal of Architecture and Urbanism 37 (2013).

4. Siu Kei Wong, Alex King-Chung Cheung, Yung Yau, Daniel Chi-Wing Ho and Kwong-Wing Chau, 'Are Our Residential Buildings Healthy and Safe? A Survey in Hong Kong', Structural Survey 24, no. 1 (2006).

5. E.g. Nayanthara De Silva, 'Maintainability of Condominiums Constructed for Low-Income Families in Sri Lanka', Built-Environment Sri Lanka 11, no. 2 (2015); Tuan Hai Dinh, 'Current Status of Existing Condominium Buildings in Vietnam: Common Problems, Main Causes and Proposed Maintenance Strategies', in International Conference on Sustainable Architectural Design and Urban Planning (Hanoi: Hanoi Architectural University, Vietnam Green Building Database and Network, 2007).

6. Yung Yau, Daniel Chi-Wing Ho and Kwong-Wing Chau, 'Determinants of the Safety Performance of Private Multi-Storey Residential Buildings in Hong Kong', Social Indicators Research 89, no. 3 (2008); Nigel Law, 'An Evaluation of the Mandatory Building Inspection Scheme in Hong Kong', masters dissertation, University of Hong Kong, 2009.

7. Yau et al., 'Determinants of the Safety Performance'.

8. Cathy Sherry, 'Lessons in Personal Freedom and Functional Land Markets: What Strata and Community Title Can Learn from Traditional Doctrines of Property', UNSW Law Journal 36, no. 1 (2013), 280.

9. Hazel Easthope, Bill Randolph and Sarah Judd, Governing the Compact City: The Role and Effectiveness of Strata Management (Sydney: City Futures Research Centre, 2012); Martti Lujanen, 'Legal Challenges in Ensuring Regular Maintenance and Repairs of Owner-Occupied Apartment Blocks', International Journal of Law in the Built Environment 2, no. 2 (2010); Ekaterina I. Borisova, Leonid Polishchuk and Anatoly Peresetsky, 'Collective Management of Residential Housing in Russia: The Importance of Being Social', paper presented at Workshop Colloquium Series, Indiana University 
Bloomington, 24 October 2011; Ngai-ming Yip, Chin-oh Chang and Tzu-ying Hung, 'Modes of Condominium Management: A Principal-Agent Perspective', Facilities 25, nos. 5-6 (2007).

10. James M. Buchanan and Yong J. Yoon, 'Symmetric Tragedies: Commons and Anticommons', Journal of Law and Economics 43, no. 1 (April 2000).

11. Lujanen, 'Legal Challenges in Ensuring Regular Maintenance'.

12. Hazel Easthope, Bill Randolph and Sarah Judd, Managing Major Repairs in Residential Strata Developments: A study by the City Futures Research Centre at UNSW provided with the assistance of the NSW Office of Fair Trading in New South Wales (Sydney: City Futures Research Centre, 2009).

13. In Russia: Borisova, Polishchuk and Peresetsky, 'Collective Management'. In Canada, the USA, England and Germany: Lujanen, 'Legal Challenges'. In Hong Kong and Taiwan: Yip, Chang and Hung, 'Modes of Condominium Management'.

14. Easthope, Randolph and Judd, Governing the Compact City, 2.

15. Laurence Troy, Bill Randolph, Laura Crommelin, Hazel Easthope and Simon Pinnegar, Renewing the Compact City: Economically Viable and Socially Sustainable Approaches to Urban Development, Final Report (Sydney: City Futures Research Centre, 2015).

16. Troy et al., Renewing the Compact City.

17. Troy et al., Renewing the Compact City.

18. City of Toronto (2011) Tower Renewal Implementation Book, accessed 24 October 2016, www1.toronto.ca/city_of_toronto/social_development_finance__administration/files/ pdf/tr_implementation_book.pdf.

19. Flavie Halais, 'How Toronto Is Revitalizing Its Aging Suburban Residential Towers', Citiscope (13 August 2015), accessed 29 October 2016, http://citiscope.org/story/2015/ how-toronto-revitalizing-its-aging-suburban-residential-towers. Citiscope is a nonprofit news outlet that covers innovations in cities around the world.

20. City of Toronto (2016) High-Rise Retrofit Improvement Support Program (Hi-RIS), accessed 24 October 2016, www1.toronto.ca/wps/portal/contentonly?vgnextoid= ab3147e94c5b3410VgnVCM10000071d60f89RCRD.

21. See for example, Bill Randolph and Andrew Tice, 'Who Lives in Higher Density Housing? A Study of Spatially Discontinuous Housing Sub-Markets in Sydney and Melbourne', Urban Studies 50, no. 13 (2013).

22. Randolph and Tice, 'Who Lives in Higher Density Housing?', 2664.

23. Hazel Easthope and Andrew Tice, 'Children in Apartments: Implications for the Compact City', Urban Policy and Research 29, no. 4 (2011).

24. See Ellis Woodman, 'Post-war Estate Regeneration: Improvement over Replacement', in Exemplary Housing Estate Regeneration in Europe, ed. James McLachlan (London: EMAP, 2015), 7-8, accessed 15 March 2016, http://www.architectsjournal.co.uk/ Journals/2015/06/29/g/y/m/KCA-book_all_low-res.pdf.

25. James McLachlan, ed., Exemplary Housing Estate Regeneration in Europe (London: EMAP, 2015), 34-35. The reference to the variety of socio-economic and ethnic backgrounds evident in Ommoord's resident profile is repeated by Hans van der Heijden, the former design director at biq architects at the time. See van der Heijden's website, accessed 15 March 2016, http://hvdha.com/splayed-apartment-blocks.

26. Cited in Woodman, 'Post-War Estate Regeneration'.

27. Anneke Bokern, 'Amsterdam-Slotervaart', in Making Heimat: Germany, Arrival Country, ed. Peter Cachola Schmal, Oliver Elser and Anna Scheuermann (Ostfildern: Hatje Cantz, 2016), 188.

28. Bokern, 'Amsterdam-Slotervaart', 193.

29. David Cascaro and Claire Staebler, 'Interview with Lacaton \& Vassal: Comme un Paysage Sans Limite / Like an Endless Landscape', Palais 15 (Numéro spécial histoire du Palais de Tokyo) (2012), 100, 102.

30. See for example, Denise Lawrence-Zúñiga's discussion of the aesthetic aspirations of Chinese immigrants in the US: 'Bungalows and Mansions: White Suburbs, Immigrant Aspirations, and Aesthetic Governmentality', Anthropological Quarterly 87, no. 3 (Summer 2014).

31. Gernot Böhme, Ästhetischer Kapitalismus (Berlin: Suhrkamp, 2016).

32. A 2008 report cites immigration as a major factor in population growth. See Parliament of Australia, Senate Select Committee on Housing Affordability in Australia, report tabled 
16 June 2008, in particular, Chapter 4: 'Factors Influencing the Demand for Housing, Subsections 4.4-4.13: Demographics', accessed 12 February 2016, www.aph.gov.au/ Parliamentary_Business/Committees/Senate/Former_Committees/hsaf/report/c04.

33. Bob Birrell, Committee Hansard (24 April 2008), 31. Cited in Parliament of Australia, Senate Select Committee, Chapter 4, Subsection 4.7.

34. Figure published by the Bundesamt für Migration und Flüchtlinge, 2015.

35. Bob Birrell and David McCloskey, The Housing Affordability Crisis in Sydney and Melbourne Report One: The Demographic Foundations (Melbourne: The Australian Population Research Institute, October 2015), 3-10, accessed 12 February 2016, http://tapri.org.au/ wp-content/uploads/2016/02/housing-affordability-crisis-in-sydney-and-melbourne_ part-1.pdf.

36. Mike Berry and Peter Williams, Investigative Panel on a Socially Sustainable Housing System for Australia, AHURI Final Report No. 169 (Melbourne: RMIT Research Centre, June 2011), 7, accessed 12 February 2016, www.ahuri.edu.au/_data/assets/pdf_file/0002/2000/ AHURI_Final_Report_No169_Investigative_Panel_on_a_socially_sustainable_housing_ system_for_Australia.pdf.

37. Sylvie Lemmet, 'Building Opportunities for Tackling Climate Change', foreword to UNEP United Nations Environment Program, Buildings and Climate Change: Summary for Decision-Makers (Paris: UNEP United Nations Environment Program, 2009), 3, accessed 25 June 2017, http://staging.unep.org/sbci/pdfs/SBCI-BCCSummary.pdf.

38. UNEP Buildings and Climate Change.

39. Anon., 'Keep the Faith', RIBA Journal (1 September 2015), accessed 26 February 2015, www.ribaj.com/intelligence/championing-the-vision.

40. Patricia Crawford, Zenia Kotval, Warren Rauhe and Zeenat Kotval, 'Social Capital Development in Participatory Community Planning and Design,' Town Planning Review 79, no. 5 (2008).

41. Ade Kearns, Rosemary Hiscock, Anne Ellaway and Sally Macintyre, 'Beyond Four Walls. The Psycho-Social Benefits of Home: Evidence from West Central Scotland', Housing Studies 15, no. 3 (2000); Cameron Parsell, 'Home Is where the House Is: The Meaning of Home for People Sleeping Rough', Housing Studies 27, no. 2 (2012); Hazel Easthope, Edgar Liu, Bruce Judd and Ian Burnley, 'Feeling at Home in a Multigenerational Household: The Importance of Control', Housing, Theory and Society 32, no. 2 (2015).

42. The project approach was cited as an answer to the housing crisis in Britain, where the progressive demolition of post-war estates such as the Heygate Estate in south London is seen as unsustainable and the implementation of the demolition process often extends over several decades. See Rowan Moore, '10 Solutions to the Housing Crisis - in Pictures', The Guardian (7 July 2013). For a detailed discussion of the La Tour Bois le Prêtre project, see Ilka and Andreas Ruby with the German Architecture Museum (DAM), eds, Druot, Lacaton \& Vassal: La Tour Bois le Prêtre in Paris (Berlin: Ruby Press, 2012).

43. Michael Kimmelman, 'At the Edge of Paris, A Housing Project Becomes a Beacon', The New York Times (28 March 2012), accessed 26 January 2016, www.nytimes.com/2012/03/ 28/arts/design/renovated-tour-bois-le-pretre-brightens-paris-skyline.html?_r=1.

44. For the project details, drawings and photographs, please refer to the architects' website, accessed 26 January 2016, www.lacatonvassal.com/?idp=56\#.

45. Cited in Carson Chan, 'Lacaton \& Vassal: Game Changer', 032c 23 (Winter 2012/13), accessed 2 November 2015, http://032c.com/2013/o-architects-where-art- thou-gamechanger-lacaton-vassal.

46. Anne Lacaton cited in Kimmelman, 'Edge of Paris'. For a discussion of ethics and aesthetics in Lacaton's adaptive reuse projects - in particular, the Palais de Tokyo Paris - see Sandra Karina Löschke, "Materials in Fact": Material Aesthetics and Ethics in Lacaton \& Vassal's Palais de Tokyo', in Materiality and Architecture, ed. Sandra Karina Löschke (London: Routledge, 2016).

47. For an extended discussion of German approaches to the current housing shortage, see Stefan Rettich, 'Regulate. Reduce. Accelerate', in Making Heimat: Germany, Arrival Country, ed. Peter Cachola Schmal, Oliver Elser and Anna Scheuermann (Ostfildern: Hatje Cantz, 2016).

48. For details of the initiative see 'Förderrichtlinie für Modellvorhaben zum nachhaltigen und bezahlbaren Bau von Variowohnungen', published on the official website of the Bundesministerium für Umwelt, Bau, Naturschutz, und Reaktorsicherheit, accessed 23 
September 2016, www.bmub.bund.de/themen/bauen/bauwesen/details-bauwesen/ artikel/foerderrichtlinie-fuer-modellvorhaben-zum-nachhaltigen-und-bezahlbaren-bauvon-variowohnungen.

49. Rettich, 'Regulate. Reduce. Accelerate', 92.

50. Andres Lepik and Marjetica Potrc, 'Cities in Transition', in Architektonika, ed. Gabriele Knapstein and Matilda Felix (Nuremberg: Verlag für moderne Kunst, 2013), 157.

51. Markus Miessen, The Nightmare of Participation (Crossbench Praxis as a Mode of Criticality) (Berlin: Sternberg Press, 2011).

52. See Jane Rendell's discussion of collaboration, and in particular architecture practice muf's collaborative practices. Jane Rendell, Art and Architecture: A Place Between (London/ New York: I.B. Tauris, 2006), 153-61.

53. As Isabelle Priest pointed out, the UK Cohousing Network identifies three main forms of co-housing: new build, property renovation and retrofit, which can be related to adaptive redesign projects. In both co-housing and adaptive redesign approaches, the notion of community is important, although in the latter the formation of community might have occurred post- rather than pre-development. See Isabelle Priest, 'Different Kind of Living', RIBA Journal (17 September 2015), accessed 4 February 2016, www.ribaj.com/intelligence/ different-kind-of-living.

54. To address the issue of knowledge transfer, the UK Cohousing Network ran a seminar titled 'ESRC Seminar Six: Mainstreaming Cohousing in Urban Development: Barriers to Knowledge Transfer', 21 June 2016, accessed 28 August 2016, https://collaborativehousing. net/seminars/six.

55. UK Cohousing Network, 'ESRC Seminar Six’.

\section{Chapter 5}

1. The Getty Conservation Institute, Historic Urban Environment, Conservation Challenges and Priorities for Action, Experts Meeting Report (Los Angeles: Getty Conservation Institute, 2010), 3.

2. United Nations Human Settlements Programme, State of the World's Cities 2010/11 - Cities for All: Bridging the Urban Divide (Abingdon: Earthscan, 2011).

3. United Nations Department of Economic and Social Affairs, World Urbanization Prospects: The 2014 Revision Highlights (New York: UNDESA, 2014).

4. Marc Antrop, 'Landscape Change and the Urbanization Process in Europe', Landscape and Urban Planning 67 (2004).

5. Valentina Russo, Abandoned Historic Towns in the South of Italy: Conservation and Sustainability Issues (Bressanone: Edizioni Arcadia Ricerche Estratti del $30^{\circ}$ Convegno di Studi Scienza e Beni Culturali, 2014), 436.

6. Salvatore Settis, 'Un patto per la tutela del paesaggio', La Repubblica (17 November 2006).

7. Eamon O'Hara, Local Communities Leading the Way to a Low Carbon Society (Brussels: AEIDL, 2013), 4

8. Russo, Historic Towns, 443.

9. Vito Teti, Il senso dei luoghi: Memoria e storia dei paesi abbandonati (Rome: Donzelli, 2004).

10. Michel de Certeau, The Practice of Everyday Life, trans. Steven Rendall (Berkeley: University of California Press, 1984), 143.

11. Robert L. Brown, Ghost Towns of the Colorado Rockies (Caldwell: Caxton Press, 1968).

12. Lindsey T. Baker, Ghost Towns of Texas (Norman: University of Oklahoma Press, 1991).

13. Lambert Florin, Ghost Towns of the West (New York: Promontory Press, 1971), 7.

14. Luca Di Figlia, 'Revitalisation of Abandoned Villages: Design Process in the Memory of Places'. Paper presented at the Dublin AESOP-ACSP Congress, 12-13 July 2013, 1.

15. Russo, Historic Towns, 433.

16. Di Figlia, 'Abandoned Villages', 2.

17. Interview with Paolo Guarnaccia. University of Catania, Department of Agriculture (2015).

18. Confcommercio Legambiente, Eccellenze e ghost town nell'Italia dei piccoli comuni: Rapporto dell'Italia del Disagio Insediativo1996/2016 (n.p.: Serico Gruppo Cresme, 2008).

19. Russo, Historic Towns, 435.

20. Di Figlia, 'Abandoned Villages', 5. 
21. European Commission, Mainstreaming Sustainable Development into EU Policies: 2009 Review of the European Union Strategy for Sustainable Development, COM/2009/0400 (n.p.: European Commission, 2009).

22. European Commission, Europe 2020: A Strategy for Smart, Sustainable and Inclusive Growth (n.p.: European Commission, 2010).

23. O'Hara, Local Communities, 4.

24. 'About Ecovillages', Global Ecovillage Network Europe, accessed 4 June 2015, http://gen-europe.org/ecovillages/about-ecovillages/index.htm.

25. Jonathan Dawson, Ecovillages: New Frontiers for Sustainability, Schumacher Briefings 12 (Totnes: Chelsea Green Publishing, 2013).

26. 'About Ecovillages' Global Ecovillage Network Europe.

27. Ted Trainer, 'Where Are We, Where Do We Want to Be, How Do We Get There?', Democracy and Nature 6, no. 2 (2000), accessed on 4 June 2017, www.democracynature.org/vol6/ trainer_where.htm.

28. Takis Fotopoulos, 'The Limitations of Life-Style Strategies: The Ecovillage 'Movement' is NOT the Way towards a New Democratic Society', Democracy and Nature 6, no. 2 (2000), accessed on 4 June 2017, www.democracynature.org/vol6/takis_trainer_reply.htm.

29. Christopher E. Mare, The Urban Village: Synergy of Ecology and Urbanism (Seattle: Village Design Institute, 2005).

30. Mary Garden, 'The Eco-Village Movement: Divorced from Reality', The International Journal of Inclusive Democracy 2, no. 3 (2003), accessed on 4 June 2017, www.inclusivedemocracy.org/journal/vol2/vol2_no3_Garden_eco_village.htm.

31. Dawson, Ecovillages, 3.

32. Michael Cockram, 'GEN's Torri Superiore', Architecture Week (30 August 2006), accessed on 25 June 2017, www.architectureweek.com/2006/0830/environment_1-1.html.

33. Albert Bates, Peter Bane and Keith Johnson, 'City Form: Country Venue: A Village for the Ages', The Permaculture Activist 58 (2005).

34. Lucilla Borio, 'The Passages of Time', Permaculture Magazine 41 (2004), 28.

35. Anon., 'Storia di Torri Superiore'. accessed 10 December 2015, www.torri-superiore.org.

36. Borio, 'Passages of Time', 27.

37. Borio, 'Passages of Time', 29.

38. D.H. Lawrence, 'Penetrating into Italy', in The Fatal Gift of Beauty: The Italies of British Travellers. An Annotated Anthology, ed. Manfred Pfister, 414-16 (Amsterdam: Rodopi, 1996), 415.

39. Luigi Fuscu Girard and Peter Nijkamp, eds, Cultural Tourism and Sustainable Local Development (Abingdon: Routledge, 2009).

40. Russo, Historic Towns, 443.

41. Giancarlo Dall'Ara, Manuale dell' Albergo Diffuso: L'idea, las gestione, il marketing dell'ospitalita diffusa (Milan: FrancoAngeli, 2003).

42. Giorgio Bulgarelli, The 'Albergo Diffuso': A Way to Develop Tourism by Mean of Innovation and Tradition (n.p.: IDEASS Innovation by Development and South-South, 2007).

43. Russo, Historic Towns, 437.

44. Di Figlia, 'Abandoned Villages', 7.

45. Luigi Trajano, 'Il Borgo dei Borboni Business Plan', Associazione Nationale Alberghi Diffusi, accessed 26 July 2015, www.itcfortunato.it/PUBLIC/upload/documenti/111_Business\%20 Plan\%20AD.pdf.

46. Angela Cresta, 'Rural Tourism as a Factor of Competitive Development: Empirical Evidence in the Campania Region' (2011), accessed on 4 June 2017, www.academia.edu/1991286/ Rural_tourism_as_a_factor_of_competitive_development_empirical_evidence_in_the Campania_Region.

47. Russo, Historic Towns, 437.

48. Hicran Topçu, 'Change with/versus Conservation: Architectural Interventions and Their Effects on the Character of the Historic Urban Patterns' (2002), accessed on 4 June 2017, www.arcchip.cz/w03/w03_topcu.pdf.

49. Di Figlia, 'Abandoned Villages', 7.

50. Stefania Ianella, 'Apice vecchio: perché paese fantasma?', Art'Empori: Arte ed economia dell'EcoVicinanza (30 November 2012), accessed 18 July 2015, https://artempori. wordpress.com/2012/11/30/apice-vecchio. 
51. Ron Redmond, 'High Commissioner António Guterres Starts Work', accessed 1 July 2016, www.unhcr.org/uk/news/latest/2005/6/42b0064d4/high-commissioner-antonioguterres-starts-work-unhcr.html.

52. 'Mediterranean Crisis', Human Rights Watch, accessed 10 December 2015, www.hrw.org/ $\mathrm{tag} /$ mediterranean-crisis.

53. UNCHR, Italy: Sea Arrivals, UNHCR UPDATE 4 (December 2015).

54. UNHCR, Italy: Sea Arrivals, UNHCR UPDATE 8 (October 2016).

55. Jean-Luc Janot, 'Italy: Migrants Bring New Life to Deserted Villages', 2015, accessed 1 July 2017, www.aeidl.eu/images/stories/pdf/italie-en.pdf.

56. Confcommercio Legambiente, 'Eccellenze e ghost town'.

57. Pierre Frey, 'New Vernacular Architecture vs Sustainable Development?', in Versus: Heritage for Tomorrow, ed. Mariana Correia, Letzia Dipasquale and Saverio Mecca (Florence: Firenze University Press, 2014).

58. Di Figlia, 'Abandoned Villages', 1.

59. Ervin Laszlo, Science and the Akashic Field: An Integral Theory of Everything (Rochester, VT: Inner Traditions International, 2004).

60. Luca Di Figlia, 'The Abandoned Village as a Regional Resource', Paper presented at the AESOP Ankara Congress (2013), 13.

\section{Chapter 6}

1. Libby Porter, 'Informality, the Commons and the Paradoxes for Planning: Concepts and Debates for Informality and Planning', Planning Theory and Practice 12 (2011), 115.

2. Kim Dovey, 'Informal Urbanism and Complex Adaptive Assemblage', International Development Planning Review 34 (2012), 349.

3. Somsook Boonyabancha, 'Savings and Loans: Drawing Lessons from some Experiences in Asia', Environment and Urbanization 13 (2001), 9.

4. Gareth Jones and Kavita Datta, Housing and Finance in Developing Countries (London: Routledge, 1998).

5. Porter, 'Informality', 115.

6. See Ananya Roy, 'Urban Informality: Towards an Epistemology of Planning', Journal of the American Planning Association 71 (2005), 147.

7. UN-HABITAT, The Challenge of Slums: Global Report on Human Settlement (Nairobi: Earthscan Publications, 2003).

8. Hernando De Soto, The Other Path: The Invisible Revolution in the Third World (London: I.B. Tauris, 1989).

9. Vanessa Watson, 'Seeing from the South: Refocusing Urban Planning on the Globe's Central Urban Issues', Urban Studies 46 (2009), 2259.

10. Ananya Roy, 'Why India Cannot Plan Its Cities: Informality, Insurgence and the Idiom of Urbanization', Planning Theory, 8 (2009), 76.

11. See for example Colin Marx, 'Conceptualizing the Potential of Informal Land Markets to Reduce Urban Poverty', International Development Planning Review 31 (2009), 335.

12. Colin McFarlane, 'Rethinking Informality: Politics, Crisis and the City', Planning Theory and Practice 13 (2012), 89.

13. Roy, 'Why India Cannot Plan', 76.

14. Porter, 'Informality', 115.

15. See for example Vanessa Watson, 'The Planned City Sweeps the Poor Away: Urban Planning and the 21st Century Urbanisation', Progress in Planning 72 (2009), 151.

16. See Vanessa Watson, 'Conflicting Rationalities: Implications for Planning Theory and Ethics', Planning Theory and Practice 4 (2003), 395.

17. See for example Edgar Pieterse, City Futures: Confronting the Crisis of Urban Development South Africa (UCT Press, 2008).

18. See for example Edgar Pieterse, City Futures: Confronting the Crisis of Urban Development South Africa (Capetown: UCT Press, 2008).

19. See for example Kim Dovey, 'Informal Urbanism and Complex Adaptive Assemblage', International Development Planning Review 34 (2012), 349.

20. See Gareth Jones and Kavita Datta, Housing and Finance in Developing Countries (London: Routledge, 1998). 
21. See Robert Buckley, Achilles Kallergis and Laura Wainer, 'Addressing the Housing Challenge: Avoiding the Ozymandias Syndrome', Environment and Urbanization 28 (2016), 119.

22. See for example Jan Bredenoord and Paul Van Lindert, 'Backing the Self-Builders: Assisted Self-Help Housing as a Sustainable Provision Strategy', in Affordable Housing in the Urban Global South: Seeking Sustainable Solutions, ed. Jan Bredenoord, Paul Van Lindert and Peer Smeets (London: Routledge, 2015).

23. Somsook Boonyabancha and Thomas Kerr, 'Urban Poor Housing Development in Asia: From Target Group to Negotiating Partner', in From Local Action to Global Networks: Housing the Urban Poor, ed. Peter Herrle and Astrid Ley (Abingdon: Routledge, 2015).

24. John Turner, Housing by People: Towards Autonomy in Building Environments (London: Marion Boyars, 1976).

25. See Maria Tova Solo, 'Financial Exclusion in Latin America: Or the Social Costs of not Banking the Urban Poor', Environment and Urbanization 20 (2008), 47.

26. Ruth McLeod and Kim Mullard, Bridging the Finance Gap between Housing and Infrastructure (Dunmore: Homeless International, 2006).

27. David Satterthwaite and Diane Mitlin, 'Strategies for Grassroots Control of International Aid', Environment and Urbanization 19 (2009), 483.

28. See for example Dannet Liv, 'Study on the Drivers of Over-Indebtedness of Micro-Finance Borrowers in Cambodia: An In-Depth Investigation of Saturated Areas', Cambodia Institute of Development Study, 2013, accessed 10 October 2016, www.incofin.com/sites/ default/files/attachments/newsitems/Study\%20on\%20the\%20Drivers\%20of\%200verIndebtedness $\% 20$ of $\% 20$ Microfinance $\% 20$ Borrowers\%20in\%20Cambodia.pdf.

29. See Boonyabancha, 'Savings and Loans', 9.

30. See Karen Hansen and Mariken Vaa, Reconsidering Informality: Perspectives from Urban Africa (Madrid: Grafilur Artes Graficas, 2004).

31. See for example Yves Cabannes, 'Participatory Budgeting: A Significant Contribution to Participatory Democracy', Environment and Urbanization 16 (2004), 27; Ruth McLeod and Kim Mullard, Bridging the Finance Gap between Housing and Infrastructure (Dunmore: Homeless International, 2006); Somsook Boonyabancha, 'Land for Housing the Poor - by the Poor: Experiences from the Baan Mankong Nationwide Slum Upgrading Programme in Thailand', Environment and Urbanisation 21 (2009).

32. Watson, 'Seeing from the South', 2259.

33. See for example McFarlane, 'Rethinking Informality', 89.

34. Diane Archer, 'Finance as the Key to Unlocking Community Potential: Savings, Funds, and the ACCA Programme', Environment and Urbanization 24 (2012), 423.

35. Maurice Leonhardt, 'Together We Are Strong: Networks, Platforms and the Social Relations that Support a People's Process', Environment and Urbanization 24 (2012), 481.

36. See Bussara Sripanich, Vilas Nitivattananon and Ranjith Perera, 'City Development Fund: A Financial Mechanism to Support Housing and Livelihood Needs of Thailand's Urban Poor', Habitat International 49 (2015), 366, for a systematic comparison of the characteristics of these different mechanisms.

37. Asian Coalition for Housing Rights, 215 Cities in Asia: Fifth Yearly Report of the Asian Coalition for Community Action Programme, November 2014, accessed 10 October 2016: www.achr. net/upload/files/1\%20ACCA\%20How\%20it\%20works\%201-4.pdf.

38. ACHR, 215 Cities.

39. In many cases poor communities must be able to save a 10 per cent deposit of the amount of the loan to be borrowed for its access.

40. See Diane Archer, 'Empowering the Urban Poor through Community Based Slum Upgrading: The Case of Bangkok, Thailand', ISOCARP Congress 2010, accessed 10 October 2016, www.isocarp.net/Data/case_studies/1648.pdf.

41. See for example Archer, 'Finance as the Key', 423.

42. See Norberto Carcellar and Thomas Kerr, 'Assessing the ACCA Programme: Turning Asia's Community Upgrading Initiatives into an Open University', Environment and Urbanization 24 (2012), 513.

43. See Asian Coalition for Housing Rights, 107 Cities in Asia: Second Yearly Report of the Asian Coalition for Community Action Program, December 2010, accessed 10 October 2016, www. achr.net/download.php?ic $=5$. 
44. See for example Chawanad Luansang, Supawut Boonmahathanakorn and Maria Lourdes Domingo-Price, 'The Role of Community Architects in Upgrading: Reflecting on the Experience in Asia', Environment and Urbanization 24 (2012), 497.

45. See for example UN-HABITAT, Urbanization and Development: Emerging Futures, World Cities Report 2016, accessed 10 October 2016, http://wcr.unhabitat.org/main-report.

46. This information is derived from informal conversations and writings with members of ACVN and ACHR.

47. See Cities Alliance and Association of Cities of Vietnam, 'Operations Manual of Community Development Fund', Cities Alliance 2012, accessed 10 October 2016, www.citiesalliance. org/sites/citiesalliance.org/files/CAFiles/Projects/Final_CDF_Manual_with_Cover_Page. pdf.

48. This information is derived from internal documents from Vinh's City Community Development Fund in 2012.

49. This information is derived from reports and conversations with ACVN, ACHR government officials and community members in Vinh. Some documents can be accessed online, accessed 9 June 2017, www.achr.net/countries-de.php?ic $=2$.

50. This information is derived from conversations and writings from community leaders and members of the Huu Nghi community.

\section{Chapter 7}

1. Maurice Daly and Patrick Malone, 'Sydney: The Economic and Political Roots of Darling Harbour', in City, Capital and Water, ed. Patrick Malone (London: Routledge, 1994), 97.

2. Andrew Beer, Alan Morris and Chris Paris, 'Housing and Local Government in Australia in the 21st Century' (2014), accessed 25 June 2017, www.adelaide.edu.au/churp/Housing and_Local_Govt_in_the_21st_Century.pdf.

3. Michael Bounds and Alan Morris, 'Second Wave Gentrification in Inner-City Sydney', Cities 23 , no. 2 (2006).

4. Leonie Sandercock, Cities for Sale: Property, Politics and Urban Planning in Australia. (Melbourne: Melbourne University Press, 1975).

5. See Glen Searle and Michael Bounds, 'State Powers, State Land and Competition for Global Entertainment: The Case of Sydney', International Journal of Urban and Regional Research 23, no. 1 (1999), 168-70; Glen Searle and Jason Byrne, 'Selective Memories, Sanitised Futures: Constructing Visions of Future Place in Sydney', Urban Policy and Research 20, no. 1 (2002), 18-19. The early 1990s saw Pyrmont face the full force of iconic developments gentrify its neighborhood through the Star City Casino development.

6. NSW Government, Future Directions for Social Housing in NSW (NSW Government, 2015), accessed 25 June 2017, www.socialhousing.nsw.gov.au/?a=348442.

7. David Harvey, 'From Managerialism to Entrepreneurialism: The Transformation in Urban Governance in Late Capitalism', Geografiska Annaler. Series B. Human Geography 71, no. 1 (1989). Harvey identified the shift from managerialism to entrepreneurialism, a key feature of neoliberal governance strategies.

8. Larger developments in NSW fall under major project planning instruments when certain criteria are met, depending on the significance of the project, and more generally on capital value. See 'State Significant Development', accessed on 12 June 2017, www.planningportal. nsw.gov.au/understanding-planning/assessment-systems/state-significant-development.

9. Ali Madanipour, 'Roles and Challenges of Urban Design', Journal of Urban Design 11, no. 2 (2006), 189.

10. Visitors may include tourists and other non-permanent residents, whose interests tend to be prioritised in large developments that intersect the public and private.

11. David Pettigrew, Homes for the People: Public Housing in New South Wales (Sydney: David Pettigrew, 2005), 58-9.

12. Seth Nicholls, 'Perpetuating the Problem: Neoliberalism, Commonwealth Public Policy and Housing Affordability in Australia', Australian Journal of Social Issues 49, no. 3 (2014); Keith Jacobs, 'A Reverse Form of Welfarism: Some Reflections on Australian Housing Policy', Australian Journal of Social Issues 50, no. 1 (2015), 53. 
13. Spike Boydell and G.H. Searle, 'The Contemporary Urban Commons: A Case Study of Darling Harbour, Sydney', in COBRA Legal Research Symposium (London: RICS Org, 2010), 814.

14. Kane Pham, 'Ready or Not: The Inevitability of Another Casino in Sydney', Paper presented at the Urban Affairs Conference, San Diego, California, 16-19 March 2016.

15. Kane Pham, 'Vanity Unfair. Examining the Impact of Development Authorities on the Designation and Development of Public Space: Barangaroo Case Study', Proceedings of the State of Australian Cities Conference (2015).

16. Pham, 'Ready or Not'.

17. The NSW government has recently launched a website to signify the renewal of, and shift to, a strong image-driven cosmopolitan area that is a sharp about-face from the community it is currently evicting. See 'Rediscover Millers Point', accessed on 12 June 2017, http:// rediscovermillerspoint.com.au.

18. Charles Jencks, 'The Iconic Building Is Here to Stay', City 10, no. 1 (2006).

19. Fredric Jameson, quoted in Juhani Pallasmaa, Eyes of the Skin: Architecture and the Senses (Chichester: Wiley, 2012), 33.

20. For evidence of the ineffectiveness of supply-side subsidies in the US context see Beer, Morris and Paris, 'Housing'. Also see John F. McDonald, 'Affordable Housing: An Economic Perspective', Architecture_MPS 7, no. 3 (2015), 11.

21. Jacobs, 'Reverse Form', 60-1.

22. See Manuel B. Aalbers and Brett Christophers, 'Centring Housing in Political Economy', Housing, Theory and Society 31, no. 4 (2014).

23. NSW Government, East Darling Harbour Sydney Urban Design Competition (Sydney: New South Wales Government, 2005), 1.

24. Glen Searle, 'Case Study Window: Discourse, Doctrine and Habitus', in The Ashgate Research Companion to Planning and Culture, ed. Greg Young and Deborah Stevenson (Farnham: Ashgate, 2013), 144.

25. For analysis on the competitive model of connectivity, especially comparing Sydney with Melbourne on regional competitiveness, see Richard Hu, Edward J. Blakely and Yimin Zhou, 'Benchmarking the Competitiveness of Australian Global Cities: Sydney and Melbourne in the Global Context', Urban Policy and Research 31, no. 4 (2013).

26. As of late 2015 the SHFA has been consolidated under Government Property NSW within the Department of Finance, Services and Innovation portfolio.

27. Bill Randolph, East Darling Harbour and the Intermediate Housing Market, unpublished report prepared for the Sydney Harbour Foreshore Authority (2006).

28. Over the course of the development, the proponent has submitted and had approval for eight modifications that have successively granted a nearly doubling of developable GFA from the approved concept plan, iteratively allocating more prime foreshore land for private uses and shifting responsibility for provision of affordable housing onto community housing providers.

29. City of Sydney, Sustainable Sydney 2030: Final Consultation Draft (Sydney: City of Sydney, 2008).

30. Sydney, Sustainable Sydney, 256.

31. See Meredith Sussex and Shelley Penn, Barangaroo Review (2011), 45, accessed on 12 June 2017, www.barangaroo.com/media/43967/barangaroo\%20review $\% 20$ final $\% 20$ report $\% 2031 \% 20 j u l y \% 202011 \% 20$ compressed.pdf.

32. Michael Darcy and Dallas Rogers 'Place, Political Culture and Post-Green Ban Resistance: Public Housing in Millers Point, Sydney', Cities 57 (2015), 53.

33. JBA Urban, Environmental Assessment Report: Concept Plan Modification 8 and Major Development SEPP, State and Regional Development SEPP and Sydney Harbour SREP Amendments (2014), 92.

34. Nicole Hasham, 'Lend Lease Baulking at Providing Affordable Homes in Barangaroo', Sydney Morning Herald, 15 August 2014, accessed 1 June 2016, www.smh.com.au/nsw/lend-leasebaulking-at-providing-affordable-homes-in-barangaroo-20140814-1049rr.html.

35. See Darcy and Rogers, 'Place, Political', 7.

36. SGS Economics \& Planning, Millers Point and The Rocks: An Alternative Way Forward (2014), accessed on 12 June 2017, www.sgsep.com.au/assets/Millers-Point-Final-Report.pdf.

37. City of Sydney, Housing Issues Paper (Sydney: City of Sydney, 2015).

38. NSW Government, MP06_0162 MOD 8 Modification of Minister's Approval (2016), 19. 
39. See Mark Purcell, 'Excavating Lefebvre: The Right to the City and Its Urban Politics of the Inhabitant', GeoJournal 58, nos. 2-3 (2002).

40. See David Hayward, 'The Reluctant Landlords? A History of Public Housing in Australia', Urban Policy and Research 14, no. 1 (1996); observing the government as a 'reluctant landlord'.

41. See Shirley Fitzgerald and Christopher John Keating, Millers Point: The Urban Village (Ultimo: Halstead Press, 2009) for an in-depth account of the changes surrounding the condition of Millers Point from the nineteenth to the end of the twentieth century.

42. Fitzgerald and Keating, Millers Point, 104.

43. See NSW Government Family and Community Services, High Cost Harbourside Assets to Be Sold for a Fairer Social Housing System (2014), accessed on 12 June 2017, www.facs.nsw. gov.au/about_us/media_releases/pru/high_cost_harbourside_assets_to_be_sold_for_a_ fairer_social_housing_system.

44. Anita Blessing, 'Magical or Monstrous? Hybridity in Social Housing Governance', Housing Studies 27, no. 2 (2012).

45. Global and World City Database, accessed on 12 May 2016, www.lboro.ac.uk/gawc/ world2012t.html.

46. See Peabody Group website, accessed 12 June 2017, www.peabody.org.uk.

47. Tim Pitman, Luke Tozer and Edward Wainwright, 'Regarding the Residential', Arq: Architectural Research Quarterly 18, no. 2 (2014), 182.

48. 'Homes in Development: Mint Street', accessed on 12 June 2017, www.peabody.org.uk/ homes-in-development/tower-hamlets/mint-street.

49. Pitman, Tozer and Wainwright, 'Regarding the Residential', 185.

50. Pitman, Tozer and Wainwright, 'Regarding the Residential', 185.

51. The original group of architect firms were Breathe Architecture, Six Degrees Architects, Architecture Architecture, Clare Cousins Architects, MRTN, Robin Boyd Foundation, Austin Maynard Architects, Wolveridge Architects and Hip V Hype. See http://nightingalehousing.org.

52. Pham, 'Vanity Unfair'.

53. Pham, 'Ready or Not'.

54. The parkland at the northern end of the site suffers from swathes of rules and regulations for prescriptive uses. See Jillian Walliss, 'The Politics of Aesthetics: Expanding the Critique of Headland Park, Sydney', Journal of Landscape Architecture 7, no. 2 (2012), for an account of the competition phase, and Scott Hawken and Bruce Mackenzie, 'Barangaroo Reserve', Landscape Architecture Australia 149 (2016), 40 for an in-depth analysis for the completed site.

55. Kane Pham and Bligh Grant, 'Home, James, and Don't Spare the Horses: The Inevitability of a Second Sydney Casino', Australian Planner, accessed 3 July 2017, http://dx.doi.org/ 10.1080/07293682.2017.1319394.

56. Maria Kaika, 'Autistic Architecture: The Fall of the Icon and the Rise of the Serial Object of Architecture', Environment and Planning D: Society and Space 29, no. 6 (2011), 988.

57. Peggy Deamer, 'Architects, Really', in Can Architecture Be an Emancipatory Project?: Dialogues on Architecture and the Left, ed. Nadir Z. Lahiji (Alresford: John Hunt Publishing, 2016), 45.

58. Jacques Rancière, The Politics of Aesthetics (London: Bloomsbury Academic, 2014 [2000]), 35.

59. Kaika, 'Autistic Architecture'.

60. David Harvey, The New Imperialism (Oxford: Oxford University Press, 2003), 137.

61. Donna Haraway, The Haraway Reader (New York: Routledge, 2004), 83-7. Donna Haraway discusses the political semiotics of representation where 'actors' as recipients of action EW isolated from articulating the practice of forming.

62. Henri Lefebvre, 'Theses on the City', in Writings on Cities (Malden, MA: Blackwell Publishers, 1996 [1967]), 178.

63. Mark Purcell, 'Excavating Lefebvre: The Right to the City and its Urban Politics of the Inhabitant', GeoJournal 58, nos. 2-3 (2002).

64. Hayward, 'Reluctant Landlords'. Hayward explores the history of public housing in Australia, finding a gradual reluctance of the tiers of government to genuinely support the inclusion of public housing in their mandate.

65. Patsy Healey, 'The Universal and the Contingent: Some Reflections on the Transnational Flow of Planning Ideas and Practices', Planning Theory 11, no. 2 (2012), 190. 
66. Along with Barangaroo, Lend Lease are the developers of the Darling Harbour South redevelopment, which includes the public domain and convention centre renewal.

67. City of Sydney, Housing Issues.

\section{Chapter 8}

1. ArkleyWorks, accessed 13 March 2015, http://arkleyworks.com.

2. See 'Australian Home' (1993), ArkleyWorks, accessed 13 March 2015, http://arkleyworks. $\mathrm{com} / \mathrm{p}=5624$.

3. Elvis Richardson, 'Growth, Growth, Growth \& The Bedroom, Ocular Lab Inc @ Margaret Lawrence Gallery, VCA' (2012), accessed 29 November 2015, www.elvisrichardson.com/artproblems.html.

4. Herman Schwartz and Leonard Seabrooke, 'Varieties of Residential Capitalism in the International Political Economy', Comparative European Politics 6, no. 3 (2008), 239.

5. Wendell Cox and Hugh Pavletich, 10th Annual Demographia International Housing Affordability Survey (Belleville IL: Demographica, 2014), 6.

6. Museums Victoria, 'High Rise Housing in Melbourne: Atherton Gardens Estate, Fitzroy', accessed 27 March 2015, http://museumvictoria.com.au/learning-federation/infosheets/ atherton-gardens/high-rise-housing-in-melbourne.

7. Thomas Hall and Sonja Viden, 'The Million Homes Programme: A Review of the Great Swedish Planning Project', Planning Perspectives 20, no. 3 (2005).

8. Hall and Viden, 'Million Homes'.

9. Hall and Viden, 'Million Homes'.

10. Hall and Viden, 'Million Homes', 302.

11. Emma Holmqvist and Lena Magnusson Turner, 'Swedish Welfare State and Housing Markets: Under Economic and Political Pressure', Journal Housing and the Built Environment 29, no. 2 (2013), DOI 10.1007/s10901-013-9391-0.

12. Holmqvist and Magnusson Turner, 'Swedish Welfare State'.

13. Wendell Cox and Hugh Pavletich, 11th Annual Demographia International Housing Affordability Survey (Belleville IL: Demographia, 2015), 15. The data for the Australian ranking was sourced from 'the Real Estate Institute of Victoria, the Real Estate Institute of South Australia, the Real Estate Institute of Western Australia, Australian Property Monitors, the Real Estate Institute of Australia and various real estate internet web sites'.

14. Australian Bureau of Statistics, '4130.0 - Housing Occupancy and Costs, 2011-12' (28 August 2013), accessed 23 March 2015, www.abs.gov.au/AUSSTATS/abs@.nsf/Lookup/ 4130.0Main+Features12011-12?OpenDocument. The Australian Census is collected every five years and includes comprehensive housing data. The last Census was in 2016 and the next will be collected in 2021.

15. Australian Bureau of Statistics, '4130.0'.

16. National Shelter, 'Housing Australia Factsheet' (16 September 2014), accessed 23 March 2015, www.shelter.org.au/factsheets/housing-australia-factsheet.

17. Australian Government Department of Social Services, Housing Support, 'Social Housing Initiative-Fact Sheet' (2013), accessed 6 March 2015, www.dss.gov.au/our-responsibilities/ housing-support/programs-services/social-housing-initiative/social-housinginitiative-fact-sheet.

18. Sabo, 'Public housing in Sweden', accessed 23 March 2015, www.sabo.se/om_sabo/ english/Sidor/Publichousing.aspx.

19. Holmqvist and Magnusson Turner, 'Swedish Welfare State', 238.

20. State Government of Victoria, Department of Human Services, 'Public Housing Income and Asset Limits', accessed 20 March 2015, www.housing.vic.gov.au/public-housingincome-and-asset-limits.

21. See Arkitekturmuseet, Knitting House, The Swedish Museum of Architecture: A Fifty Year Perspective (Stockholm: Arkitekturmuseet, 2013); Arkdes, 'Knitting House' (2015), accessed 27 November 2015, www.arkdes.se/articles/knitting-house; Husby Konst \& Hantverks Förening, Elin Strand Ruin mfl: Knitting House, accessed 27 June 2017, www.husbygard. nu/knittinghouse.html; Elin Strand Ruin and Annika Enqvist, 'A Knitted Monument', in Arkitekturmuseet, Knitting House, 12-14.

22. Strand Ruin and Enqvist, 'Knitted Monument', 12.

23. Strand Ruin and Enqvist, 'Knitted Monument', 13. 
24. The Untitled Collective was founded in 2011 and consists of artists, graphic, industrial and urban designers, architects and housing researchers based in Melbourne (Australia) and Malmö (Sweden).

25. For an in-depth discussion of the socially engaged events for this exhibition please see Keely Macarow, 'What Use Is a Tea Towel', in Engaging Publics: Public Engagement, ed. Clare McIntosh (Auckland: Auckland Art Gallery, AUT University, 2015).

26. State Government of Victoria, Plan Melbourne, Metropolitan Planning Strategy 2014. (Melbourne: Victorian Government, 2014).

27. Rick Lowe used funding from The National Endowment for the Arts and private funds to purchase the houses. See Grant H. Kester, The One and the Many: Contemporary Collaborative Art in a Global Context (Durham NC and London: Duke University Press, 2011), 215.

28. Nato Thompson, Living as Form: Socially Engaged Art from 1991-2011 (New York and Cambridge MA: Creative Time Books and The MIT Press, 2012), 256-7.

29. Thompson, Living as Form, 33.

30. See Carlos Basualdo and Reinaldo Laddaga, 'Rules of Engagement', Artforum International 42 , no. 3 (2004).

31. Saara Liinamaa, 'Contemporary Art's "Urban Question" and Practices of Experimentation', Third Text 28, no. 6 (2014).

32. Marjetica Potrč, accessed 13 November 2015, www.potrc.org/index.html. For more on Marjetica Potrč's artistic, architectural and social practice please see Andres Lepick and Marjetica Potrč, 'Cities in Transition', in Architektonika, ed. Gabriele Knapstein and Matilda Felix (Berlin: Nationalgalerie, Staaliche Museen zu Berlin, 2013).

33. Anthony Kiendel, Informal Architectures: Space and Contemporary Cultures (London: Blackdog Publishing, 2008), 158-63.

\section{Chapter 9}

1. Mike Kelley, 'Architectural Non-Memory Replaced with Psychic Reality', in Minor Histories: Statements, Conversations, Proposals, ed. Mike Kelley et al. (Cambridge, MA: MIT Press, 2004), 322.

2. Mike Kelley quotation from Mary Elizabeth Anderson and Richard Haley, 'Going Home: Mike Kelley, Mobile Rhetoric, and Detroit', Body, Space \& Technology Journal 12 (2012), accessed 13 October 2016, www.bstjournal.com/vol12.

3. Mike Kelley, 'Mobile Homestead', in Whitney Biennial 2012, ed. Elisabeth Sussman et al. (New York: Whitney Museum of American Art, 2012), 161.

4. Kelley, 'Mobile Homestead', 159.

5. Jorge Luis Borges, 'On Exactitude in Science', in Jorge Luis Borges: Collected Fictions, trans. H. Hurley (New York: Penguin Books, 1998), 325.

6. Kelley, 'Mobile Homestead', 161.

7. Kelley, 'Architectural Non-Memory', 321.

8. George Baker, 'Sublevel', in Mike Kelley, ed. Eva Meyer-Hermann et al. (Amsterdam: Stedelijk Museum and Delmonico Books-Prestel, 2013), 354.

9. 'Kelley, 'Architectural Non-Memory', 319.

10. On the decentralisation of manufacturing see Thomas J. Sugrue, The Origins of the Urban Crisis: Race and Inequality in Postwar Detroit (Princeton: Princeton University Press, 1996), 127-30. On population data see June Manning Thomas, Redevelopment and Race: Planning a Finer City in Postwar Detroit (Detroit: Wayne State University Press, 2013), 84.

11. Robert Fishman, Bourgeois Utopias: The Rise and Fall of Suburbia (New York: Basic Books, 1987), 27.

12. Fishman, Bourgeois Utopias, 86.

13. Ben S. Bernanke, 'Housing, Housing Finance, and Monetary Policy', The Federal Reserve Bank of Kansas City's Economic Symposium. Jackson Hole (31 August 2007). Speech, accessed 2 January 2014, www.federalreserve.gov/newsevents/speech/bernanke20070831a.htm.

14. Kristen B. Crossney and David W. Bartelt, 'Residential Security, Risk, and Race: The Home Owners' Loan Corporation and Mortgage Access in Two Cities', Urban Geography 26, no. 8 (16 November 2005), 709. 
15. Kenneth T. Jackson, Crabgrass Frontier: The Suburbanization of the United States (New York: Oxford University Press, 1985), 204.

16. Jackson, Crabgrass Frontier, 204.

17. Federal Housing Administration (FHA), Underwriting Manual: Underwriting and Valuation Procedure Under Title II of the National Housing Act (Washington, DC: US Government Printing Office, 1936), Part II, Section 1, Paragraph 126 (1) (a), and Part II, Section 1, Paragraph 161.

18. FHA, Underwriting Manual, Part II, Section 2, Paragraph 284 (3) (g). See also Part II, Section 2, Paragraph 228: 'Where adjacent lots or blocks possess altogether different restrictions, especially for type and use of structures and racial occupancy, the effect of such restrictions is minimized and adequate protection cannot be considered to be present.' Also, Part II, Section 2, Paragraph 233: 'The Valuator should investigate areas surrounding the location to determine whether or not incompatible racial and social groups are present, to the end that an intelligent prediction may be made regarding the possibility or probability of the location being invaded by such groups. If a neighborhood is to retain stability it is necessary that properties shall continue to be occupied by the same social and racial classes. A change in social or racial occupancy generally leads to instability and a reduction in values.'

19. Corrigan v. Buckley, 271 U.S. 323 (1926), Page 271 U. S. 330, accessed 7 October 2016, https://supreme.justia.com/cases/federal/us/271/323/case.html.

20. The traditional Cape Cod cottage found on Cape Cod and parts of Massachusetts was a south-facing, one or one-and-a-half stories tall, side-gabled roof dwelling with wood shingle or lap siding. It featured a New England floor plan in which a central chimney stack and baffle entry separated a hall and parlour with a narrow kitchen and side rooms in the rear.

21. Greg Hise named the FHA's codified design the 'minimum house' although the term for an inexpensive, mass-produced house was used by Le Corbusier and Jeanneret in their paper "Analysis of the Fundamental Elements of the Problem of the "Minimum House", presented at the CIAM 2 conference in Frankfurt in September 1929. Greg Hise, Magnetic Los Angeles: Planning the Twentieth-Century Metropolis (Baltimore: The Johns Hopkins University Press, 1997).

22. Only the 'two-story sidewall stair plan' employed a different floor plan from the others; bedrooms and bathroom were sited on the second floor above a living room, dining or utility room, and kitchen.

23. Hise, Magnetic Los Angeles, 65. Of the loans accepted for insurance by the FHA for new single-family homes from 1934 to December 1940, 69.7 per cent were for four- or fiveroom houses. Federal Housing Administration (FHA), FHA Homes in Metropolitan Districts: Characteristics of Mortgages, Homes, Borrowers Under the FHA Plan 1934-1940 (Washington DC: US Government Printing Office, 1942), 216.

24. Northlawn Subdivision Restrictions Liber 2978, page 493, 2 October 1928; Liber 3449, page 35, 4 September 1930; Liber 4629, page 542, 26 February 1936; Liber 4725, page 193, 24 September 1936; Liber 9207, page 47, 13 April 1948. Northlawn Subdivision Plat Liber 54, page 91. Wayne County Register of Deeds Office, Detroit, Michigan.

25. Message from the Ann Arbor Board of Realtors regarding Michigan State Corporations and Securities Commission's housing non-discrimination proposal. 'Censure Denied by Ann Arbor President of Realty Board: Discrimination', Ypsilanti Daily Press, 24 June 1960, 1.

26. David Kushner, Levittown: Two Families, One Tycoon, and the Fight for Civil Rights in America's Legendary Suburb (New York: Walker \& Company, 2009); Barbara Kelly, Long Island History Journal 21, no. 2 (Spring 2010), accessed 12 October 2016, https://lihj. cc.stonybrook.edu/2010/reviews/levittown-two-families-one-tycoon-and-the-fight-forcivil-rights-in-america\%E2\%80\%99s-legendary-suburb.

27. United States, Housing and Home Finance Agency, An Introduction to Urban Renewal as Authorized by the Housing Act of 1954 (Washington, DC: Housing and Home Finance Agency, Office of the Administrator, 1954), 12; Alexander Von Hoffman, Enter the Housing Industry, Stage Right: A Working Paper on the History of Housing Policy (Cambridge, MA: Joint Center for Housing Studies, Harvard University, February 2008), 12, 33-5.

28. Mary Karmelek, 'Does Lafayette Park's Landmark Status Whitewash History?' Newsweek, 31 August 2015, accessed 9 October 2016, www.newsweek.com/does-lafayette-parkslandmark-status-whitewash-history-367320. June Manning Thomas, Redevelopment and Race, 60 , cites 1,900 families displaced for the Lafayette Park project.

29. Sigmund Freud, The Uncanny, trans. David Mclintock (London: Penguin Books, 2003), 147. 
30. Fred Moten, 'Enjoy All Monsters' (paper presented at Museum of Contemporary Art, Los Angeles, 24 July 2014).

31. Mike Kelley, Foul Perfection: Essays and Criticism (Cambridge, MA: The MIT Press, 2003), 94.

32. Mike Kelley, Jim Shaw and John C. Welchman, On the Beyond: A Conversation Between Mike Kelley, Jim Shaw, and John C. Welchman, ed. Cristina Bechtler (Vienna and New York: Springer, 2011), 43.

33. Moten, 'Enjoy All Monsters'.

34. Freud, The Uncanny, 148.

35. Kelley, 'Mobile Homestead', 161.

\section{Chapter 10}

1. For a discussion of this change in terminology see Michael Darcy, 'De-Concentration of Disadvantage and Mixed Income Housing: A Critical Discourse Approach', Housing, Theory and Society 27, no. 1 (2010).

2. Australian Institute of Health and Welfare, 'Housing Assistance in Australia', Cat no. HOU236 (2009), 5.

3. Dallas Rogers, 'The Sydney Metropolitan Strategy as a Zoning Technology: Analysing the Spatial and Temporal Dimensions of Obsolescence', Environment and Planning D: Society and Space 32, no. 1 (2014).

4. Patrick Troy, Accommodating Australian: Commonwealth Government Involvement in Housing (Canberra: Urban Research Program, 1997).

5. To view Housos, see the producers' official YouTube station: www.youtube.com/user/ SuperchocTV? feature $=$ watch.

6. Dallas Rogers and Michael Darcy, 'Global City Aspirations, Graduated Citizenship and Public Housing: Analysing the Consumer Citizenships of Neoliberalism', Urban Planning and Transport Research 2, no. 1 (2014).

7. Loïc Wacquant, 'Territorial Stigmatization in the Age of Advanced Marginality', Thesis Eleven 91, no. 1 (2007), 67; Erving Goffman, Stigma: Notes on the Management of Spoiled Identity (New York: Simon \& Schuster, 1963).

8. Deborah Warr, 'Social Networks in a "Discredited" Neighbourhood', Journal of Sociology 41, no. 3 (2005), 16.

9. Deborah Warr, 'There Goes the Neighbourhood: The Malign Effects of Stigma', in Proceedings of State of Australian Cities Conference (Brisbane: Griffith University, 2005), 19.

10. Kathy Arthurson, Social Mix and the Cities: Challenging the Mixed Communities Consensus (Clayton: CSIRO Publishing, 2012), 110.

11. Loïc Wacquant, Urban Outcasts: A Comparative Sociology of Advanced Marginality (Cambridge: Polity, 2008), 239.

12. Didier Lapeyronnie, ‘Ghetto urbain: ségrégation, violence, pauvreté en France aujourd'hui' (Paris: Éditions Robert Laffont, 2008).

13. Keith Jacobs, Kathy Arthurson, Rob White and J. Donoghue, Developing Effective Housing Management Strategies to Address Problems of Anti-Social Behaviour (Melbourne: AHURI, 2003).

14. Dallas Rogers, 'The Politics of Space and Time within Market-Centric Urban Policy: The Case of the Bonnyrigg Living Communities Project', Polymath: An Interdisciplinary Arts and Sciences Journal 2, no. 3 (2012).

15. David Imbroscio, '[U]nited and Actuated by Some Common Sense of Passion: Challenging the Dispersal Consensus in American Housing Policy Research', Journal of Urban Affairs 30, no. 2 (2008), 123.

16. Pierre Bourdieu, 'The Forms of Capital', in Handbook of Theory and Research for the Sociology of Education, ed. John Richardson (New York: Greenwood, 1986).

17. Darcy, 'De-Concentration of Disadvantage'.

18. Kristian Ruming, Kathleen J. Mee and Pauline Mcguirk, 'Questioning the Rhetoric of Social Mix: Courteous Community or Hidden Hostility?', Australian Geographical Studies 42, no. 2 (2004).

19. See http://ice.org.au. 
20. Knut Lundby, ed., Digital Storytelling, Mediatized Stories: Self-Representations in New Media (New York: Peter Lang, 2008), 1.

21. Marilys Guillemin and Sarah Drew, 'Questions of Process in Participant-Generated Visual Methodologies', Visual Studies 25, no. 2 (2010), 175.

22. Dallas Rogers, 'Research, Practice and the Space Between: Care of the Self within Neoliberalized Institutions', Cultural Studies $<=>$ Critical Methodologies 12, no. 3 (2012).

23. All participants consented to their real names being used in dissemination of the stories and publications arising from the project, and this practice was also approved by Western Sydney University Human Research Ethics Committee.

24. Bourdieu, 'Forms of Capital'.

25. Stephanie Lawler, 'Disgusted Subjects: The Making of Middle Class Identities', The Sociological Review 53, no. 3 (2005), 429.

26. Jayne Raisborough and Matt Adams, 'Mockery and Morality in Popular Cultural Representations of the White, Working Class', Sociological Research Online 12, no. 3 (2008).

27. Lawler, 'Disgusted Subjects', 429.

28. Beverley Skeggs, 'Imagining Personhood Differently: Person Value and Autonomist Working-Class Value Practices', The Sociological Review 59, no. 3 (2011).

29. For a detailed description of methods for this study see Dallas Rogers, Michael Darcy and Kathy Arthurson, 'Researching Territorial Stigma with Social Housing Tenants: Tenant-Led Digital Media Production about People and Place', in Negative Neighbourhood Reputation and Place Attachment: The Production and Contestation of Territorial Stigma, ed. Paul Kirkness and Andreas Tijé-Dra (London: Routledge, 2017).

30. See www.roarfootage.com.au.

31. View trailer at www.youtube.com/watch? $v=r P j S q Y r o Y D g$, accessed 20 June 2017.

32. Information and Cultural Exchange, The Making of 'Lost in the Woods', accessed on 20 June 2017, www.youtube.com/watch?v=CVUtYuOj_Jo.

33. Loïc Wacquant, 'Territorial Stigmatisation in the Age of Advanced Marginality', Thesis Eleven 91 (2007).

\section{Chapter 11}

1. See www.experimentalresidential.wordpress.com.

2. Studio Polpo is a not-for-profit architecture practice based in Sheffield. It was set up by Mark Parsons and Cristina Cerulli in 2008 and is now run by six directors including me. See www.studiopolpo.com.

3. BAVO, 'Introduction', in Urban Politics Now: Re-Imagining Democracy in the Neoliberal City, ed. BAVO (Rotterdam: NAi Publishers, 2007), 7.

4. The Right to the City originates from the writing of Henri Lefebvre. More recently the geographer David Harvey has argued that this is one of our most important but least championed rights; 'the right to the city is far more than the individual liberty to access urban resources: it is a right to change ourselves by changing the city.' David Harvey, 'The Right to the City', New Left Review 53 (September-October 2008), accessed on 21 June 2017, http://newleftreview.org/II/53/david-harvey-the-right-to-the-city, para. 4

5. This refers not only to policing of public space by the police force and private security guards, but also 'spatial policing'. See, for example, Erik Swyngedouw, 'The Post-Political City', in Urban Politics Now: Re-Imagining Democracy in the Neoliberal City, ed. BAVO (Rotterdam: NAi Publishers, 2007), 62.

6. Henri Lefebvre, The Production of Space, trans. Donald Nicholson-Smith (Oxford: Blackwell, 1991), 49.

7. Lefebvre, Production of Space, 33.

8. Jürgen Habermas, The Structural Transformation of the Public Sphere: An Inquiry into a Category of Bourgeois Society (Cambridge: Polity, 1989).

9. See for example Chantal Mouffe's work on agonism and public space: Chantal Mouffe, 'Some Reflections on an Agonistic Approach to the Public', in Making Things Public: Atmospheres of Democracy, ed. Bruno Latour and Peter Weibel (Cambridge, MA: The MIT Press, 2005), 806. 
10. Nancy Fraser, 'Rethinking the Public Sphere: A Contribution to the Critique of Actually Existing Democracy', Social Text 25/26 (1990): 73.

11. Fraser, 'Rethinking the Public Sphere', 61.

12. Bruno Latour, 'From Realpolitik to Dingpolitik or How to Make Things Public', in Making Things Public: Atmospheres of Democracy, ed. Bruno Latour and Peter Weibel (Cambridge, MA: The MIT Press, 2005).

13. This is the title of Latour's book, which makes the case for the modern illusion in science. See Bruno Latour, We Have Never Been Modern, trans. Catherine Porter (Cambridge, MA: Harvard University Press, 1993).

14. Latour, 'From Realpolitik to Dingpolitik', 15.

15. John Law, 'Objects, Spaces and Others', published by the Centre for Science Studies, Lancaster University (2000), accessed 21 June 2017, www.lancaster.ac.uk/fass/resources/ sociology-online-papers/papers/law-objects-spaces-others.pdf.

16. 'About', Spatial Agency, accessed 10 March 2015, www.spatialagency.net.

17. Latour, 'From Realpolitik to Dingpolitik', 14.

18. Stephen Wright, 'The Future of the Reciprocal Readymade: An Essay on Use-Value and Art Related Practice', accessed 10 March 2015, www.turbulence.org/blog/archives/000906. html.

19. Wright quoted in Doina Petrescu, 'How to Make a Community as Well as the Space for It', in Space Shuttle (Belfast: PS2, 2007), 48, accessed 10 March 2015, www.spaceshuttle.org.uk/ Publication.pdf.

20. Petrescu, 'How to Make a Community'.

21. Petrescu, 'How to Make a Community', 48.

22. Agnieszka Gratza, 'On the Evolution of "Performance Architecture"', Frieze 157 (2013), 141.

23. Alex Schweder La, 'Performance Architecture', in Urban Interior: Informal Explorations Interventions and Occupations, ed. Rochus Urban Hinkel (Germany: Spurbuchverlag, 2011), 131-2.

24. Alex Schweder, 'Performance Architecture', Le Journal Spéciale'Z 4 (2012), 104.

25. Schweder, 'Performance Architecure', 104.

26. Schweder La, 'Performance Architecture', 131.

27. Nicolas Bourriaud uses micro-utopia to describe artworks that create lasting alternative social realities in the here and now. He argues that this type of 'Relational Art' creates temporary communities that reject privatised spaces of consumption: 'New "life possibilities" appear to be possible. It seems more pressing to invent possible relations with our neighbours in the present than to bet on happier tomorrows.' Nicolas Bourriaud, Relational Aesthetics (Dijon: Presses du réel, 2002), 45.

28. Carlos Mínguez Carrasco, 'Ikea Disobedients at MoMA PS1', Domus (3 October 2012), accessed 10 March 2015, www.domusweb.it/en/architecture/2012/10/03/ikeadisobedients-at-moma-ps1.html.

29. Andrés Jaque Arquitectos, 'Ikea Disobedients', video, accessed 10 March 2015, www.moma. org/explore/multimedia/videos/235/1158.

30. Mínguez Carrasco, 'Ikea Disobedients'.

31. Agnieszka Gratza, 'On the Evolution', 141.

32. Unpublished recorded interview with Nicolas Henninger (2012).

33. Interview with Henninger.

34. The Institute for the Art and Practice of Dissent at Home, Four Boys [for Beuys], (Liverpool: The Institute for the Art and Practice of Dissent at Home, 2016).

35. The Institute for the Art and Practice of Dissent at Home, ed., Five (Liverpool: The Institute for the Art and Practice of Dissent at Home, 2014), 17.

36. The Institute, Five, 4.

37. Bruce Bennett and Imogen Tyler, 'The Art of Disobedience: The Domopolitics of The Institute for the Art and Practice of Dissent at Home', in Five, ed. The Institute for the Art and Practice of Dissent at Home (Liverpool: The Institute for the Art and Practice of Dissent at Home, 2014), 15.

38. Albena Yaneva, Made by the Office for Metropolitan Architecture: An Ethnography of Design (Rotterdam: 010 Publishers, 2009), 100.

39. Yaneva, Made by the Office, 12 .

40. Andrés Jaque Arquitectos, 'Ikea Disobedients'.

41. Accessed 21 June 2017, www.youtube.com/user/exyzt. 
42. The Institute, Five, 30.

43. Accessed 21 June 2017, www.youtube.com/user/dissentathome.

44. David Hayano is usually credited as the originator of autoethnography, first using it in 1979: see David Hayano, 'Auto-Ethnography: Paradigms, Problems and Prospects', Human Organisation 38 (1979).

45. James Clifford 'Introduction', in Writing Culture: The Poetics and Politics of Ethnography, ed. James Clifford and George E. Marcus (Berkeley and Los Angeles: University of California Press, 1986), 15.

46. See, for example, Carolyn Ellis, The Ethnographic I: A Methodological Novel about Autoethnography (Walnut Creek, CA: Alta Mira Press, 2004).

47. Deborah E. Reed-Danahay, 'Introduction', in Auto/Ethnography: Rewriting the Self and the Social, ed. Deborah E. Reed-Danahay (Oxford: Berg, 1997), 6; for further information on the history of the term, see pages 4-9.

48. Heewon Chang, Autoethnography as Method (Walnut Creek, CA: Left Coast Press, 2008), 47.

49. Carolyn Ellis, Revision: Autoethnographic Reflections on Life and Work (Walnut Creek, CA: Left Coast Press, 2009), 18.

50. Ellis, Revision, 34.

51. Reed-Danahay, 'Introduction', 8.

52. Emma Gieben-Gamal and Juliette MacDonald, 'The Mobile Office: An Autoethnographic Account', Idea Journal: Interior Economies (2011).

53. Gieben-Gamal and MacDonald, 'Mobile Office', 91.

54. Gieben-Gamal and MacDonald, 'Mobile Office', 100.

55. The Moor, Sheffield, Theatre Delicatessen North, accessed 21 June 2017, http://theatredelicatessen.co.uk/about/the-moor-sheffield.

56. Accessed 21 June 2017, https://experimentalresidential.wordpress.com.

57. Studio Polpo, 'A Scrapbook From OPERA \#1 at Castle House', accessed 21 June 2017, https://issuu.com/studiopolpo/docs/opera_scrapbook.

58. Lee Gutkind, 'The Creative Nonfiction Police?', in In Fact: The Best of Creative Nonfiction, ed. Lee Gutkind (New York: W.W. Norton, 2015).

59. Jonathan Orlek, paper presented to 'Housing: A Critical Perspective Conference', Liverpool, 8-9 April 2015, accessed 21 June 2017, http://architecturemps.com/ housing-critical-perspective.

60. Laurel Richardson and Elizabeth Adams St Pierre, 'Writing, A Method of Inquiry', in The Sage Handbook of Qualitative Research, ed. N.K. Denzin and Y.S. Lincoln (Thousand Oaks: Sage Publications, 2005).

61. Jonathan Orlek, Mark Parsons and Cristina Cerulli, 'Prototyping Shared Living: Collective Residential Experiments', Circular Economy and Symbiosis: The Sustainable Regenerative City Model, BDC Journal 16, no. 2 (2016).

62. Malcom Miles, 'IAPDH', in Five, ed. The Institute for the Art and Practice of Dissent at Home(Liverpool: The Institute for the Art and Practice of Dissent at Home, 2014), 24.

63. Ben Walmsley, 'Deep Hanging Out in the Arts: An Anthropological Approach to Capturing Cultural Value', International Journal of Cultural Policy (2016), 3, accessed 21 June 2017, http://www.tandfonline.com/doi/pdf/10.1080/10286632.2016.1153081.

\section{Chapter 12}

1. Originally published as 'The Dilapidated Dwelling', in The View from the Train: Cities and Other Landscapes (London: Verso Books, 2013); also reprinted in Architecture_media_ politics_society 6, no. 3 (2015), accessed on 21 June 2017, http://architecturemps.com/ back-issues.

2. Keiller, 'Dilapidated Dwelling', 54.

3. Keiller, 'Dilapidated Dwelling', 54.

4. See John F.C. Turner's much-cited essay 'Housing as a Verb', in Freedom to Build, ed. John F.C. Turner and Robert Fichter (New York: Collier Macmillan, 1972).

5. This is encapsulated by a growing body of research on the phenomenon of 'shrinking cities', which for Liverpool's context see Chris Couch and Matthew Cocks, 'Housing Vacancy and the Shrinking City: Trends and Policies in the UK and the City of Liverpool', Housing Studies 28 , no. 3 (2013). 
6. Tony Lane, Liverpool: City of the Sea, 2nd ed. (Liverpool: Liverpool University Press, 1997), 46.

7. From the 1960 s to the 1980s, Liverpool's port activity suffered a huge decline through economic restructuring alone, with the 7.5-mile-long southern dock system closing entirely in 1971. See Olivier Sykes et al., 'A City Profile of Liverpool', Cities 35 (2013).

8. Lane, Liverpool.

9. Much of the information on HMR in this paper is gathered from the author's doctoral research and these key sources: Ian Cole, 'Housing Market Renewal and Demolition in England in the 2000s: The Governance of "Wicked Problems", International Journal of Housing Policy 12, no. 3 (2012); Chris Allen, Housing Market Renewal and Social Class (Abingdon: Routledge, 2008); David Webb, 'Conceptualising the Bounded Agency of Housing Researchers: The Case of Housing Market Renewal in England', International Journal of Housing Policy 12, no. 3 (2012); Webb, "Problem Neighbourhoods" in a PartLinear, Part-Network Regime: Problems with, and Possible Responses to, the Housing Market Renewal Leviathan', unpublished PhD thesis, Newcastle University, 2011; Matthew Cocks and Chris Couch, 'The Governance of a Shrinking City: Housing Renewal in the Liverpool Conurbation, UK', International Planning Studies 17, no. 3 (August 2012).

10. Friedrich Engels, The Housing Question (Moscow: Progress Publishers, 1954 [1872]).

11. Friedrich Engels, Housing Question.

12. Friedrich Engels, The Condition of the Working Class in England in 1844 (New York: Cosimo Classics, 2008 [1892]), 36.

13. Throughout this paper I draw on Henri Lefebvre, The Production of Space (Oxford: Blackwell, 1991).

14. Japhy Wilson, "The Devastating Conquest of the Lived by the Conceived": The Concept of Abstract Space in the Work of Henri Lefebvre', Space and Culture 16, no. 3 (15 May 2013).

15. For the interpretation of Lefebvre offered here, I draw on the 'third wave' of Lefebvrean scholarship, such as: Lucasz Stanek, 'Space as Concrete Abstraction: Hegel, Marx, and Modern Urbanism in Henri Lefebvre', in Space, Difference, Everyday life: Reading Henri Lefebvre, ed. Kanishka Goonewardena et al. (Abingdon: Routledge, 2008); Wilson, 'Devastating Conquest'; Andy Merrifield, 'Place and Space: A Lefebvrian Reconciliation', Transactions of the Institute of British Geographers 18, no. 4 (2013).

16. See Robert MacDonald, 'The City as a Laboratory of Shadows: Exposing Secret Histories While Thinking of the Future', Architecture_media_politics_society 4, no. 1 (2014).

17. See key works by Lefebvre, The Urban Revolution (Minneapolis: University of Minnesota Press, 2003) and Production of Space, and secondary literature, notably: Nathaniel Coleman, 'Utopian Prospect of Henri Lefebvre', Space and Culture 16, no. 3 (2013); Fran Tonkiss, 'Austerity Urbanism and the Makeshift City', City: Analysis of Urban Trends, Culture, Theory, Policy, Action 17, no. 3 (2013); David Pinder, 'Reconstituting the Possible: Lefebvre, Utopia and the Urban Question', International Journal of Urban and Regional Research 39, no. 1 (2013).

18. For a detailed first-hand account of the Weller Streets' campaign, see Alan McDonald, The Weller Way: The Story of the Weller Street Housing Cooperative (London: Faber \& Faber).

19. Slavoj Žižek, The Year of Dreaming Dangerously (London: Verso, 2012).

20. CLTs are a model imported from the USA, originally innovated to promote black property rights, and recently established in the UK predominantly to tackle issues of rural affordability and urban gentrification and financial speculation, rather than disinvestment and decline. For an up-to-date comparative overview of the British CLT movement, see Tom Moore, Affordable Homes for Local Communities: The Effects and Prospects of Community Land Trusts in England (St Andrews: University of St Andrews Centre for Housing Research, 2014).

21. This is explored in detail in another article: Matthew Thompson, 'Between Boundaries: From Commoning and Guerrilla Gardening to Community Land Trust Development in Liverpool', Antipode 47, no. 4 (2015).

22. For an exegesis on Lefebvre's theory of abstract space see Wilson, 'Devastating Conquest'.

23. Lefebvre, Production of Space.

24. See Colin Ward, When We Build Again: Let's Have Housing That Works! (London: Pluto Press, 1985).

25. Karl Marx, Capital: Critique of Political Economy, vol. 1 (Harmondsworth: Penguin Classics, 1976). 
26. Lefebvre, Production of Space.

27. Andy Merrifield, 'Place and Space: A Lefebvrian Reconciliation', Transactions of the Institute of British Geographers 18, no. 4 (2013).

28. Marx quoted in Stanek, 'Space as Concrete Abstraction', 62.

29. Patrick Keiller, 'Port Statistics', in View from the Train. This essay directly precedes 'The Dilapidated Dwelling', which I take as no accident, in framing for Keiller the structural causes of the latter.

30. Keiller, 'Port Statistics', 41.

31. Lefebvre, Production of Space, 113.

32. Lefebvre, Production of Space, 113.

33. Lefebvre, Production of Space, 95-6.

34. Lefebvre, Production of Space, 93.

35. See the original critique by Rod Burgess, 'Petty Commodity Housing or Dweller Control? A Critique of John Turner's Views on Housing Policy', World Development 6, no. 9-10 (September 1978), and Turner's response: John F.C. Turner, 'Housing in Three Dimensions: Terms of Reference for the Housing Question Redefined', World Development 6, no. 9-10 (September 1978).

36. Interview with Ward quoted in Colin Ward and David Goodway, Talking Anarchy(Oakland: Five Leaves Publications, 2003), 74-5.

37. CDS, Building Democracy: Housing Cooperatives on Merseyside. Update '94 (Liverpool: Cooperative Development Services (Liverpool) Ltd, 1994), 7.

38. José Ospina, Housing Ourselves (London: Hilary Shipman, 1987).

39. Graham Towers, Building Democracy: Community Architecture in the Inner Cities (Abingdon: Routledge, 1995).

40. McDonald, Weller Way, 84.

41. For the definitive historical account of the Eldonian community and their development of the Eldonian Village see Jack McBane, The Rebirth of Liverpool: The Eldonian Way (Liverpool: Liverpool University Press, 2008).

42. This and other information in this section is derived mainly from the findings of PhD research conducted between 2011 and 2015, including around 40 semi-structured interviews with architects, housing managers, politicians, co-op activists and residents involved in projects from the 1960s to today. Augmenting this original research are secondary sources: some of CDS's retrospective reports and key academic evaluations of the co-op movement, such as David Clapham and Keith Kintrea, Housing Co-Operatives in Britain (Harlow: Longman, 1992); CDS, Building Democracy; Johnston Birchall, Building Communities the Co-Operative Way (Abingdon: Routledge, 1988); Paul Lusk, 'Citizenship and Consumption in the Development of Social Rights: The Liverpool New-Build Housing Co-Operative Movement', unpublished thesis, Salford University, 1998.

43. For a political history of Militant in Liverpool told through participants see Diane Frost and Peter North, Militant Liverpool: A City on the Edge (Liverpool: Liverpool University Press, 2013).

44. For a critical account of the URS programme, and its clash with the co-op movement, see the series of articles in the Architects' Journal and ROOF, notably Anne Grosskurth, 'Bringing Back the Braddocks', ROOF 10, no. 1 (January-February 1985); Tim Mars, 'Mersey Tunnel Vision?', ROOF 12, no. 6 (November-December 1987).

45. Mars, 'Mersey Tunnel Vision?', 26.

46. See Jane Jacobs and Loretta Lees, 'Defensible Space on the Move: Revisiting the Urban Geography of Alice Coleman', International Journal of Urban and Regional Research 37, no. 5 (27 September 2013).

47. See the most famous defence of Militant politics from two leading Militants: Peter Taafe and Tony Mulhearn, Liverpool: A City that Dared to Fight (London: Fortress Books, 1988), 159.

48. Grosskurth, 'Bringing Back the Braddocks'.

49. Owen Hatherley, A Guide to the New Ruins of Great Britain (London: Verso, 2011), 335.

50. Interview with author in 2013.

51. Quoted in Mars, 'Mersey Tunnel Vision?', 27.

52. Interview with author in 2014.

53. For a more detailed account of the complex mix of factors behind the rationale in Liverpool's HMR Pathfinder for targeting the terraced house, see David Webb's PhD thesis, 'Problem Neighbourhoods'. 
54. For critical accounts of the abstract market logic of Liverpool's HMR programme, see Allen, Housing Market Renewal; Webb, 'Conceptualising the Bounded Agency'.

55. Author interviews with residents and activists in HMR areas, 2013-14.

56. Hatherley, Guide to the New Ruins, 336-8.

57. Interview with author in 2014.

58. Thompson, 'Between Boundaries'.

59. See the website for 2Up2Down, accessed 21 June 2017, www.2up2down.org.uk; and Homebaked's new website, accessed 21 June 2017, http://homebaked.org.uk.

60. Author biography for Jeanne in Jeanne Van Heeswijk and Britt Jurgensen, 'Introduction', Stages: Liverpool Biennial 2, Homebaked: A Perfect Recipe (2014), accessed 21 June 2017, www.biennial.com/journal/issue-2. This and many of the following quotes are taken from contributions to a special edition of Stages, the online journal published by the Liverpool Biennial.

61. See Moore, Affordable Homes, for a comparative case study of the CLT project.

62. Author interview in 2013.

63. Heeswijk and Jurgensen, 'Introduction'.

64. Jeanne Van Heeswijk and Britt Jurgensen, "We Are Here to Stay', Stages: Liverpool Biennial 1, Future City (2014), accessed 21 June 2017, www.biennial.com/journal/issue-1.

65. Samantha Jones, 'Becoming Homebaked', Stages: Liverpool Biennial 2, Homebaked: A Perfect Recipe (2014), accessed 21 June 2017, www.biennial.com/journal/issue-2.

66. This reflects current debates in temporary experiments growing in the cracks of austerity urbanism; see Tonkiss, 'Austerity Urbanism'.

67. Interviews with author, 2014.

68. See his review of The View from the Train in the London Review of Books: Will Self, 'The Frisson: Book Review of The View From the Train', London Review of Books (20 January 2014), accessed 21 June 2017, www.lrb.co.uk/2014/01/20/will-self/the-frisson.

69. Interviews with author, 2014.

70. Lefebvre, Production of Space, 189-90. 


\section{References}

\section{Chapter 1}

Arantes, Pedro Fiori. Arquitetura Nova: Sérgio Ferro, Flávio Império e Rodrigo Lefèvre, de Artigas Aos Mutirões. São Paulo: EDITORA 34, 2002.

Bonduki, Nabil. Origens da Habitação Social no Brasil: Arquitetura Moderna, Lei do Inquiliniato e Difusão da Casa Própria. 6th ed. São Paulo: Estação Liberdade, 2006.

Brillembourg, Alfredo, and Hubert Klumpner. Torre David: Informal Vertical Communities. Zurich: Lars Müller Publishers, 2012.

Campos, Candido Malta. Os Rumos da Cidade: Urbanismo e Modernização em São Paulo. São Paulo: Editora Senac, 2002.

Freire, Paulo. A Pedagogia do Oprimido. Rio de Janeiro: Paz e Terra, 1968.

Frugoli, Heitor Junior. Centralidade em São Paulo: Trajetórias, Conflitos e Negociações na Metrópole. São Paulo: Editora da Universidade de São Paulo, 2000.

Fundação João Pinheiro. Déficit Habitacional no Brasil: 2011-2012. Belo Horizonte: Fundação João Pinheiro, 2015.

Gonçalves, Fábio Mariz, Anna Gabriela Hoverter Callejas and Rodrigo Minoru Hayakawa Tanaka. Estudo Para Implantação de Unidades Habitacionais no Centro de São Paulo. São Paulo: Fundação para Pesquisa Ambiental, 2009.

Harms, Hans. 'Historical Perspectives on the Practice and Purpose of Self-Help Housing'. In Self-Help Housing: A Critique, edited by Peter Ward, 17-53. London: Mansell Publishing Limited, 1982.

Holm, Andrej, and Armin Kuhn. 'Squatting and Urban Renewal: The Interaction of the Squatters' Movements and the Strategies of Urban Restructuring in Berlin'. In Squatting in Europe: Radical Spaces, Urban Struggles, edited by SqEK Squatting Europe Kollective, 16184. New York: Autonomedia, 2013.

Holston, James. Insurgent Citizenship: Disjunctions of Democracy and Modernity in Brazil. Princeton: Princeton University Press, 2008.

Instituto Brasileiro de Geografia e Estatística (IBGE). 'Censon Demográficos', 2010.

Lévi-Strauss, Claude. The Savage Mind. Chicago: University of Chicago Press, 1962.

Levy, Charmaine. 'Brazilian Urban Popular Movements: The 1997 Mobilization of the Inner-City Slum Movement in São Paulo', Studies in Political Economy 85 (2010): 35-68.

Mehrotra, Raul, and Felipe Vera. Kumbh Mela: Mapping the Ephemeral Megacity. New Delhi: Niyogi Books, 2015.

Nakano, Kazuo, Candido Malta Campos and Raquel Rolnik. 'Dinâmicas dos Subespaços da Área Central de São Paulo'. In Caminhos Para O Centro: Estratégias de Desenvolvimento Para a Região Central de São Paulo, edited by Alvaro Comin and Nadia Somekh, 123-58. São Paulo: EMURB, Prefeitura de São Paulo, 2004.

Pasternack Tascher, Suzana. 'Squatter Settlements and Slums in Brazil: Twenty Years of Research and Policy'. In Housing the Urban Poor: Policy and Practice in Developing Countries, edited by B.C. Aldrich and R. Sandhu, 185-223. London: Zed Books, 1995.

Remy, Jean, and Liliane Voyé. Ville, Ordre et Violence: Formes Spatiales et Transaction Sociale. Espace et Liberté vol. 4. Paris: Presses Universitaires de France, 1981. 
Sanches, Débora. 'Processo Participativo Como Instrumento de Moradia Digna: Uma Avialiação dos Projetos da Área Central de São Paulo - 1990 a 2012'. Doctoral thesis, Universidade Presbiteriana Mackenzie, 2015.

Silva, Helena Menna Barreto. Habitação no Centro de São Paulo: Como Viabilizar Essa Idéia? Documento Preparatório. São Paulo: LABHAB/FAUUSP, 2000.

Silva, Helena Menna Barreto, Adriano Henrique Rebelo Biava and Letícia Moreira Sígolo. 'Tributos Imobiliários e Imóveis Vazios no Centro de São Paulo: Relatório Final'. São Paulo: FAU-USP, 2009.

Solnit, Rebecca. A Paradise Built in Hell: The Extraordinary Communities that Arise in Disaster. New York: Viking Adult, 2010.

Somekh, Nadia. A Cidade Vertical e o Urbanismo Modernizar. São Paulo: Editora Mackenzie, 2014.

Somekh, Nadia, and Candido Malta Campos. A Cidade que Não Pode Parar: Planos Urbanisticos de São Paulo no Século XX. São Paulo: Editora Mackenzie, 2002.

SqEK Squatting Europe Kollective. Squatting in Europe: Radical Spaces, Urban Struggles. New York: Autonomedia, 2013.

Steen, Bart van der, Ask Katzeff and Leendert van Hoogenhuijze, eds. The City Is Ours: Squatting and Autonomous Movements in Europe. Oakland: PM Press, 2014.

Stevens, Jeroen, Bruno De Meulder and Débora Sanches. 'Cortiços: Interstitial Urbanization in Central São Paulo'. In The Political Meaning of Informal Urbanization, edited by Roberto Rocco and Jan Van Ballegooien. Abingdon: Routledge, forthcoming.

Turner, John F.C., and Robert Fichter. Freedom to Build: Dweller Control of the Housing Process. New York: Macmillan, 1972.

Turner, Victor. Dramas, Fields and Metaphors: Symbolic Action in Human Society. Ithaca and London: Cornell University Press, 1974.

Ward, Colin. Cotters and Squatters: Housing's Hidden History. Nottingham: Five Leaves, 2002.

Ward, Colin. Housing: An Anarchist Approach. London: Freedom Press, 1976.

Zibechi, Raul. Territories in Resistance: A Cartography of Latin American Social Movements. Oakland: AK Press, 2012.

\section{Chapter 2}

Association of Chief Police Officers (ACPO). ACPO Guidance on Unauthorised Encampments, version 13 June 2011. Association of Chief Police Officers of England, Wales and Northern Ireland.

Bancroft, Angus. Roma and Gypsy-Travellers in Europe: Modernity, Race, Space and Exclusion, Aldershot: Ashgate Press, 2005.

Bauman, Zygmunt. Modernity and the Holocaust. Cambridge: Polity Press, 1989.

Fisher, Roger, and William Ury. Getting to Yes: Negotiating an Agreement Without Giving In. London: Random House, 1999.

Forester, John. Dealing with Differences: Dramas of Mediating Disputes. Oxford: Oxford University Press, 2009.

Healey, Patsy. Collaborative Planning: Shaping Places in Fragmented Societies. 2nd ed. Basingstoke: Palgrave Macmillan, 2006.

Holloway, Sarah. 'Outsiders in Rural Society? Constructions of Rurality and Nature-Social Relations in the Racialisation of English Gypsy-Travellers, 1869-1934'. Environment and Planning D: Society and Space 21 (2002): 695-715.

Kaufman, Sanda, and Janet Smith. 'Framing and Reframing in Land Use Change Conflicts'. Journal of Architectural and Planning Research 16, no. 2 (1999): 164-80.

Kenrick, Donald. The Gypsies During the Second World War: In the Shadow of the Swastika. Hatfield: University of Hertfordshire, 1999.

Kenrick, Donald. Gypsies: From the Ganges to the Thames. Hatfield: University of Hertfordshire Press, 2004.

Kenrick, Donald, and Colin Clark. Moving On: The Gypsies and Travellers of Britain. Hatfield: University of Hertfordshire Press, 1999.

Lefebvre, Henri. The Production of Space. Oxford: Blackwell, 1991.

Liégeois, J.-P. Roma in Europe. Strasbourg: Council of Europe Publishing, 2007. 
Morris, Rachel, and Luke Clements. At What Cost? The Economics of Gypsy and Traveller Encampments, Bristol: Policy Press, 2002.

Porter, Libby. Unlearning the Colonial Cultures of Planning. Farnham: Ashgate, 2010.

Richardson, Jo. Contentious Spaces: The Gypsy/Traveller Site Issue: York/Coventry: JRF/CIH, 2007.

Richardson, Jo. The Gypsy Debate: Can Discourse Control? Exeter: Imprint Academic, 2006.

Richardson, Jo. The Impact of Planning Circular 1/06 on Gypsies and Travellers in England. Leicester: De Montfort University, 2011.

Richardson, Jo, and Janie Codona. Managing and Delivering Gypsy and Traveller Sites: Negotiating Conflict. York: JRF, 2016.

Sturzaker, John, and Mark Shucksmith. 'Planning for Housing in Rural England: Discursive Power and Spatial Exclusion'. Town Planning Review 82, no. 2 (2011): 169-204.

Susskind, Lawrence. Dealing with an Angry Public: The Mutual Gains Approach to Resolving Disputes. New York: The Free Press, 1996.

Turner, R., M. Hewstone and A. Voci. 'Reducing Explicit and Implicit Outgroup Prejudice via Direct and Extended Contact: The Mediating Role of Self-Disclosure and Intergroup Anxiety'. Journal of Personality and Social Psychology 93, no. 3 (2007): 369-88.

\section{Chapter 3}

Barenstein, Jennifer Duyne. A Comparative Analysis of Six Housing Reconstruction Approaches in Post-Earthquake Gujarat (SUPSI, 2005).

Barenstein, Jennifer Duyne. People-Driven Reconstruction and Rehabilitation in Aceh: A Review of Uplink's Concepts, Strategies and Achievements. Aachen: Misereor, 2008.

Barenstein, Jennifer Duyne, and Sushma Iyengar. 'Towards Owner-Driven Housing Reconstruction in India'. Paper presented at the Conference on Development from Disaster Scaling up Owner-Driven Reconstruction, IFRC, Practical Action and London South Bank University, London, 2009.

BRR, Housing, Roofing the Pillars of Hope. Jakarta: The Executing Agency of Rehabilitation, and Reconstruction for Aceh and Nias, 2009.

Davidson, Colin H., Cassidy Johnson, Gonzalo Lizarralde, Alicia Sliwinski and Nese Dikmen. 'Truth and Myths about Community Participation in Post-Disaster Housing Projects'. Habitat International 31 (2007): 100-15.

DTE. 'Community-Centred Reconstruction Needed'. Down to Earth 64 (2005): 5-10.

Fallahi, Alireza. 'Lessons Learned from the Housing Reconstruction Following the Bam Earthquake in Iran'. The Australian Journal of Emergency Management 22, no. 1 (2007): 26-35.

Hirschon, R., and S. Thakurdesai. 'Housing and Cultural Priorities: The Asia Minor Greek Refugees of 1922'. Disaster 2, no. 4 (1979): 247-50.

Hurgronje, C. Snouck. The Acehnese. 2 vols. Leiden: E.J. Brill, 1906.

Kennedy, Jim, Joseph Ashmore, Elizabeth Babister and Ilan Kelman. 'The Meaning of "Build Back Better": Evidence from Post-Tsunami Aceh and Sri Lanka'. Journal of Contingencies and Crisis Management 16, no. 1 (2008): 24-36.

Lawrence, Roderick J. 'Integrating Architectural, Social and Housing History'. Urban History 19, no. 1 (1992): 39-63.

Lizarralde, Gonzalo. 'Post-Disaster Low-Cost Housing Solutions, Learning from the Poor'. In Rebuilding after Disaster: From Emergency to Sustainability, edited by Gonzalo Lizarralde, Cassidy Johnson and Colin Davidson. New York: Spon Press, 2010: 25-48.

Oliver-Smith, Anthony. 'Anthropological Research on Hazards and Disasters'. Annual Review of Anthropology 25 (1996): 303-28.

Rodríguez, Havidán, Enrico L. Quarantelly and Russell R. Dynes. Handbook of Disaster Research. New York: Springer, 2006.

Steinberg, Florian. 'Housing Reconstruction and Rehabilitation in Aceh and Nias, Indonesia: Rebuilding Lives'. Habitat International 31 (2007): 150-66.

Zetter, Roger, and Camillo Boano. 'Space and Place after Natural Disaster and Forced Displacement'. In Rebuilding after Disaster: From Emergency to Sustainability, edited by Gonzalo Lizarralde, Cassidy Johnson and Colin Davidson, 206-30. New York: Spon Press, 2010. 


\section{Chapter 4}

ABS (Australian Bureau of Statistics). Basic Community Profiles. Canberra: ABS, 2012.

Anon. 'Keep the Faith'. RIBA Journal (1 September 2015). Accessed 26 February 2015. www. ribaj.com/intelligence/championing-the-vision.

Berry, Mike and Peter Williams. Investigative Panel on a Socially Sustainable Housing System for Australia, AHURI Final Report No. 169. Melbourne: RMIT Research Centre, June 2011. Accessed 12 February 2016. www.ahuri.edu.au/_data/assets/pdf_file/0002/2000/ AHURI_Final_Report_No169_Investigative_Panel_on_a_socially_sustainable_housing_ system_for_Australia.pdf.

Birrell, Bob, and David McCloskey. The Housing Affordability Crisis in Sydney and Melbourne Report One: The Demographic Foundations. Melbourne: The Australian Population Research Institute, 2015. Accessed 12 February 2016. http://tapri.org.au/wp-content/uploads/ 2016/02/housing-affordability-crisis-in-sydney-and-melbourne_part-1.pdf.

Böhme, Gernot. Ästhetischer Kapitalismus. Berlin: Suhrkamp, 2016.

Bokern, Anneke. 'Amsterdam-Slotervaart'. In Making Heimat: Germany, Arrival Country, edited by Peter Cachola Schmal, Oliver Elser and Anna Scheuermann, 176-97. Ostfildern: Hatje Cantz, 2016.

Borisova, Ekaterina I., Leonid Polishchuk and Anatoly Peresetsky. 'Collective Management of Residential Housing in Russia: The Importance of Being Social.' Paper presented at Workshop Colloquium Series, Indiana University Bloomington, 24 October 2011.

Buchanan, James M., and Yong J. Yoon. 'Symmetric Tragedies: Commons and Anticommons'. Journal of Law and Economics 43, no. 1 (April 2000): 1-13.

Cascaro, David, and Claire Staebler. 'Interview with Lacaton \& Vassal: Comme Un Paysage Sans Limite / Like an Endless Landscape'. Palais 15 (Numéro spécial histoire du Palais de Tokyo) (2012): 97-109.

Chan, Carson. 'Lacaton \& Vassal: Game Changer'. 032c 23 (Winter 2012/13): 130-41. Accessed 2 November 2015. http://032c.com/2013/o-architects-where-art-thou-gamechanger-lacaton-vassal.

Crawford, Patricia, Zenia Kotval, Warren Rauhe and Zeenat Kotval. 'Social Capital Development in Participatory Community Planning and Design'. Town Planning Review 79, no. 5 (2008): 533-53.

De Silva, Nayanthara. 'Maintainability of Condominiums Constructed for Low-Income Families in Sri Lanka'. Built-Environment Sri Lanka 11, no. 2 (2015): 25-39.

Dinh, Tuan Hai. 'Current Status of Existing Condominium Buildings in Vietnam: Common Problems, Main Causes and Proposed Maintenance Strategies'. In International Conference on Sustainable Architectural Design and Urban Planning. Hanoi: Hanoi Architectural University, Vietnam Green Building Database and Network, 2007.

Easthope, Hazel, Edgar Liu, Bruce Judd and Ian Burnley. 'Feeling at Home in a Multigenerational Household: The Importance of Control'. Housing, Theory and Society 32, no. 2 (2015): 151-70.

Easthope, Hazel, Bill Randolph and Sarah Judd. Governing the Compact City: The Role and Effectiveness of Strata Management. Sydney: City Futures Research Centre, 2012.

Easthope, Hazel, Bill Randolph and Sarah Judd. Managing Major Repairs in Residential Strata Developments: A Study by the City Futures Research Centre at UNSW provided with the assistance of the NSW Office of Fair Trading in New South Wales. Sydney: City Futures Research Centre, 2009.

Easthope, Hazel, and Andrew Tice. 'Children in Apartments: Implications for the Compact City'. Urban Policy and Research 29, no. 4 (2011): 415-34.

Easthope, Hazel, Jan Warnken, Cathy Sherry, Eddo John Coiacetto, Dianne Dredge, Christopher John Guilding, Nicole Johnston, Dawne Martha Lamminmaki and Sacha Reid. 'How Property Title Impacts Urban Consolidation: A Lifecycle Examination of Multi-Title Developments'. Urban Policy and Research 32, no. 3 (2014): 289-304.

Glasgow and West of Scotland Forum of Housing Associations, Our Crumbling Tenements: A New Approach for the 21st Century. Glasgow: Glasgow and West of Scotland Forum of Housing Associations, 2015.

Halais, Flavie. 'How Toronto Is Revitalizing Its Aging Suburban Residential Towers'. Citiscope (13 August 2015). Accessed 29 October 2016. http://citiscope.org/story/2015/ how-toronto-revitalizing-its-aging-suburban-residential-towers. 
Hulse, Kath, Vivienne Milligan and Hazel Easthope. Secure Occupancy in Rental Housing: Conceptual Foundations and Comparative Perspectives, Final Report. Melbourne: Australian Housing and Urban Research Institute, 2011.

Kearns, Ade, Rosemary Hiscock, Anne Ellaway and Sally Macintyre. 'Beyond Four Walls. The Psycho-Social Benefits of Home: Evidence from West Central Scotland'. Housing Studies 15, no. 3 (2000): 387-410.

Kimmelman, Michael. 'At the Edge of Paris, A Housing Project Becomes a Beacon'. The New York Times (28 March 2012). Accessed 26 January 2016. www.nytimes.com/2012/03/28/arts/ design/renovated-tour-bois-le-pretre-brightens-paris-skyline.html?_r=1.

Law, Nigel. 'An Evaluation of the Mandatory Building Inspection Scheme in Hong Kong'. Master's dissertation, University of Hong Kong, 2009.

Lawrence-Zúñiga, Denise. 'Bungalows and Mansions: White Suburbs, Immigrant Aspirations, and Aesthetic Governmentality'. Anthropological Quarterly 87, no. 3 (Summer 2014): 819-54.

Lepik, Andres, and Marjetica Potrc. 'Cities in Transition'. In Architektonika, edited by Gabriele Knapstein and Matilda Felix, 155-63. Nuremberg: Verlag für moderne Kunst, 2013.

Löschke, Sandra Karina. "Materials in Fact": Material Aesthetics and Ethics in Lacaton \& Vassal's Palais de Tokyo'. In Materiality and Architecture, edited by Sandra Karina Löschke, 27-46. London: Routledge, 2016.

Lujanen, Martti. 'Legal Challenges in Ensuring Regular Maintenance and Repairs of Owneroccupied Apartment Blocks'. International Journal of Law in the Built Environment 2, no. 2 (2010): 178-97.

McClelland, Michael, Graeme Stewart and Asrai Ord. 'Reassessing the Recent Past: Tower Neighbourhood Renewal in Toronto'. Journal of Preservation Technology 42, nos. 2-3 (2011): 9-14.

McLachlan, James, ed. Exemplary Housing Estate Regeneration in Europe. London: EMAP, 2015. Publication issued with AJ The Architects' Journal (1 July 2015).

Miessen, Markus. The Nightmare of Participation (Crossbench Praxis as a Mode of Criticality). Berlin: Sternberg Press, 2011.

Moore, Rowan. '10 Solutions to the Housing Crisis - in Pictures'. The Guardian (7 July 2013).

Muliuolyte, Justina. 'Rediscovering Large Scale Social Housing Estates in Post Socialist Cities'. Journal of Architecture and Urbanism 37 (2013): 51-8.

Parliament of Australia. Senate Select Committee on Housing Affordability in Australia, report tabled on 16 June 2008. Accessed 12 February 2016. www.aph.gov.au/Parliamentary_ Business/Committees/Senate/Former_Committees/hsaf/report/c04.

Parsell, Cameron. 'Home Is where the House Is: The Meaning of Home for People Sleeping Rough'. Housing Studies 27, no. 2 (2012): 159-73.

Priest, Isabelle. 'Different Kind of Living'. RIBA Journal (17 September 2015). Accessed 4 February 2016. www.ribaj.com/intelligence/different-kind-of-living.

Randolph, Bill, and Andrew Tice. 'Who Lives in Higher Density Housing? A Study of Spatially Discontinuous Housing Sub-Markets in Sydney and Melbourne'. Urban Studies 50, no. 13 (2013): 2661-81.

Rendell, Jane. Art and Architecture: A Place Between. London/New York: I.B. Tauris, 2006.

Rettich, Stefan. 'Regulate. Reduce. Accelerate.' In Making Heimat: Germany, Arrival Country, edited by Peter Cachola Schmal, Oliver Elser and Anna Scheuermann, 86-99. Ostfildern: Hatje Cantz, 2016.

Ruby, Ilka and Andreas, with the German Architecture Museum (DAM), eds. Druot, Lacaton \& Vassal: La Tour Bois le Prêtre in Paris. Berlin: Ruby Press, 2012.

Sherry, Cathy. 'Lessons in Personal Freedom and Functional Land Markets: What Strata and Community Title Can Learn from Traditional Doctrines of Property'. UNSW Law Journal 36, no. 1 (2013): 280-315.

Soaita, Adriana Mihaela. 'Strategies for In Situ Home Improvement in Romanian Large Housing Estates'. Housing Studies 27, no. 7 (2012): 1008-30.

Troy, Laurence, Hazel Easthope, Bill Randolph and Simon Pinnegar. Renewing the Compact City: Interim Report. Sydney: City Futures Research Centre, 2015.

Troy, Laurence, Bill Randolph, Laura Crommelin, Hazel Easthope and Simon Pinnegar. Renewing the Compact City: Economically Viable and Socially Sustainable Approaches to Urban Redevelopment, Final Report. Sydney: City Futures Research Centre, 2015.

UNEP (United Nations Environment Program). Buildings and Climate Change: Summary for Decision-Makers. Paris: UNEP, 2009. 
Wiesel, Ilan, and Hazel Easthope. 'Moving into a Disadvantaged Tenure? Pathways into Social Housing'. Geography Research Forum 33 (2013): 147-62.

Wong, Siu Kei, Alex King-Chung Cheung, Yung Yau, Daniel Chi-Wing Ho and Kwong-Wing Chau. 'Are Our Residential Buildings Healthy and Safe? A Survey in Hong Kong'. Structural Survey 24, no. 1 (2006): 77-86.

Woodman, Ellis. 'Post-War Estate Regeneration: Improvement over Replacement'. In Exemplary Housing Estate Regeneration in Europe, edited by James McLachlan, 6-9. London: EMAP, 2015. Publication issued with AJ The Architects' Journal (1 July 2015). Accessed 15 March 2016. www.architectsjournal.co.uk/Journals/2015/06/29/g/y/m/KCA-book_all_low-res. pdf.

Yau, Yung, Daniel Chi-Wing Ho and Kwong-Wing Chau. 'Determinants of the Safety Performance of Private Multi-Storey Residential Buildings in Hong Kong'. Social Indicators Research 89, no. 3 (2008): 501-21.

Yip, Ngai-ming, Chin-oh Chang and Tzu-ying Hung. 'Modes of Condominium Management: A Principal-Agent Perspective'. Facilities 25, nos. 5-6 (2007): 215-26.

\section{Chapter 5}

Antrop, Mark. 'Landscape Change and the Urbanization Process in Europe'. Landscape and Urban Planning 67 (2004): 9-26.

Baker, Lindsey T. Ghost Towns of Texas. Norman: University of Oklahoma Press, 1991.

Bates, Albert, Peter Bane and Keith Johnson. 'City Form: Country Venue: A Village for the Ages'. The Permaculture Activist 58, 2005.

Borio, Lucilla. 'The Passages of Time'. Permaculture Magazine 41 (2004): 27-41.

Brennan, Bridget. 'Six of the Best Ghost Towns'. Accessed 20 July 2015 www.australiangeographic.com.au.

Brown, Robert L. Ghost Towns of the Colorado Rockies. Caldwell: Caxton Press, 1968.

Bulgarelli, Giorgio. The 'Albergo Diffuso': A Way to Develop Tourism by Means of Innovation and Tradition. N.p.: IDEASS Innovation by Development and South-South, 2007.

Candella, Massimo. 'Storia di Torri Superiore'. Ecovillaggio Torri Superiore. Accessed 10 December 2015. www.torri-superiore.org.

Cockram, Michael. 'GEN's Torri Superiore', Architecture Week (30 August 2006). Accessed on 8 August 2015. www.architectureweek.com/2006/0830.

Confcommercio - Legambiente. Eccellenze e ghost town nell'Italia dei piccoli comuni: Rapporto dell'Italia del Disagio Insediativo1996/2016. n.p.: Serico Gruppo Cresme, 2008.

Cresta, Angela. Rural Tourism as a Factor of Competitive Development: Empirical Evidence in the Campania Region. 2011. Accessed 4 July 2017. www.academia.edu/1991286/Rural_tourism_as_a_factor_of_competitive_development_empirical_evidence_in_the_Campania_ Region.

Dall'Ara, Giancarlo. Manualle dell'Albergo Diffuso: L'idea, las gestione, il marketing dell'ospitalita diffusa. Milan: FrancoAngeli, 2003.

Dawson, Jonathan. Ecovillages: New Frontiers for Sustainability. Schumacher Briefings 12. Totnes: Chelsea Green Publishing, 2013.

De Certeau, Michel. L'Invention du Quotidien. Paris: Gallimard, 1990.

De Certeau, Michel. The Practice of Everyday Life, trans. Steven Rendall. Berkeley: University of California Press, 1984.

De Certeau, Michel. Practices of Space. Baltimore: The Johns Hopkins University Press, 1985.

Descamps, Françoise. 'The Conservation of Historic Cities and Urban Settlements Initiative'. The Getty Conservation Institute Newsletter 26, no. 2 (2011).

Di Figlia, Luca. 'The Abandoned Village as a Regional Resource'. Paper presented at the AESOP Ankara Congress, 2013.

Di Figlia, Luca. 'Revitalisation of Abandoned Villages: Design Process in the Memory of Places'. Paper presented at the Dublin AESOP-ACSP Congress, 12-13 July 2013.

Easdown, Martin. Adventures in Oysterville: Of the Failed Oyster and Seaside Development of Hampton-on-Sea, Herne Bay. Michaels Bookshop, 2008.

European Commission. Europe 2020: A Strategy for Smart, Sustainable and Inclusive Growth. European Commission, 2010. 
European Commission. Lessons from Vernacular Heritage to Sustainable Architecture. Versus Project, 2014.

European Commission. Mainstreaming Sustainable Development into EU Policies: 2009 Review of the European Union Strategy for Sustainable Development. European Commission COM/ 2009/0400, 2009.

Florin, Lambert. Ghost Towns of the West. New York: Promontory Press, 1971.

Fotopoulos, Takis. "The Limitations of Life-Style Strategies: The Ecovillage "Movement" is NOT the Way towards a New Democratic Society'. Democracy and Nature 6, no. 2 (2000): 287-308. Accessed on 4 June 2017. www.democracynature.org/vol6/takis trainer_reply.htm.

Frey, Pierre. 'New Vernacular Architecture vs Sustainable Development?' In Versus: Heritage for Tomorrow, ed. Mariana Correia, Letzia Dipasquale and Saverio Mecca, 12-13. Florence: Firenze University Press, 2014.

Garden, Mary. 'The Eco-Village Movement: Divorced from Reality'. The International Journal of Inclusive Democracy 2, no. 3 (2003). Accessed 4 June 2017. www.inclusivedemocracy.org/ journal/vol2/vol2_no3_Garden_eco_village.htm.

The Getty Conservation Institute. Historic Urban Environment Conservation Challenges and Priorities for Action, Experts Meeting Report. Los Angeles: Getty Conservation Institute, 2010.

Giani, Alberto. Novelties, Retro-Innovation and Fantasy: Torri Superiore Ecovillage as a Form of Resistance to the Abandonment of Rural Marginal Areas in Italy. Wageningen: Wageningen University, 2011.

Girard, Luigi Fusco, and Peter Nijkamp, eds. Cultural Tourism and Sustainable Local Development. Abingdon: Routledge, 2009.

Global Ecovillage Network Europe. 'About Ecovillages'. Accessed 4 June 2015. http://geneurope.org/ ecovillages/about-ecovillages/index.htm.

Human Rights Watch. 'Mediterranean Crisis'. Accessed 10 December 2015. www.hrw.org.

Ianella, Stefania. 'Apice vecchio: perché paese fantasma?' Accessed 18 July 2015. https://artempori.wordpress.com/2012/11/30/apice-vecchio.

Janot, Jean-Luc. 'Italy: Migrants Bring New Life to Deserted Villages'. EC Europe Webgate, 2015.

Jones, Paul Anthony. The British Isles: A Trivia Gazetteer. Chichester: Summersdale, 2013.

Laszlo, Ervin. Science and the Akashic Field: An Integral Theory of Everything. Rochester, VT: Inner Traditions International, 2004

Lawrence, D.H. 'Penetrating into Italy'. In The Fatal Gift of Beauty: The Italies of British Travellers. An Annotated Anthology, edited by Manfred Pfister, 414-16. Amsterdam: Rodopi, 1996.

Macdonald, Susan. Leveraging Heritage: Public-Private, and Third Sector Partnerships for the Conservation of the Historic Urban Environment. Paris: ICOMOS, 2011.

O'Hara, Eamon. Local Communities Leading the Way to a Low Carbon Society. N.p.: AEIDLEuropean Association for Information on Local Development, 2013.

Russo, Valentina. Abandoned Historic Towns in the South of Italy: Conservation and Sustainability Issues. Bressanone: Edizioni Arcadia Ricerche Estratti del $30^{\circ}$ Convegno di Studi Scienza e Beni Culturali, 2014.

Settis, Salvatore. 'Un patto per la tutela del paesaggio'. La Repubblica (17 November 2006).

Sheehan, Lorn, and Angelo Presenza. Albergo Diffuso: A Sustainable Tourism Innovation or Niche Accommodation? International Forum on Knowledge Asset Dynamics, 2012.

Speck, Gary B. 'Ghost Towns USA's Listings Index to 50 states'. Accessed 1 August 2015. http:// freepages.history.rootsweb.ancestry.com/ gtusa/usa.htm.

Trainer, Ted. 'Where Are We, Where Do We Want to Be, How Do We Get There?' Democracy and Nature 6, no. 2 (2000): 267-86. Accessed 4 June 2017. www.democracynature.org/vol6/ trainer_where.htm.

Trajano, Luigi. Il Borgo dei Borboni Business Plan. Associazione Nationale Alberghi Diffusi, 2013.

United Nations Centre for Human Settlements. Global Report on Human Settlement: Cities in a Globalizing World. London: Earthscan, 2010.

United Nations Department of Economic and Social Affairs. World Urbanisation Prospects: The 2014 Revision Highlights. New York: UNDESA, 2014.

United Nations High Commissioner for Refugees. Italy: Sea Arrivals, UNHCR Update \#4, December 2015.

United Nations High Commissioner for Refugees. Italy: Sea Arrivals, UNHCR Update \#8, October 2016.

United Nations Human Settlements Programme. State of the World's Cities 2010/11 Cities for All: Bridging the Urban Divide. Abingdon: Earthscan, 2011. 


\section{Chapter 6}

Archer, Diane. 'Empowering the Urban Poor through Community Based Slum Upgrading: The Case of Bangkok, Thailand'. ISOCARP Congress. Accessed 10 October 2016. www.isocarp. net/Data/case_studies/1648.pdf.

Archer, Diane. 'Finance as the Key to Unlocking Community Potential: Savings, Funds, and the ACCA Programme'. Environment and Urbanization 24 (2012): 423-40. Accessed 10 July 2016. doi: 10.1177/0956247812449235.

Asian Coalition for Housing Rights. 107 Cities in Asia: Second Yearly Report of the Asian Coalition for Community Action Program. December 2010. Accessed 10 October 2016. www.achr.net/ download.php?ic $=5$.

Asian Coalition for Housing Rights. 215 Cities in Asia: Fifth Yearly Report of the Asian Coalition for Community Action Programme. November 2014. Accessed 10 October 2016. www.achr.net/ upload/files/1\%20ACCA\%20How\%20it\%20works\%201-4.pdf.

Boonyabancha, Somsook. 'Land for Housing the Poor by the Poor: Experiences from the Baan Mankong Nationwide Slum Upgrading Programme in Thailand'. Environment and Urbanisation 21 (2009): 309-29. Accessed 30 June 2016. doi: 10.1177/ 0956247809342180.

Boonyabancha, Somsook. 'Savings and Loans: Drawing Lessons from Some Experiences in Asia'. Environment and Urbanization 13 (2001): 9-21. Accessed 10 July 2016. doi: 10.1177/ 0956247807082817.

Boonyabancha, Somsook, and Thomas Kerr. 'Urban Poor Housing Development in Asia: From Target Group to Negotiating Partner'. In From Local Action to Global Networks: Housing the Urban Poor, edited by Peter Herrle and Astrid Ley. Abingdon: Routledge, 2015.

Bredenoord, Jan, and Paul Van Lindert. 'Backing the Self-Builders: Assisted Self-Help Housing as a Sustainable Provision Strategy'. In Affordable Housing in the Urban Global South: Seeking Sustainable Solutions, 55-72. Edited by Jan Bredenoord, Paul Van Lindert and Peer Smeets. London: Routledge, 2015.

Buckley, Robert, Achilles Kallergis and Laura Wainer. 'Addressing the Housing Challenge: Avoiding the Ozymandias Syndrome'. Environment and Urbanization 28 (2016): 119-38. Accessed 30 July 2016. doi:10.1177/0956247815627523.

Cabannes, Yves. 'Participatory Budgeting: A Significant Contribution to Participatory Democracy'. Environment and Urbanization 16 (2004): 27-46. Accessed 28 June 2016. doi: 10.1177/095624780401600104.

Carcellar, Norberto, and Thomas Kerr. 'Assessing the ACCA Programme: Turning Asia's Community Upgrading Initiatives into an Open University'. Environment and Urbanization 24 (2012): 513-29. Accessed 28 June 2016. doi: 10.1177/0956247812455766.

Cities Alliance and Association of Cities of Vietnam. 'Operations Manual of Community Development Fund'. 2012. Accessed 10 October 2016. www.citiesalliance.org/sites/citiesalliance.org/files/CAFiles/Projects/Final_CDF_Manual_with_Cover_Page.pdf.

De Soto, Hernando. The Other Path: The Invisible Revolution in the Third World. London: I.B. Tauris, 1989.

Dovey, Kim. 'Informal Urbanism and Complex Adaptive Assemblage'. International Development Planning Review 34 (2012): 349-67. Accessed 10 September 2016. doi:10.3828/ idpr.2012.23.

Hansen, Karen, and Mariken Vaa. Reconsidering Informality: Perspectives from Urban Africa. Grafilur Artes Graficas, 2004.

Jones, Gareth, and Kavita Datta. Housing and Finance in Developing Countries. London: Routledge, 1998.

Leonhardt, Maurice. 'Together We Are Strong: Networks, Platforms and the Social Relations that Support a People's Process'. Environment and Urbanization 24 (2012): 481-96. Accessed 10 July 2016. doi: 10.1177/0956247812455771.

Liv, Dannet. 'Study on the Drivers of Over-Indebtedness of Micro-Finance Borrowers in Cambodia: An In-Depth Investigation of Saturated Areas'. Cambodia Institute of Development Study, 2013. Accessed 10 October 2016. www.incofin.com/sites/default/files/attachments/ newsitems/Study\%20on\%20the\%20Drivers\%20of\%20Over-Indebtedness $\% 20$ of $\% 20$ Microfinance\%20Borrowers\%20in\%20Cambodia.pdf. 
Luansang, Chawanad, Supawut Boonmahathanakorn and Maria Lourdes Domingo-Price. 'The Role of Community Architects in Upgrading: Reflecting on the Experience in Asia'. Environment and Urbanization 24 (2012): 497-512. Accessed 10 May 2016. doi: 10.1177/ 0956247812456125.

Marx, Colin. 'Conceptualizing the Potential of Informal Land Markets to Reduce Urban Poverty'. International Development Planning Review 31 (2009): 335-53. Accessed 16 May 2016. doi: 10.3828/idpr.2009.1.

McFarlane, Colin. 'Rethinking Informality: Politics, Crisis and the City'. Planning Theory and Practice 13 (2012): 89-108. Accessed 12 August 2016. doi: 10.1080/ 14649357.2012.649951.

McLeod, Ruth, and Kim Mullard. Bridging the Finance Gap between Housing and Infrastructure. Dunmore: Homeless International, 2006.

Pieterse, Edgar. City Futures: Confronting the Crisis of Urban Development South Africa. Capetown: UCT Press, 2008.

Porter, Libby. 'Informality, the Commons and the Paradoxes for Planning: Concepts and Debates for Informality and Planning'. Planning Theory and Practice 12 (2011): 115-53. Accessed 30 September 2016: doi: 10.1080/14649357.2011.545626.

Roy, Ananya. 'Urban Informality: Towards an Epistemology of Planning'. Journal of the American Planning Association 71 (2005): 147-58. Accessed 10 August 2016. doi: 10.1080/ 01944360508976689.

Roy, Ananya. 'Why India Cannot Plan Its Cities: Informality, Insurgence and the Idiom of Urbanization'. Planning Theory 8 (2009): 76-87. Accessed 10 July 2016. doi: 10.1177/ 1473095208099299.

Satterthwaite, David, and Diane Mitlin. 'Strategies for Grassroots Control of International Aid'. Environment and Urbanization 19 (2009): 483-500. Accessed 10 February 2016. doi: $10.1177 / 0956247807082831$.

Solo, Tova Maria. 'Financial Exclusion in Latin America: Or the Social Costs of Not Banking the Urban Poor'. Environment and Urbanization 20 (2008): 47-66. Accessed 18 June 2016. doi: 10.1177/0956247808089148.

Sripanich, Bussara, Vilas Nitivattananon and Ranjith Perera. 'City Development Fund: A Financial Mechanism to Support Housing and Livelihood Needs of Thailand's Urban Poor'. Habitat International 49 (2015): 366-74. Accessed 10 May 2016. doi: 10.1016/ j.habitatint.2015.05.011.

Turner, John. Housing by People: Towards Autonomy in Building Environments. London: Marion Boyars, 1976.

UN-HABITAT. The Challenge of Slums: Global Report on Human Settlement. Nairobi: Earthscan Publications, 2003.

UN-HABITAT. Urbanization and Development: Emerging Futures. World Cities Report 2016. Accessed 10 October 2016. http://wcr.unhabitat.org/main-report.

Watson, Vanessa. 'Conflicting Rationalities: Implications for Planning Theory and Ethics'. Planning Theory and Practice 4 (2003): 395-407. Accessed 16 June 2016. doi: 10.1080/ 1464935032000146318.

Watson, Vanessa. 'The Planned City Sweeps the Poor Away: Urban Planning and the 21st Century Urbanisation'. Progress in Planning 72 (2009): 151-93. Accessed 2 June 2016. doi: 10.1016/ j.progress.2009.06.002.

Watson, Vanessa. 'Seeing from the South: Refocusing Urban Planning on the Globe's Central Urban Issues'. Urban Studies 46 (2009): 2259-75. Accessed 10 May 2016. doi: 10.1177/ 0042098009342598.

\section{Chapter 7}

Aalbers, Manuel B., and Brett Christophers. 'Centring Housing in Political Economy'. Housing, Theory and Society 31, no. 4 (2014): 373-94.

Beer, Andrew, Alan Morris and Chris Paris. 'Housing and Local Government in Australia in the 21st Century' (2014). Accessed 25 June 2017. www.adelaide.edu.au/churp/Housing_and_ Local_Govt_in_the_21st_Century.pdf. 
Blessing, Anita. 'Magical or Monstrous? Hybridity in Social Housing Governance'. Housing Studies 27, no. 2 (2012): 189-207.

Bounds, Michael, and Alan Morris. 'Second Wave Gentrification in inner-City Sydney'. Cities 23, no. 2 (2006): 99-108.

Boydell, Spike, and G.H. Searle. 'The Contemporary Urban Commons: A Case Study of Darling Harbour, Sydney'. In COBRA Legal Research Symposium, 809-26. London: RICS Org, 2010.

City of Sydney. Housing Issues Paper (Sydney: City of Sydney, 2015).

Cred Community Planning. Social Impact Assessment of the potential social impacts on the existing Millers Point community, and the broader social housing system, that may result from the sale of any further social housing in Millers Point (2013).

Daly, Maurice, and Patrick Malone. 'Sydney: The Economic and Political Roots of Darling Harbour'. City, Capital and Water (1996): 90-108.

Darcy, Michael, and Dallas Rogers. 'Place, Political Culture and Post-Green Ban Resistance: Public Housing in Millers Point, Sydney'. Cities 57 (2015): 1-8.

Deamer, Peggy. 'Architects, Really'. In Can Architecture Be an Emancipatory Project?: Dialogues on Architecture and the Left, edited by Nadir Z. Lahiji, 33-47. Alresford: John Hunt Publishing, 2016.

Fitzgerald, Shirley, and Christopher John Keating. Millers Point: The Urban Village. Ultimo: Halstead Press, 2009.

Harraway, Donna. The Harraway Reader. New York: Routledge, 2004.

Harvey, David. 'From Managerialism to Entrepreneurialism: The Transformation in Urban Governance in Late Capitalism'. Geografiska Annaler. Series B. Human Geography (1989): 3-17.

Harvey, David. The New Imperialism. Oxford: Oxford University Press, 2003.

Hasham, Nicole. 'Lend Lease Baulking at Providing Affordable Homes in Barangaroo'. The Sydney Morning Herald (15 August 2014). Accessed 1 June 2016. www.smh.com.au/nsw/lendlease-baulking-at-providing-affordable-homes-in-barangaroo-20140814-1049rr.html.

Hawken, Scott, and Bruce Mackenzie. 'Barangaroo Reserve'. Landscape Architecture Australia 149 (2016): 40-50.

Hayward, David. 'The Reluctant Landlords? A History of Public Housing in Australia.' Urban Policy and Research 14, no. 1 (1996): 5-35.

Healey, Patsy. 'The Universal and the Contingent: Some Reflections on the Transnational Flow of Planning Ideas and Practices'. Planning Theory 11, no. 2 (2012): 188-207.

$\mathrm{Hu}$, Richard, Edward J. Blakely and Yimin Zhou. 'Benchmarking the Competitiveness of Australian Global Cities: Sydney and Melbourne in the Global Context'. Urban Policy and Research 31, no. 4 (2013): 435-52.

Jacobs, Keith. 'A Reverse Form of Welfarism: Some Reflections on Australian Housing Policy'. Australian Journal of Social Issues 50, no. 1 (2015): 53-68.

JBA Urban. Environmental Assessment Report: Concept Plan Modification 8 and Major Development SEPP, State and Regional Development SEPP and Sydney Harbour SREP Amendments (2014).

Jencks, Charles. 'The Iconic Building Is Here to Stay'. City 10, no. 1 (2006): 3-20.

Kaika, Maria. 'Autistic Architecture: The Fall of the Icon and the Rise of the Serial Object of Architecture'. Environment and Planning D: Society and Space 29, no. 6 (2011): 968-92.

Lefebvre, Henri. 'The Right to the City'. in Writings on Cities, 63-181. Malden, MA: Blackwell Publishers, 1996 [1967]).

Madanipour, Ali. 'Roles and Challenges of Urban Design'. Journal of Urban Design 11, no. 2 (2006): 173-93.

McDonald, John F. 'Affordable Housing: An Economic Perspective'.Architecture_MPS 7, no. 3 (2015): 1-16.

NSW Government for Family and Community Services. High Cost Harbourside Assets to Be Sold for a Fairer Social Housing System (2014). Accessed on 12 June 2017. www.facs.nsw.gov.au/ about_us/media_releases/pru/high_cost_harbourside_assets_to_be_sold_for_a_fairer_ social_housing_system.

Nicholls, Seth. 'Perpetuating the Problem: Neoliberalism, Commonwealth Public Policy and Housing Affordability in Australia'. Australian Journal of Social Issues 49, no. 3 (2014): 329-47.

Pettigrew, David. Homes for the People: Public Housing in New South Wales. Sydney: David Pettigrew, 2005. 
Pham, Kane. 'Ready or Not: The Inevitability of Another Casino in Sydney'. Paper presented at the Urban Affairs Conference, San Diego, California, 16-19 March (2016).

Pham, Kane. 'Vanity Unfair. Examining the Impact of Development Authorities on the Designation and Development of Public Space: Barangaroo Case Study'. Proceedings of the State of Australian Cities Conference (2015).

Pitman, Tim, Luke Tozer and Edward Wainwright. 'Regarding the Residential'. Arq: Architectural Research Quarterly 18, no. 2 (2014): 182-7.

Purcell, Mark. 'Excavating Lefebvre: The Right to the City and Its Urban Politics of the Inhabitant'. GeoJournal 58, nos. 2-3 (2002): 99-108.

Rancière, Jacques, The Politics of Aesthetics. London: Bloomsbury Academic, 2014 [2000].

Randolph, Bill. East Darling Harbour and the Intermediate Housing Market. Unpublished report prepared for the Sydney Harbour Foreshore Authority (2006).

Sandercock, Leonie. Cities for Sale: Property, Politics and Urban Planning in Australia. Melbourne: Melbourne University Press, 1975.

Searle, Glen, 'Case Study Window: Discourse, Doctrine and Habitus'. In The Ashgate Research Companion to Planning and Culture, edited by Greg Young and Deborah Stevenson, 135-50. Farnham: Ashgate, 2013.

Searle, Glen, and Michael Bounds. 'State Powers, State Land and Competition for Global Entertainment: The Case of Sydney'. International Journal of Urban and Regional Research 23, no. 1 (1999): 165-72.

Searle, Glen, and Jason Byrne. 'Selective Memories, Sanitised Futures: Constructing Visions of Future Place in Sydney'. Urban Policy and Research 20, no. 1 (2002): 7-25.

SGS Economics and Planning, Millers Point and The Rocks: An Alternative Way Forward (2014). Accessed 12 June 2017, www.sgsep.com.au/assets/Millers-Point-FinalReport.pdf.

Sussex, Meredith, and Shelley Penn. Barangaroo Review (2011). Accessed 12 June 2017. www.barangaroo.com/media/43967/barangaroo $\% 20$ review $\% 20$ final $\% 20$ report $\% 20$ 31\%20july\%202011\%20compressed.pdf.

Walliss, Jillian. 'The Politics of Aesthetics: Expanding the Critique of Headland Park, Sydney'. Journal of Landscape Architecture 7, no. 2 (2012): 6-13.

\section{Chapter 8}

Arkdes. 'Knitting House' (2015). Accessed 27 November 2015. www.arkdes.se/articles/ knitting-house.

Arkitekturmuseet. Knitting House, The Swedish Museum of Architecture: A Fifty Year Perspective. Stockholm: Arkitekturmuseet, 2013.

ArkleyWorks. 'Australian Home'. Accessed 13 March 2015. http://arkleyworks.com/?p=5624.

Australian Bureau of Statistics. '4130.0 - Housing Occupancy and Costs, 2011-12' (28 August 2013). Accessed 23 March 2015. www.abs.gov.au/AUSSTATS/abs@.nsf/Lookup/ 4130.0Main+Features12011-12?OpenDocument.

Australian Government Department of Social Services, Housing Support, 'Social Housing Initiative - Fact Sheet' (2013). Accessed 6 March 2015. www.dss.gov.au/ our-responsibilities/housing-support/programs-services/social-housing-initiative/ social-housing-initiative-fact-sheet.

Basualdo, C., and R. Laddaga. 'Rules of Engagement'. Artforum International 42, no. 3 (2004): 166-9.

Cox, Wendell, and Hugh Pavletich. 10th Annual Demographia International Housing Affordability Survey. Belleville IL: Demographia, 2014.

Cox, Wendell, and Hugh Pavletich. 11th Annual Demographia International Housing Affordability Survey. Belleville IL: Demographia, 2015.

Hall, Thomas, and Sonja Viden. 'The Million Homes Programme: A Review of the Great Swedish Planning Project'. Planning Perspectives 20, no. 3 (2005): 301-28.

Holmqvist, Emma, and Lena Magnusson Turner. 'Swedish Welfare State and Housing Markets: Under Economic and Political Pressure'. Journal Housing and the Built Environment 29, no. 2 (2013): 237-54. doi:10.1007/s10901-013-9391-0. 
Liinamaa, Saara. 'Contemporary Art's "Urban Question" and Practices of Experimentation'. Third Text 28, no. 6 (2014): 529-44.

Kester, Grant H. The One and the Many: Contemporary Collaborative Art in a Global Context. Durham, NC: Duke University Press, 2011.

Kiendel, Anthony. Informal Architectures: Space and Contemporary Cultures. London: Blackdog Publishing, 2008.

Lepick, Andres, and Marjetica Potrč. 'Cities in Transition'. In Architektonika, edited by Gabriele Knapstein and Matilda Felix, 155-63. Berlin: Nationalgalerie and Staaliche Museen zu Berlin, 2013.

Liinamaa, Saara. 'Contemporary Art's “Urban Question” and Practices of Experimentation'. Third Text 28, no. 6 (2014): 529-44.

Macarow, Keely. 'What Use Is a Tea Towel'. In Engaging Publics: Public Engagement, ed. Clare McIntosh, 60-8. Auckland: Auckland Art Gallery and AUT University, 2015.

Museum Victoria. 'High Rise Housing in Melbourne: Atherton Gardens Estate, Fitzroy'. Accessed 27 March 2015. http://museumvictoria.com.au/learning-federation/infosheets/athertongardens/high-rise-housing-in-melbourne.

National Shelter. 'Housing Australia Factsheet' (16 September 2014). Accessed 23 March 2015 www.shelter.org.au/factsheets/housing-australia-factsheet.

Potrč, Marjetica. Accessed 13 November 2015. www.potrc.org/index.html.

Potrč, Marjetica. 'Cities in Transition', in Architektonika, ed. Gabriele Knapstein and Matilda Felix (Berlin: Nationalgalerie, Staaliche Museen zu Berlin, 2013).

Richardson, Elvis. 'Growth, Growth, Growth \& The Bedroom, Ocular Lab Inc @ Margaret Lawrence Gallery, VCA'. Accessed 29 November 2015. www.elvisrichardson.com/growth2.html.

Sabo. 'Public Housing in Sweden'. Accessed 23 March 2015. www.sabo.se/om_sabo/english/ Sidor/Publichousing.aspx.

Schwartz, Herman, and Leonard Seabrooke. 'Varieties of Residential Capitalism in the International Political Economy'. Comparative European Politics 6, no. 3 (2008): 237-61.

State Government of Victoria, Department of Human Services. 'Public Housing Income and Asset Limits'. Accessed 20 March 2015. www.housing.vic.gov.au/public-housingincome-and-asset-limits.

State Government of Victoria. 'Plan Melbourne, Metropolitan Planning Strategy 2014'. Melbourne: Victorian Government, 2014.

Strand Ruin, Elin. 'Knitting House 2010', Accessed 27 November 2015. www.arkdes.se/articles/ knitting-house.

Strand Ruin, Elin, and Annika Enqvist. 'A Knitted Monument'. In Knitting House, the Swedish Museum of Architecture: A Fifty Year Perspective, 12-14. Stockholm: Arkitekturmuseet, 2013.

Thompson, Nato. Living as Form: Socially Engaged Art from 1991-2011. New York and Cambridge: Creative Time Books and The MIT Press, 2012.

\section{Chapter 9}

Baker, George. 'Sublevel'. In Mike Kelley, ed. Eva Meyer-Hermann and Lisa Gabrielle Mark, 345-65. Amsterdam: Stedelijk Museum and Delmonico Books-Prestel, 2013.

Bernanke, Ben S. 'Housing, Housing Finance, and Monetary Policy'. The Federal Reserve Bank of Kansas City's Economic Symposium. Jackson Hole (31 August 2007). Accessed 2 January 2014. www.federalreserve.gov/newsevents/speech/bernanke20070831a.htm.

Borges, Jorge Luis. 'On Exactitude in Science'. In Jorge Luis Borges: Collected Fictions, translated by H. Hurley, 325. New York: Penguin Books, 1998.

Le Corbusier and Pierre Jeanneret. 'Analysis of the Fundamental Elements of the Problem of "the Minimum House": CIAM 2, Frankfurt 1929'. In The Radiant City: Elements of a Doctrine of Urbanism to Be Used as the Basis of our Machine-Age Civilization, translated by Pamela Knight, Eleanor Levieux and Derek Coltman. London: Faber, 1967.

Crossney, Kristen B., and David W. Bartelt. 'Residential Security, Risk, and Race: The Home Owners' Loan Corporation and Mortgage Access in Two Cities'. Urban Geography 26, no. 8 (16 November 2005): 707-36.

Federal Housing Administration. FHA Homes in Metropolitan Districts: Characteristics of Mortgages, Homes, Borrowers Under the FHA Plan 1934-1940. Washington, DC: US Government Printing Office, 1942. 
Federal Housing Administration. Principles of Planning Small Houses: Technical Bulletin No.4. Washington, DC: US Government Printing Office, 1936; revised 1 July 1940 and 1948.

Federal Housing Administration. Underwriting Manual: Underwriting and Valuation Procedure Under Title II of the National Housing Act. Washington, DC: US Government Printing Office, 1936.

Federal Housing Administration. Underwriting Manual. Washington, DC: US Government Printing Office, 1938.

Fishman, Robert. Bourgeois Utopias: The Rise and Fall of Suburbia. New York: Basic Books, 1987.

Freud, Sigmund. The Uncanny, translated by David Mclintock. London: Penguin Books, 2003.

Hirsch, Arnold R. 'Searching for a "Sound Negro Policy": A Racial Agenda for the Housing Acts of 1949 and 1954'. Housing Policy Debate 11, no. 2 (2000): 393-441.

Hise, Greg. Magnetic Los Angeles: Planning the Twentieth-Century Metropolis. Baltimore: The Johns Hopkins University Press, 1997.

Jackson, Kenneth T. Crabgrass Frontier: The Suburbanization of the United States. New York: Oxford University Press, 1985.

Kelley, Mike. 'Architectural Non-Memory Replaced with Psychic Reality'. In Minor Histories: Statements, Conversations, Proposals, edited by John Welchman, 316-23. Cambridge, MA: The MIT Press, 2004.

Kelley, Mike. Foul Perfection: Essays and Criticism, edited by John C. Welchman. Cambridge, MA: The MIT Press, 2003.

Kelley, Mike. 'Mobile Homestead'. In Whitney Biennial 2012, edited by Elisabeth Sussman and Jay Sanders, 158-63. New York: Whitney Museum of American Art, 2012.

Kelley, Mike, Jim Shaw and John C. Welchman. On the Beyond: A Conversation Between Mike Kelley, Jim Shaw, and John C. Welchman, edited by Cristina Bechtler. Vienna and New York: Springer, 2011.

Kushner, David. Levittown: Two Families, One Tycoon, and the Fight for Civil Rights in America's Legendary Suburb. New York: Walker \& Company, 2009.

Meyer-Hermann, Eva, and Lisa Gabrielle Mark, eds. Mike Kelley. Amsterdam: Stedelijk Museum and Delmonico Books-Prestel, 2013.

Moten, Fred. 'Enjoy All Monsters'. Paper presented at Museum of Contemporary Art, Los Angeles, 24 July 2014.

Sugrue, Thomas J. The Origins of the Urban Crisis: Race and Inequality in Postwar Detroit. Princeton: Princeton University Press, 1996.

Thomas, June Manning. Redevelopment and Race: Planning a Finer City in Postwar Detroit. Detroit: Wayne State University Press, 2013.

United States, Housing and Home Finance Agency. An Introduction to Urban Renewal as Authorized by the Housing Act of 1954. Washington, DC: Housing and Home Finance Agency, Office of the Administrator, 1954.

US Department of Housing and Urban Development. Urban Renewal: Title I of Housing Act of 1949 and Related Laws as Amended Through Sept. 1, 1968. Washington, DC: US Department of Housing and Urban Development, n.d.

Vergara, Camilo José. American Ruins. New York: The Monacelli Press, 1999.

Vergara, Camilo José. The New American Ghetto. New Brunswick: Rutgers University Press, 1995. Von Hoffman, Alexander. Enter the Housing Industry, Stage Right: A Working Paper on the History of Housing Policy. Cambridge, MA: Joint Center for Housing Studies, Harvard University, 2008.

\section{Chapter 10}

AIHW. Housing Assistance in Australia. Cat no: HOU236. Canberra: Australian Institute of Health and Welfare, 2009.

Arthurson, Kathy. Social Mix and the Cities: Challenging the Mixed Communities Consensus in Housing and Urban Planning Policies. Sustainable Cities Series. Sydney: CSIRO, 2012.

Arthurson, Kathy. 'Social Mix and the Cities'. Urban Policy and Research 23, no. 4 (2005): 519-23. Arthurson, Kathy. 'Social Mix, Reputation and Stigma: Exploring Residents' Perspectives of Neighbourhood Effects'. In Neighbourhood Effects Research: New Perspectives, edited by 
Maarten van Ham, David Manley, Nick Bailey, Ludi Simpson and Duncan Maclennan. London: Springer, 2012.

Blokland, T. "'You Got to Remember You Live in Public Housing": Place-Making in an American Housing Project'. Housing, Theory and Society 25 (2008): 31-46.

Bourdieu, Pierre. 'The Forms of Capital'. In Handbook of Theory and Research for the Sociology of Education, edited by John Richardson, 241-58. New York: Greenwood, 1986.

Bradbury, Bruce, and Jenny Chalmers. Housing, Location and Employment. Sydney: Australian Housing and Urban Research Institute, 2003.

Darcy, Michael. 'De-Concentration of Disadvantage and Mixed Income Housing: A Critical Discourse Approach'. Housing, Theory and Society 27, no. 1 (2010): 1-22.

Darcy, Michael, and Dallas Rogers. 'Inhabitance, Place-Making and the Right to the City: Public Housing Redevelopment in Sydney'. International Journal of Housing Policy 14, no. 3 (2014): 236-56.

Devereux, Eoin, Amanda Haynes and M. Power. 'At the Edge: Media Constructions of a Stigmatised Irish Housing Estate'. Journal of the Built Environment 26 (2011): 123-42.

Goffman,Erving.Stigma:NotesontheManagementofSpoiledIdentity. NewYork:Touchstone, 1986.

Guillemin, Marilys, and Sarah Drew. 'Questions of Process in Participant-Generated Visual Methodologies.' Visual Studies 25, no. 2 (2010): 175-88.

Hastings, Annette. 'Poor Neighbourhoods and Poor Services: Evidence on the "Rationing" of Environmental Service Provision to Deprived Neighbourhoods'. Urban Studies 46, no. 13 (2009): 2907-27.

Hastings, Annette. 'Stigma and Social Housing Estates: Beyond Pathological Explanations'. Journal of Housing and the Built Environment 19, no. 3 (2004): 233-54.

Hastings, A., and J. Dean. 'Challenging Images: Tackling Stigma through Estate Regeneration'. Policy \& Politics 31, no. 2 (2003): 171-84.

Hulse, Kath, and Terry Burke. 'Private Rental Housing in Australia: Political Inertia and Market Change'. In Housing in Twenty-First Century Australia: People, Practices and Politices, edited by Rae Dufty-Jones and Dallas Rogers. Aldershot: Ashgate, 2015.

Imbroscio, David. '[U]nited and Actuated by Some Common Sense of Passion: Challenging the Dispersal Consensus in American Housing Policy Research'. Journal of Urban Affairs 30, no. 2 (2008): 111-30.

Jacobs, Keith, Kathy Arthurson, Rob White and J. Donoghue. Developing Effective Housing Management Strategies to Address Problems of Anti-Social Behaviour. Melbourne: Australian Housing and Urban Research Institute, 2003.

Kelaher, M., Deborah Warr, P. Feldma and T. Tacticos. 'Living in "Birdsville": Exploring the Impact of Neighbourhood Stigma on Health'. Health and Place 16 (2010): 381-8.

Lapeyronnie, D. Ghetto Urbain: Ségrégation, Violence, Pauvreté En France Aujourd'Hui. Paris: Éditions Robert Laffont, 2008.

Lawler, Stephanie. 'Disgusted Subjects: The Making of Middle Class Identities'. The Sociological Review 53, no. 3 (2005): 429-46.

Lee, Murray. 'The Blame Game: Struggles over the Representation of the "Macquarie Fields Riots"، In Outrageous! Moral Panics in Australia, edited by Scott Poynting and George Morgan. Hobart: ACYS Publishing, 2007.

Lovejoy, Tracey, and Nelle Steele. 'Engaging Our Audience through Photo Stories'. Visual Anthropology Review 20, no. 1 (2004): 70-81.

Lundby, Knut, ed. Digital Storytelling, Mediatized Stories: Self-Representations in New Media. New York: Peter Lang Publishing, 2008.

Palmer, Catherine, Anna Ziersch, Kathy Arthurson and Fran Baum. 'Challenging the Stigma of Public Housing: Preliminary Findings from a Qualitative Study in South Australia'. Urban Policy and Research 22, no. 4 (2004): 411-26.

Pawson, Hal, Gethin Davison and Ilan Wiesel. Addressing Concentrations of Disadvantage: Policy, Practice and Literature Review. Sydney: Australian Housing and Urban Research Institute, 2012.

Pinnegar, Simon, Bill Randolph and Gethin Davidson. Feasibility Study to Undertake a Multi-Year Research Project: Addressing Concentrations of Social Disadvantage. Melbourne: AHURI, 2011.

Raisborough, Jayne, and Matt Adams. 'Mockery and Morality in Popular Cultural Representations of the White, Working Class'. Sociological Research Online 12, no. 3 (2008). 
Rogers, Dallas. 'The Politics of Space and Time within Market-Centric Urban Policy: The Case of the Bonnyrigg Living Communities Project'. Polymath: An Interdisciplinary Arts and Sciences Journal 2, no. 3 (2012): 16-34.

Rogers, Dallas. 'Research, Practice and the Space Between: Care of the Self within Neoliberalized Institutions'. Cultural Studies $<=>$ Critical Methodologies 12, no. 3 (2012): 242-54.

Rogers, Dallas. 'The Sydney Metropolitan Strategy as a Zoning Technology: Analysing the Spatial and Temporal Dimensions of Obsolescence', Environment and Planning D: Society and Space 32, no. 1 (2014): 108-27.

Rogers, Dallas, and Michael Darcy. 'Global City Aspirations, Graduated Citizenship and Public Housing: Analysing the Consumer Citizenships of Neoliberalism'. Urban, Planning and Transport Research 2, no. 1 (2014): 78-88.

Rogers, Dallas, Michael Darcy and Kathy Arthurson. 'Researching Territorial Stigma with Social Housing Tenants: Tenant-Led Digital Media Production about People and Place'. In Negative Neighbourhood Reputation and Place Attachment: The Production and Contestation of Territorial Stigma, ed. Paul Kirkness and Andreas Tijé-Dra, 178-93. London: Routledge, 2017.

Ruming, Kristian, Kathleen J. Mee and Pauline Mcguirk. 'Questioning the Rhetoric of Social Mix: Courteous Community or Hidden Hostility?' Australian Geographical Studies 42, no. 2 (2004): 234-48.

Skeggs, Beverley. 'Imagining Personhood Differently: Person Value and Autonomist WorkingClass Value Practices'. The Sociological Review 59, no. 3 (2011): 496-513.

Troy, P. Accommodating Australian: Commonwealth Government Involvement in Housing. Sydney: The Federation Press, 2011.

Wacquant, Loïc. 'Territorial Stigmatisation in the Age of Advanced Marginality'. Thesis Eleven 91, no. 1 (2007): 66-77.

Wacquant, Loïc. Urban Outcasts: A Comparative Sociology of Advanced Marginality. Cambridge: Polity Press, 2008.

Warr, Deborah. 'Social Networks in a Discredited Neighbourhood'. Journal of Sociology 41, no. 3 (2005): 285-308.

Warr, Deborah. 'There Goes the Neighbourhood: The Malign Effects of Stigma'. In Proceedings of State of Australian Cities Conference. Brisbane: Griffith University, 2005.

Ziersch, Anna, and Kathy Arthurson. 'Social Networks in Public and Community Housing: The Impact on Employment Outcomes'. Urban Policy and Research 23, no. 4 (2005): 429-45.

\section{Chapter 11}

Andrés Jaque Arquitectos. 'Ikea Disobedients', video. Accessed 10 March 2015. www.moma.org/ explore/multimedia/videos/235/1158.

BAVO. 'Introduction'. In Urban Politics Now: Re-Imagining Democracy in the Neoliberal City, ed. BAVO, 6-11. Rotterdam: NAi Publishers, 2007.

Bennett, Bruce, and Imogen Tyler. 'The Art of Disobedience: The Domopolitics of The Institute for the Art and Practice of Dissent at Home'. In Five, edited by The Institute for the Art and Practice of Dissent at Home, 9-17. Liverpool: The Institute for the Art and Practice of Dissent at Home, 2014.

Bourriaud, Nicolas. Relational Aesthetics. Dijon: Presses du réel, 2002.

Chang, Heewon. Autoethnography as Method. Walnut Creek, CA: Left Coast Press, 2008.

Clifford, James. 'Introduction'. In Writing Culture: The Poetics and Politics of Ethnography, edited by James Clifford and George E. Marcus, 1-26. Berkeley: University of California Press, 1986.

Ellis, Carolyn. The Ethnographic I: A Methodological Novel about Autoethnography. Walnut Creek, CA: Alta Mira Press, 2004.

Ellis, Carolyn. Revision: Autoethnographic Reflections on Life and Work. Walnut Creek, CA: Left Coast Press, 2009.

Fraser, Nancy, 'Rethinking the Public Sphere: A Contribution to the Critique of Actually Existing Democracy'. Social Text 25/26 (1990): 56-80. 
Gieben-Gamal, Emma, and Juliette MacDonald. 'The Mobile Office: An Autoethnographic Account'. Idea Journal: Interior Economies (2011): 90-101.

Gratza, Agnieszka. 'On the Evolution of "Performance Architecture"'. Frieze 157 (2013): 140-4.

Gutkind, Lee. 'The Creative Nonfiction Police?' In In Fact: The Best of Creative Nonfiction, ed. Lee Gutkind, xix-xxxiv. New York: W.W. Norton, 2015.

Habermas, Jürgen. The Structural Transformation of the Public Sphere: An Inquiry into a Category of Bourgeois Society. Cambridge: Polity, 1989.

Harvey, David. 'The Right to the City'. New Left Review 53 (September-October 2008). Accessed on 21 June 2017. http://newleftreview.org/II/53/david-harvey-the-right-to-the-city.

Hayano, David. 'Auto-Ethnography: Paradigms, Problems and Prospects'. Human Organisation 38 (1979): 113-20.

The Institute for the Art and Practice of Dissent at Home, eds. Five. Liverpool: The Institute for the Art and Practice of Dissent at Home, 2014.

The Institute for the Art and Practice of Dissent at Home. Four Boys [for Beuys]. Liverpool: The Institute for the Art and Practice of Dissent at Home, 2016.

Latour, Bruno. 'From Realpolitik to Dingpolitik or How to Make Things Public'. In Making Things Public: Atmospheres of Democracy, edited by Bruno Latour and Peter Weibel, 14-43. Cambridge, MA: The MIT Press, 2005.

Latour, Bruno. We Have Never Been Modern, translated by Catherine Porter. Cambridge, MA: Harvard University Press, 1993.

Law, John. 'Objects, Spaces and Others'. Lancaster: Centre for Science Studies, Lancaster University, 2003. Accessed 21 June 2017. www.lancaster.ac.uk/fass/resources/sociologyonline-papers/papers/law-objects-spaces-others.pdf.

Lefebvre, Henri. The Production of Space, translated by Donald Nicholson-Smith. Oxford: Blackwell, 1991.

Miles, Malcom. 'IAPDH'. In Five, edited by The Institute for the Art and Practice of Dissent at Home, 24-6. Liverpool: The Institute for the Art and Practice of Dissent at Home, 2014.

Mínguez Carrasco, Carlos. 'Ikea Disobedients at MoMA PS1'. Domus (3 October 2012). Accessed 10 March 2015. www.domusweb.it/en/architecture/2012/10/03/ikea-disobedients-atmoma-ps1.html.

Mouffe, Chantal. 'Some Reflections on an Agonistic Approach to the Public'. In Making Things Public: Atmospheres of Democracy, edited by Bruno Latour and Peter Weibel, 804-9. Cambridge, MA: The MIT Press, 2005.

Orlek, Jonathan, Mark Parsons and Cristina Cerulli. 'Prototyping Shared Living: Collective Residential Experiments'. Circular Economy and Symbiosis: The Sustainable Regenerative City Model, BDC Journal 16, no. 2 (2016): 251-64.

Petrescu, Doina. 'How to Make a Community as Well as the Space for it'. In Space Shuttle, 45-50. Belfast: PS2, 2007. Accessed 10 March 2015 www.spaceshuttle.org.uk/Publication.pdf.

Reed-Danahay, Deborah E. 'Introduction'. In Auto/Ethnography: Rewriting the Self and the Social, edited by Deborah E. Reed-Danahay, 1-17. Oxford: Berg, 1997.

Richardson, Laurel, and Elizabeth Adams St Pierre. 'Writing, A Method of Inquiry'. In The Sage Handbook of Qualitative Research, 3rd ed., edited by N.K. Denzin and Y.S. Lincoln, 959-78. Thousand Oaks: Sage Publications, 2005.

Schweder, Alex. 'Performance Architecture'. Le Journal Spéciale'Z 4 (2012): 102-29.

Schweder La, Alex. 'Performance Architecture'. In Urban Interior: Informal Explorations Interventions and Occupations, edited by Rochus Urban Hinkel, 131-44. Germany: Spurbuchverlag, 2011.

Spatial Agency. 'About'. Accessed 10 March 2015. www.spatialagency.net.

Studio Polpo. 'A Scrapbook From OPERA \#1 at Castle House'. Accessed 21 June 2017. https:// issuu.com/studiopolpo/docs/opera_scrapbook.

Swyngedouw, Erik. 'The Post-Political City'. In Urban Politics Now: Re-Imagining Democracy in the Neoliberal City, ed. BAVO, 58-77. Rotterdam: NAi Publishers, 2007.

Walmsley, Ben. 'Deep Hanging Out in the Arts: An Anthropological Approach to Capturing Cultural Value'. In International Journal of Cultural Policy (2016). Accessed 21 June 2017. www.tandfonline.com/doi/pdf/10.1080/10286632.2016.1153081.

Wright, Stephen. 'The Future of the Reciprocal Readymade: An Essay on Use-Value and Art Related Practice'. Accessed 10 March 2015. www.turbulence.org/blog/archives/000906.html.

Yaneva, Albena. Made by the Office for Metropolitan Architecture: An Ethnography of Design. Rotterdam: 010 Publishers, 2009. 


\section{Chapter 12}

Allen, Chris. Housing Market Renewal and Social Class. Abingdon: Routledge, 2008.

Birchall, Johnston. Building Communities the Co-Operative Way. Abingdon: Routledge, 1988.

Burgess, Rod. 'Petty Commodity Housing or Dweller Control? A Critique of John Turner's Views on Housing Policy'. World Development 6, nos. 9-10 (September 1978): 1105-33.

CDS. Building Democracy: Housing Cooperatives on Merseyside. Update '94. Liverpool: Cooperative Development Services (Liverpool) Ltd, 1994.

Clapham, David, and Keith Kintrea. Housing Co-Operatives in Britain. Harlow: Longman, 1992.

Cocks, Matthew, and Chris Couch. 'The Governance of a Shrinking City: Housing Renewal in the Liverpool Conurbation, UK'. International Planning Studies 17, no. 3 (August 2012): 277-301.

Cole, Ian. 'Housing Market Renewal and Demolition in England in the 2000s: The Governance of "Wicked Problems"'. International Journal of Housing Policy 12, no. 3 (2012): 347-66.

Coleman, Nathaniel. 'Utopian Prospect of Henri Lefebvre'. Space and Culture 16, no. 3 (2013): 349-63.

Couch, Chris, and Matthew Cocks. 'Housing Vacancy and the Shrinking City: Trends and Policies in the UK and the City of Liverpool'. Housing Studies 28, no. 3 (2013): 499-519.

Engels, Friedrich. The Condition of the Working Class in England in 1844. New York: Cosimo Classics, 2008 [1892].

Engels, Friedrich. The Housing Question. Moscow: Progress Publishers, 1954 [1872].

Frost, Diane, and Peter North. Militant Liverpool: A City on the Edge. Liverpool: Liverpool University Press, 2013.

Grosskurth, Anne. 'Bringing Back the Braddocks'. ROOF 10, no. 1 (January-February 1985): 19-23.

Hatherley, Owen. A Guide to the New Ruins of Great Britain. London: Verso, 2011.

Heeswijk, Jeanne Van, and Britt Jurgensen. 'Introduction'. Stages: Liverpool Biennial 2, Homebaked: A Perfect Recipe (2014). Accessed 21 June 2017. www.biennial.com/journal/ issue- 2 .

Heeswijk, Jeanne Van, and Britt Jurgensen. 'We Are Here to Stay'. Stages: Liverpool Biennial 1, Future City (2014). Accessed 21 June 2017. www.biennial.com/journal/issue-1.

Jacobs, Jane, and Loretta Lees. 'Defensible Space on the Move: Revisiting the Urban Geography of Alice Coleman'. International Journal of Urban and Regional Research 37, no. 5 (27 September 2013): 1559-83.

Jones, Samantha. 'Becoming Homebaked.' Stages: Liverpool Biennial 2, Homebaked: A Perfect Recipe (2014). Accessed 21 June 2017. www.biennial.com/journal/issue-2.

Keiller, Patrick. 'The Dilapidated Dwelling.' In The View from the Train: Cities and Other Landscapes, 51-63. London: Verso Books, 2013.

Keiller, Patrick. 'Port Statistics'. In The View from the Train: Cities and Other Landscapes, 35-49. London: Verso Books, 2013.

Kilfoyle, Peter, with Ian Parker. Left Behind: Winning Back a Labour Heartland and the Defeat of Militant. London: Politicos Publishing, 2000.

Lane, Tony. Liverpool: City of the Sea. 2nd ed. Liverpool: Liverpool University Press, 1997.

Lefebvre, Henri. The Production of Space. Oxford: Blackwell, 1991.

Lefebvre, Henri. The Urban Revolution. Minneapolis: University of Minnesota Press, 2003.

Lusk, Paul. 'Citizenship and Consumption in the Development of Social Rights: The Liverpool New-Build Housing Co-Operative Movement'. Unpublished thesis, Salford University, 1998.

MacDonald, Robert. 'The City as a Laboratory of Shadows: Exposing Secret Histories While Thinking of the Future'. Architecture_media_politics_society 4, no. 1 (2014): 1-15.

Mars, Tim. 'Mersey Tunnel Vision?' ROOF 12, no. 6 (November-December 1987).

Marx, Karl. Capital: Critique of PoliticalEconomy, vol. 1. Harmondsworth: Penguin Classics, 1976.

McBane, Jack. The Rebirth of Liverpool: The Eldonian Way. Liverpool: Liverpool University Press, 2008.

McDonald, Alan. The Weller Way: The Story of the Weller Street Housing Cooperative. London: Faber \& Faber, 1986.

Merrifield, Andy. 'Place and Space: A Lefebvrian Reconciliation'. Transactions of the Institute of British Geographers 18, no. 4 (2013): 516-31. 
Moore, Tom. Affordable Homes for Local Communities: The Effects and Prospects of Community Land Trusts in England. St Andrews: University of St Andrews Centre for Housing Research, 2014.

Ospina, José. Housing Ourselves. London: Hilary Shipman, 1987.

Pinder, David. 'Reconstituting the Possible: Lefebvre, Utopia and the Urban Question'. International Journal of Urban and Regional Research 39, no. 1 (2013): 28-45.

Self, Will. 'The Frisson: Book Review of The View From the Train'. London Review of Books (20 January 2014). Accessed 21 June 2017. www.lrb.co.uk/2014/01/20/will-self/the-frisson.

Stanek, Lukasz. 'Space as Concrete Abstraction: Hegel, Marx, and Modern Urbanism in Henri Lefebvre'. In Space, Difference, Everyday Life: Reading Henri Lefebvre, edited by Kanishka Goonewardena, Stefan Kipfer, Richard Milgrom and Christian Schmid. Abingdon: Routledge, 2008.

Sykes, Olivier, Jonathan Brown, Matthew Cocks, David Shaw and Chris Couch. 'A City Profile of Liverpool'. Cities 35 (2013): 299-318.

Taafe, Peter, and Tony Mulhearn. Liverpool: A City that Dared to Fight. London: Fortress Books, 1988.

Thompson, Matthew. 'Between Boundaries: From Commoning and Guerrilla Gardening to Community Land Trust Development in Liverpool'. Antipode 47, no. 4 (2015): 1021-42.

Tonkiss, Fran. 'Austerity Urbanism and the Makeshift City'. City: Analysis of Urban Trends, Culture, Theory, Policy, Action 17, no. 3 (2013): 312-24.

Towers, Graham. Building Democracy: Community Architecture in the Inner Cities. Abingdon: Routledge, 1995.

Turner, John F.C. 'Housing in Three Dimensions: Terms of Reference for the Housing Question Redefined'. World Development 6, nos. 9-10 (September 1978): 1135-45.

Turner, John F.C. 'Housing as a Verb'. In Freedom to Build, edited by John F.C. Turner and Robert Fichter, 148-75. New York: Collier Macmillan, 1972.

Ward, Colin. When We Build Again: Let's Have Housing That Works! London: Pluto Press, 1985.

Ward, Colin, and David Goodway. Talking Anarchy. Oakland: Five Leaves Publications, 2003.

Webb, David. 'Conceptualising the Bounded Agency of Housing Researchers: The Case of Housing Market Renewal in England'. International Journal of Housing Policy 12, no. 3 (2012): 315-30.

Webb, David. "Problem Neighbourhoods" in a Part-Linear, Part-Network Regime: Problems with, and Possible Responses to, the Housing Market Renewal Leviathan'. Unpublished PhD thesis, Newcastle University, 2011.

Wilson, Japhy. "The Devastating Conquest of the Lived by the Conceived": The Concept of Abstract Space in the Work of Henri Lefebvre'. Space and Culture 16, no. 3 (15 May 2013): 364-80.

Žižek, Slavoj. The Year of Dreaming Dangerously. London: Verso Books, 2012. 


\section{Index}

Aalto, Alvar, 79

ACPO Gypsy and Traveller Portfolio, 50

ADB (Asian Development Bank), 60, 64

affordable housing/housing programmes, 144

Al-Imdaad (South Africa), 60, 64

albergo diffuso, 96-100

Albergo Diffuso Borgo di Castelvetere, 98

Andres Jaque Arquitectos, 184

Ikea Disobedients 2011, 183-84, 187

Andreson, Gary, 186

Anfield Village, 224

Anhangabau River, 27

Anhangabau Valley, 25

Apice Vecchia, 99

Appleby Fair, 42

Approach to reconstruction

'bottom up', 58, 62

'top down', 58, 62

Arkley, Howard, 135-37, 139

Australian Home, 1993, 136

Armed conflict, 88, 91

Artangel, 150, 157

Asian Coalition for Housing Rights, 103, 107, 112,114

Associations of Cities of Vietnam, 110, 112, 114

Autoethnography, 188, 198

Avenida Faria Lima, 27

Avenida Nove de Julho, 25, 29, 34

Avenida Paulista, 27

Baker, Lindsey T., 88

Baker, George, 155

Bam (Iran), 59

Banda Aceh (Indonesia), 56, 60

Bangaroo precinct development, 117, 122-24, 132

Barenstein, Jennifer Duyne, 58

Bauman, Zygmunt, 45

Badan Rehabilitasi dan Reknostruksi Aceh-Nias, 60, 64

Beck, Francisco, 25

Big Fat Gypsy Weddings, 48

biq architects, 76,85

Bundesministerium für Umwelt, Naturschutz, Bau und Reaktorsicherheit, 84

Bohme, Gernot, 78

Bourdieu, Pierre, 170

Botany Bay (NSW - Australia), 120

Bouchain, Patrick, 185

Brasilia, 26

Brazilian Partido dos Trabalhadores, 32
Breakey, Kate, 137, 139

Brown, Robert L., 88

'building back better', 57, 59, 64, 66

Bulgarelli, Giorgio, 97

Burgess, Rod, 210

Byrne, Tony, 215

Cambodia, 108

Caracas (Venezuela), 147

Caravan Site Control of Development Act (1960) (UK), 42

Caravan Sites Act (1968) (UK), 42

CARE (Co-operative for Assistance and Relief Everywhere), 61

Carrickmines, 53

Cartesian, 182

Castelvetere sul Calore, 89, 97, 98, 101

Children's Act (1908) (UK), 42

Cities Alliance, 110

City of Sydney Local Government Area, 118,124

Clements, Luke, 51

Clinton, Bill, 57

Code of Cultural and Landscape Heritage, 87

Codona, Janie, 48

Companhia Metropolitana de Habitação, 32

Coleman, Alice, 215

Collective action, 108-9

Commonwealth Rental Assistance, 121

Community Development Fund (Vihn) (Vietnam), 110-13, 115-16

Community Land Trusts, 203-5, 210, 221, 226

Granby Four Streets, 204, 220-21

Homebaked, 204-5, 221-26

'contradictory space', 46

Cooperative Development Services (Liverpool), 213, 217

Planning for Real, 222

Copenhagen (Denmark), 128

Corbett, Jane, 214

Corrigan v. Buckley (1926), 159, 162

cortiços, 29

Craco (Matera, South Italy), 92

Craco Peschiera, 92

Criminal Justice and Public Order Act (1994) (UK), 42

Dall'Ara, Giancarlo, 96

Darling Harbour (NSW Australia), 118-20, $122,127,131$ 
Darling Harbour - East, 123

Dawson, 94

Demographia International Housing Affordability Housing Survey, 139, 140

Detroit, 149

Detroit Institute of Arts (DIA), 153

Di Figlia, Luca, 88, 91

Di Prete, Danilo, 26

'dilapidated dwelling', 199ff, 200

Disease, 88, 91

Disney Main Street, 150

Disneyland, 155

Douglas, Mick, 143

Druot, Frédéric, 81

Dynes, Russell R., 57

earthquake, 88,89

ecovillage, 94, 95

Eldonians, 213-14, 222

Ellis, Carolyn, 188-89

Enda Vietnam, 110

Engels, Friedrich, 202, 205-7, 210, 215

The Condition of the Working Class in England, 202

Housing Questions, 225

Environmental contamination, 88, 90

Environmental Planning and Assessment Act Part 3A (2007), 122, 124

ERA Architects, 82

EU Sustainable Development Strategy, 92

Europe 2020 Strategy, 92

European Association for Information on Local Development (AEIDL), 93

EXYZT, 185, 187

Metavilla Sessions, 187

Fair Housing Act of 1968 (Title VIII of the Civil Rights Act of 1968), 162

FAU-USP (Foundation for Environmental Research at the University of São Paulo), 32

Federal Housing Administration (1934) USA, 158-61

Principles of Planning Small Homes, 159-61

Underwriting Manual (1934), 158-59, 161-62

Fichter, Robert, 36

fire, 88,89

Fisher, Roger, 47

Frente de Luta por Moradia, 23-24, 31, $33,36,38$

flood, 88, 89

Florin, Lambert, 88

Ford, Henry, 154

Forester, John, 5, 44, 47

Fotopoulos, Takis, 93

Fraser, Nancy, 181

Freire, Paolo, 33, 37

Freud, Sigmund, 165

Fundacao Pinheiros, 28

Fundacao para Pesquisa Ambienta, 32-33

Gadanho, Pedro, 183

Garden, Mary, 94

Germany, 83-84

greenhouse gas, 80

ghost towns, 87, 101
Gieben-Gamal, Emma, 189

global south, 103-5, 114

globalisation, 87

Goffman, 168

Government neglect, 88, 91

green belt, 44

Greenfield Village, 154

Gropius, Walter, 79

Growth Growth Growth \& The Bedroom 2012, 137

Grupo Técnico de Analyse de Imóveis, 32

Gypsies and Travellers, 40

Halsall, Bill, 213

Harris, Jackie, 214

Harvey, David, 118, 130

Haslem, Neal, 143

'Hatton Houses', 216-17

Hatton, Derek, 217

Healy, Patsy, 47

Henninger, Nicholas, 185

Hewson, Miles, 45

Hi-RIS (High-rise Retrofit Improvement Support programme), 75

high density housing, 71

Hill Thalias Architecture + Urban Projects, 122

Hills Hoist, 136

Holmqvist, Emma, 140-41

Home Owners' Loan Corporation (USA), 158

Hong Kong, 73

Hotel Cambridge, 23-26, 29-34

Hotel São Paulo, 147

Housing Act (1949) USA, 164

Housing Act (2004) UK, 43

housing finance

community driven, 107,109

formal, 103, 106

informal, 103

Housing Market Renewal Pathfinders (Liverpool City Council), 202-3, 218-19, 220-21

Housing: A Critical Perspective Conference (AMPS) (Liverpool, April 2015), 196

houso, 4, 18, 167ff, 175

Housos, 167-68, 171, 174-76

Houston (Texas, USA), 147-48

Hughs, Phil, 214

Huu Nghi community, Vinh, 103, 110-13, 115

Indonesia, 108

Indy Gems - emerging filmmaker festival (Australia), 178

Information and Cultural Exchange (Australia), 172, 177-78

Institute for the Art and Practice of Dissent at Home, The, 186, 188

The Hazardous Family 2008，186

Into the Woods, 171

Irpinia (Campania, South Italy), 97

Italy, 87

Jacobs, Keith, 121

Jane Irwin Landscape Architecture, 122

Joseph Rowntree Foundation, 41, 48

Foundation Study, 50

Research Study, 51 
Kaika, Maria, 130

Kaufman, 47

Keiller, Patrick, 199, 202-3, 208, 224

'View from the train', 208

Kelley, Mike, 149-55

American Ruins, 1999, 154

Antiqued (Prematurely Aged), 1987, 155

Educational Complex, 1995, 155-56

Going West on Michigan Avenue from Westland to Downtown Detroit, 152

John Glenn Memorial Detroit River Reclamation Project, 1968-1972, 156

Mobile Homestead, 2013, 149-53, 156-57, 164-65

The New American Ghetto , 1995, 154

Notebook Sketch for Entry Way (Genealogical Chart) (Welcome to Wasteland), 1995, 150

La Tour Bois le Pretre, Paris (2011) Lacacton \& Vassal, 81, 83, 84, 85

Lacaton, Anne, 78, 81, 83, 85

Lafayette Park, 164

Land Consolidation Planning, 62

landslide, 88, 89

Lane, Tony, 200

Langrove Co-op (Liverpool), 214

Lapeyronnie, Didier, 170

Lathouris, Nicholas, 178

Latour, Bruno, 182

Le Corbusier, 79

Lefebvre, Henri, 41, 45-48, 52, 54, 130, 181, 203-10, 226

Lend Lease, 120, 125, 129

Lepik, Andres, 84

Levittown, New York (1948), 159, 162

LGBTQ, 191

Liegeois, 41

Liinamaa, Saara, 146

liminal space, 47

Lions Club, 60

Liverpool (UK), 200-4, 208, 210-11, 217-19

London (UK), 123, 127

Lowe, Rick, 145-47

Project Rowe, 1993, 145

Macarow, Keely, 143

MacDonald, Juliette, 189

Madre de Deus, 32

Magnussen Turner, Lena, 140-41

Maluf, Alexandre Issa, 25

Mare, Christopher E., 93

Marshall, Kerry James, 156

Visible Means of Support: Monticello, 156

Visible Means of Support: Mount Vernon, 156

Martinelli Building/Edificio Martinelli, 25, 30

Marx, Karl, 78, 205-6, 208

McKay, Margie, 143

McMartin Preschool, 155

medium density housing, 71

Mehrotra, Raul, 38

Melbourne (Australia), 75, 79, 135-37, 140,148

Meredith, Catherine, 217

Merrifield, Andy, 208

meunasah, 65

micro-utopian, 184
Miessen, Markus, 84

Militant (Militant Tendency), 214-15, 217-19, 225

Miljonprogrammet (1965-74), 139-44

Millers Point (NSW, Australia), 118-20, 122-23, 126-27

Mint Street Building, Bethnal Green (UK), 127, 128

Modernity, 199

Moorabbin, 135, 137

Morris, 51

Moten, Fred, 164-65

Movimento dos Trabalhadores Rurais Sem Terra, 31

Movimento Sem Teto do Centro, 23-24, 31-33

Museum of Contemporary Art (Los Angeles), 152

Museum of Contemporary Art (Detroit), 149-51, 153-54, 157

Muslim Aid, 60, 63

Mutirão, 38-39

Myanmar, 108

Myers, Bill and Daisy, 163

National Network of Community Development Fund, 110

National Shelter (Australia), 141

National Women's Union (Vietnam), 110

Neues Bauen - New Building, 79

New York, 73, 123

Nightingale, 128, 132

Ocupação Cambridge, 36, 39

Ocupação Maua, 38

Office for Metropolitan Architecture, 187

Ommoord (Rotterdam, the Netherlands), 76, 85

OPERA: Open Public Experimental Residential Activity 180, 189, 192-194, 196-98

OPERA 1, 191, 195

OPERA 2, 192, 195

'othering', 45

P2KP (Overcoming Urban Poorness Project), 61-62

Paradise Valley (USA), 164

participatory design, 73

Paul Berkemeier Architects, 122

Peabody Group, 127, 128, 132

Peduli Bangsa, 61

Penn, Shelley, 124

Pentedattilo, 92

People's Committee of Nghe An province, 110

'performance architecture', 183

Petrescu, Doina, 183

Philippines, 108

Planning Policy for Traveller Sites (2015), 49

Plano de Avenidas, 25, 27

Pop Art, 136, 139

Potrč, Marjetica, 145-47

Praca da Se, 27

Prefabrication, 81, 146

Prestes, Maia, 25

Proudhorn, 202, 210, 215

public housing, 167

Pyrmont (NSW, Australia), 118 
Quarantelly, Enrico L., 57

Ranciere, Jacques, 129

reconstruction - post disaster, 58

Redfern (NSW, Australia), 120

Reed-Danahay, Deborah, 189

Rem Koolhaas, 187

residential capitalism, 138

residential performances, 184

Residents' Voices: Advantage, Disadvantage, Community and Place, 171-73, 175,177

Rettich, Stefan, 84

Riace, Calabria, 92, 100-1

Richardson, Elvis, 137-38

Richardson, Jo, 48, 52

'Right to the City' movement, 181

Robert MacDonald, The City as a laboratory of Shadows; Exposing Secrete Histories while thinking of the Future, 203

Rocks, The, 127

Rodriguez, Havidán, 57

Rogers, Richard, 122

Roosevelt, Franklin, 158, 162

Royal Institute of British Architects, 80

Russo, 97

Sandercock, Leonie, 118

São Paulo, 23-26, 28

Sarajevo (Bosnia and Herzegovina), 147

Schwartz, Herman, 138

Schwender, Alex, 183

Performing Architecture 2013, 183

Se, 28

Seabrooke, Leonard, 138

Seang, Vanna, 178

Seang and Lathouris, Lost in the Woods, 178

Secretaria Municipal de Habitacao, 32

Self, Will, 224

semiotic objects, 182, 197

Shelley v. Kraemer (1948), 162-63

Sicily, 91

Simic, Lena, 186

Singapore, 73

Slotervaard, 77

Slum Dwellers International, 107

Smith, Janet, 47

Solnit, Rebecca, 35

Staalmanplien (Amsterdam, the Netherlands), 77

Stanek, Lukasz, 208

'stealth architecture', 183

'stealth art', 183

Steinberg, Florian, 57

Stewart, Graeme, 82

Stockholm, 148

Strand Ruin, Elin; Enqvist, Annika; The New Beauty Council Knitting House, 2010, 141-43

Studio Polpo, 180, 190, 192-94, 197-98

Surry Hills (NSW, Australia), 120

Sussex-Penn Review (2011), 124

Sussex, Meredith, 124

Susskind, Lawrence, 52

Sweden, 139, 141

Sydney (Australia), 74, 75, 79, 119-21, 129-31, 137, 140
'Sydney global city', 117, 118, 122

Sydney Harbour Foreshore Authority 122

talk back, 178

Taut, Bruno, 79

Thailand, 108

Tice, Andy, 76

Torre David, 39

Torri Superiore, 94, 95, 96, 101

Tower and Neighbourhood Revitalization Program (2008) Toronto (Canada), 74

Trainer, Ted, 93

Tsunami, 56, 63, 64

Turkish Red Crescent, 60

Turner Prize, 221

Turner, John, 36

Turner, John F.C., 200, 203, 206, 210

Turner, Victor, 33

Turnpike Act (1822) (UK), 42

UEA Government, 61

UK Cohousing Network, 85

Unificacao de Lutas dos Corticos, 31

Uniao de Movimentos de Moradia, 32

UN-ESCAP, 110

UN-HABITAT, 110

unauthorised encampments, 50-51

UNDP, 110

Untitled Collective, Homefullness, 143

Untitled Collective, Open for Inspection, 2014, 142-43

Uplink, 61, 64

'urban informality', 104

Urban Regeneration Strategy (Liverpool), 215, 217

Urban (2015), 146

URBED, 222

URBED 'Building for Change', 222

Ury, William, 47

van Heeswijk, Jeanne, 221-22

'2Up2Down', 221-23

Vario apartment, 84

Vassal, Jean-Philippe, 78, 81, 83, 85

Venice Biennale, 186

Ventimiglia (Liguria, Italy), 94

Vera, Felipe, 38

Vergara, Camilo Jose, 154

Vietnam, 108

Vihn City People's Committee (Vietnam), 112

Wacquant, 168,179

Ward, Colin, 206, 210-211

Watson, Vanessa, 105

Webb, David, 218

Weller Streets (Co-op), 204, 211-14

Whiting, Mim, 143

Whitney Biennial, 153

Wilson, Japhy, 203

Woodville Community Services, 177

World Bank, 110

World Vision, 60

Wright, Stephen, 183

Yaneva, Albena, 187

Žižek, Slavoj, 204 


\section{Housing: Critical Futures \\ Series Editor: Graham Cairns}

Socio-political views on housing have been brought to the fore in recent years by global economic crises, a notable rise of international migration and intensified trans-regional movement phenomena. Adopting this viewpoint, From Conflict to Inclusion in Housing maps the current terrain of political thinking, ethical conversations and community activism that complements the current discourse on new opportunities to access housing. Its carefully selected case studies cover many geographical contexts, including the UK, the US, Brazil, Australia, Asia and Europe.

Importantly, the volume presents the views of stakeholders that are typically left unaccounted for in the process of housing development, and presents them with an interdisciplinary audience of sociologists, planners and architects in mind. Each chapter offers new interpretations of real-world problems, local community initiatives and successful housing projects, and together construct a critique on recent governmental and planning policies globally. Through these studies, the reader will encounter a narrative that encompasses issues of equality for housing, the biopolitics of dwelling and its associated activism, planning initiatives for social sustainability, and the cohabitation of the urban terrain.

Graham Cairns is an academic and author in the field of architecture. He is the director of the academic research organisation AMPS, and Executive Editor of its associated journal Architecture_MPS.

Georgios Artopoulos is Assistant Professor at the Cyprus Institute, Nicosia, Cyprus. His work has been published in numerous peer-reviewed journals, architectural books, conference proceedings and exhibition catalogues.

Kirsten Day is a registered architect, lecturer (Interior Architecture, Swinburne University of Technology) and researcher (Centre for Design Innovation, Swinburne University of Technology).

${ }^{\circledR}$ UCLPRESS

Free open access versions available from www.ucl.ac.uk/ucl-press
Cover image: Night photograph of Chamberlin,

Powell and Bon's Golden Lane Estate in London. (c) Georgios Artopoulos Cover design: www.ironicitalics.com $£ 40.00$

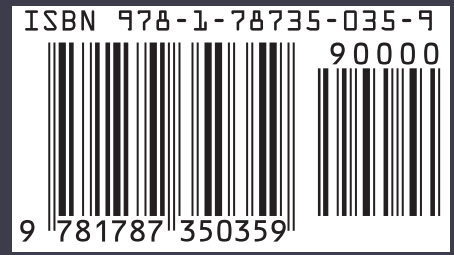

